\title{
CONTRIBUIÇÕES DO TURISMO À ECONOMIA BRASILEIRA
}

\author{
FRANCISCO CASIMIRO FILHO
}

Tese apresentada à Escola Superior de Agricultura "Luiz de Queiroz", Universidade de São Paulo, para obtenção do título de Doutor em Ciências, Área de Concentração : Economia Aplicada

PIRACICABA

Estado de São Paulo - Brasil

Julho - 2002 


\title{
CONTRIBUIÇÕES DO TURISMO À ECONOMIA BRASILEIRA
}

\author{
FRANCISCO CASIMIRO FILHO
}

Engenheiro Agrônomo

Orientador: Prof. Dr. JOAQUIM JOSÉ MARTINS GUILHOTO

Tese apresentada à Escola Superior de Agricultura "Luiz de Queiroz", Universidade de São Paulo, para obtenção do título de Doutor em Ciências, Área de Concentração: Economia Aplicada

PIRACICABA

Estado de São Paulo - Brasil Julho -2002 
Dados Internacionais de Catalogação na Publicação (CIP) DIVISÃO DE BIBLIOTECA E DOCUMENTAÇÃO - ESALQ/USP

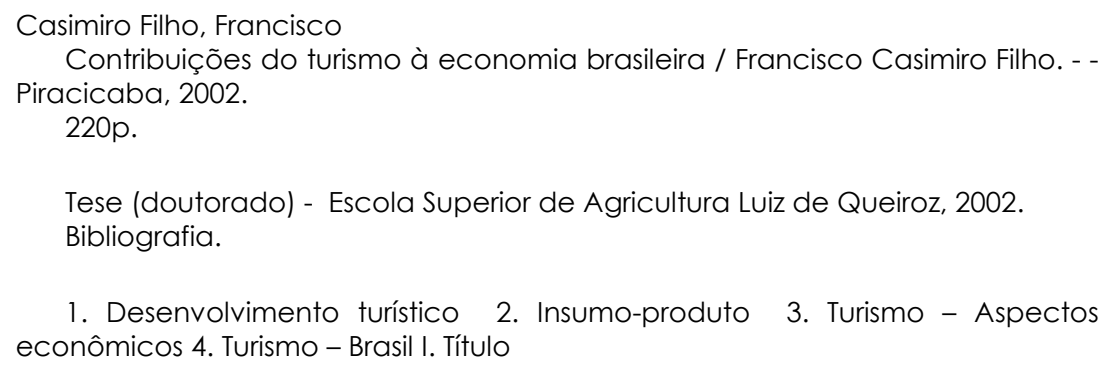

CDD 338.4791

\section{"Permitida a cópia total ou parcial deste documento, desde que citada a fonte - O autor"}




\section{AOS MEUS PAIS,}

pelo amor incondicional que sempre recebi e pelos sacrifícios e dificuldades que tiveram que passar em prol da formação de seus filhos.

DEDICO

À minha família, em especial a Sandra, Juliana e Sâmea, pela presença constante e admiração.

À Regma, pelo amor, estímulo e compreensão da minha ausência em alguns momentos.

Ao meu sobrinho Mateus, que na sua inocência trouxe mais harmonia e felicidade para nossa família.

OFEREÇO 


\section{AGRADECIMENTOS}

A elaboração de um trabalho de tese é, em alguns momentos, tarefa árdua e solitária. No entanto, durante todo o programa de doutoramento recebi ajuda de algumas pessoas e instituições, às quais, mesmo correndo um sério risco de esquecer alguém, gostaria de registrar publicamente os meus sinceros agradecimentos.

Ao Professor Joaquim José Martins Guilhoto, pela orientação dedicada e competente, pelos incentivos constantes e por sempre acreditar na capacidade dos seus orientandos, tratando-nos com imenso respeito.

Aos Professores Francisco Crócomo, Márcia Azanha e Cristina Furtuoso, pelas críticas e sugestões por ocasião do exame de qualificação.

Aos professores do Departamento de Economia, Sociologia e Administração da ESALQ/USP, pelos ensinamentos.

Aos funcionários do Departamento de Economia, Sociologia e Administração da ESALQ/USP Maielle, Cristiane, Helena, Márcia, Pedro, Elenice, Maria Helena e Fernando, pelo convívio, pelo aprendizado e pela grande colaboração em alguns momentos de minha estada em Piracicaba.

À Luciane, agora funcionária da Biblioteca Central da ESALQ/USP, pelo carinho, pela atenção e agilidade na busca de bibliografias, pela grande amizade, "pelas consultas" e pelo apoio durante a minha permanência em Piracicaba. 
Aos funcionários da Biblioteca Érico da Rocha Nobre e Álvaro, pela ajuda na busca de bibliografias; e Ligiana, pela revisão da normatização deste trabalho.

Aos meus amigos e companheiros da Pós-Graduação em Economia Aplicada, em especial a Piedade, Sílvia, Paulo Martins, Márcia, Patrícia, Marcos, Cleise, Emerson, Elaine, Ricardo, Magno, Carla, Cristiane, Denise e Alexandre, pelas ajudas desinteressadas e pelas palavras de ânimo em todos os momentos.

Aos meus amigos, próximos ou distantes, e este espaço não seria suficiente para nomeá-los e expressar minha gratidão, alimentanram este trabalho com paciência, solidariedade e torcida.

E por fim, a todas as demais pessoas que, direta ou indiretamente, contribuíram para a realização desta tese. 


\section{SUMÁRIO}

Página

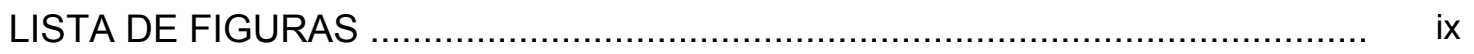

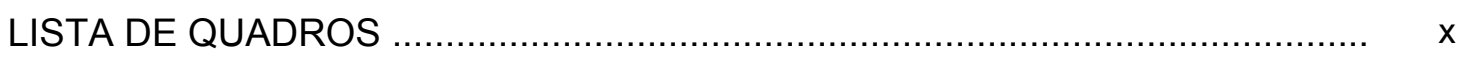

LISTA DE TABELAS …............................................................................

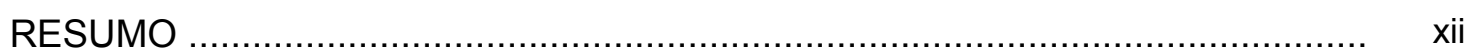

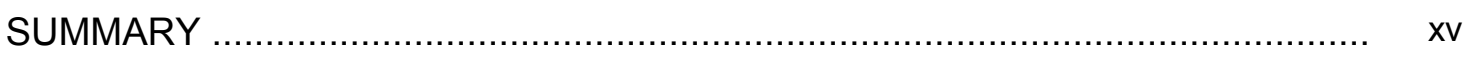

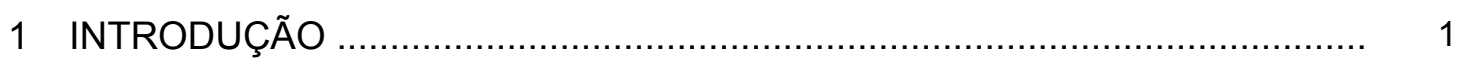

1.1 O problema e sua importância ................................................................... 1

1.2 Objetivos ................................................................................... 4

1.3 Organização da tese ............................................................................ 4

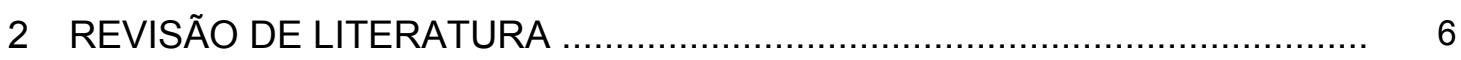

2.1 Evidências empíricas ........................................................................ 6

2.2 Desenvolvimento do turismo no Brasil .................................................... 13

2.2.1 Aspectos econômicos do turismo ........................................................ 14

2.2.2 Políticas e programas do turismo no Brasil ............................................ 25

2.2.2.1 Os programas e os incentivos fiscais para o desenvolvimento do

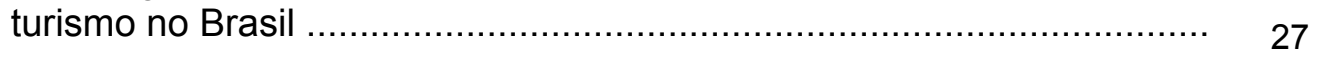

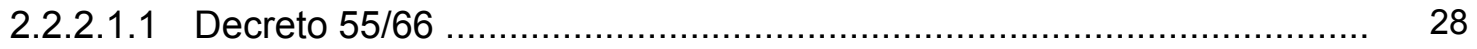

2.2.2.1.2 Fundo geral do turismo - Fungetur ............................................. 31

2.2.2.1.3 Fundo de investimentos setoriais - FISET/Turismo ........................... 33

2.2.2.1.4 Programa de ação para o desenvolvimento do turismo no Nordeste - 36 PRODETUR/NE

2.2.21.5 Programa nacional de financiamento do turismo - Sistema BNDES ... 39

3 REFERENCIAL TEÓRICO …........................................................... 43

3.1 A teoria básica do modelo de insumo-produto ............................................ 43

3.1.1 O modelo aberto ......................................................................... 45 
3.1.2 O modelo fechado em relação às famílias ............................................. 50

3.2 Métodos utilizados na construção dos modelos de insumo-produto .............. 53

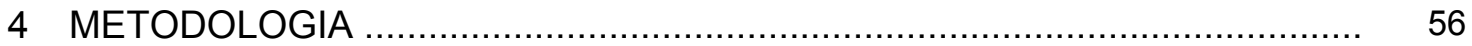

4.1 A construção da matriz de insumo-produto do turismo no Brasil .................. 57

4.1.1 Setores econômicos do segmento do turismo ...................................... 57

4.1.2 A abertura das matrizes de produção e uso dos Insumos ....................... 59

4.1.2.1 A abertura da matriz de produção …………..................................... 65

4.1.2.2 A abertura da matriz de uso dos insumos ....................................... 67

4.1.2.3 O balanceamento das matrizes pelo método RAS …............................ 74

4.2 Obtenção da matriz de coeficientes técnicos ………………................. 78

4.3 Conceitos e cálculos dos métodos de análise das relações intersetoriais na economia brasileira

4.3.1 Índices de ligação Hirschman-Rasmussen ........................................... 80

4.3.2 Índice de dispersão ........................................................................... 81

4.3.3 Campo de influência ................................................................... 82

4.3.4 Índices puros de ligação ............................................................... 83

4.4 Conceitos e cálculo dos impactos do segmento do turismo na economia brasileira

4.4.1 Multiplicadores de produção ……………………............................ 89

4.4.2 Multiplicadores de renda .............................................................. 90

4.4.3 Multiplicadores de emprego ........................................................ 91

4.5 Dimensionamento do segmento do turismo no Brasil: Produto Interno Bruto e pessoal ocupado

5 RESULTADOS E DISCUSSÃO

5.1 Análise das relações intersetoriais na economia brasileira e o segmento do turismo

5.1.1 A participação setorial no valor da produção e no valor adicionado .......... 99

5.1.2 Ligações industriais e setores-chave ................................................... 101

5.1.2.1 Os índices de ligação Hirschman-Rasmussen ..................................... 101

5.1.2.2 Campo de influência ..................................................................... 112

5.1.3 Índices puros de ligação ............................................................... 116

5.2 Os impactos de modificações na demanda final sobre a produção, a renda e a geração de empregos ..................................................................... 127

5.2.1 Os impactos na produção .................................................................. 127 
5.2.2 Os impactos na renda das famílias

5.2.3 Os impactos no emprego .............................................................. 132

5.2.3.1 A geração de empregos .............................................................. 133

5.3 Dimensionamento do segmento do turismo no Brasil: Produto Interno Bruto e pessoal ocupado ..................................................................... 143

5.3.1 O valor adicionado no segmento do turismo ..................................... 143

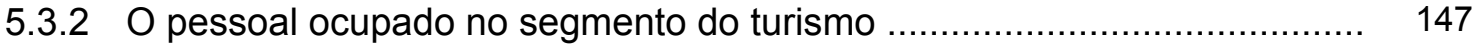

6 UMA APLICAÇÃO DO MODELO DE INSUMO-PRODUTO NA ANÁLISE DE POLÍTICAS ECONÔMICAS .................................................................... 153

6.1 Os programas e projetos de turismo no Plano Plurianual 2000-2003 .......... 153

6.2 Os impactos que poderão ser gerados na economia brasileira .................... 162

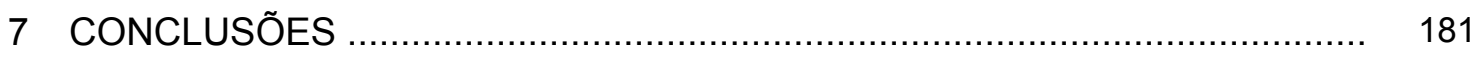

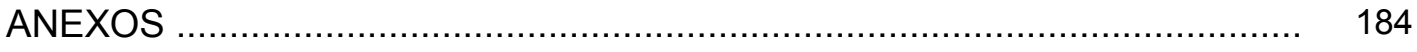

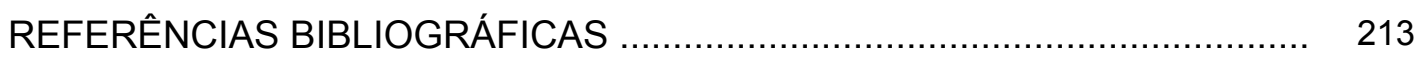




\section{LISTA DE FIGURAS}

Página

1 Evolução do turismo mundial, 1980/1999 (índice base 1980=100)

2 Evolução do turismo internacional no Brasil, 1980/1999 (índice base $1980=100$ )

3 Índices de ligações para trás de Hirschman-Rasmussen, Brasil, 1999

105

4 Índices de ligações para frente de Hirschman-Rasmussen, Brasil, 1999

106

5 Coeficiente de dispersão dos índices de ligações para trás de Hirschman-Rasmussen, Brasil, 1999

6 Coeficiente de dispersão dos índices de ligações para frente de Hirschman-Rasmussen, Brasil, 1999

7 Setores-chave, Brasil, 1999

8 Coeficientes setoriais com maior campo de influência, Brasil, 1999

Índice puro de ligações para frente normalizados, Brasil, 1999 ..

118

10 Índice puro de ligações para trás normalizados, Brasil, 1999 ....

119

11 Índice puro de ligações totais normalizados, Brasil, 1999

12 Composição do emprego total gerado devido um aumento de R\$ 1 milhão na demanda final, Brasil, 1999

13 Dimensionamento do segmento de turismo no Brasil em 1999: Valor Adicionado

14 Dimensionamento do segmento de turismo no Brasil em 1999: Pessoal Ocupado 


\section{LISTA DE QUADROS}

Página

Contribuições do turismo (diretos, indiretos e induzidos) na economia das Bermudas

Multiplicadores setoriais para os setores relacionados com o turismo da economia de Seychelles

Multiplicadores de emprego, renda, importação e impostos, por categoria de consumo, Brasil - 1991

$4 \quad$ Matriz de insumo-produto simplificada conforme Leontief

5 Agregação e desagregação dos setores usados na construção do modelo de insumo-produto do turismo

6 Produtos componentes dos setores do modelo de insumoproduto do turismo

7 Relações de insumo-produto usadas na construção das matrizes para o turismo

8 Setores-chave consolidados: critério dos índices de HirschmanRasmussen e critério do índice puro total de ligação

9 Investimento previsto por programas e projetos do segmento do turismo contemplados no Plano Plurianual 2000-2003 


\section{LISTA DE TABELAS}

Página

$1 \quad$ Evolução do turismo mundial - 1980/1999 ................................. 16

2 Evolução do turismo internacional no Brasil - 1980/1999 ........... 18

3 Fluxo interno - movimento de passageiros nos aeroportos do Brasil - 1988/1999 ................................................................ 20

4 Estimativa do PIB turístico e a sua participação no PIB brasileiro 1987 a 1996 ........................................................ 22 diretos) e de pessoas ocupadas por grupos de ocupação do trabalho principal, inclusive atividades turísticas, Brasil, 1995 1998

Sistema de incentivos fiscais para o segmento do turismo no Brasil - 1969 a 1999 (em R\$)

$7 \quad$ Sistema do Fundo Geral de Turismo - 1976 a 1999 .................. 32

8 Recursos setoriais captados, via incentivos fiscais, pelas respectivas áreas de aplicação, de 1975 a 1986

Recursos do Programa de Ação para o Desenvolvimento do Turismo no Nordeste - PRODETUR/NE

10 Metas globais do Prodetur/NE e acompanhamento ................... 39

11 Desembolsos do Sistema BNDES para o turismo segundo as regiões do país - 1990/98

12 Participação setorial na produção e no valor adicionado, Brasil, 1999

13 Índices de ligações para frente e para trás de HirschmanRasmussen e coeficientes de dispersão dos índices de ligações, Brasil, 1999

14 Índices puros de ligações normalizados para trás, para frente e total, Brasil, 1999

15 Comparação dos índices de ligações de HirschmanRasmussen e índices puros de ligações, Brasil, 1999 
16 Multiplicadores do tipo I e tipo II de produção, renda e emprego, Brasil, 1999

17 Empregos diretos, indiretos, induzidos e total gerados devido a um aumento de $\mathrm{R} \$ 1$ milhão na demanda final

18 Composição do emprego total gerado devido a um aumento de $\mathrm{R} \$ 1$ milhão na demanda final

19 Valor adicionado do segmento do turismo, participação dos agregados (Insumos, Turismo e Serviços) no valor adicionado total de cada setor componente do segmento do turismo, Brasil, 1999

20 Participação setorial no valor adicionado dos agregados (insumos, turismo e serviços), no valor adicionado total do segmento do turismo e no valor adicionado do Brasil, Brasil, 1999

21 Dimensionamento do segmento do turismo no Brasil em 1999: Valor Adicionado

22 Dimensionamento do segmento do turismo no Brasil em 1999: Pessoal Ocupado

23 Pessoal ocupado no segmento do turismo, participação dos agregados (Insumos, Turismo e Serviços) no pessoal ocupado total de cada setor componente do segmento do turismo, Brasil, 1999

24 Participação setorial no pessoal ocupado dos agregados (Insumos, Turismo e Serviços), no pessoal ocupado total do segmento do turismo e no pessoal ocupado do Brasil, Brasil, 1999

25 Investimentos previstos para o segmento do turismo no Plano Plurianual 2000-2003, por região

26 Variação dos insumos diretos utilizados no processo produtivo, devido à implantação dos projetos de turismo contemplado no Plano Plurianual 2000-2003, por região de ocorrência do investimento

Variação dos insumos indiretos utilizados no processo produtivo, devido à implantação dos projetos de turismo contemplados no Plano Plurianual 2000-2003, por região de ocorrência do investimento ....

28 Variação dos insumos totais utilizados no processo produtivo, devido à implantação dos projetos de turismo contemplado no Plano Plurianual 2000-2003, por região de ocorrência do investimento 
29 Impactos gerados na economia brasileira, devido à implantação dos projetos do turismo contemplados pelo Plano Plurianual 2000/2003

30 Variação percentual dos Impactos gerados na economia brasileira, devido à implantação dos projetos do turismo contemplados pelo Plano Plurianual 2000/2003

31 Variação dos insumos diretos, indiretos e totais utilizados no processo produtivo, devido a um aumento no consumo dos turistas domésticos e internacionais

32 Variação percentual dos insumos diretos, indiretos e totais utilizados no processo produtivo, devido a um aumento no consumo dos turistas brasileiros e internacionais

33 Impactos gerados na economia brasileira, devido a um aumento no consumo dos turistas brasileiros e internacionais no Brasil

34 Variação percentual dos impactos gerados na economia brasileira, devido a um aumento no consumo dos turistas brasileiros e internacionais no Brasil 


\title{
CONTRIBUIÇÕES DO TURISMO À ECONOMIA BRASILEIRA
}

\author{
Autor: FRANCISCO CASIMIRO FILHO \\ Orientador: Prof. JOAQUIM JOSÉ MARTINS GUILHOTO
}

\section{RESUMO}

Esta pesquisa teve como objetivo geral analisar as contribuições do turismo à economia brasileira, considerando-se a sua estrutura produtiva de 1999. Para isso, procurou-se caracterizar as relações intersetoriais e mensurar os impactos da variação na demanda final sobre produto, emprego e renda, destacando-se os setores que compõem o segmento do turismo. Procurou-se, também, dimensionar esse segmento em termos de produto interno bruto e pessoal ocupado. Para realização deste trabalho, foi necessário desagregar a matriz de insumo-produto construída para o país em setores que foram considerados turísticos e não-turísticos. $\mathrm{Na}$ análise foram utilizados, dentre outros, o método dos índices de ligações de HirschmannRasmussem, o enfoque do campo de influência, os índices puros de ligações e os multiplicadores. Os índices de ligações intersetoriais permitiram a identificação dos setores-chave, considerando-se o modelo de insumo-produto aqui construído e o nível de agregação utilizado. Dentre os setores classificados como setores-chave, utilizando-se o conceito mais abrangente, seis foram inicialmente considerados como componentes do segmento do turismo: transporte aéreo regular, transporte aéreo não- 
regular, agências e organizadores de viagens, atividades auxiliares dos transportes aéreos, estabelecimentos hoteleiros e outros tipos de alojamento temporário e restaurantes e outros estabelecimentos de serviços de alimentação. A análise dos impactos que poderiam ocorrer na produção, renda e emprego caso houvesse variações na demanda final evidenciou que os setores que compõem o segmento do turismo apresentaram elevados multiplicadores setoriais, para produção e renda, ao contrário do multiplicador de emprego, que exibiu valores relativamente baixos na estrutura produtiva aqui considerada. No entanto, a análise do poder de geração de novos empregos, caso ocorresse aumento no investimento de $\mathrm{R} \$ 1$ milhão nos setores da economia, permitiu a conclusão de que o segmento do turismo compõe-se de setores com grandes possibilidades de gerar novos postos de trabalho, principalmente quando se considerou o consumo das famílias como endógeno ao sistema. Com relação ao Produto Interno Bruto (PIB), os resultados indicam uma participação do turismo de $7,54 \%$ do PIB nacional, havendo amplo espaço para crescimento, como observado neste trabalho. Verificou-se, também, que o aumento no consumo dos turistas domésticos e dos turistas internacionais no Brasil tem impactos diferentes sobre a geração de empregos, os impostos indiretos líquidos, a renda das famílias e o valor adicionado. De maneira geral, o turismo doméstico apresentou-se um pouco mais eficiente que o turismo internacional no Brasil, medindo-se essa eficiência em termos de unidades de emprego e unidades monetárias de impostos indiretos líquidos, renda das famílias e valor adicionado por unidade de acréscimo no consumo dos turistas. No entanto, o turismo internacional não deve ser colocado em segundo plano, uma vez que constitui importante gerador de divisas para o país. Diante disso, ressalta-se a importância da implantação de políticas e programas para promover o desenvolvimento do segmento turístico do Brasil, tendo em vista que o turismo contribui para o crescimento da economia nacional. 


\title{
TOURISM CONTRIBUTION TO THE BRAZILIAN ECONOMY
}

\author{
Author: FRANCISCO CASIMIRO FILHO \\ Adviser: Prof. JOAQUIM JOSÉ MARTINS GUILHOTO
}

\section{SUMMARY}

This study aimed to analyze the tourism contributions to the Brazilian economy, considering the productive framework of 1999. For that, it was aimed to characterize the inter-sectors relations and measure the impacts on product, employment and income, deriving from variations in the final demand, focusing on sectors that form the tourism segment. It was also aimed to outline this segment in terms of Gross Domestic Product (GDP) and working people. In order to perform this study, it was needed to share the input-output matrix constituted to the country into sectors which were considered touristy and non-touristy. In the analysis, it was used, among others, the linkage index of Hirschmann-Rasmussem, the field of influence, the pure linkages indexes and the multipliers. The linkages inter-sector indexes allowed the identification of key-sectors, considering the input-output model here developed and the level of aggregation used. Among the sectors classified as key-sectors, using the most extensive concept, six (06) were initially considered as compounds of the tourism segment: regular air transport, non-regular air transport, travel agents and agencies, supporting activities of air transport, hotels and other types of temporary accommodation, restaurants and other food establishments. The analysis of impacts 
which might occur in production, income and employment in case there were variations in the final demand evidenced that the sectors which form the tourism segment showed high sectors multipliers, for production and income, on the contrary of employment multiplier, which showed relatively low values in the productive framework here considered. However, the analysis of the power to generate new employment, in case there was an increase of investment of $\mathrm{R} \$ 1$ million in sectors of economy, allowed to conclude that the segment of tourism is formed of sectors with major possibilities to generate new employment, especially when it was considered the family consumption as "endogenus" to the system. As for the Gross Domestic Product (GDP), results show a share of $7.54 \%$ of the GDP deriving from tourism, revealing vast space for growth, as stated in this study. It was also noticed, that the increase in consumption of domestic and foreign tourists in Brazil have different impacts on employment generating, the net direct tax, families income, added value and total production. Overall, the domestic tourism has shown a bit more efficient than the international tourism in Brazil, measuring this efficiency in terms of employment units and monetary units of net indirect taxes, families income and added value per unit of increase in the tourist consumption. However, the international tourism must not be placed in second plan, once it constitutes a major foreign exchange for the country. In face of this, it is pointed out the importance of implementing policies and programs to promote the development of the sector of tourism in Brazil, considering that tourism contributes to the growth of the national economy. 


\section{INTRODUÇÃO}

\subsection{0 problema e sua importância}

O turismo é um dos segmentos econômicos que mais têm crescido no mundo. Segundo a World Tourism Organization - WTO (2000), nos últimos anos ele vem apresentando crescimento médio de $7 \%$ ao ano, enquanto setores como agricultura e indústria vêm tendo crescimentos médios anuais de 2,3\% e $3 \%$, respectivamente (World Bank, 2001). Com base nesse fato, alguns países atribuem a esse importante segmento econômico parte da tarefa de equilibrar e até obter superávit em suas balanças de serviços apenas com receitas advindas do turismo (Informe BB, 1999). Outros países, principalmente aqueles em desenvolvimento, analisam o turismo como uma das alternativas capazes de induzir melhoria na qualidade de vida de suas populações, ou seja, como uma atividade propulsora de desenvolvimento, gerando renda e emprego, principalmente em regiões possuidoras de paisagens exóticas e com recursos financeiros escassos (Lopes, 1990). Uma das razões para isso é o baixo nível relativo de investimentos requeridos para sua implantação, em comparação com qualquer outra indústria.

O Brasil, apesar de apresentar características naturais favoráveis para o desenvolvimento do turismo, como extenso litoral de características paisagísticas as mais diferenciadas e clima tropical, regiões de serras com clima temperado, o pantanal mato-grossense com sua beleza incomparável e a região amazônica, tem dedicado pouca importância a esta atividade. Uma vez que não há grande divulgação do país no exterior, o Brasil tem inexpressiva classificação no ranking dos países mais visitados do mundo, segundo a OMT - Organização Mundial do Turismo. Além disso, há também carência de infra-estrutura turística e de transporte e um baixo nível de 
segurança para os turistas (Saab, 1999).

Segundo Cruz (2000), as regiões litorâneas, que dispõem de belas praias ensolaradas e de águas com temperaturas agradáveis (em torno de $28^{\circ} \mathrm{C}$ ), isso aliado ao clima quente, com temperatura média entre 25 e $30^{\circ} \mathrm{C}$ praticamente o ano inteiro, encontram-se entre os espaços mais visitados do mundo pelos turistas, as quais constituem um recurso escasso do ponto de vista do uso pela atividade. Apesar dessa escassez, os governantes e as demais autoridades responsáveis pelo planejamento de políticas públicas no Brasil, até pouco tempo atrás, não tinham despertado para essa possibilidade de uso do nosso litoral.

Como atividade econômica, o segmento do turismo tem grande capacidade de gerar receitas nos núcleos receptores. Assim, estima-se que a receita do turismo internacional no mundo foi de US\$ 443,77 bilhões em 1997. Nesse mesmo ano no Brasil, a receita gerada pelo turismo internacional foi de US\$2,6 bilhões, sendo considerado um mercado de baixo fluxo (Saab, 1999). Com relação ao turismo doméstico ou turismo interno, não há estimativas disponíveis para o ano de 1997, mas para o ano de 1998, segundo informações da Fundação Instituto de Pesquisas Econômicas - FIPE, a receita gerada foi de $\mathrm{R} \$ 13,2$ bilhões. Considerando o efeito multiplicador na geração de renda que o turismo apresenta, o referido estudo aponta uma renda indireta de $\mathrm{R} \$ 31,9$ bilhões, o que corresponde a $3,5 \%$ do PIB nacional (Instituto Brasileiro de Turismo - Embratur, 2000a) ${ }^{1}$.

Outro ponto que merece ser destacado é a vocação do segmento para a geração de empregos diretos e indiretos. Estima-se que 5,8 milhões de pessoas $(7,83 \%)$ da população economicamente ativa estavam empregadas no turismo em 1995 no Brasil, o que por si só já constitui efeito relevante em termos de política econômica, tendo em vista o desemprego ${ }^{2}$ existente no país (Saab, 1999).

Além dos benefícios econômicos anteriormente referidos, a atividade turística poderá contribuir também para melhoria da distribuição de renda entre as diferentes regiões, uma vez que a infra-estrutura montada nas regiões pobres permite que elas

\footnotetext{
1 Este assunto é tratado com maiores detalhes no capítulo 2.

2 Os índices de desemprego no Brasil nos anos de 1996, 1997, 1998 e 1999 foram, respectivamente, de 5,4\%; 5,7\%; 7,6\%; e 7,6\% (Conjuntura Econômica, vários anos).
} 
recebam os turistas das regiões mais desenvolvidas e com maior renda, fazendo com que ocorra migração de renda para aquelas áreas.

Desse modo, pode-se dizer que o turismo constitui uma possibilidade concreta de minimização das disparidades regionais entre as regiões do país (Cruz, 2000). Assim, a atividade turística constitui alternativa capaz de fomentar o crescimento e o desenvolvimento regional. No entanto, apesar de reconhecer que a atividade turística exerce grande importância sobre a economia de determinado país ou de determinada região, funcionando como atividade propulsora do desenvolvimento econômico, no caso brasileiro ainda não há estimativas específicas para o segmento do turismo, isto é, no Brasil existem poucos estudos que quantificam, com maior rigor, os impactos desse segmento sobre a economia, conforme se pode observar na Revisão de Literatura, apresentada no capítulo seguinte, demonstrando, assim, a necessidade de estudos sobre o turismo brasileiro, à luz de uma análise econômica.

A falta de estudos dessa natureza pode ser um dos entraves para o crescimento do turismo no país, uma vez que os formuladores de política e planejadores não dispõem de informações confiáveis sobre o referido segmento, dificultando, assim, a determinação de qual a melhor diretriz a ser adotada.

Desse modo, torna-se necessário identificar e quantificar a contribuição dos setores que compõem o segmento do turismo relativamente aos demais setores da economia brasileira, buscando verificar as relações intersetoriais estabelecidas, bem como estimar o valor adicionado referente ao turismo, usando-o como uma "proxy" para o produto interno bruto, e, a partir daí, colaborar com os órgãos responsáveis pela elaboração e implementação de políticas econômicas que visam promover o crescimento nacional e, ou, regional, bem assim com o próprio turismo, no direcionamento de seus investimentos.

Neste trabalho, a quantificação da contribuição do turismo à economia brasileira será feita utilizando como instrumental de análise o modelo de insumoproduto. Alguns autores têm defendido o uso dos modelos de insumo-produto com essa finalidade, como Archer (1995) e Archer \& Fletcher (1996), que argumentaram que a análise de insumo-produto pode, mais do que simplesmente quantificar impactos, gerar informações que são importantes não somente para os formuladores 
de políticas, mas também para os agentes do mercado. Também, poderá gerar informações para o governo sobre quais os setores da economia que deveriam ser incentivados por reunir condições particulares para a otimização de determinada política, como aumento na renda e, ou, no emprego etc.

\subsection{Objetivos}

Este trabalho teve como objetivo geral analisar a contribuição do segmento do turismo para a economia brasileira, bem como as relações econômicas desse segmento com os demais setores da economia sob a ótica de um modelo de insumoproduto construído para o ano de 1999.

Especificamente, pretendeu-se:

- Construir um modelo de insumo-produto para o segmento do turismo no Brasil.

- Avaliar a importância relativa das relações interindustriais e os setoreschave, a partir deste modelo.

- Avaliar a capacidade de indução dos investimentos nos setores que compõem o segmento do turismo sobre o crescimento da economia brasileira.

- Estimar o Produto Interno Bruto do conjunto de setores vinculados ao segmento do turismo, através do modelo de insumo-produto.

\subsection{Organização da tese}

Além desta parte introdutória, este trabalho contará com mais cinco capítulos. O segundo, que trata da revisão de literatura, encontra-se dividido em duas partes, sendo na primeira apresentadas algumas evidências empíricas do uso do modelo de insumo-produto para análise do segmento do turismo em nível internacional e no Brasil; na segunda parte, são feitas algumas considerações sobre desenvolvimento da atividade turística no Brasil, dando enfoque a alguns dos principais 
aspectos econômicos da atividade, bem como às principais políticas e programas conduzidos para o referido segmento.

Em seguida, apresentam-se, no terceiro e quarto capítulos, respectivamente, o referencial teórico sobre insumo-produto e os procedimentos utilizados na construção do modelo de insumo-produto para o segmento do turismo no Brasil, bem como os conceitos e cálculos dos métodos de análise das relações intersetoriais e dos impactos do segmento do turismo sobre a economia brasileira.

No quinto capítulo são apresentados e discutidos os resultados obtidos a partir do modelo anteriormente referido. No sexto capítulo, encontra-se uma aplicação do modelo de insumo-produto construído no presente trabalho, onde se procurou analisar os impactos da implementação de uma política para o segmento do turismo sobre a economia brasileira. Por último, são colocadas as conclusões e recomendações finais. 


\section{REVISÃO DE LITERATURA}

Este capítulo foi subdividido em duas seções. Na primeira, procurou-se apresentar e discutir algumas evidências empíricas do uso do instrumental de insumoproduto para analisar o segmento do turismo. São apresentados alguns dos trabalhos que foram desenvolvidos sobre este tema no Brasil e em outros países. Já na segunda seção, buscou-se apresentar e analisar a forma como vem se dando o desenvolvimento do turismo no Brasil, dando ênfase aos principais aspectos econômicos desse segmento, bem como às principais políticas e aos principais programas conduzidos no país nesse sentido.

\subsection{Evidências empíricas}

As atividades que compõem o segmento do turismo vêm ganhando, ao longo dos anos, atenção especial no que diz respeito à análise econômica dessas atividades, bem como na elaboração de propostas de políticas para este segmento, principalmente por parte de institutos de pesquisas e pesquisadores fora do Brasil, por exemplo o Instituto de Estudos Turísticos na Espanha. No Brasil, o Instituto Brasileiro de Turismo também vem conduzindo estudos dessa natureza, embora ainda de forma um pouco tímida. Sabe-se que o segmento de turismo exerce grande influência sobre os demais setores da economia de um país ou região onde se desenvolve, bem como sobre os setores econômicos fora desses limites, ou seja, exerce influência inter-regional.

A Espanha é um dos países que já vêm se preocupando em estudar o segmento do turismo do ponto de vista econômico há bastante tempo, tendo elaborado suas primeiras matrizes de insumo-produto para sua economia turística na década de 70 e publicando-as de forma contínua nas últimas décadas. A última matriz de insumo- 
produto publicada pela Espanha foi em 1996, a Tabela Intersetorial da Economia Turística - TIOT 92, tendo como ano-base 1992, e a sua principal diferença em relação às outras matrizes de insumo-produto analisada diz respeito a uma desagregação do consumo privado, que tradicionalmente aparece nessas matrizes, ou seja, o consumo privado foi desagregado em consumo turístico dos residentes, consumo turístico dos não-residentes e consumo privado não-turístico (Espanha, 1996).

Na referida publicação, encontra-se, com maiores detalhes, a construção da TIOT-92, bem como uma análise dos efeitos da demanda turística sobre a economia espanhola. Os resultados indicam que o consumo dos turistas residentes tem maior influência na produção e na renda, apresentando os multiplicadores ${ }^{3}$ 1,62 e 0,92, respectivamente, enquanto dos turistas não-residentes os multiplicadores são: 1,60 para a produção e 0,90 para a renda; mas, para a remuneração dos assalariados, a demanda dos turistas estrangeiros apresenta multiplicador maior $(0,36)$ do que a dos turistas nacionais $(0,34)$.

Na literatura internacional, vários autores vêm utilizando a análise de insumoproduto para descrever e avaliar os impactos econômicos do segmento do turismo em determinada economia. Dentre esses autores, podem ser citados: Wien (1989), Archer (1995), Archer \& Fletcher (1996) e Lin et al. (1999).

Wien (1989) reconheceu que o impacto do turismo sobre a economia de uma região é mais bem analisado através do uso da matriz de insumo-produto regional. No entanto, segundo ele, quando não se dispõe de matrizes específicas para a região, a solução é usar estimativas baseadas em matrizes nacionais, considerando-se as características regionais. Partindo da premissa de que esta afirmativa era verdadeira, o autor conduziu um trabalho onde procurou examinar os efeitos do turismo sobre o valor adicionado, os impostos e o emprego em Vorarlber (Áustria). Os efeitos do turismo sobre essa região foram os seguintes: aumento de um bilhão de austrian schillings (AS) provocaria incremento de \$450 milhões de AS no valor adicionado, $\$ 340$ milhões de impostos e 1.200 novos empregos.

3 Os multiplicadores podem ser definidos como os impactos econômicos ocorridos na economia decorrentes de variações exógenas na demanda final. Este assunto será tratado com maiores detalhes na subseção 4.4 . 
Archer (1995), utilizando o instrumental de insumo-produto, analisou a contribuição relativa do segmento do turismo na exportação, renda, emprego e renda do setor público, em comparação com os impactos gerados por outros setores exportadores da economia das Bermudas. A análise foi dos anos de 1985, 1987 e 1992 comparados. O referido autor partiu da matriz de insumo-produto original das Bermudas, tendo procedido a uma desagregação de alguns setores considerados importantes para o segmento do turismo. Calculando os índices de ligações para frente e para trás, ele verificou que o turismo tem forte ligação para trás, mostrando que o mesmo é bem interligado dentro da economia, tendo pouca ligação para frente, uma vez que a atividade é direcionada para o turismo internacional. Os principais resultados desse estudo podem ser visualizados no Quadro 1.

\begin{tabular}{|c|c|c|c|c|c|c|c|c|c|}
\hline \multirow[t]{2}{*}{ Item } & \multicolumn{3}{|c|}{ Gastos dos turistas } & \multicolumn{3}{|c|}{ Exportações } & \multicolumn{3}{|c|}{ Estação Militar } \\
\hline & 1985 & 1987 & 1992 & 1985 & 1987 & 1992 & 1985 & 1987 & 1992 \\
\hline Renda* & 391,3 & 542,6 & 555,0 & 288,0 & 433,7 & 642,1 & 37,1 & 43,4 & 39,4 \\
\hline Renda do setor público* & 67,8 & 118,7 & 137,7 & 56,4 & 92,0 & 152,4 & 4,0 & 7,1 & 14,2 \\
\hline Balanço de pagamentos* a & 87,8 & 146,3 & 24,2 & 123,7 & 125,5 & 80,6 & 4,3 & 11,4 & 20,1 \\
\hline Emprego ** & 21.500 & 19.410 & 15.380 & 14.027 & 13.003 & 12.946 & 1.486 & 1.150 & 889 \\
\hline
\end{tabular}

Quadro 1 - Contribuições do turismo (diretos, indiretos e induzidos) na economia das Bermudas.

* em milhões de dólares $\quad$ a impacto líquido (exportação - importação) * número de pessoas ocupadas

Verifica-se, nesse quadro, que o turismo tem diminuído sua contribuição, enquanto o segmento de exportações tem-na aumentado. Archer (1995) concluiu que esses dois segmentos podem ser incentivados de forma harmoniosa e paralela.

Um modelo de insumo-produto foi construído por Archer \& Fletcher (1996) para a República de Seychelles (conjunto de ilhas situadas no oceano Índico), tomando por base o ano de 1991, com o objetivo de mensurar o impacto econômico do turismo e, com base nos resultados, indicar quais os setores produtivos nos quais os gastos dos turistas produziriam maiores retornos econômicos. Na construção do modelo, esses autores fizeram uma desagregação dos principais setores que compõem o segmento do turismo e uma agregação daqueles que não eram diretamente ligados a esse segmento. Tais procedimentos resultaram num modelo com 18 setores, tendo como setores do turismo os seguintes: hotéis, outras acomodações turísticas, aluguel de carros, transporte terrestre (táxi e ônibus), transporte aéreo e transporte marítimo. 
Os resultados encontrados pelos citados autores evidenciam que os gastos dos turistas no ano analisado foram de SEYRs 528 milhões (US\$ 98 milhões). Esses gastos produziram os seguintes impactos na economia: geraram uma renda de SEYRs 467 milhões e uma receita do governo (impostos) de SEYRs 149 milhões; geraram também 8.312 empregos, sendo 3.772 gerados diretamente no segmento do turismo. Para apontar quais os setores produtivos que os gastos dos turistas produziriam maiores retornos econômicos, calcularam-se os multiplicadores setoriais de renda, emprego e receita do governo, conforme apresentados no Quadro 2.

\begin{tabular}{|l|c|c|c|}
\hline \multirow{2}{*}{\multicolumn{1}{c|}{ Setor }} & \multicolumn{2}{|c|}{ Multiplicadores setoriais } \\
\cline { 2 - 4 } & Renda & Emprego & Receita do Governo \\
\hline Grandes hotéis & 0,866 & 0,014 & 0,268 \\
Pequenos hotéis & 0,962 & 0,020 & 0,306 \\
Restaurantes & 0,771 & 0,015 & 0,321 \\
Aluguel de carros & 0,962 & 0,012 & 0,210 \\
Táxi/ônibus & 0,940 & 0,029 & 0,243 \\
Shopping & 0,929 & 0,008 & 0,134 \\
Outros serviços & 1,068 & 0,023 & 0,850 \\
Transporte aéreo & 0,911 & 0,013 & 0,243 \\
Transporte marítimo & 1,045 & 0,018 & 0,217 \\
\hline
\end{tabular}

Quadro 2 - Multiplicadores setoriais para os setores relacionados com o turismo da economia de Seychelles, 1991.

Assim, dependendo do objetivo da política a ser implantada, os turistas deverão ser encorajados a gastar mais em alguns setores e em outros nem tanto. Por exemplo, se o objetivo da política governamental é aumentar o número de empregos, os turistas devem ser encorajados a gastar mais em táxis e ônibus $(0,029)$. Se o objetivo for maximizar a receita do governo, então os setores outros serviços $(0,850)$, restaurantes $(0,321)$ e pequenos hotéis $(0,306)$ são os que deveriam ser colocados como os setores-alvo da política, tendo em vista que são os setores que apresentam os multiplicadores mais elevados.

Cabe ressaltar, no entanto, que nem sempre os efeitos da adoção de determinada política restringe-se exclusivamente a certos setores. Isso ocorre porque os setores da economia estão todos interligados em menor ou maior grau de ligações setoriais. Assim, caso a política a ser implementada tenha como objetivo aumentar a renda das famílias, os turistas devem ser incentivados a gastar mais nos setores cujos multiplicadores de renda são mais elevados. Entretanto, isso irá provocar, também, 
aumento de renda nos demais setores, mesmo que em menor proporção, bem como ocasionará aumento no número de pessoas ocupadas e na receita do governo.

Lin et al. (1999) mostraram que é importante conhecer o segmento do turismo e o poder de sua ligação com os demais setores da economia, por isso avaliaram o impacto dos gastos dos turistas sobre a economia do Estado de Vermont. A análise indicou que o turismo era muito importante para aquele Estado, tendo em vista que o segmento do turismo responde por $15 \%$ do valor total do produto, $23 \%$ do emprego e 24\% dos impostos indiretos do Estado. Para cada milhão de dólares gastos pelos turistas em Vermont, 38 empregos serão gerados, um adicional de US\$ 690.000 mil do valor do produto será produzido, a renda pessoal aumentará em US\$545.363 mil e os impostos indiretos crescerão US\$ 120.754 mil. Comparado com os outros setores do Estado, o turismo tem alta capacidade de gerar emprego e impostos indiretos.

Cabe esclarecer que uma análise comparativa dos resultados dos trabalhos listados nesta seção não foi possível, visto que esses resultados são apresentados em diferentes moedas, não permitindo fazer as devidas conversões. Também, não foi possível comparar os outros setores da economia com os setores do segmento do turismo, pois nos referidos estudos somente foram apresentados os resultados referentes a esse segmento.

Outro ponto que merece ser ressaltado com relação aos trabalhos apresentados nesta seção é o fato de que, com exceção do trabalho para a economia turística da Espanha, todos eles analisaram apenas o turismo receptivo internacional, ou seja, os impactos gerados na economia advindos do turismo de estrangeiros nos países ou regiões estudados.

No Brasil, no entanto, a maior parte dos trabalhos publicados referentes ao segmento do turismo trata-o sob a ótica da Geografia, Sociologia e Antropologia, sendo escassos os estudos que abordam o turismo como um fenômeno econômico, sendo muito mais escassos os que utilizam o modelo de insumo-produto como instrumental de análise. Dentro dessa linha de análise, podem ser citados os seguintes trabalhos: Embratur (1991), Teixeira (1996) e Wagner (1997).

A primeira matriz de insumo-produto da economia turística para o Brasil foi construída em 1991 pela Embratur, com a finalidade de quantificar a influência do 
turismo no conjunto da economia. Tal matriz foi construída partindo-se da matriz geral de insumo-produto do Brasil para o ano de 1980, elaborada pelo Instituto Brasileiro de Geografia e Estatística - IBGE (Embratur, 1991). Neste trabalho, seguiu-se a metodologia de estimação que vem sendo adotada pela Espanha; assim, os impactos analisados referem-se aos causados pelo consumo turístico de brasileiros no Brasil (CTBB) e pelo consumo turístico de estrangeiros no Brasil (CTEB). Os multiplicadores encontrados para emprego, renda, importação e impostos estão descritos no Quadro 3, por categoria de consumo.

\begin{tabular}{|l|c|c|c|c|c|c|}
\hline & \multicolumn{3}{|c|}{ Renda } & \multirow{2}{*}{ Emprego } & Importação & Impostos \\
\cline { 2 - 7 } & Salários & Excedente & Valor adicionado & & & \\
\cline { 1 - 6 } $\begin{array}{l}\text { Consumo turístico de brasileiros no } \\
\text { Brasil }\end{array}$ & 1,73 & 1,75 & 1,73 & 2,40 & 3,06 & 1,38 \\
$\begin{array}{l}\text { Consumo turístico de estrangeiros no } \\
\text { Brasil }\end{array}$ & 1,74 & 2,03 & 1,88 & 2,16 & 3,93 & 1,23 \\
\hline
\end{tabular}

Quadro 3 - Multiplicadores de emprego, renda, importação e impostos, por categoria de consumo, Brasil, 1991.

Com relação aos multiplicadores de produção, verificou-se que a faixa de variação para o conjunto de setores da economia foi de 1,22 (educação) até 2,73 (produtos metálicos). Já os setores considerados de maior projeção turística apresentaram os seguintes multiplicadores de produção: 1,66 (transporte rodoviário de passageiros), 2,26 (transporte ferroviário de passageiros), 2,01 (transporte hidroviário de passageiros), 1,75 (transporte aéreo de passageiros), 2,2 (hospedagem e alimentação), 1,2 (serviços de apoio turístico) e 1,36 (serviços de recreação).

Com o objetivo de quantificar os efeitos dos gastos do setor público via investimentos em projetos ligados ao segmento do turismo e os gastos efetuados pelos turistas sobre a renda, o produto e o emprego da economia cearense, Teixeira (1996) utilizou um modelo de insumo-produto construído para aquela economia referente ao ano de 1985 , construído por Soares $(1993)^{4}$ a partir da regionalização da matriz do Nordeste brasileiro. Nesse trabalho, a autora considerou os investimentos previstos para execução de obras de saneamento básico, construção de rodovias e ampliação do aeroporto Pinto Martins. Assim, o setor da matriz de insumo-produto escolhido para sofrer a alteração exógena foi o setor de construção civil, por ser o que mais se

${ }^{4}$ SOARES, F.A. Matriz de insumo-produto do Estado do Ceará - 1985. Fortaleza: CAEN/UFC, 1993. (Relatório de pesquisa, 35) 
aproximou dos projetos relacionados. Com relação aos gastos efetuados pelos turistas, consideraram-se os gastos nos setores: hospedagem e alimentação, transporte e diversões, sendo este último incluído no setor de serviços prestados às famílias.

Os resultados encontrados por aquela autora foram os seguintes: considerando-se o total de investimentos previstos nos projetos selecionados da ordem de $\mathrm{R} \$ 113.467 .562,00$, os impactos alcançados serão de $\mathrm{R} \$ 153.016 .237,00$ no produto e $\mathrm{R} \$ 92.719 .677,89$ na renda, com a criação de 4.107,5 novos empregos. Com relação aos gastos dos turistas, os resultados encontrados pela referida autora são mais animadores, uma vez que, se para cada $\mathrm{R} \$ 1$ milhão gasto no setor do turismo, aumentará em $\mathrm{R} \$ 1.354 .836,00$ o produto e a renda em $\mathrm{R} \$ 839.672,10$; no que se refere ao emprego, serão criados 75,9 novos postos de trabalho, sendo, portanto, esses impactos muito mais significativos que os anteriores.

Os resultados encontrados por Teixeira (1996) devem ser vistos com muita restrição, tendo em vista que os setores que ela considerou como componentes do segmento do turismo se encontravam bastante agregados. Sabe-se que o setor de transporte é composto por subsetores (transporte de passageiros e de cargas aéreos, rodoviários, marítimos e ferroviários) que não devem ser considerados como componentes do segmento do turismo. O setor de serviços prestados às famílias também é formado por outros subsetores que não o setor de diversões, sendo este, provavelmente, o de menor participação dentro do setor de serviços. Assim, os resultados encontrados podem estar superestimados, não refletindo, portanto, a realidade do segmento do turismo no Estado do Ceará.

Wagner (1997) apresentou uma abordagem alternativa, o uso da matriz de contabilidade social, para estimar os impactos do turismo na economia de uma região. Assim, ele analisou os benefícios econômicos regionais do turismo no Município de Guaraqueçaba, no litoral norte do Paraná. Para atingir o objetivo proposto, o referido autor, inicialmente, estimou a Matriz de Contabilidade Social para o município e, em seguida, obteve os multiplicadores de produção, de emprego, de impostos indiretos e distribuição de renda. Levando em consideração que aquele município recebe a visita de 7.500 turistas por ano, em média, e que eles gastam US\$113.625,00, o impacto anual, pela análise da matriz de contabilidade social, no produto foi de US $\$ 244.575,00$, 
no emprego de 32, no salário de US\$19.425,00 e nos impostos indiretos de US $\$ 675,00$.

Com relação aos trabalhos realizados aqui no Brasil que utilizam o modelo de insumo-produto para análise do segmento do turismo, deve-se ressaltar os seguintes pontos: o modelo construído no trabalho da Embratur (1991) pode não mais refletir o comportamento desse segmento na economia brasileira, uma vez que já se passaram 10 anos da elaboração do referido modelo e, nesse período, ocorreram algumas mudanças estruturais significativas na economia que, provavelmente, ocasionaram modificações também no segmento do turismo; o trabalho de Teixeira (1996), além de tratar-se de uma análise regional, quantifica os impactos dos investimentos que foram feitos no segmento do turismo utilizando a matriz geral para a economia cearense e não uma matriz para a economia turística.

Assim, uma das contribuições do presente estudo é a construção do modelo de insumo-produto para a economia turística brasileira no ano de 1999, levando-se em consideração as mudanças estruturais ocorridas na economia, bem como uma melhor desagregação dos setores de maior projeção turística. Procurou-se, também, desenvolver uma metodologia para cálculo do valor adicionado para o segmento do turismo a partir do modelo de insumo-produto, que poderá ser usado como uma proxy do seu Produto Interno Bruto.

\subsection{Desenvolvimento do turismo no Brasil}

Conforme mencionado anteriormente, nesta subseção se fez uma análise econômica do turismo no Brasil, apresentando os principais resultados econômicos do referido segmento. Essa análise ocorreu num primeiro momento, sendo no segundo apresentados as principais políticas e programas de turismo implementados nas últimas décadas, o que permite entender, de forma mais objetiva, o desenvolvimento deste segmento no Brasil. 


\subsubsection{Aspectos econômicos do turismo}

O fenômeno turismo surgiu na Grécia Antiga em 776 a.C., por ocasião dos primeiros Jogos Olímpicos, quando foram realizadas as primeiras viagens, tendo crescido como atividade econômica até a Primeira Guerra Mundial, momento que passou por um período de estagnação. Com o fim da guerra, o automóvel passou a ser utilizado como o meio de transporte mais popular, fazendo com que, no período compreendido entre as Grandes Guerras, parte da população passasse a viajar (Oliveira, 2000).

Durante a Segunda Guerra Mundial, novamente o turismo sofreu uma parada brusca. Com o fim da guerra, houve grande desenvolvimento dos meios de transporte (utilização de avião como meio de transporte de civis) e de comunicação, o que fez com que a atividade turística surgisse novamente, principalmente na Europa e na América do Norte. Desde então, a cada ano que passa esta atividade vem ganhando mais espaço na economia mundial. Sua taxa de crescimento anual é da ordem de $7 \%$ e, de acordo com a Organização Mundial de Turismo, até o final deste século será o setor que mais irá aumentar as exportações (Ito, 1996).

Segundo WTO (2000), as exportações mundiais de bens e serviços em 1998 foram de US $\$ 6.738$ bilhões, sendo o turismo o principal exportador, com 7,9\%, seguido pela indústria de automóvel com $7,8 \%$ e de alimentos com $6,6 \%$ do valor total exportado.

O desempenho do segmento do turismo geralmente é analisado observandose o total de turistas, bem como a receita gerada por estes. Considerando o período de 1980 a 1999, o total de turistas no mundo cresceu de 285,3 milhões para 656,9 milhões, ou seja, um crescimento de aproximadamente 130\% (Figura 1 e Tabela 1). Para WTO (2000), além do crescimento do número de pessoas viajando, ocorreu aumento no número de países que estão obtendo sucesso com essa atividade. 


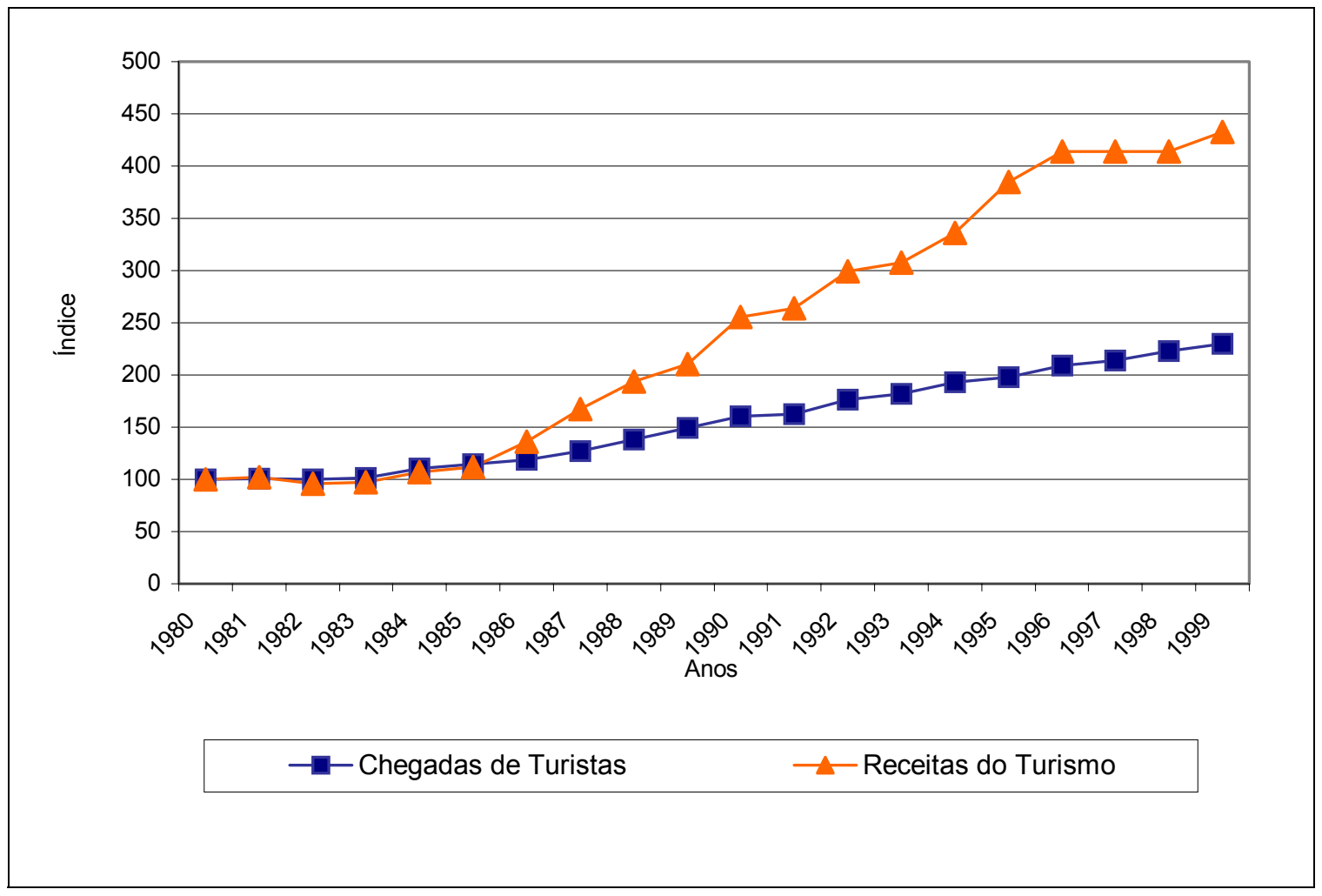

Figura 1 - Evolução do turismo mundial, 1980/1999 (índice base 1980=100).

Fonte: Construído pelo autor com dados básicos da Tabela 1.

A movimentação desses turistas entre os países gera divisas e empregos. Com relação à receita gerada pelo turismo no mundo, pode-se observar que esta vem apresentando bom desempenho, conforme pode ser observado na Tabela 1, uma vez que em 1980 essa atividade gerou em torno de US\$105,3 bilhões e, em 1999, US\$ 455,5 bilhões, refletindo um aumento de aproximadamente $332 \%$ (Figura 1).

No que diz respeito ao número de empregos gerados pelo segmento do turismo no mundo, estima-se que em 1996 essa atividade empregava em torno de 265 milhões de pessoas, o que corresponde a $10 \%$ do total de pessoas empregadas, sendo reconhecido como o segmento que mais gera empregos no mundo (Lage \& Milone, 2000). 
Tabela 1. Evolução do turismo mundial - 1980/1999.

\begin{tabular}{ccccc}
\hline & \multicolumn{3}{c}{ Número de turistas } & \multicolumn{2}{c}{ Receita do turismo } \\
\cline { 2 - 5 } ANOS & Milhões de turistas & TX. anual de crescimento & US $\$$ bilhões & Tx. anual de crescimento \\
\hline 1980 & 285,3 & & 105,3 & 2,1 \\
1981 & 286,4 & 0,4 & 107,5 & $-6,1$ \\
1982 & 285,3 & $-0,4$ & 100,9 & 1,6 \\
1983 & 289,0 & 1,3 & 102,5 & 10,0 \\
1984 & 315,9 & 9,3 & 112,7 & 4,6 \\
$1985^{(1)}$ & 326,7 & 3,4 & 117,9 & 21,5 \\
1986 & 338,4 & 3,6 & 143,2 & 23,1 \\
1987 & 363,3 & 7,4 & 176,3 & 15,6 \\
1988 & 394,3 & 8,5 & 203,8 & 8,6 \\
1989 & 426,5 & 8,2 & 221,3 & 21,5 \\
1990 & 458,2 & 7,4 & 268,9 & 3,2 \\
1991 & 464,0 & 1,3 & 277,6 & 13,5 \\
1992 & 503,4 & 8,5 & 315,1 & 2,9 \\
1993 & 519,0 & 3,1 & 324,1 & 9,2 \\
1994 & 550,5 & 6,1 & 354,0 & 14,4 \\
1995 & 565,5 & 2,7 & 405,1 & 7,5 \\
1996 & 596,5 & 5,5 & 435,6 & 0,1 \\
1997 & 610,8 & 2,4 & 436,0 & 0,0 \\
1998 & 636,7 & 4,2 & 436,0 & 4,5 \\
$1999^{(2)}$ & 656,9 & 3,2 & 455,5 & \\
\hline
\end{tabular}

Fonte: Embratur (2000b)

Notas: (1) Dados de 1985 a 1998 foram revisados

(2) Dados de 1999 são estimados pela Embratur

No Brasil, o turismo receptivo internacional apresentou taxas crescentes de desempenho até a primeira metade da década de 80. Do ano de 1987 até o início dos anos 90, esse segmento passou a ter taxas decrescentes de desempenho. Em seguida a essa fase, o turismo vem apresentando reações positivas no que diz respeito ao número de chegadas de turistas, bem como na receita gerada por este importante segmento econômico, conforme pode ser observado na Figura 2.

Essa melhoria no desempenho do turismo receptivo internacional pode estar associada à forma como este segmento vem sendo tratado na última década pelos órgãos competentes, conforme mostrado, com mais detalhes, na subseção seguinte, período em que ocorreu crescimento nos investimentos. Outra hipótese que pode ser levantada, com relação à melhoria do desempenho do turismo receptivo internacional, é que com a abertura da economia, que vem ocorrendo desde o início dos anos 90, 
houve aumento no número de turistas que vêm ao Brasil para fazer negócios, ou seja, vêm fazer turismo de negócios.

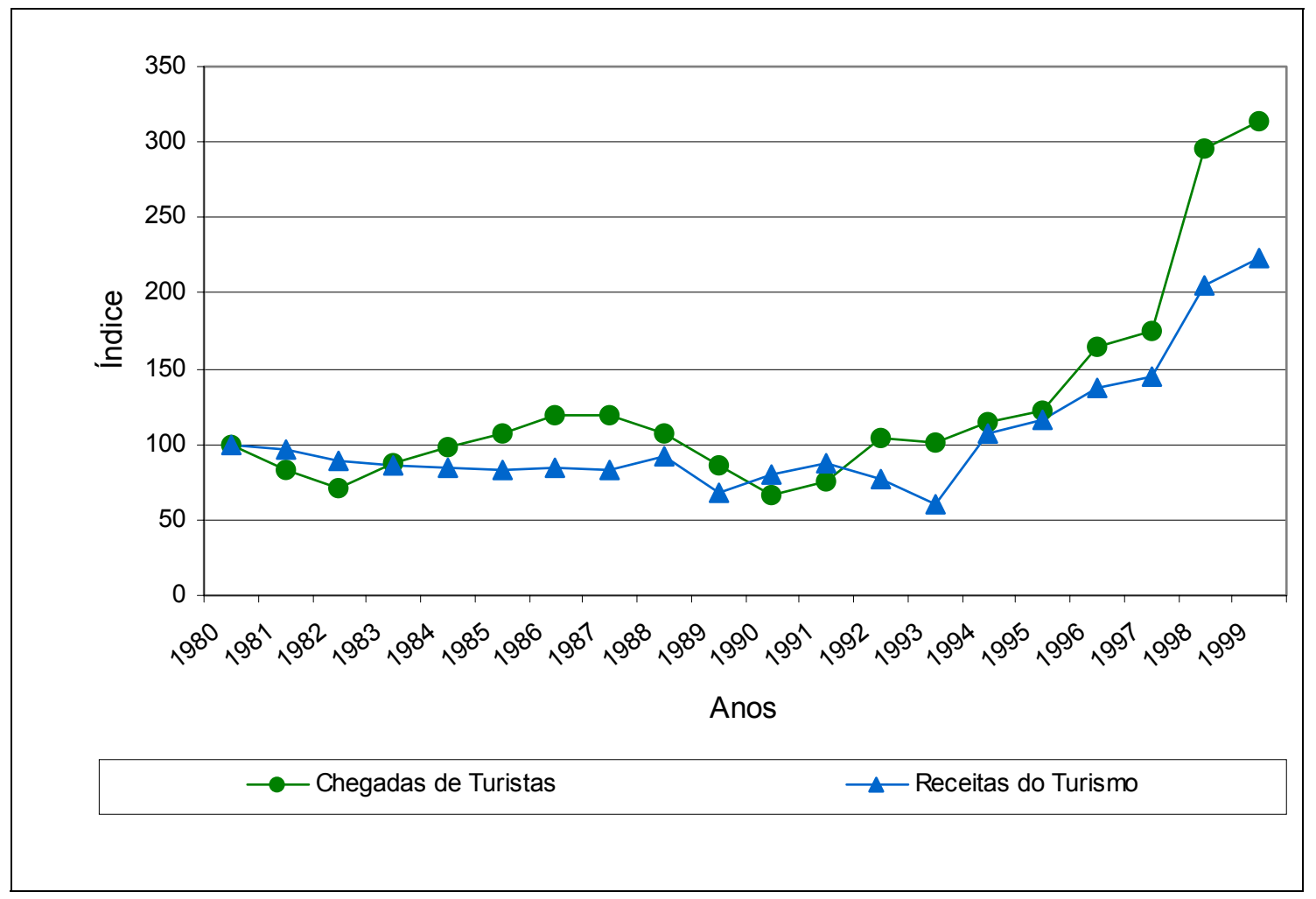

Figura 2 - Evolução do turismo internacional no Brasil, 1980/1999 (índice base 1980=100).

Fonte: Construído pelo autor com dados básicos da Tabela 2.

No que se refere à taxa de crescimento anual, tanto com relação à entrada de turistas quanto com à receita gerada pelo turismo receptivo internacional no Brasil, verificou-se um crescimento bastante significativo no período de 1997/98, isto é, aumentos de $69 \%$ e 41,7\%, respectivamente (ver Tabela 2). Esse aumento significativo, segundo Saab (1999), deve-se em parte a um aperfeiçoamento na metodologia de coleta e análise do fluxo turístico para o país a partir de 1998, o qual passou a incorporar, com maior precisão, o cálculo relativo ao ingresso de turistas nas fronteiras por via terrestre. 
Tabela 2. Evolução do turismo internacional no Brasil - 1980/1999.

\begin{tabular}{rcccc}
\hline & \multicolumn{2}{c}{ Número de turistas } & \multicolumn{2}{c}{ Receita do turismo } \\
\cline { 2 - 5 } ANOS & No de turistas & Tx. anual de crescimento & US\$1.000 & Tx. anual de crescimento \\
\hline 1980 & 1.625 .422 & - & $1.794 .363,00$ & $-3,8$ \\
1981 & 1.357 .879 & $-16,5$ & $1.726 .726,00$ & $-6,9$ \\
1982 & 1.146 .681 & $-15,6$ & $1.607 .739,00$ & $-4,7$ \\
1983 & 1.420 .481 & 23,9 & $1.532 .647,00$ & $-1,4$ \\
$1984(2)$ & 1.595 .726 & 12,3 & $1.511 .508,00$ & $-1,2$ \\
$1985(2)$ & 1.735 .962 & 8,8 & $1.492 .639,00$ & 2,3 \\
$1986(2)$ & 1.934 .091 & 11,4 & $1.527 .222,00$ & $-1,6$ \\
$1987(2)$ & 1.929 .063 & $-0,3$ & $1.502 .393,00$ & 9,3 \\
$1988(2)$ & 1.742 .939 & $-9,6$ & $1.642 .759,00$ & $-25,4$ \\
$1989(1)$ & 1.402 .897 & $-19,5$ & $1.224 .821,00$ & 17,9 \\
$1990(1)$ & 1.091 .067 & $-22,2$ & $1.444 .171,00$ & 7,9 \\
$1991(1)$ & 1.228 .178 & 12,6 & $1.558 .800,00$ & $-11,0$ \\
$1992(2)$ & 1.692 .078 & 37,8 & $1.387 .065,00$ & $-21,3$ \\
$1993(1)$ & 1.641 .138 & $-3,0$ & $1.091 .419,00$ & 76,4 \\
$1994(1)$ & 1.853 .301 & 12,9 & $1.924 .800,00$ & 9,0 \\
$1995(3)$ & 1.991 .416 & 7,5 & $2.097 .100,00$ & 17,7 \\
$1996(3)$ & 2.665 .508 & 33,8 & $2.469 .146,00$ & 5,1 \\
$1997(3)$ & 2.849 .750 & 6,9 & $2.594 .884,00$ & 41,7 \\
$1998(3)$ & 4.818 .084 & 69,1 & $3.678 .029,00$ & 8,6 \\
$1999(3)$ & 5.107 .169 & 6,0 & $3.994 .144,00$ & \\
\hline
\end{tabular}

Fonte: Embratur (2000b)

Notas relativas a receita gerada (1) Dados fornecidos pelo Banco Central do Brasil

(2) Dados estimados através de pesquisas

(3) Banco Central / EMBRATUR

Apesar dessa melhoria no desempenho, o Brasil ainda ocupa uma posição pouco expressiva no ranking internacional dos países mais visitados do mundo. Em pesquisa anual realizada pela OMT, o Brasil, em 1997, ocupava a 39a posição do referido ranking, liderado pela França, que recebeu 67.310.000 turistas, seguida pelos Estados Unidos, que receberam 47.752.000 turistas internacionais (WTO, 2000).

Segundo Saab (1999, p. 291), vários são os fatores que têm contribuído para que não ocorra maior crescimento do turismo internacional no Brasil, dentre os quais podem ser destacados os seguintes:

- Carência de infra-estrutura completa de serviços turísticos (ausência de ampla e adequada infra-estrutura hoteleira, inadequação dos serviços prestados por 
agências de viagens e operadoras de turismo e pouca oferta de serviços complementares aos de hospedagem, principalmente no que diz respeito a entretenimento e lazer).

- Nível de segurança aos turistas ainda insatisfatório (intensificação da criminalidade nos grandes centros urbanos, principalmente no Rio de Janeiro e em São Paulo, cidades mais procuradas pelos turistas).

- Carência de adequada infra-estrutura de transportes aos turistas (preços ainda elevados das passagens aéreas domésticas, restringindo a flexibilidade de circulação do turista em mais de uma região do país; aproveitamento insignificante dos transportes ferroviário, marítimo e fluvial; e necessidade de ampliação, reforma e modernização dos aeroportos nacionais).

- Carência de investimentos na divulgação do país no exterior e internamente, cujo montante se deu em níveis inferiores ao mínimo recomendado pela OMT, isto é, pelo menos $2 \%$ das receitas turística auferidas.

Diante desse cenário, Saab \& Daemon (2001) argumentaram que, para o turismo brasileiro tornar-se mais competitivo, será necessário maior integração entre os diversos setores do segmento do turismo. Deverá, também, haver melhor planejamento do trabalho de marketing, melhor potencialização dos atrativos turísticos, melhoria da infra-estrutura, redução dos custos de deslocamentos internos e expansão do setor de eventos e congressos. Argumentaram ainda que o setor hoteleiro também deverá melhorar, principalmente no tocante à capacitação profissional, visando ao aprimoramento da administração dos hotéis e à melhoria da qualidade dos serviços prestados e da estratificação da oferta de alojamentos e também de serviços diferenciados, de modo a tornar os empreendimentos hoteleiros mais competitivos. Algumas dessas ações já vêm sendo implementadas e devem ser continuadas.

Vale ressaltar que, a partir de 1990, os governos federal e estaduais vêm trabalhando para melhorar o quadro anteriormente descrito, por exemplo promovendo incentivos para instalação de melhor infra-estrutura hoteleira, atraindo, dessa forma, alguns hotéis de grandes redes internacionais e promovendo a reforma e modernização dos aeroportos. Essas medidas foram implantadas principalmente na Região Nordeste, que por sua vez já vem apresentando melhores resultados. 
Com relação ao turismo doméstico ou turismo interno no Brasil, não há estatísticas disponíveis, visto que não existem controles administrativos dos deslocamentos das pessoas que não ultrapassam as fronteiras internacionais (Embratur, 1998), o que demonstra, ainda, certa falta de planejamento para o segmento por parte dos órgãos competentes ${ }^{5}$. Dessa forma, o comportamento dos fluxos turísticos internos é analisado utilizando uma variável proxy, isto é, através das estatísticas do movimento de embarque e desembarque de passageiros nos aeroportos do país (Tabela 3). Isso é possível, considerando-se que a Organização Mundial de Turismo define turismo como as viagens em que as pessoas permanecem mais de 24 horas nos locais visitados e que durante essa permanência não venham exercer ocupação remunerada.

Tabela 3. Fluxo interno: movimento de passageiros nos aeroportos do Brasil $1988 / 1999$.

\begin{tabular}{cccccccc}
\hline \multirow{2}{*}{ Anos } & \multicolumn{3}{c}{ Embarque } & & \multicolumn{3}{c}{ Desembarque } \\
\cline { 2 - 3 } & Vôo Regular & Vôo não regular & Total & & Vôo Regular & Vôo não regular & Total \\
\hline 1988 & 13.821 .437 & 476.099 & 14.297 .536 & & 13.660 .295 & 487.059 & 14.147 .354 \\
1989 & 15.254 .521 & 518.148 & 15.772 .669 & & 14.977 .937 & 542.559 & 15.520 .496 \\
1990 & 14.760 .024 & 422.581 & 15.182 .605 & 14.660 .147 & 436.583 & 15.096 .730 \\
1991 & 14.750 .368 & 493.517 & 15.243 .885 & 14.999 .054 & 503.260 & 15.502 .314 \\
1992 & 11.851 .432 & 464.434 & 12.315 .866 & 12.164 .793 & 480.821 & 12.645 .614 \\
1993 & 12.260 .314 & 645.953 & 12.906 .267 & 12.461 .735 & 633.412 & 13.095 .147 \\
1994 & 12.699 .527 & 1.155 .188 & 13.854 .715 & 12.707 .571 & 1.137 .801 & 13.845 .372 \\
1995 & 14.843 .796 & 1.522 .821 & 16.366 .617 & 15.140 .666 & 1.622 .748 & 16.763 .414 \\
1996 & 17.847 .806 & 1.483 .349 & 19.331 .155 & 18.097 .967 & 1.434 .427 & 19.532 .394 \\
1997 & 19.312 .596 & 1.477 .116 & 20.789 .712 & 20.096 .045 & 1.429 .409 & 21.525 .454 \\
1998 & 23.349 .954 & 1.702 .176 & 25.052 .130 & 24.817 .036 & 1.687 .599 & 26.504 .635 \\
1999 & 23.847 .722 & 1.778 .406 & 25.626 .128 & 24.966 .812 & 1.769 .558 & 26.736 .370 \\
\hline
\end{tabular}

Fonte: Embratur (2000b)

${ }^{5}$ Existe uma ficha da Embratur que é preenchida no hotel pelos turistas, mas somente nos hotéis classificados, não sendo preenchida pelos hóspedes dos hotéis não-classificados, pousadas, "flats" e outros meios de hospedagem. 
Ao analisar o movimento interno de passageiros nos aeroportos do Brasil, pôde-se perceber que, depois de uma redução do movimento no início dos anos 90, o fluxo interno vem aumentado a cada ano. Uma provável explicação para essa melhoria de desempenho no setor pode ser devida à estabilidade econômica instalada no país nesse período, que, provavelmente, fez com que a população de menor renda aumentasse sua renda real e, com isso, passasse a consumir alguns bens ou serviços que antes não faziam parte da sua cesta de mercadorias, por exemplo as viagens de turismo.

Cabe ressaltar que os fatores restritivos ao crescimento do turismo receptivo internacional, descritos anteriormente, podem ser estendidos também ao turismo doméstico, principalmente no tocante aos elevados preços das passagens aéreas nacionais.

Conforme visto anteriormente, as estatísticas sobre o turismo doméstico são bastante escassas. Assim, neste trabalho foi perseguido o objetivo de quantificar o segmento do turismo em termos de renda gerada. Para isso, procurou-se desenvolver uma proposta metodológica, apresentada no próximo capítulo. Vale ressaltar que algumas estimativas da renda turística já foram feitas, a exemplo das apresentadas por Embratur/FADE (1998). No entanto, os valores não podem ser comparados com os aqui estimados, pois os referidos autores não especificaram a metodologia utilizada no citado trabalho. Mesmo assim, optou-se por mencionar os valores do PIB turístico apresentados por Embratur/FADE (1998), conforme se pode observar na Tabela 4.

Analisando o turismo em termos de geração de renda, percebeu-se que a participação do PIB turístico no PIB brasileiro vem apresentando bom desempenho. No ano de 1987, esse PIB foi de $R \$ 38.685$ milhões, o que representou uma participação de 6,62\% no PIB nacional. Já no ano de 1995 essa participação chegou a 8\% (Tabela 4). É importante destacar que, no tocante aos valores do PIB turístico, leva-se em consideração a renda gerada pelo turismo internacional e pelo turismo interno, sendo este o principal responsável pelo bom desempenho ao longo desse período. 
Tabela 4. Estimativa do PIB turístico e a sua participação no PIB brasileiro - 1987 a 1995 (R\$ milhões).

\begin{tabular}{cccc}
\hline Anos & $\begin{array}{c}\text { PIB } \\
\text { (preços constantes, base 1995) }\end{array}$ & $\begin{array}{c}\text { PIB Turístico } \\
\text { (preços constantes, base 1995) }\end{array}$ & $\begin{array}{c}\text { PIB Turístico/PIB Total } \\
\text { (valores em percentagem) }\end{array}$ \\
\hline 1987 & 584.206 & 38.685 & 6,62 \\
1988 & 583.74 & 40.431 & 6,93 \\
1989 & 601.890 & 50.972 & 8,47 \\
1990 & 575.995 & 52.419 & 9,10 \\
1991 & 577.890 & 42.938 & 7,43 \\
1992 & 572.838 & 39.610 & 6,91 \\
1993 & 596.873 & - & - \\
1994 & 631.574 & 48.740 & 7,72 \\
1995 & 658.100 & 52.670 & 8,00 \\
\hline
\end{tabular}

Fonte: Embratur/FADE (1998)

Segundo Carvalho (2000), a contribuição do turismo no PIB mundial é de 10,7\%, mas em alguns lugares, como no Caribe, a contribuição ao PIB da região sobe para 50\%, sendo em países como Estados Unidos de 10,2\% e na Espanha de 17,9\%. No Brasil, pode-se perceber que a participação do segmento do turismo no PIB no início da década de 90 apresentou ligeira redução, mas em seguida veio tendo recuperação nesse desempenho. Percebeu-se, também, que essa participação do segmento do turismo na economia nacional não fica muito abaixo da apresentada pelos países anteriormente citados e que se encontram entre os destinos mais procurados pelos turistas.

No que diz respeito à geração de empregos pelo turismo no Brasil, estima-se que este segmento empregou, direta e indiretamente, em torno de $9 \%$ da população economicamente ativa em 1997, ou seja, 6,7 milhões de empregos diretos e indiretos (Lage \& Milone, 2000), e vem apresentando bom desempenho em termos de empregos gerados, conforme pode ser observado na Tabela $5 .^{6}$

Analisando a referida tabela, percebe-se que o número de pessoas ocupadas nos macro-setores Agropecuária e Indústria de transformação, considerados macrosetores importantes na geração de empregos no Brasil, apresentou reduções de 9,27\%

6 Convém ressaltar que as informações relativas ao número de pessoas ocupadas nas atividades turísticas, apresentadas na Tabela 5, referem-se somente ao mercado de trabalho formal, enquanto nos demais macro-setores se referem tanto ao mercado de trabalho formal quanto ao informal. 
e 10,98\%, respectivamente, levando em conta o período de 1995 a 1998 . Nesse mesmo período, ao contrário dos dois macro-setores anteriormente referidos, os macro-setores transporte, construção civil e serviços apresentaram crescimento, no número de pessoas ocupadas, de $8,37 \%, 5,93 \%$ e $3,25 \%$, respectivamente. É importante ressaltar que os setores que compõem o segmento do turismo fazem parte do conjunto de setores que deram origem aos macro-setores transportes e serviços.

Tabela 5. Número de empregados em atividades turísticas (empregos diretos) e de pessoas ocupadas por grupos de ocupação do trabalho principal, inclusive atividades turísticas - Brasil, 1995-1998.

\begin{tabular}{|c|c|c|c|c|}
\hline \multirow[t]{2}{*}{ Atividade } & \multicolumn{4}{|c|}{ Pessoas ocupadas } \\
\hline & 1995 & 1996 & 1997 & 1998 \\
\hline Agropecuária (a) & 15.163 .000 & 13.905 .800 & 13.679 .000 & 13.758 .000 \\
\hline Ind. de transformação (a) & 8.807 .700 & 8.459 .200 & 8.214 .300 & 7.840 .200 \\
\hline Construção civil (a) & 3.429 .400 & 3.523 .000 & 3.671 .500 & 3.632 .600 \\
\hline Comércio (a) & 8.870 .700 & 8.744 .300 & 8.852 .300 & 8.789 .900 \\
\hline Comunicações (a) & 182.600 & 174.00 & 168.200 & 162.800 \\
\hline 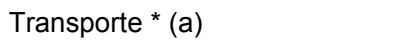 & 2.265 .000 & 2.259 .800 & 2.408 .800 & 2.454 .600 \\
\hline Serviços* (a) & 22.507 .700 & 22.698 .500 & 22.995 .100 & 23.239 .200 \\
\hline Atividades turísticas (b) & 911.354 & 882.215 & 1.448 .993 & 936.825 \\
\hline Alojamento & 175.511 & 181.073 & 292.600 & 191.028 \\
\hline Alimentação & 450.258 & 473.345 & 854.178 & 532.287 \\
\hline Agências de viagens & 46.439 & 44.202 & 59.653 & 30.966 \\
\hline Transp. rodoviário regular & 194.851 & 140.409 & 190.483 & 137.319 \\
\hline Transp. aéreo regular & 41.134 & 39.965 & 47.623 & 41.804 \\
\hline Transp. aéreo não-regular & 3.161 & 3.221 & 4.456 & 3.421 \\
\hline
\end{tabular}

Fonte: (a) IBGE (2001); (b) Embratur (2001)

* inclusive atividades turísticas

Considerando apenas o número de pessoas empregadas no segmento do turismo, percebe-se que este vem crescendo de forma expressiva, ou seja, no período de 1995 a 1998 houve aumento em torno de 2,8\% no número de pessoas empregadas. Dos setores que compõem esse segmento, o setor de alimentação foi o que apresentou maior crescimento no número de pessoas empregadas (18,22\%), seguido 
pelos setores de alojamento $(8,84 \%)$ e transporte aéreo regular $(7,94 \%)$. As reduções no número de pessoas empregadas foram observadas nos setores agências de viagens $(33,32 \%)$ e transporte rodoviário regular $(29,53 \%)$.

Além dos benefícios descritos anteriormente, a atividade turística poderá promover melhoria nas condições de vida da população residente na região onde se encontram os atrativos turísticos. Isso ocorrerá tendo em vista que, para desenvolver o turismo em uma região, torna-se necessário implantar uma boa infra-estrutura básica, como: saneamento, transportes, comunicação, estradas e segurança, dentre outros. Assim, essa infra-estrutura, uma vez montada, em alguns casos, também poderá ser utilizada pela população onde se encontram os recursos turísticos. ${ }^{7}$

Vale ressaltar que a atividade turística também poderá trazer alguns impactos negativos, como diminuição na qualidade física do meio ambiente, bem como na qualidade da atividade. Além disso, também poderá desencadear nos núcleos receptores aumento nos preços dos bens e serviços comercializados nesses locais, 0 que provocará maior impacto se estes forem também consumidos pela população local, bem como valorização excessiva das terras, que serão utilizadas na instalação dos empreendimentos imobiliários ${ }^{8}$. Porém, esses impactos poderão ser minimizados através de um planejamento adequado da atividade turística. ${ }^{9}$

Diante disso e sendo o Brasil possuidor de condições climáticas e de uma costa com formações dunares e vegetação típica da floresta amazônica - a maior floresta tropical do mundo - e do pantanal mato-grossense, que são amplamente utilizados pelo turismo como recurso paisagístico, esta atividade vem ao longo dos anos recebendo incentivos para tornar-se um dos segmentos importantes da economia de algumas regiões do país, conforme descrito na subseção seguinte.

\footnotetext{
${ }^{7}$ Como exemplo dessa afirmativa, pode-se citar o caso do PRODETUR-NE, que prioriza a implantação de infra-estrutura de saneamento básico e de acesso (disposição de lixo sólido, transporte, reforma e ampliação de aeroportos e qualificação de mão-de-obra), não sendo contempladas pelo programa obras de infra-estrutura turística. Assim, pode-se dizer que se trata de uma política de turismo que "faz as vezes" de uma política urbana (Cruz, 2000).

${ }^{8}$ De acordo com Aulicino (1994), este é um dos impactos negativos mais significativos que o turismo pode provocar sobre uma localidade qualquer, pois essa valorização das terras pressionará a população residente a vendê-la, o que acaba acontecendo, e a mesma fica sem ter onde se instalar novamente, principalmente se for em área costeira, onde a maioria vive da pesca.

${ }^{9}$ Segundo Ferraz (1992), o planejamento turístico pode ser entendido como a ação intervencionista, que, por instrumentos legais próprios, visa ordenar o patrimônio turístico, os investimentos setoriais, a qualidade dos serviços e o incremento do consumo.
} 


\subsubsection{Políticas e programas do turismo no Brasil}

$\mathrm{Na}$ elaboração e condução de uma política, o Estado pode intervir em dado segmento econômico, segundo Ferraz (1992), através de diferentes modalidades, que podem ser agrupadas em participação, indução e controle.

$\mathrm{Na}$ modalidade participação, o Estado exerce alguma atividade econômica dentro do conjunto de atividades que definem certo segmento da economia. No caso do turismo, poderia ser explorando uma companhia aérea ou um hotel, por exemplo; atualmente, a participação do Estado no segmento do turismo ocorre somente na administração de alguns centros de convenções.

Já na modalidade indução, o Estado atua como orientador do comportamento dos agentes de mercado, em geral pela concessão de incentivos fiscais e financeiros para certos investimentos ou, ainda, pela criação de uma infra-estrutura capaz de

promover o desenvolvimento da atividade. Nesse caso, pode-se citar como exemplo o Programa de Desenvolvimento do Turismo no Nordeste.

Em se tratando da modalidade controle, o Estado atua como regulador, estabelecendo as regras a serem seguidas pela iniciativa privada na condução de determinada atividade econômica.

No caso do segmento do turismo, a maior intervenção do Estado tem sido nas modalidades indução e controle, ou seja, segundo Cruz (2000), a política nacional de turismo, até meados da década de 90 , acabou restringindo-se a uma política de incentivos financeiros e fiscais, especialmente direcionados para o setor hoteleiro.

As políticas de turismo no Brasil são relativamente recentes, visto que até meados da década de 60 se pode dizer que não existiam políticas nacionais de turismo, pois o que havia eram políticas resultantes de leis e decretos-lei desconexos e restritos a aspectos parciais da atividade, uma vez que versavam principalmente sobre a regulamentação de agências de viagens e turismo. Esse período, que vai de 1938 até 1966, é o que Cruz (2000) chamou de a "pré-história" jurídico-institucional das políticas nacionais do turismo.

Em 1966, inicia-se um novo período para o segmento do turismo com a promulgação do Decreto-Lei № 55 , de 18 de novembro, que cria os organismos 
oficiais, o Conselho Nacional do Turismo (CNTur) e a Empresa Brasileira de Turismo (Embratur) e define a primeira política nacional de turismo. Essa segunda fase do turismo vai de 1966 até 1991, quando é reestruturada a Embratur e dá início ao terceiro período das políticas nacionais do turismo, que se estende até o momento atual. Nesse período, o turismo começa a ser reconhecido como atividade capaz de contribuir para a atenuação dos desníveis regionais que caracterizam o país. Assim, os incentivos financeiros e fiscais criados em razão dessa atividade privilegiaram as regiões Norte e Nordeste (Cruz, 2000).

O Decreto-Lei № 60.224, de 16 de fevereiro de 1967, que regulamentou o Decreto-Lei № 55/66, também criou o Sistema Nacional de Turismo, formado pela Embratur (que teria como atribuição, dentre outras, "estudar e propor ao CNTur os atos normativos necessários à promoção da política nacional de turismo e, bem assim, aqueles que digam respeito ao seu funcionamento." - Art. $2^{\circ}$ ), pelo CNTur (cuja principal atribuição seria "formular as diretrizes a serem obedecidas na política nacional de turismo." - Art. 6º) e pelo Ministério das Relações Exteriores (que seria o responsável pela divulgação do turismo nacional no exterior, por meio de suas tarefas diplomáticas - Art. $7^{\circ}$ ).

O terceiro período para o segmento do turismo no Brasil inicia-se a partir de 1991 e vai até os dias atuais, quando pela Lei № 8.181, de 29 de março, a Embratur transforma-se em autarquia especial (antes era uma empresa pública); com isso, é modificado parte de sua denominação de Empresa Brasileira de Turismo para Instituto Brasileiro de Turismo e passa a ser vinculado à Secretaria de Desenvolvimento Regional. Pelo mesmo diploma legal, o CNTur é extinto, sendo transferidas para a Embratur todas as atribuições e competências desse conselho.

A Lei № 8.181 é regulamentada pelo Decreto № 448 , de 14 de fevereiro de 1992, que também define os objetivos da política nacional de turismo, em que mostra que o setor público federal amplia sua visão no que se refere à prática do turismo, passando a incorporar a infra-estrutura de lazer como setor importante no conjunto dos serviços que compõem a atividade. No entanto, mais uma vez a política nacional de turismo não chegou a ser implementada, e as principais razões para isso foram a instabilidade política no período, que culminou com o impeachment de um presidente, acompanhada de acentuada instabilidade econômica, que refletiu, de forma negativa, 
sobre todos os segmentos econômicos do país, incluindo-se o turismo (Cruz, 2000).

Em 1996, início do primeiro mandato do presidente Fernando Henrique Cardoso (1996 - 1998), foi instituída a política nacional de turismo conforme havia sido descrita no Decreto № 448/92, com os seguintes objetivos:

a) a ordenação das ações do setor público orientando o esforço do Estado e a utilização dos recursos públicos para o bem-estar social;

b) a definição de parâmetros para o planejamento e a execução das ações dos governos estaduais e municipais; e

c) a orientação referencial para o setor privado.

Nessa fase das políticas de turismo no Brasil já se pode perceber uma clara reorientação dessas políticas, uma vez que, dentre as suas estratégias, encontram-se uma maior parceria entre o setor público e o setor privado, a implantação de infraestrutura básica e turística adequada às potencialidades regionais etc. E é dentro dessa perspectiva que os programas de desenvolvimento do turismo estão sendo implantados, como é o caso do PRODETUR/NE.

\subsubsection{Os programas e os incentivos federais para o desenvolvimento do turismo no Brasil}

As políticas setoriais têm como principal estratégia a geração de recursos para o desenvolvimento das atividades econômicas, sendo esses recursos os responsáveis, na maioria das vezes, pelos sucessos das referidas políticas. As principiais fontes de recursos para o desenvolvimento do turismo no Brasil são os incentivos fiscais e financeiros ${ }^{10}$ que vêm sendo dados a esse segmento ao longo da sua história.

Nesta subseção, abordam-se os benefícios fiscais (incentivos e isenções) concedidos ao segmento do turismo no Brasil, bem como os principais programas de incentivo ao desenvolvimento do turismo.

10 O incentivo fiscal é uma dedução do imposto de renda devido. A dedução fiscal consiste na arrecadação potencial do imposto de renda devido, que é apurado em certas atividades, desde que o recurso originado desta dedução seja aplicado em setores ou regiões específicos (Bacha, 1995). Já os incentivos financeiros consistem na existência de linhas de crédito oficial para determinados investimentos setoriais ou regionais, com prazos e condições de pagamento mais favoráveis que as linhas de crédito comercial (Ferraz, 1992). 


\subsection{Decreto-Lei № 55/66}

Desde a década de 50 que o governo federal estabeleceu uma política de incentivos fiscais para promover o desenvolvimento regional e, ou, setorial no Brasil. No entanto, somente na segunda metade da década de 60 é que se iniciam os mecanismos de financiamento para o desenvolvimento do turismo no país, quando foi definida a primeira política nacional de turismo.

Os incentivos fiscais e financeiros a serem aplicados ao turismo foram definidos pelo Decreto-Lei № 55/66. Cabe ressaltar, no entanto, que as isenções e incentivos fiscais foram instituídos apenas para a construção, ampliação ou reforma de hotéis cujos projetos fossem aprovados pelo Conselho Nacional de Turismo, conforme expresso nos Artigos 23, 24, 25 e 26, como se segue:

Art. 23 - A construção, ampliação ou reforma de hotéis, obras e serviços específicos de finalidades turísticas, constituindo atividades econômicas de interesse nacional, desde que aprovadas pelo Conselho Nacional de Turismo, ficam equiparadas à instalação e ampliação de

indústrias básicas e, assim, incluídas nos itens IV do Artigo 25 da Lei № 2.973, de 26 de novembro de 1956.

Art. 24 - Os hotéis em construção e os que se construírem dentro dos próximos 5 (cinco) anos da data de publicação do Decreto-Lei № $55 / 66$, desde que seus projetos tenham sido ou venham a ser aprovados pelo Conselho Nacional de Turismo e tenham as obras terminadas dentro do prazo, gozarão de isenção fiscal de todos os tributos federais, exceto os da Previdência Social, pelo prazo de 10 (dez) anos da aceitação de suas obras pelo referido órgão. Art. 25 - As pessoas jurídicas poderão pleitear o desconto de até $50 \%$ (cinqüenta por cento) do imposto de renda e adicionais não-restituíveis que devam pagar, para investimento na construção, ampliação ou reforma de hotéis, e em obras e serviços específicos de finalidades turísticas, desde que tenham seus projetos aprovados pelo CNTur, com parecer fundamentado da Embratur.

Art. 26 - Até o exercício de 1971, inclusive, os hotéis de turismo que estiverem operando à data de publicação do Decreto-Lei № $55 / 66$ poderão pagar com a redução de até $50 \%$ (cinqüenta por cento) o imposto de renda e os adicionais não-restituíveis, desde que a outra parte venha a reverter em melhoria de suas condições operacionais.

O Decreto-Lei № 157, de 10 de fevereiro de 1967, em seu Artigo 17, fixou que, a partir do exercício financeiro de 1968, os incentivos fiscais estabelecidos no 
Artigo 25 do Decreto-Lei № $55 / 66$ só seriam concedidos se a pessoa jurídica beneficiada aplicasse na construção de hotéis de turismo capitais próprios de igual montante ao incentivo fiscal a que se fizesse jus (Bacha, 1995). ${ }^{11}$

Observando a Tabela 6, pode-se verificar o desempenho dos incentivos fiscais dados ao segmento do turismo no Brasil. Analisando os dados da referida tabela, constata-se que os incentivos fiscais apresentam comportamento oscilatório, sem tendência definida.

Apesar de todos esses incentivos, o turismo no Brasil nesse período não chegou a se transformar num segmento econômico de relevâncias interna e externa, como pretendiam tais políticas. Parte desse insucesso pode ser atribuído à maneira errônea como sempre foi tratada a atividade turística, ou seja, foi resumida à hospedagem em hotéis.

Sabe-se que o fazer turismo vai muito mais além da hospedagem, isto é, o produto turístico é complexo e composto de vários outros produtos, como: recursos naturais (clima, paisagem etc.), alimentação, segurança, transporte, lazer e produtos culturais (patrimônio histórico e cultural, qualidade dos serviços, comportamento etc.). Conforme Cruz (2000), a posição marginal do Brasil, relativamente ao conjunto dos principais pólos receptores de turistas no mundo, é conseqüência, em grande parte, dessa visão estreita que se tem do turismo no país.

Dando continuidade ao fomento à atividade turística, dois fundos foram criados, a partir do Decreto-Lei № 55/66: o Fundo Geral de Turismo (Fungetur) e os Fundos de Investimentos Setoriais (FISET) para o segmento do turismo, para o setor de pesca e para o setor florestal (que eram supervisionados por diferentes órgãos; no caso específico dos incentivos voltados para o turismo, o FISET/Turismo era supervisionado pela Embratur). Esses dois fundos são apresentados com maiores detalhes nas duas subseções subseqüentes.

\footnotetext{
11 O trabalho de Bacha (1995) tem por objetivo fazer uma análise de custo-benefício dos programas federais de incentivos ao reflorestamento no Brasil. No entanto, no capítulo 2 o autor faz uma análise dos principais programas de desenvolvimentos regional e setorial baseados em incentivos fiscais, dentre eles os incentivos fiscais concedidos ao desenvolvimento do turismo.
} 
Tabela 6. Sistema de incentivos fiscais ao segmento do turismo no Brasil - 1969 a $1999\left(\mathrm{em} \mathrm{R} \$^{*}\right)$.

\begin{tabular}{|c|c|c|c|c|c|}
\hline Ano & $\begin{array}{c}\text { Projetos } \\
\text { Aprovados }\end{array}$ & $\begin{array}{l}\text { Recursos } \\
\text { próprios }\end{array}$ & $\begin{array}{l}\text { Incentivos } \\
\text { Fiscais }\end{array}$ & Financiamentos & Total \\
\hline 1969 & 46 & 60.553 .551 & 40.254 .008 & 379.016 & 101.186 .574 \\
\hline 1970 & 86 & 20.587 .978 & 11.997 .708 & 378.206 & 32.963 .892 \\
\hline 1971 & 94 & 28.345 .537 & 17.400 .784 & 725.233 & 46.471 .555 \\
\hline 1972 & 104 & 32.012 .256 & 26.442 .319 & 1.636 .866 & 60.091 .442 \\
\hline 1973 & 151 & 39.434 .637 & 14.586 .788 & 16.505 .403 & 70.526 .828 \\
\hline 1974 & 121 & 27.556 .347 & 8.560 .995 & 19.062 .356 & 55.179 .698 \\
\hline 1975 & 112 & 31.195 .312 & 4.247 .693 & 33.946 .841 & 69.389 .845 \\
\hline 1976 & 53 & 11.076 .013 & 14.496 .475 & 10.628 .171 & 36.200 .660 \\
\hline 1977 & 100 & 23.749 .800 & 11.952 .078 & 5.948 .129 & 41.650 .007 \\
\hline 1978 & 114 & 19.580 .560 & 10.374 .377 & 8.497 .131 & 38.452 .067 \\
\hline 1979 & 74 & 15.027 .293 & 3.987 .591 & 12.337 .448 & 31.352 .332 \\
\hline 1980 & 44 & 17.460 .672 & 8.204 .074 & 4.029 .282 & 29.694 .027 \\
\hline 1981 & 51 & 33.961 .965 & 25.430 .859 & 3.639 .250 & 63.032 .075 \\
\hline 1982 & 37 & 6.406 .078 & 15.336 .298 & 2.602 .183 & 24.344 .559 \\
\hline 1983 & 22 & 7.706 .690 & 7.638 .688 & 2.102 .258 & 17.447 .637 \\
\hline 1984 & 30 & 12.686 .262 & 7.548 .207 & 2.128 .734 & 22.363 .202 \\
\hline 1985 & 63 & 59.947 .171 & 24.873 .445 & 23.568 .263 & 108.388 .878 \\
\hline 1986 & 20 & 18.530 .209 & 13.333 .515 & 2.627 .239 & 34.490 .963 \\
\hline 1987 & 25 & 86.362 .755 & 58.326 .172 & 24.961 .542 & 169.650 .469 \\
\hline 1988 & 26 & 30.710 .168 & 21.059 .799 & 15.504 .234 & 67.274 .200 \\
\hline 1989 & 13 & 46.067 .870 & 52.178 .723 & 33.115 .783 & 131.362 .375 \\
\hline 1990 & 2 & 2.617 .716 & 2.617 .962 & 3.337 .922 & 8.573 .600 \\
\hline 1991 & 6 & 23.712 .818 & 13.044 .232 & 11.691 .269 & 48.448 .319 \\
\hline 1992 & 1 & 8.296 .017 & 34.706 & 8.296 .017 & 16.626 .740 \\
\hline 1993 & 7 & 19.891 .343 & 29.990 .290 & 15.440 .537 & 65.322 .169 \\
\hline 1994 & 1 & 8.296 .017 & 34.706 & 8.296 .017 & 16.626 .740 \\
\hline 1995 & 0 & - & - & - & - \\
\hline 1996 & 1 & 13.258 .737 & 13.258 .737 & - & 26.517 .475 \\
\hline 1997 & 4 & 22.775 .270 & 31.997 .358 & 22.751 .175 & 77.523 .803 \\
\hline 1998 & 6 & 39.965 .395 & 54.685 .090 & 19.862 .711 & 114.513 .197 \\
\hline 1999 & 11 & 61.013 .509 & 62.373 .755 & 8.392 .652 & 131.779 .917 \\
\hline TOTAL & 1.425 & 828.785 .944 & 606.267 .435 & 322.391 .866 & 1.757 .445 .245 \\
\hline
\end{tabular}

Fonte: Embratur (2001b)

${ }^{*}$ A preços de dezembro de 1999. 


\subsection{Fundo Geral do Turismo - Fungetur}

O Fungetur foi criado pelo Decreto-Lei № 1.191, de 27 de outubro de 1971. Conforme seus Artigos 11 e 12, a sua gestão ficaria sob a responsabilidade e competência da Empresa Brasileira de Turismo, ou seja:

Art. 11 - Destinado a fomentar e prover recursos para o financiamento de obras, serviços e atividades turísticas consideradas de interesse para o desenvolvimento do turismo nacional, de acordo com o parágrafo único do Artigo 19 do Decreto-Lei № 55/66, de 18 de novembro de 1966.

Art. 12 - Em casos especiais, considerados pela Embratur de alto interesse turístico, o Conselho Nacional de Turismo poderá aprovar projetos, ampliando a aplicação de recursos originados dos incentivos fiscais até o limite de $75 \%$ (setenta e cinco por cento) do custo global do empreendimento.

A regulamentação do diploma legal que criou o Fungetur veio quatro anos depois pelo Decreto-Lei № 1.439, de 30 de novembro de 1975, e trouxe algumas modificações no seu texto, no que se refere à isenção de todos os tributos federais, em seu Artigo 4은

"Os hotéis e outros empreendimentos turísticos definidos pelo Poder Executivo, em construção, ou que venham a ser construídos, conforme projetos aprovados até 31 de dezembro de 1985 pelo Conselho Nacional de Turismo - CNTur, poderão gozar de redução de até $70 \%$ (setenta por cento) do imposto sobre a renda e adicionais não restituíveis, por períodos anuais sucessivos, até o total de 10 (dez) anos, a partir da data de conclusão das obras, segundo forma, condições e critérios de prioridades estabelecidos pelo Poder Executivo."

Outro ponto importante presente na regulamentação do Fungetur é que este passou a favorecer os empreendimentos de pequeno e médio portes e a incentivar a criação de infra-estrutura de lazer e hospedagem para uma demanda de menor poder aquisitivo, conforme expresso em seu Artigo 14:

"Destina-se o Fungetur a prover recursos para o financiamento das atividades turísticas referidas no parágrafo único, do artigo $1^{\circ}$, e especialmente:

I - as de pequeno e médio portes; as localizadas em áreas prioritárias; as de preços ou tarifas médios de exploração;

II - as de propriedade ou iniciativa de pequenas e médias empresas turísticas, como tais definidas pelo Conselho Nacional de Turismo (CNTur); 
III - as de iniciativa das autoridades locais, mediante convênio com a Embratur, e, em particular, as destinadas ao lazer e, ou, hospedagem das classes da população de menor poder aquisitivo."

A atuação do Fungetur ao longo do período 1976/99 é apresentada na Tabela 7, na qual se pode verificar que, embora venha apoiando o segmento do turismo há bastante tempo, sua participação financeira ainda é um pouco tímida quando se comparam os valores dos incentivos fiscais (Tabela 6) com os do Fungetur.

Tabela 7. Sistema do Fundo Geral de Turismo - 1976 a 1999 (em R $\left.\$^{*}\right)$.

\begin{tabular}{|c|c|c|c|c|c|c|}
\hline Ano & $\begin{array}{c}\text { Contratos e projetos } \\
\text { aprovados }\end{array}$ & $\begin{array}{l}\text { Recursos } \\
\text { próprios }\end{array}$ & Fungetur & $\begin{array}{c}\text { Agentes } \\
\text { financeiros }\end{array}$ & Outros & Total \\
\hline 1976 & 9 & 772.471 & 842.733 & 153.949 & 259.097 & 2.028 .249 \\
\hline 1977 & 142 & 21.964.212 & 20.735 .646 & 2.787 .274 & 1.739 .461 & 47.226 .593 \\
\hline 1978 & 80 & 18.833 .557 & 19.465 .781 & 1.323 .372 & 788.691 & 40.411 .401 \\
\hline 1979 & 124 & 11.953 .643 & 16.683 .011 & 2.287 .285 & 774.401 & 31.698 .341 \\
\hline 1980 & 146 & 16.090 .926 & 21.766 .394 & 2.418 .379 & 242.956 & 40.518 .655 \\
\hline 1981 & 108 & 12.239 .102 & 13.493 .916 & 1.403 .993 & 1.181 .693 & 28.318 .705 \\
\hline 1982 & 61 & 7.666 .202 & 14.786 .367 & 1.280 .675 & 10.431 & 23.743 .675 \\
\hline 1983 & 78 & 12.191.182 & 15.700 .691 & 1.440 .154 & 508.571 & 29.840 .597 \\
\hline 1984 & 117 & 11.679 .518 & 23.227.398 & 2.906 .771 & 859.966 & 38.673 .653 \\
\hline 1985 & 68 & 10.400 .728 & 10.349 .279 & 1.059 .534 & 3.966 .228 & 25.775 .770 \\
\hline 1986 & 22 & 7.674 .056 & 3.911 .579 & 443.739 & 136.894 & 12.166 .269 \\
\hline 1987 & 26 & 9.561 .536 & 12.824 .671 & 798.689 & 614.512 & 23.799 .408 \\
\hline 1988 & 30 & 16.846 .244 & 13.591 .760 & 3.290 .790 & 2.757 .701 & 36.486 .494 \\
\hline 1989 & 36 & 11.217 .485 & 36.242 .035 & 1.027 .404 & 2.081 .541 & 50.568 .465 \\
\hline 1990 & 13 & 15.455 .594 & 6.382 .587 & 692.283 & 4.135 .018 & 26.665 .482 \\
\hline 1991 & 3 & 805.271 & 299.889 & 35.116 & 438.570 & 1.578 .846 \\
\hline 1994 & 5 & 6.840 .666 & 5.157 .690 & - & 3.709 .164 & 15.707 .520 \\
\hline 1995 & 31 & 39.407 .658 & 26.766 .011 & - & 10.363 .277 & 76.536 .946 \\
\hline 1996 & 25 & 29.891 .284 & 18.700 .010 & 208.508 & 12.641 .238 & 61.441 .041 \\
\hline 1997 & 15 & 12.571 .013 & 18.533 .014 & - & 2.321 .196 & 33.425 .223 \\
\hline 1998 & 2 & 2.189 .849 & 551.655 & - & - & 2.741 .503 \\
\hline 1999 & 2 & 3.488 .546 & 3.696 .423 & - & - & 7.184 .969 \\
\hline TOTAL & 1.143 & 279.740 .742 & 303.708 .538 & 23.557 .916 & 49.530 .606 & 656.537 .803 \\
\hline
\end{tabular}

Fonte: Embratur (2001b)

${ }^{*}$ A preços de dezembro de 1999. 
Segundo Saab (1999), a atual estrutura financeira do Fungetur não possibilita um maior alcance quanto aos financiamentos concedidos aos investimentos turísticos a serem empreendidos pelas pequenas e microempresas turísticas.

Além da baixa participação financeira, a aplicação dos recursos do Fungetur não ocorreu conforme havia sido regulamentada, ou seja, para atender especialmente às atividades turísticas e empresas turísticas de pequeno e médio portes, bem como às empresas de lazer e, ou, hospedagem destinadas à população de menor poder aquisitivo. De acordo com Cruz (2000) e Beni (1991), a aplicação de recursos ao turismo dava-se de forma contrária, ou seja, embora pelo Decreto-Lei № 1.439 as classes menos privilegiadas da sociedade é que deveriam ser favorecidas na obtenção de recursos, na prática isso não acontecia.

\subsection{Fundo de Investimento Setorial para o Turismo - FISET/Turismo}

Segundo Bacha (1995), o sistema de concessão de incentivos fiscais para os desenvolvimentos regional e setorial, na maneira como se encontrava regulamentado no período de 1961 a 1973, gerava excesso de demanda sobre a oferta de incentivos. Assim, visando controlar a alocação dos recursos dos incentivos fiscais de maneira mais centralizada e também tentando corrigir o desequilíbrio de mercado de incentivos fiscais, o governo federal promulgou o Decreto-Lei № 1.376 , de 12 de dezembro de 1974 (Abdallah, 1998).

Esse Decreto-Lei criou os seguintes fundos de investimentos: o Fundo de Investimento do Nordeste (FINOR), o Fundo de Investimento da Amazônia (FINAM) e os Fundos de Investimentos Setoriais (FISET) destinados ao setor de pesca, ao setor florestal e ao segmento do turismo. Este último tendo limitado sua ação à região centro-sul, haja vista que, nas Regiões Norte e Nordeste, foram utilizados recursos do FINAM e do FINOR, respectivamente.

Os Fundos de Investimentos Setoriais eram supervisionados por diferentes órgãos; no caso específico dos incentivos voltados para o turismo, o FISET/Turismo era supervisionado pela Embratur. Na Tabela 8, mostra-se a evolução dos recursos dos Fundos de Investimentos Setoriais captados pelas respectivas áreas de aplicação. 
Tabela 8. Recursos setoriais captados, via incentivos fiscais, pelas respectivas áreas de aplicação, de 1975 a 1986 (em 1.000 R\$ de agosto de 1994).

\begin{tabular}{cccc}
\hline Ano & Turismo & Pesca & Floresta \\
\hline 1975 & $51.477,34$ & $43.561,25$ & $389.047,09$ \\
1976 & $64.390,24$ & $34.325,72$ & $683.813,74$ \\
1977 & $44.606,89$ & $29.675,71$ & $818.601,75$ \\
1978 & $39.412,62$ & $24.616,07$ & $976.168,59$ \\
1979 & $64.284,15$ & $23.495,15$ & $1.178 .426,37$ \\
1980 & $38.111,50$ & $13.866,65$ & $671.965,98$ \\
1981 & $28.349,07$ & $11.855,44$ & $585.118,29$ \\
1982 & $25.892,46$ & $9.210,71$ & $554.060,54$ \\
1983 & $19.909,50$ & $10.929,97$ & $409.913,68$ \\
1984 & $14.760,46$ & $8.178,09$ & $298.600,17$ \\
1985 & $11.028,11$ & $6.707,68$ & $278.224,92$ \\
1986 & $57.896,72$ & $5.921,25$ & $349.683,03$ \\
TOTAL & $460.119,06$ & $222.343,69$ & $7.193 .624,15$ \\
\hline
\end{tabular}

Fonte: Abdallah (1998)

Analisando os dados a partir de 1975 (ano que começou a ter efeito o Decreto-Lei № 1.376 , de 12 de dezembro de 1974, que criou os fundos de investimentos regionais e setoriais), constatou-se que o FISET/Turismo foi o fundo com participação média nos recursos dos incentivos fiscais destinados aos setores: de 1975 a 1986, os empreendimentos de turismo captaram $R \$ 460,12$ milhões (cerca de $\mathrm{R} \$ 38,34$ milhões ao ano). Os empreendimentos pesqueiros captaram $\mathrm{R} \$ 222,3$ milhões (cerca de 18,5 milhões de reais ao ano), com a menor participação nos recursos dos incentivos fiscais; já as atividades de reflorestamento captaram $\mathrm{R} \$ 7.193,62$ milhões (cerca de $\mathrm{R} \$$ 599,5 milhões de reais ao ano), com a maior participação nos recursos.

Durante uma década, vultosos recursos foram alocados a esses fundos, o que gerou muitas denúncias de mau uso e desvio dos mesmos. Com isso, em 1985 foi criada a Comissão de Avaliação de Incentivos Fiscais (COMIF), com o objetivo de avaliar, econômica e financeiramente, os fundos de investimentos setoriais e regionais.

Em 1986, a COMIF apresentou um relatório de avaliação dos incentivos fiscais regidos pelo Decreto-Lei № 1.376, de 12 de dezembro de 1974. No que se refere ao 
FISET/Turismo, alguns resultados relatados no relatório do IPEA/COMIF (1986) foram:

a) A construção de hotéis absorveu cerca de 95\% dos recursos do FISET/Turismo desde a sua criação. Essa situação começou a se modificar em 1985, quando a Embratur passou a alocar mais recursos para investimentos não-hoteleiros, chegando essa participação a $10 \%$ dos recursos do FISET/Turismo.

b) A participação do FISET/Turismo no montante investido em empreendimentos turísticos no país não foi muito expressiva. No período de 1975 a 1983, a participação nos projetos aprovados com apoio de recursos públicos foi de $14,1 \%$ do investimento total.

c) Do total de 215 projetos aprovados para o FISET/Turismo, apenas cinco estavam paralisados, mas com estágio de obras bem adiantado, sendo todos eles passíveis de recuperação.

Ainda segundo o relatório do IPEA/COMIF (1986), os recursos para investimentos no setor turístico deveriam ser alocados mais em atividades nãohoteleiras, isso porque a atividade hoteleira apresentava uma boa rentabilidade, um prazo de maturação não muito longo, uma baixa taxa de risco e um imobilizado facilmente conversível para outras atividades. Dessa forma, a atividade hoteleira dispunha de todas as características de uma atividade que poderia e deveria ser assumida completamente pela iniciativa privada, sem 0 aporte de recursos governamentais subsidiados.

Diante disso, o IPEA/COMIF (1986) sugeriu que a forma de apoio adequada para os investimentos no setor seria a criação de linhas de financiamento de longo prazo, sem subsídios.

Vale ressaltar que, durante a década de 80 , o país entra em uma crise econômica interna, o que fez com que fossem reduzidos os investimentos em todas as áreas. Além disso, houve alteração na legislação que abaixou o teto de $25 \%$ estabelecido anteriormente por lei. No segmento do turismo, no entanto, ocorreram incentivos financeiros e fiscais para fomentar o desenvolvimento do turismo na Região Nordeste, sendo nesse período que começaram a ser implantados os megaprojetos turísticos naquela região. 
Apesar de ter recebido todos esses investimentos nas décadas de 70 e 80, o segmento do turismo não apresentava resultados satisfatórios, ou seja, não viria a se transformar num segmento relevante dentro do conjunto das atividades econômicas desenvolvidas no país como pretendiam os formuladores de tais políticas.

\subsection{Programa de ação para o desenvolvimento do turismo no Nordeste - PODETUR/NE}

Como o segmento do turismo vinha apresentando resultados aquém das expectativas, o Instituto Brasileiro do Turismo - EMBRATUR elaborou uma pesquisa de demanda turística internacional em 1991, tendo como um dos objetivos identificar os fatores apontados como inibidores do turismo, bem como os novos destinos turísticos brasileiros. Os resultados apontaram a Região Nordeste como capaz de competir com os demais destinos, visto que entre $11 \%$ e $35 \%$ dos turistas estrangeiros preferem as capitais nordestinas (Melo \& Souza, 1997).

Ainda segundo esses autores, os fatores apontados como inibidores do turismo no Nordeste foram a falta de adequada infra-estrutura de serviços urbanos e turísticos, o pequeno investimento de promoções no exterior, a pouca qualificação da mão-de-obra e a carência de recursos para financiar empreendimentos privados.

Para solucionar os problemas inibidores do turismo naquela região, foi implementado o Programa de Ação para o Desenvolvimento do Turismo do Nordeste PRODETUR/NE, que, com o apoio do Banco Interamericano de Desenvolvimento, do governo federal e dos governos estaduais, irá aplicar cerca de US\$800 milhões na região, conforme pode ser observado na Tabela 9 , em que se mostra como serão distribuídos os recursos do PRODETUR/NE por categoria de investimento.

Pode-se perceber, na referida tabela, que o PRODETUR/NE contempla investimentos em três componentes principais, a saber:

a) Desenvolvimento institucional, que objetiva ampliar a capacidade dos órgãos para executar suas funções.

b) Obras múltiplas em infra-estrutura básica e serviços públicos, que consistem em projetos voltados para cinco setores: saneamento, administração de resíduos sólidos, proteção e recuperação ambiental, transporte (obras viárias urbanas e 
rodovias) e recuperação de patrimônios históricos.

c) Melhoramento de oito aeroportos localizados nas seguintes cidades: São Luís-MA, Fortaleza-CE, Natal-RN, Aracaju-SE, Porto Seguro-BA, Salvador-BA, Lençóis-BA e Recife-PE.

Tabela 9. Recursos do Programa de Ação para o Desenvolvimento do Turismo no Nordeste - PRODETUR/NE (em US\$ mil).

\begin{tabular}{|c|c|c|c|c|}
\hline \multirow[t]{2}{*}{ Usos } & \multicolumn{4}{|c|}{ Fonte do Financiamento } \\
\hline & BID & Governo & Total & $\%$ Total \\
\hline Engenharia e Administração & 0 & 59.410 & 59.410 & 7,4 \\
\hline Estudos & & 9.300 & 9.300 & 1,1 \\
\hline Supervisão & & 26.230 & 26.230 & 3,3 \\
\hline Administração & & 23.880 & 23.880 & 3,0 \\
\hline Desenvolvimento Institucional & 11.940 & 17.940 & 29.870 & 3,7 \\
\hline Custos Diretos de Obras Múltiplas & 328.050 & 174.972 & 503.022 & 62,9 \\
\hline Saneamento & 131.780 & 77.370 & 209.150 & 26,2 \\
\hline Disposição de resíduos sólidos & 9.210 & 5.390 & 14.600 & 1,8 \\
\hline Recuperação ambiental & 16.760 & 8.240 & 25.000 & 3,1 \\
\hline Transporte & 77250 & 38.900 & 116.150 & 14,6 \\
\hline Recuperação de patrimônio histórico & 39.050 & 19.450 & 28.500 & 7,3 \\
\hline Custos sem destinação específica & 50.000 & 29.622 & 79.622 & 9,9 \\
\hline Aeroportos & 46.760 & 46.750 & 93.520 & 11,7 \\
\hline Custos Concorrentes & 0 & 9.700 & 9.700 & 1,2 \\
\hline Aquisição de terrenos & & 8.000 & 8.000 & 1,0 \\
\hline Relocalização da população & & 1.700 & 1.700 & 0,2 \\
\hline Contigentes (DI e aeroportos) & 9.250 & 9.250 & 18.500 & 2,3 \\
\hline Contingências & 5.575 & 5.575 & 11.150 & 1,4 \\
\hline Imprevistos (escalonamento de preços) & 3.675 & 3.675 & 7.350 & 0,9 \\
\hline Custos Financeiros & 4.000 & 81.978 & 85.978 & 10,7 \\
\hline Juros & & 75.544 & 75.544 & 9,4 \\
\hline Comissão de crédito & & 6.434 & 6.434 & 0,8 \\
\hline Inspeção e Supervisão & 4.000 & & 4.000 & 0,5 \\
\hline TOTAL & 400.000 & 400.000 & 800.000 & 100 \\
\hline
\end{tabular}

Fonte: Teixeira (1996) 
O PRODETUR/NE é um programa integrado que se propõe impulsionar o desenvolvimento de cada estado do Nordeste, levando-se em consideração suas potencialidades turísticas. Esse programa faz parte de um projeto nacional de desenvolvimento do turismo que visa mudar a posição marginal do país entre os destinos mundiais.

Vale salientar que o PRODETUR/NE não é um programa específico do turismo, mas sim de todos os setores que estão diretamente relacionados com o turismo, como: transporte, comunicação, saneamento e conservação do meio ambiente e do patrimônio histórico (Banco do Nordeste do Brasil - BNB, 1995), ou seja, é um programa de infra-estrutura básica e turística. Cabe ressaltar que essas obras de infraestrutura básica, além de atenderem aos anseios do segmento do turismo, capacitam a região para atrair investimentos privados, aumentando, assim, a renda, o número de empregos etc. Além disso, melhoram a qualidade de vida da população local, que é bastante carente desses serviços.

Os objetivos básicos do referido programa são: a) aumentar o turismo receptivo regional e a permanência do turista no Nordeste, b) induzir novos investimentos na infra-estrutura turística e c) promover a geração de emprego e renda com a exploração direta ou indireta da atividade turística.

Conforme apresentado anteriormente, os investimentos a serem realizados pelo PRODETUR/NE eram de cerca de US\$ 800 milhões. No decorrer dos anos da implantação do programa, no entanto, a realidade econômica do país se modificou, e isso fez com que os recursos desse programa fossem reduzidos para U\$ 670 milhões. Além disso, devido à menor capacidade de endividamento dos estados nordestinos, o BID aumentou sua contrapartida no programa para $60 \%$, ficando o restante $(40 \%)$ sob a responsabilidade dos próprios estados e do governo federal.

Tendo em vista que o PRODETUR/NE vem atingindo os objetivos anteriormente traçados (Tabela 10), um novo programa já foi assinado com o BID para a segunda fase do PRODETUR/NE e terá os mesmos investimentos e fontes que o anterior. Os objetivos desse novo programa serão: estimular as vocações econômicas locais, contribuir para a criação e fortalecimento dos empreendimentos empresariais e gerar novas oportunidades de emprego e rendas sustentáveis (Ayres et al., 2001). 
Tabela 10. Metas globais do PRODETUR/NE e acompanhamento.

\begin{tabular}{lcrrc}
\hline \multicolumn{1}{c}{ Descrição } & $\begin{array}{c}\text { Unidade de } \\
\text { medida }\end{array}$ & $\begin{array}{c}\text { Metas } \\
\text { Globais }\end{array}$ & $\begin{array}{c}\text { Realizado } \\
\text { (até dez./99) }\end{array}$ & Execução \\
\hline Empregos diretos & unid. & 1.687 .000 & 1.119 .215 & 66,3 \\
Emprego indiretos & unid. & 2.183 .000 & 1.448 .277 & 66,3 \\
Serv. de esg. sanit. e abast. d'água & Mil hab. & 809,1 & 647 & 80,0 \\
Implantação/melhoria de rodovias & $\mathrm{km}$ & 647,4 & 642,1 & 99,2 \\
Recp. de patrim. histórico & $\mathrm{m}^{2}$ & $287.792,7$ & $287.492,7$ & 99,9 \\
Preservação do meio ambiente & ha & 47.679 & $44.024,4$ & 92,3 \\
Ampl./ moder. de aeroportos & unid. & 08 & 07 & 87,5 \\
Estrut./capac. de órgãos do gov. (desenv. Institucional) & Projeto & 127 & 74 & 46,0 \\
\hline
\end{tabular}

Fonte: BNB (2001)

Além da continuidade desse PRODETUR/NE, outros programas de desenvolvimento regionais foram incluídos no projeto nacional de desenvolvimento do turismo, como: o Programa de Desenvolvimento do Turismo Ecológico da Amazônia, estando previsto o investimento de US\$ 212 milhões em projetos destinados à exploração do ecoturismo; o PRODETUR/Amazônia Legal/Centro-Oeste, em que serão aplicados US\$ 400 milhões, que beneficiarão o ecoturismo na região do pantanal matogrossense; e o PRODETUR/Sul para a Região Sul, em que serão aplicados US\$ 465 milhões, com o objetivo de preparar a região para receber os turistas procedentes do Mercosul (Embratur, 2001c).

\subsection{Programa Nacional de Financiamento do Turismo - Sistema BNDES}

Inicialmente, os financiamentos do sistema BNDES ${ }^{12}$ para o segmento do turismo destinavam-se, quase que exclusivamente, à implantação, expansão e modernização do parque hoteleiro. No entanto, a partir de 1994 começaram a despontar os financiamentos para os projetos destinados à implantação de parques temáticos e aquáticos (Saab, 1999), e com a criação do programa de turismo esses financiamentos deverão se encaminhar também para outros setores.

${ }^{12}$ O sistema BNDES é formado pelo Banco Nacional de Desenvolvimento Econômico e Social (BNDES), a Agência Especial de Financiamento Industrial (FINAME) e a BNDES Participações (BNDES PAR). 
$\mathrm{Na}$ Tabela 11, pode-se verificar a evolução do desembolso do sistema BNDES para o segmento do turismo por região do país. A partir de 1994, verifica-se também expressivo aumento no volume dos investimentos, e isso pode ser atribuído, principalmente, ao aumento no número de projetos turísticos financiados nas Regiões Sudeste e Nordeste (Saab, 1999).

Tabela 11. Desembolsos do Sistema BNDES para o turismo segundo as regiões do país - 1990/99 (em US\$ mil) *.

\begin{tabular}{|c|c|c|c|c|c|c|}
\hline \multirow[t]{2}{*}{ Anos } & \multicolumn{5}{|c|}{ Regiões } & \multirow{2}{*}{ Total } \\
\hline & Norte & Nordeste & Sudeste & Sul & Centro-Oeste & \\
\hline \multirow[t]{2}{*}{1990} & 318,9 & $7.595,4$ & $3.850,1$ & $4.250,2$ & $4.377,7$ & $20.392,3$ \\
\hline & $(1,6)$ & $(37,2)$ & $(18,9)$ & $(20,8)$ & $(21,5)$ & $(100)$ \\
\hline \multirow[t]{2}{*}{1991} & 640,3 & $4.643,2$ & $2.717,9$ & $2.807,1$ & $1.317,4$ & $12.125,9$ \\
\hline & $(5,3)$ & $(38,3)$ & $(22,4)$ & $(23,1)$ & $(10,9)$ & $(100)$ \\
\hline \multirow[t]{2}{*}{1992} & 137,7 & $3.430,2$ & $18.716,9$ & $8.132,8$ & 359,7 & $30.777,3$ \\
\hline & $(0,4)$ & $(11,1)$ & $(60,8)$ & $(26,4)$ & $(1,2)$ & (100) \\
\hline \multirow[t]{2}{*}{1993} & 80,3 & $6.211,1$ & $22.442,7$ & $7.870,0$ & 336,5 & $36.940,6$ \\
\hline & $(0,2)$ & $(16,8)$ & $(60,8)$ & $(21,3)$ & $(0,9)$ & $(100)$ \\
\hline \multirow[t]{2}{*}{1994} & 27,2 & $25.381,9$ & $30.729,7$ & $20.036,9$ & $2.964,2$ & $79.139,9$ \\
\hline & $(0,0)$ & $(32,1)$ & $(38,8)$ & $(25,3)$ & $(3,7)$ & (100) \\
\hline \multirow[t]{2}{*}{1995} & 634,3 & $46.522,2$ & $58.382,9$ & $30.585,4$ & $1.822,9$ & $137.947,7$ \\
\hline & $(0,5)$ & $(33,7)$ & $(42,3)$ & $(22,2)$ & $(1,3)$ & (100) \\
\hline \multirow[t]{2}{*}{1996} & 750,7 & $61.972,9$ & $61.642,6$ & $50.473,0$ & $3.857,0$ & $178.696,2$ \\
\hline & $(0,4)$ & $(34,7)$ & $(34,5)$ & $(28,2)$ & $(2,2)$ & $(100)$ \\
\hline \multirow[t]{2}{*}{1997} & 167,5 & $68.971,8$ & $103.988,0$ & $41.598,7$ & $3.069,7$ & $217.795,7$ \\
\hline & $(0,1)$ & $(31,7)$ & $(47,7)$ & $(19,1)$ & $(1,4)$ & (100) \\
\hline \multirow[t]{2}{*}{1998} & 68,4 & $27.882,9$ & $49.770,2$ & $26.679,1$ & $3.133,1$ & $107.533,7$ \\
\hline & $(0,1)$ & $(25,9)$ & $(46,3)$ & $(24,8)$ & $(2,9)$ & (100) \\
\hline \multirow[t]{2}{*}{1999} & - & $24.890,7$ & $30.494,1$ & $6.073,6$ & $2.088,3$ & $63.546,7$ \\
\hline & - & $(39,2)$ & $(48,0)$ & $(9,6)$ & $(3,3)$ & $(100)$ \\
\hline TOTAL & $2.825,3$ & $277.502,3$ & $382.735,1$ & $198.506,8$ & $23.326,5$ & $884.896,0$ \\
\hline
\end{tabular}

Fonte: no período de 1990 a 1998 (Saab, 1999) e no ano de 1999 (Saab, 2001). ${ }^{13}$

*Os valores entre parênteses referem-se à participação do desembolso para cada região no desembolso total anual.

${ }^{13}$ SAAB, W.G.L. (BNDES, Gerência Setorial de Turismo, Comércio e Serviços, Rio de Janeiro). Comunicação Pessoal, 2001. 
Segundo Saab (1999), o programa de turismo do sistema BNDES foi criado com a Decisão da Diretoria № 310/99, do dia 1o de julho de 1999, sendo complementado pelas modificações trazidas pela Decisão da Diretoria № 321/99, de 5 de julho de 1999. O referido programa tem por objetivo apoiar empreendimentos conduzidos pelo setor privado do segmento do turismo nas localidades que apresentem potencial para tal, contribuindo para o desenvolvimento e competitividade do segmento no país (Banco de Desenvolvimento Econômico e Social - BNDES, 2001).

Dentre os itens que são financiáveis pelo programa de turismo do sistema BNDES, podem-se citar: meios de hospedagem (hotéis, resorts, pousadas e assemelhados, exceto hotel-residência); equipamentos e prédios históricos (igrejas, casas de cultura e museus); parques temáticos; teatros e anfiteatros; teleféricos; sítios históricos, ambientais e arqueológicos; centros de compras e de convenções; parques de exposições e rodeios; parques de estâncias climáticas, termais e hidrominerais; marinas que incluam a guarda de embarcações, prestação de serviços náuticos e serviços públicos básicos; infra-estrutura turística, como urbanização, estradas, ferrovias, terminais rodoviários e ferroviários, estações marítimas e de passageiros; escolas destinadas à qualificação de mão-de-obra para o setor; e outros segmentos integrados ao turismo.

Vale ressaltar que, além das fontes acessíveis para financiar investimentos exclusivamente no segmento do turismo, como os expostos anteriormente, existem outras fontes de financiamento que não são específicas para este segmento, mas que financiam alguns investimentos nessa área, como:

- Fundo de Investimentos no Nordeste (FINOR) e o Fundo de Investimentos na Amazônia (FINAM), que foram criados pelo Decreto-Lei № 1.376/74 e alterados pela Lei № 8.167/91, sendo regulamentado pelo Decreto-Lei № 101/91.

- O Fundo Constitucional do Norte (FNO) e o Fundo Constitucional do Nordeste (FNE), que foram criados com a Constituição Federal do Brasil de 1988, em seu Artigo 159. Estes fundos de investimentos foram regulamentados pela Lei № 7.827 , de 27 de setembro de 1989 . 
Pelo exposto, pôde-se observar que o turismo no Brasil é um segmento relativamente novo, tendo suas ações iniciadas por volta de 1938, mas que vem ganhando expressão no cenário nacional com tendência a ocupar um espaço crescente na pauta das políticas de desenvolvimento do país. Para isso, percebeu-se que o segmento do turismo recebeu quantia expressiva de investimentos na última década.

Apesar desses investimentos, o segmento do turismo ainda enfrenta problemas, como: infra-estrutura turística insuficiente qualitativa e quantitativamente $\mathrm{e}$ concentrada espacialmente; a falta de mão-de-obra especializada e a ausência de marketing do turismo brasileiro nos principais países emissores; altos preços das passagens aéreas, má conservação das estradas; e falta de segurança e saneamento básico. Esses problemas constituem-se em gargalos que devem ser superados, para que o segmento do turismo venha a tornar-se um propulsor de desenvolvimento. Para isso, necessita-se de ações não só de intervenção do Estado, como também de atores privados.

No próximo capítulo é estabelecido um arcabouço teórico básico para a construção e implementação empírica de um modelo de insumo-produto para a economia turística, e com isso se espera estar contribuindo tanto com o poder público quanto com o setor privado no planejamento e implementação das ações para um melhor funcionamento do segmento do turismo no Brasil. 


\section{REFERENCIAL TEÓRICO}

O instrumental de análise escolhido para desenvolver este trabalho foi a teoria de insumo-produto proposta inicialmente por Leontief. Assim, nas seções seguintes deste capítulo, procurou-se apresentar primeiro alguns conceitos básicos dessa teoria, dando ênfase a dois modelos de insumo-produto, o modelo aberto e o modelo fechado em relação às famílias. Em seguida, são apresentados os métodos utilizados na construção dos modelos de insumo-produto mais utilizados na literatura. Essas apresentações tornaram-se necessárias para facilitar o entendimento do instrumental metodológico descrito no capítulo posterior.

\subsection{A teoria básica de insumo-produto}

Pode-se dizer que o embrião do modelo de insumo-produto surgiu com o fisiocrata François Quesnay, em 1758, quando publicou o Tableau Économique, no qual tinha a preocupação de verificar a interdependência das atividades econômicas. Segundo Miernyk (1974), ao longo dos anos vários foram os economistas que contribuíram para o desenvolvimento da teoria do equilíbrio geral. No entanto, somente na década de 30 , do século 20 , é que foi atingido o ponto mais alto do trabalho iniciado por Quesnay. Isso ocorreu quando Wassily Leontief apresentou uma teoria geral da produção, baseada na interdependência econômica.

Após os trabalhos de Leontief, este instrumento de análise passou por outro período de estagnação, dessa vez devido à sofisticação matemática necessária e à relativa complexidade para os cientistas sociais naquele tempo, vindo a ficar novamente em evidência, por ocasião da Segunda Guerra Mundial, nos Estados Unidos. A partir daí, tem cada vez mais se tornado instrumental bastante utilizado nas mais diversas regiões do mundo, principalmente após o progresso dos computadores 
eletrônicos, bem como de outros métodos eficientes de computação (Miller, 1998).

Ao longo do tempo, o modelo de insumo-produto vem evoluindo e, atualmente, é considerado um poderoso instrumento de análise. Nos últimos anos, além de ser utilizado no planejamento econômico através da análise e mensuração das estruturas econômicas e dos impactos das políticas econômicas em um país ou região, vem sendo empregado também em estudos inter-regionais, poluição ambiental, emprego associado com a produção industrial etc. (Miller \& Blair, 1985).

O modelo de insumo-produto, como é conhecido, consiste de um conjunto de $n$ equações e $m$ incógnitas que pode ser resolvido utilizando-se a inversão de matrizes. A solução do sistema fornece os requerimentos necessários de cada produto para satisfazer a demanda final de determinado setor, consistindo, assim, numa solução de equilíbrio geral na esfera produtiva da economia (Dervis et al., 1982).

Segundo Considera et al. (1997), o conjunto de tabelas de um modelo de insumo-produto pode ser dividido em dois grupos, a saber:

- Tabelas básicas, atualmente denominadas tabelas de recurso e uso, que resumem e organizam as informações econômicas de determinado país ou região, como produção, consumo intermediário, salários e encargos sociais pagos, investimentos etc.

- Tabelas resultantes da aplicação de um modelo sobre as informações contidas nas tabelas básicas e que servem para obtenção dos parâmetros desse modelo. Sua derivação mais conhecida é a matriz de Leontief.

O modelo de insumo-produto, conforme apresentado por Leontief, considerava o sistema fechado, ou seja, não existiam setores exógenos no modelo. Os setores que comumente aparecem na demanda final eram todos incorporados à matriz de produção. No entanto, com o passar dos tempos, percebeu-se que alguns setores deveriam ser exógenos, e criou-se o setor demanda final, formado pelo consumo do governo, pelas exportações, pela formação bruta de capital fixo e pelo consumo das famílias. Neste caso, tem-se o modelo aberto.

Vale ressaltar que, embora o modelo aberto seja atualmente o mais usado, em alguns estudos o consumo das famílias é endogeneizado, e nesse caso tem-se o 
modelo de insumo-produto fechado em relação às famílias, significando que o setor família é deslocado para o processo produtivo, e, dessa forma, o consumo de bens e serviços das famílias por bens e serviços produzidos na economia é determinado endogenamente. Nos dois subitens seguintes, são analisadas essas duas maneiras de abordar o modelo de insumo-produto.

\subsubsection{O modelo aberto}

Para facilitar a visualização e a integração de um sistema econômico, as informações do modelo de insumo-produto podem ser organizadas em um quadro que descreve os insumos e as produções dos diferentes setores, em dado período de tempo (Quadro 4). Suas linhas representam a distribuição da produção e suas colunas, os insumos absorvidos pelos setores da produção.

\begin{tabular}{|c|c|c|c|c|c|c|c|c|c|}
\hline \multirow{3}{*}{\multicolumn{2}{|c|}{ Setores }} & \multicolumn{7}{|c|}{ Compras (j) } & \multirow{4}{*}{$\begin{array}{c}\begin{array}{c}\text { Valor Bruto } \\
\text { da }\end{array} \\
\text { Produção }\end{array}$} \\
\hline & & \multicolumn{3}{|c|}{ Demanda Intermediária } & \multicolumn{4}{|c|}{ Demanda Final } & \\
\hline & & Setor 1 & Setor 2 & Setor 3 & C & I & $G$ & $E$ & \\
\hline \multirow{3}{*}{$\begin{array}{l}\text { Vendas } \\
\qquad(i)\end{array}$} & Setor 1 & $z_{11}$ & $z_{12}$ & $z_{13}$ & $C_{1}$ & $I_{1}$ & $G_{1}$ & $E_{l}$ & \\
\hline & Setor 2 & $z_{21}$ & $z_{22}$ & $z_{23}$ & $C_{2}$ & $I_{2}$ & $G_{2}$ & $E_{2}$ & $X_{2}$ \\
\hline & Setor 3 & $z_{31}$ & $z_{32}$ & $z_{33}$ & $C_{3}$ & $I_{3}$ & $G_{3}$ & $E_{3}$ & $X_{3}$ \\
\hline \multicolumn{2}{|c|}{ Importações } & $M_{1}$ & $M_{2}$ & $M_{3}$ & $M_{C}$ & $M_{I}$ & $M_{G}$ & $M_{E}$ & \\
\hline \multicolumn{2}{|c|}{$\begin{array}{c}\text { Tributos Indiretos } \\
\text { Líquidos }\end{array}$} & $T_{1}$ & $T_{2}$ & $T_{3}$ & $T_{C}$ & $T_{I}$ & $T_{G}$ & $T_{E}$ & \\
\hline \multicolumn{2}{|c|}{ Salários } & $L_{1}$ & $L_{2}$ & $L_{3}$ & & & & & \\
\hline \multicolumn{2}{|c|}{ Valor Adicionado } & $V A_{1}$ & $V A_{2}$ & $V A_{3}$ & & & & & \\
\hline \multicolumn{2}{|c|}{$\begin{array}{l}\text { Valor Bruto da } \\
\text { Produção }\end{array}$} & $X_{1}$ & $X_{2}$ & $X_{3}$ & & & & & \\
\hline
\end{tabular}

Quadro 4 - Matriz de insumo-produto simplificada conforme Leontief.

Fonte: Adaptado conforme apresentado em Miller \& Blair (1985). 
em que:

$X_{i}$ é a produção total do setor $i$ (consumo intermediário e demanda final);

$z_{i j}$ é a produção do setor $i$ utilizada como insumo intermediário pelo setor $j$ (consumo intermediário);

$C_{i}$ é a produção do setor $i$ que é consumida pelas famílias;

$I_{i}$ é a produção do setor $i$ destinada ao investimento;

$G_{i}$ é a produção do setor $i$ que é consumida pelo governo;

$E_{i}$ é a produção do setor $i$ que é destinada à exportação;

$X_{j}$ é o custo de produção total do setor $j$;

$M_{j}$ são as importações feitas pelo setor $j$;

$M_{C}$ são as importações feitas para o consumo das famílias;

$M_{I}$ são as importações destinadas ao investimento;

$M_{G}$ são as importações destinadas ao governo;

$M_{E}$ são as importações destinadas à exportação, ressaltando-se que estas passam por alguma transformação para serem reexportadas;

$L_{j}$ são os salários pagos pelo setor $j$ no processo de produção;

$V A_{j}$ é total do valor adicionado do setor $j$; e

$T_{j}$ é total dos impostos indiretos líquidos recolhidos pelo setor $j$ (aluguéis, juros, lucros, impostos indiretos líquidos e depreciações).

As transações especificadas no Quadro 4 podem ser representadas das seguintes maneiras:

- Pelo vetor-linha, que representa a distribuição do produto através do próprio setor, dos demais setores da economia e dos componentes da demanda final. A partir desse vetor, pode-se estabelecer a seguinte igualdade:

$$
\begin{gathered}
X_{i}=z_{i 1}+z_{i 2}+C_{i}+I_{i}+G_{i}+E_{i} \\
Y_{i}=C_{i}+I_{i}+G_{i}+E_{i} \\
X_{i}=\sum_{j=1}^{n} z_{i j}+Y_{i}
\end{gathered}
$$


Essa expressão mostra que, para cada produto $i$, o total da oferta é igual ao total da demanda.

- Pelo vetor-coluna, que representa a distribuição dos insumos através de todos os setores da economia e a despesa com os produtos importados e com os componentes do valor adicionado bruto do setor. São eles:

$$
\begin{gathered}
X_{j}=z_{1 j}+z_{2 j}+M_{j}+L_{j}+T_{j} \\
X_{j}=\sum_{i=1}^{n} z_{i j}+M_{j}+V A_{j}
\end{gathered}
$$

A expressão (5) indica que a produção total em cada setor corresponde ao valor dos insumos comprados dos outros setores, inclusive os importados, mais o valor adicionado nesse setor.

Por se tratar de um sistema de equilíbrio geral, conforme mencionado anteriormente, a soma dos elementos nas colunas é igual à soma dos elementos nas linhas, isto é:

$$
X_{i}=X_{j}
$$

Todas essas equações representam duas óticas do valor bruto da produção. No entanto, para definir o sistema de equações lineares simultâneas será considerada, nos passos seguintes, a igualdade obtida no vetor-linha.

Em dada economia com $n$ setores, existe um fluxo contínuo de produtos entre cada setor dessa economia. Esse fluxo pode ser determinado por fatores tecnológicos e econômicos, que podem ser descritos por um sistema de equações lineares simultâneas, representadas por

$$
\begin{aligned}
& X_{1}=z_{11}+z_{12}+\cdots+z_{1 n}+Y_{1} \\
& X_{2}=z_{21}+z_{22}+\cdots+z_{2 n}+Y_{2} \\
& \vdots \\
& X_{n}=z_{n 1}+z_{n 2}+\cdots+z_{n n}+Y_{n}
\end{aligned}
$$


Admitindo a hipótese de que a quantidade de insumo do setor $i$ utilizada pelo setor $j$ é diretamente proporcional à produção do setor $j$, pode-se estabelecer uma constante de proporcionalidade para as duas variáveis, chamada de coeficiente técnico de produção, como se segue:

$$
z_{i j}=a_{i j} \cdot X_{j} \quad \text { ou } \quad a_{i j}=\frac{z_{i j}}{X_{j}}
$$

Substituindo a eq. (8) na eq. (7), tem-se como resultado um sistema de equações lineares simultâneas que possui como parâmetros os coeficientes técnicos de produção, podendo ser escrito da seguinte forma:

$$
\begin{aligned}
& X_{i}=a_{i 1} X_{1}+a_{i 2} X_{2}+\cdots+a_{i n} X_{n}+Y_{i} \\
& X_{2}=a_{21} X_{2}+a_{22} X_{2}+\cdots+a_{2 n} X_{n}+Y_{2} \\
& \vdots \\
& X_{n}=a_{n 1} X_{1}+a_{n 2} X_{2}+\cdots+a_{n n} X_{n}+Y_{n}
\end{aligned}
$$

Isolando $Y_{1}$ e colocando $X_{1}$ em evidência, tem-se

$$
\left(1-a_{i 1}\right) X_{1}-a_{i 2} X_{2}-\cdots-a_{i n} X_{n}=Y_{1}
$$

Procedendo-se dessa forma para os $n$ setores, é possível definir, de forma genérica, as seguintes matrizes:

$$
\boldsymbol{A}=\left[\begin{array}{lccccc}
a_{11} & a_{12} & \ldots & a_{1 i} & \ldots & a_{1 n} \\
a_{21} & a_{22} & \ldots & a_{2 i} & \ldots & a_{2 n} \\
\vdots & \vdots & & \vdots & & \vdots \\
a_{n 1} & a_{n 2} & \ldots & a_{n i} & \ldots & a_{n n}
\end{array}\right], \quad \boldsymbol{X}=\left[\begin{array}{c}
X_{1} \\
X_{2} \\
\vdots \\
X_{n}
\end{array}\right], \quad \text { e } \quad \boldsymbol{Y}=\left[\begin{array}{c}
Y_{1} \\
Y_{2} \\
\vdots \\
Y_{n}
\end{array}\right]
$$

em que

$\boldsymbol{A}$ é a matriz dos coeficientes técnicos, de ordem ( $\mathrm{n} \times \mathrm{n})$;

$X$ é o vetor do valor bruto da produção, de ordem ( $\mathrm{x} \times 1)$; e

$Y$ é o vetor da demanda final, de ordem $(n \times 1)$. 
Como observado, a matriz $\boldsymbol{A}$ é formada por um conjunto de coeficientes técnicos de produção $a_{i j}$, que representam a quantidade de insumo $i$ para se obter uma unidade do produto $j$, sendo $a_{i j}<1$ e $\left(1-a_{i j}\right)>0$. Cada coluna da matriz $\boldsymbol{A}$ descreve a estrutura tecnológica do setor correspondente. Admite-se que os coeficientes técnicos $a_{i j}$ sejam medidas fixas, uma vez que o modelo de insumo-produto pressupõe retornos constantes de escala.

Em notação matricial, as matrizes anteriormente descritas podem ser assim expressas:

$$
\begin{gathered}
X=A X+Y \\
X-A X=Y \\
(I-A) X=Y \\
X=(I-A)^{-1} Y
\end{gathered}
$$

A matriz $(\boldsymbol{I}-\boldsymbol{A})^{-1}$ é denominada matriz inversa de Leontief e capta os efeitos diretos e indiretos das modificações exógenas da demanda final sobre a produção dos $n$ setores. A partir da expressão (14), portanto, podem ser avaliados os impactos de políticas setoriais sobre os outros setores da economia.

Fazendo-se $\boldsymbol{B}=(\boldsymbol{I}-\boldsymbol{A})^{-1}$, cada elemento $b_{i j}$ corresponde aos requisitos diretos e indiretos da produção total do setor $i$ necessários para produzir uma unidade de demanda final do setor $j$. Assim, a expressão (14) passará a ser escrita da seguinte forma:

$$
\boldsymbol{X}=\boldsymbol{B} \boldsymbol{Y}
$$

De acordo com Haddad (1989), os elementos $b_{i j}$ apresentam as seguintes características:

a) $b_{i j} \geq a_{i j}$, ou seja, cada elemento da matriz inversa de Leontief é superior ou igual ao respectivo elemento da matriz tecnológica, uma vez que o elemento $b_{i j}$ indica os efeitos diretos e indiretos sobre a produção do setor $i$ para atender a uma unidade monetária de demanda final do setor $j$, enquanto o elemento $a_{i j}$ indica apenas os efeitos diretos; a igualdade entre os dois coeficientes ocorre no caso particular em que os efeitos indiretos são nulos. 
b) $b_{i j} \geq 0$, vale dizer que não há possibilidade de substituição de insumos, uma vez que os coeficientes técnicos de produção são fixos, de tal forma que uma expansão na demanda final do setor $j$ irá provocar efeito positivo ou nulo sobre a produção do setor $i$, nunca efeito negativo. O efeito nulo surgirá se não houver interdependência direta entre os setores $i \mathrm{e} j$.

c) $b_{i j} \geq 1$, para $i=j$, isto é, os elementos da diagonal principal da matriz inversa de Leontief serão sempre iguais ou superiores a 1, uma vez que o acréscimo de uma unidade monetária na demanda final de um setor deverá provocar expansão na produção desse setor de pelo menos uma unidade monetária.

\subsubsection{O modelo fechado em relação às famílias}

O modelo que foi tratado até aqui tinha como elementos exógenos o consumo das famílias, vendas ao governo, investimentos e exportações. Nesta subseção, trata-se do modelo fechado em relação às famílias, isto é, o setor de consumo das famílias será endogeneizado. Sabe-se que a participação das famílias no consumo final depende de sua renda, que é proveniente do pagamento pelo trabalho delas no processo produtivo, dependendo, assim, do que é produzido em cada setor. Desse modo, é possível trazer o setor família (consumo) da demanda final para a matriz $X$, endogeneizando-o aos demais setores. Quando isso ocorre, tem-se um modelo fechado em relação às famílias. Nesse caso, criam-se uma nova linha e uma nova coluna $(n+1)$ para o setor família na matriz $\boldsymbol{X}^{14}$

Desse modo, o conjunto de equações como apresentado em (07) passará, agora, a ser escrito da seguinte forma:

$$
\begin{aligned}
& X_{1}=z_{11}+z_{12}+\cdots+z_{1 n}+z_{1, n+1}+Y_{1}^{*} \\
& X_{2}=z_{21}+z_{22}+\cdots+z_{2 n}+z_{2, n+1}+Y_{2}^{*} \\
& \vdots \\
& X_{n+1}=z_{n+1,1}+z_{n+1,2}+\cdots+z_{n+1, n}+z_{n+1, n+1}+Y_{n+1}^{*}
\end{aligned}
$$

\footnotetext{
${ }^{14}$ A nova coluna criada na matriz de demanda intermediária é a transferência da coluna consumo das famílias da matriz $\boldsymbol{Y}$ (demanda final). Já a linha criada é a transferência dos insumos primários (remuneração e rendimento de autônomos) para a matriz de demanda intermediária $(\boldsymbol{X})$.
} 
De acordo com Miller \& Blair (1985), os coeficientes técnicos de produção para o modelo fechado em relação às famílias podem ser obtidos de maneira semelhante à dos que foram conseguidos no modelo aberto para os $n$ setores. E no caso dos coeficientes técnicos do setor $n+1$, setor família ("coeficiente de consumo" do setor família), eles podem também ser obtidos da mesma maneira, como se segue:

$$
a_{i, n+1}=\frac{z_{i, n+1}}{X_{n+1}} \quad \text { ou } \quad z_{i, n+1}=a_{i, n+1} X_{n+1}
$$

Substituindo (17) no conjunto de equações (16), este passará a ser escrito do seguinte modo:

$$
\begin{aligned}
& X_{i}=a_{i 1} X_{1}+a_{i 2} X_{2}+\cdots+a_{i n} X_{n}+a_{1, n+1} X_{n+1}+Y_{1}^{*} \\
& X_{2}=a_{21} X_{2}+a_{22} X_{2}+\cdots+a_{2 n} X_{n}+a_{2, n+1} X_{n+1}+Y_{2}^{*} \\
& \vdots \\
& X_{n+1}=a_{n=1,1} X_{1}+a_{n+1,2} X_{2}+\cdots+a_{n+1, n} X_{n}+a_{n+1, n+1} X_{n+1}+Y_{n+1}^{*}
\end{aligned}
$$

Procedendo de maneira similar à da equação (10), temse, agora, um conjunto de equações que podem ser expressas de forma genérica no seguinte conjunto de matrizes:

$$
\overline{\boldsymbol{A}}=\left(\begin{array}{c:c}
\boldsymbol{A} & \boldsymbol{H}_{\boldsymbol{C}} \\
\hdashline \boldsymbol{H}_{\boldsymbol{R}} & \boldsymbol{h}
\end{array}\right), \overline{\boldsymbol{X}}=\left(\begin{array}{c}
\boldsymbol{X} \\
\hdashline \boldsymbol{X}_{n+1}
\end{array}\right) \quad \text { e } \overline{\boldsymbol{Y}}=\left(\begin{array}{c}
\boldsymbol{Y}^{*} \\
\boldsymbol{Y}_{n+1}^{*}
\end{array}\right)
$$

em que

$\bar{A}$ é a matriz dos coeficientes técnicos com o setor família endogeneizado, com dimensão $(n+1 \times n+1)$;

$\boldsymbol{H}_{C}$ vetor-coluna dos coeficientes de consumo dos $n$-setores iniciais $\left(a_{i, n+1}\right.$ com $i=1,2, \ldots, n)$;

$\boldsymbol{H}_{R}$ vetor-linha dos coeficientes de insumos das famílias, considerando-se os $n$-setores $\left(a_{n+1, j} \operatorname{com} j=1,2, \ldots, n\right)$;

$\boldsymbol{h}$ é a interação do setor família com ele mesmo $\left(a_{n+1, n+1}\right)$, em geral zero;

$\bar{X}$ é o vetor do valor bruto da produção, cuja dimensão é $[(n+1) \times 1]$;

$Y^{*}$ é a demanda final com o consumo endógeno das famílias, considerando-se 
os $n$-setores;

$\bar{Y}$ é o vetor da demanda final sem o consumo das famílias.

Assim, o modelo de Leontief, após a endogeneização do setor família, passará a ser escrito em termos matriciais, como se segue:

$$
\begin{gathered}
\overline{\boldsymbol{X}}=(\boldsymbol{I}-\overline{\boldsymbol{A}})^{-1} \overline{\boldsymbol{Y}} \\
\text { ou } \\
\left(\begin{array}{c}
\boldsymbol{X}_{\ldots} \\
\hdashline \boldsymbol{X}_{n+1}
\end{array}\right)=\left(\begin{array}{cc}
\boldsymbol{I}-\boldsymbol{A} & -\boldsymbol{H}_{\boldsymbol{C}} \\
\hdashline \boldsymbol{H}_{\boldsymbol{R}} & 1-\boldsymbol{h}
\end{array}\right)^{-1}\left(\begin{array}{c}
\boldsymbol{Y}^{*} \\
\hdashline \boldsymbol{Y}_{n+1}^{*}
\end{array}\right)
\end{gathered}
$$

Conforme mencionado anteriormente, existe um fluxo contínuo de produtos entre cada setor da economia. Originalmente, do ponto de vista teórico, as variáveis utilizadas no modelo seriam expressas em unidades físicas, o que impossibilitaria a utilização dessa tabelas em estudos empíricos. Isso acontece devido às dificuldades de mensuração dos fluxos intersetoriais que surgem quando um setor produz mais de um produto e quando os produtos são expressos em unidades físicas diferentes. Assim, para eliminar esse problema, as tabelas de insumo-produto são expressas em termos monetários. Devido a esse fato, apresenta-se a crítica de que os valores dos coeficientes poderiam ser afetados em razão das mudanças nos preços relativos. De acordo com Miller \& Blair (1985), uma forma de resolver tal problema foi assumir que os preços relativos são constantes.

Além dessa pressuposição, é importante ressaltar que a teoria de insumoproduto original apresenta ainda os seguintes pressupostos:

- assume-se que os coeficientes técnicos são fixos (a quantidade de insumos para produzir uma unidade de produto é constante), isto é, retornos constantes de escala;

- assume-se que cada setor produz somente um tipo de produto por meio de um único processo de produção;

- não existe substituição entre insumos;

- $\quad$ assume-se eficiência na alocação de recursos;

- não há restrições de recursos; 
- equilíbrio geral na economia a dado nível de preço; e

- inexistência de ilusão monetária por parte dos agentes econômicos.

Essas pressuposições são vistas por muitos autores como dificuldades ou limitações da análise de insumo-produto. No entanto, não impediram a sua rápida difusão pelo mundo, sendo adotada por vários países como mais um instrumento utilizado para o planejamento de suas economias (Miernyk, 1974). Com relação ao turismo, a análise de insumo-produto vem sendo utilizada por diversos autores, com um grau de sucesso variado. Segundo Bull (1991), alguns dos insucessos se devem, principalmente: à escassez de dados, particularmente em nível regional; e às dificuldades específicas com a natureza do segmento do turismo, como a determinação do que é e do que não é parte deste segmento.

Segundo Guilhoto (1995), a análise de insumo-produto pode ser considerada um dos melhores instrumentos para se analisarem as relações intersetoriais, sejam elas em níveis nacional, regional, inter-regional ou internacional. Bull (1991) complementou, afirmando que os estudos dos multiplicadores e a análise de insumo-produto têm sido a maneira mais adequada de examinar os impactos secundários do turismo sobre uma economia. Archer (1995) concordou com essa afirmativa, acrescentando que as limitações somente trarão problemas se o modelo for utilizado para fazer previsões. Fletcher (1989) disse que a análise de insumo-produto é, sem dúvida, a melhor maneira para estudar os impactos econômicos do turismo, uma vez que nenhuma outra técnica pode oferecer a flexibilidade e o nível de detalhes produzidos por ela.

\subsection{Métodos utilizados na construção dos modelos de insumo-produto}

Comumente, na literatura, encontra-se que as matrizes dos modelos de insumo-produto, para um segmento econômico de determinada economia, podem ser elaboradas e estimadas através de dois métodos: o método com informações censitárias e o método sem informações censitárias. 
- Método com informações censitárias: consiste na elaboração de tabelas de insumo-produto, utilizando-se informações diretas ou dados primários sobre os fluxos de mercadorias entre os setores.

Este método, segundo a Embratur (1991), apresenta vantagens e desvantagens que merecem ser consideradas. As vantagens são as seguintes: i) adaptar-se temporalmente ao período que se deseja analisar; ii) adaptar-se estruturalmente de acordo com os interesses do processo de análise; e, iii) dar uma maior liberdade de ação para definir os setores. Já as desvantagens são: i) custos econômicos elevados e custos temporais, ii) exigência de formação de uma equipe de especialistas em diferentes setores produtivos do sistema econômico, iii) recebimento de apoio institucional e das empresas para formulação e execução da pesquisa e iv) ausência de marco informativo suficiente para basear as pesquisas.

- Método sem informações censitárias: consiste na elaboração de tabelas de insumo-produto, utilizando-se informações de tabelas já existentes. De acordo com Montoya (1998), a técnica consiste em calcular a proporção de suprimentos de mercadorias produzidas internamente e importadas a partir de uma matriz de insumo-produto.

Como no método com informações censitárias, o método sem informações censitárias também apresenta vantagens e desvantagens. De acordo com a Embratur (1991), as vantagens podem ser assim enumeradas: i) existência de um modelo de qualidade já definido, ii) existência de marco estrutural já delineado, iii) custos econômicos menores e iv) maior rapidez na estimação do modelo pretendido. Já as desvantagens são: i) obrigatoriedade de estimar o modelo para determinado ano, que pode ser antigo não mostrando as relações intersetoriais e outras atualmente existentes; ii) assumir erros que implicitamente uma tabela pode conter; e iii) assumir uma estrutura intersetorial pouco adequada às análises que se pretendem fazer.

Segundo Round ${ }^{15}$, citado por Rodrigues (2000), embora os termos métodos censitários e não-censitários, sugiram dois grupos bem definidos e mutuamente excludentes; na prática, todas as tabelas de insumo-produto são híbridas, ou seja, são

15 ROUND, J.I. Nonsurvey techiques: a critical review of the theory and the evidence. International Regional Science Review, v.8, n.3, p.189-212, 1983. 
construídas por meio de técnicas semicensitárias, utilizando-se de informações provenientes de fontes primárias e secundárias em maior ou menor escala. Segundo Montoya (1998), o termo sem informação censitária ou com informação semicensitária também é utilizado, na literatura, para designar métodos de construção de matrizes baseados em dados censitários, quando as observações diretas não estão disponíveis ou os dados do censo são inconsistentes

Montoya (1998) relatou que a forma mais adequada de distinguir os métodos empregados na construção de matrizes de insumo-produto é classificá-los, de acordo com a natureza dos dados utilizados, em:

- Métodos com informação censitária: quando as informações estatísticas utilizadas são diretas.

- Métodos com informação censitária limitada: quando as informações utilizadas são estimativas das informações diretas requeridas. Assim, estarão incluídos nesta categoria os métodos comumente denominados na literatura como sem informação censitária e com informação semicensitária.

No capítulo seguinte, aborda-se, com maiores detalhes, a forma como o modelo de insumo-produto proposto neste trabalho será estimado, tendo em vista que se dispõe de informações muito limitadas para o segmento do turismo no Brasil. 


\section{METODOLOGIA}

Para construir o modelo de insumo-produto da economia turística no Brasil, utilizou-se o método com informação censitária limitada, que foi apresentado no capítulo anterior, uma vez que as informações relacionadas com o segmento do turismo no Brasil são bastante escassas.

Dessa forma, para construção do referido modelo, tomou-se como ponto de partida o modelo de insumo-produto geral da economia brasileira, elaborado por Guilhoto et al. (2001) para o ano de 1999, a partir das informações obtidas das Contas Nacionais do Brasil. Tal procedimento foi adotado tendo em vista que a última versão disponível da matriz de insumo-produto geral da economia brasileira até a época de início da realização do presente trabalho, elaborada pelo Instituto Brasileiro de Geografia e Estatística, foi para o ano de 1996.

Nas seções seguintes deste capítulo são descritos os procedimentos utilizados na construção do modelo de insumo-produto para a economia turística no Brasil. Além disso, são descritos os meios de obtenção da matriz de coeficientes técnicos, uma vez que não se dispõe de matrizes de insumo-produto, conforme descrito anteriormente. Em seguida, apresentam-se os conceitos e cálculos dos métodos de análises das relações intersetoriais da economia, bem como dos impactos

do segmento do turismo na economia. É apresentada também uma metodologia através da qual se procurou dimensionar o segmento do turismo no Brasil, considerando-se o valor adicionado e o pessoal ocupado. 


\subsection{A construção do modelo de insumo-produto do turismo no Brasil}

O modelo de insumo-produto geral para economia brasileira, elaborado por Guilhoto et al. (2001) para o ano de 1999, apresenta as informações numa abordagem do tipo enfoque produto por setor a preços básicos ${ }^{16}$, permitindo que cada produto seja produzido por mais de um setor e que cada setor produza mais de um produto, ou seja, existe uma matriz de produção e outra de uso dos insumos. A dimensão da matriz de produção é de 42 setores por 80 produtos e a matriz de uso, de 80 produtos por 42 setores.

A elaboração do modelo de insumo-produto para o turismo, a partir da matriz de insumo-produto geral para a economia brasileira, dar-se-á por meio da agregação de alguns setores (os que, segundo a literatura, têm pouca relação com o turismo) e da desagregação de outros setores (os que podem ser considerados de maior projeção turística). A descrição da agregação e desagregação será tratada nas subseções seguintes.

\subsubsection{Setores econômicos do segmento do turismo}

Segundo Paci (1996), os termos setor turismo e produto turístico não existem no sentido econômico, pois o turismo é um conjunto de atividades econômicas (bens e serviços) que satisfazem as necessidades dos turistas, ou seja, o turismo compreende as atividades que as pessoas realizam durante suas viagens e estadas em lugares diferentes de sua residência por um tempo superior a 24 horas e inferior a um ano com fins de ócio, negócios e outros motivos (visitas a parentes e amigos, tratamento de saúde etc.). Excluem-se os trabalhadores das fronteiras, as viagens para estudos e para procurar emprego, os diplomatas e o pessoal das forças armadas quando em serviço.

Esse conjunto de atividades econômicas que compõem o segmento do turismo ainda não se encontra bem definido na literatura, ou seja, não existe consenso entre os autores para definir quais atividades compõem esse segmento. Para Lage \& Milone (1991), o conjunto de atividades econômicas que compõem o segmento do

${ }^{16}$ Preço básico é o preço de mercado dos bens e serviços menos os imposto indiretos líquidos e as margens de transporte e comercialização, ou seja, é o preço dos bens na porta da fábrica. 
turismo são: transporte de passageiros (rodoviário, aéreo, marítimo, táxi), hospedagem (hotéis, pousadas, "flats"), alimentação (restaurantes, bares, lanchonetes), serviços culturais e de recreação (teatros, casas de espetáculos etc.). Já para Lundberg et al. (1995), os setores econômicos do turismo são: hotéis, restaurantes, transporte aéreo, aluguel de carros e agências de viagens. Vale salientar que os referidos autores, apesar de não apresentarem algumas atividades que foram citadas por outros autores, por exemplo Espanha (1996), não afirmaram que elas não poderiam ser incluídas no segmento do turismo.

Neste trabalho, a definição das atividades que foram utilizadas para compor o segmento do turismo foi feita, levando-se em consideração a definição dos autores anteriormente citados, além dos objetivos específicos do referido trabalho. Assim, as atividades econômicas que constituem o segmento do turismo foram reunidas em 12 setores do modelo de insumo-produto para o turismo no Brasil, a saber:

- Transporte rodoviário de passageiros, regular.

- Transporte rodoviário de passageiros, não-regular ${ }^{17}$.

- Transporte regular próprio para exploração de pontos turísticos.

- Transporte aéreo, regular.

- Transporte aéreo, não-regular ${ }^{18}$.

- Atividades de agências de viagens e organizadores de viagens.

- Atividades auxiliares do transporte terrestre ${ }^{19}$.

- Atividades auxiliares do transporte aéreo ${ }^{20}$.

- Estabelecimentos hoteleiros e outros tipos de alojamento temporário.

- Restaurantes e outros estabelecimentos de serviços de alimentação.

- Atividades recreativas, culturais e desportivas.

- Aluguel de automóveis e outros meios de transporte.

\footnotetext{
17 Inclui transporte escolar, de turismo e de pessoal de empresas.

${ }^{18}$ Inclui táxi aéreo, serviço de helicópteros e vôos fretados.

19 Inclui exploração de terminais rodoferroviários, parques de estacionamento e garagem, socorro e reboque, carga e descarga, agenciamento de cargas e guarda-volumes.

20 Inclui a exploração de aeroportos, campos de aterrissagem, de instalações de navegação, translado terrestre de passageiros, guarda-volumes e limpeza de aeronaves.
} 
No subitem seguinte, descrevem-se os procedimentos metodológicos utilizados na desagregação das atividades econômicas do modelo de insumo-produto original, isto é, do modelo de insumo-produto geral da economia brasileira para construção do modelo de insumo-produto do turismo no Brasil.

\subsubsection{A abertura das matrizes de produção e uso dos insumos}

De acordo com o descrito no subitem anterior, nas tabelas de insumo-produto não é possível ter um setor de turismo, tendo em vista a heterogeneidade de atividades econômicas que compõem o segmento do turismo, em que se deveriam integrar bens e serviços totalmente distintos e incomparáveis, o qual violaria muitos princípios da contabilidade setorial (Briassoulis, 1991; Espanha, 1996).

Como os setores e produtos das tabelas de insumo-produto do Brasil se encontram de forma agregada, não será possível fazer uma análise do segmento do turismo pelas tabelas da forma como são publicadas, devendo-se proceder a algumas alterações na estrutura da matriz de insumo-produto do Brasil, com o objetivo de adequá-la aos propósitos deste trabalho. Essas alterações referem-se à desagregação do setor de transportes, do setor de serviços prestados às famílias e do setor de serviços prestados às empresas, buscando-se colocar em evidência as atividades de maior projeção turística desenvolvidas no Brasil e a agregação de algumas atividades em um conjunto homogêneo de setores de acordo com seu interesse para a análise pretendida.

A desagregação e agregação dos setores efetuadas para este estudo e os produtos componentes de cada setor encontram-se detalhadas nos Quadros 5 e 6 . Na desagregação dos setores e dos produtos, procurou-se seguir a Classificação Internacional Uniforme das Atividades Turísticas (CIUAT) da OMT, bem como a Classificação Nacional de Atividades Econômicas (CNAE) do IBGE. Já a agregação dos setores foi feita levando-se em consideração o grau de homogeneidade das atividades de cada um. 


\begin{tabular}{|c|c|c|c|}
\hline Ordem & Setores da Matriz & Ordem & Setores Desagregados e Agregados \\
\hline 1 & Agropecuária & 1 & Agropecuária \\
\hline 2 & Extrativa Mineral & \multirow{2}{*}{2} & \multirow{2}{*}{ Extrativa Mineral } \\
\hline 3 & Petróleo e Gás & & \\
\hline 4 & Mineral não Metálico & 3 & Mineral não Metálico \\
\hline 5 & Siderurgia & 4 & Siderurgia \\
\hline 6 & Metalurgia não Ferrosos & \multirow{2}{*}{5} & \multirow{2}{*}{ Metalurgia } \\
\hline 7 & Outros Metalúrgicos & & \\
\hline 8 & Máquinas e Equipamentos & 6 & Máquinas e Equipamentos. \\
\hline 9 & Material Elétrico & 7 & Material Elétrico \\
\hline 10 & Equipamentos Eletrônicos & 8 & Equipamentos Eletrônicos \\
\hline 11 & Autom., Caminhões e Ônibus & 9 & Automóveis, caminhões e ônibus \\
\hline 12 & Peças e Outros Veículos & 10 & Peças e outros veículos \\
\hline 13 & Madeira e Mobiliário & 11 & Madeira e Mobiliário \\
\hline 14 & Celulose, Papel e Gráfica & 12 & Celulose, Papel e Gráfica \\
\hline 15 & Indústria da Borracha & 13 & Indústria da Borracha \\
\hline 16 & Elementos Químicos & \multirow{3}{*}{14} & \multirow{3}{*}{ Química } \\
\hline 17 & Refino do Petróleo & & \\
\hline 18 & Químicos Diversos & & \\
\hline 19 & Farmácia e Veterinária & 15 & Farmácia e Veterinária \\
\hline 20 & Artigos Plásticos & 16 & Artigos Plásticos \\
\hline 21 & Indústria Têxtil & 17 & Indústria Têxtil \\
\hline 23 & Fabricação de Calçados & 19 & Fabricação de calçados e produtos de couros e peles \\
\hline 22 & Artigos do Vestuário & 18 & Artigos do vestuário \\
\hline 24 & Indústria do Café & 20 & Indústria do Café \\
\hline 25 & $\begin{array}{l}\text { Beneficiamento Produtos } \\
\text { Vegetais }\end{array}$ & 21 & Beneficiamento. Produtos Vegetais \\
\hline 26 & Abate de Animais & 22 & Abate de Animais \\
\hline 27 & Indústria de Laticínios & 23 & Indústria de Laticínios \\
\hline 28 & Fabricação de Açúcar & 24 & Fabricação de Açúcar \\
\hline 29 & Fabricação de Óleos Vegetais & 25 & Fabricação de Óleos Vegetais \\
\hline 30 & Outros Produtos Alimentares & 26 & Outros Produtos Alimentares \\
\hline 31 & Indústrias Diversas & 27 & Indústrias Diversas \\
\hline 32 & $\begin{array}{l}\text { Serviços Industriais de Utilidade } \\
\text { Pública }\end{array}$ & 28 & Serviços Industriais de Utilidade Pública \\
\hline 33 & Construção Civil & 29 & Construção Civil \\
\hline 34 & Comércio & 30 & Comércio \\
\hline
\end{tabular}

Quadro 5 - Agregação e desagregação dos setores usados na construção do modelo de insumo-produto do turismo, 1999. 


\begin{tabular}{|c|c|c|c|}
\hline Ordem & Setores da Matriz & Ordem & Setores Desagregados e Agregados \\
\hline \multirow{13}{*}{35} & \multirow{13}{*}{ Transportes } & 31 & Transporte rodoviário de passageiros, regular \\
\hline & & 32 & Transporte rodoviário de passageiros, não regular \\
\hline & & 33 & Transp. regular próprios para exploração de pontos turísticos \\
\hline & & 34 & Transporte rodoviário de cargas \\
\hline & & 35 & Outros transportes terrestres \\
\hline & & 36 & Transporte aquaviário \\
\hline & & 37 & Transporte aéreo, regular \\
\hline & & 38 & Transporte aéreo, não regular \\
\hline & & 39 & Agencias de viagens e organizadores de viagens \\
\hline & & 40 & Atividades auxiliares ao transporte terrestre \\
\hline & & 41 & Atividades auxiliares ao transporte aquaviário \\
\hline & & 42 & Atividades auxiliares ao transporte aéreo \\
\hline & & 43 & Outras atividades auxiliares do transporte \\
\hline 36 & Comunicações & 44 & Comunicações \\
\hline 37 & Instituições Financeiras & 45 & Instituições Financeiras \\
\hline \multirow{4}{*}{38} & \multirow{4}{*}{ Serviços Prestados à Família } & 46 & $\begin{array}{l}\text { Estabelecimentos hoteleiros e outros tipos de alojamento } \\
\text { temporário }\end{array}$ \\
\hline & & 47 & $\begin{array}{l}\begin{array}{l}\text { Restaurantes e outros estabelecimentos de serviços de } \\
\text { alimentação }\end{array} \\
\end{array}$ \\
\hline & & 48 & Serviços Culturais e Recreativos \\
\hline & & 49 & Outros Serviços Prestados às Famílias \\
\hline 39 & Administração Pública & 50 & Administração Pública \\
\hline \multirow{2}{*}{40} & \multirow{2}{*}{ Serv. Prestados às Empresas } & 51 & Aluguel de automóveis e outros meios de transporte \\
\hline & & 52 & Outros Serviços Prestados às Empresas \\
\hline 41 & Aluguel de Imóveis & 53 & Aluguel de Imóveis \\
\hline 42 & Serv. Privados não Mercantis & 54 & Serviços Privados não Mercantis \\
\hline
\end{tabular}

Quadro 5 - Agregação e desagregação dos setores usados na construção do modelo de insumo-produto do turismo, 1999. 


\begin{tabular}{|c|c|c|c|}
\hline Ordem & Produtos da Matriz & Ordem & Setores Agregados e Desagregados \\
\hline 1 & Café em coco & \multirow{11}{*}{1} & \multirow{11}{*}{ Agropecuária } \\
\hline 2 & Cana-de-açúcar & & \\
\hline 3 & Arroz em casca & & \\
\hline 4 & Trigo em grão & & \\
\hline 5 & Soja em grão & & \\
\hline 6 & Algodão em caroço & & \\
\hline 7 & Milho em grão & & \\
\hline 8 & Bovinos e suínos & & \\
\hline 9 & Leite natural & & \\
\hline 10 & Aves vivas & & \\
\hline 11 & Outros produtos agropecuários & & \\
\hline 12 & Minério de ferro & \multirow{4}{*}{2} & \multirow{4}{*}{ Extrativa mineral } \\
\hline 13 & Outros minerais & & \\
\hline 14 & Petróleo e gás & & \\
\hline 15 & Carvão e outros & & \\
\hline 16 & Produtos minerais não-metálicos & 3 & Minerais não Metálicos \\
\hline 17 & Produtos siderúrgicos básicos & 4 & Siderurgia \\
\hline 18 & Laminados de aço & \multirow{3}{*}{5} & \multirow{3}{*}{ Metalurgia } \\
\hline 19 & Produtos metalúrgicos não-ferrosos & & \\
\hline 20 & Outros produtos metalúrgicos & & \\
\hline 21 & Fabricação e manutenção de máquinas & \multirow{2}{*}{6} & \multirow{2}{*}{ Máquinas e Equipamentos } \\
\hline 22 & Tratores e máquinas de terraplanagem & & \\
\hline 23 & Material elétrico & 7 & Material Elétrico \\
\hline 24 & Equipamentos eletrônicos & 8 & Equipamentos eletrônicos \\
\hline 25 & Automóveis, caminhões e ônibus & 9 & Automóveis, caminhões e ônibus \\
\hline 26 & Outros veículos e peças & 10 & Peças e outros veículos \\
\hline 27 & Madeira e mobiliário & 11 & Madeira e Mobiliário \\
\hline 28 & Papel, celulose, papelão e artefatos & 12 & Celulose, papel e gráfica \\
\hline 29 & Produtos derivados da borracha & 13 & Indústria da borracha \\
\hline 30 & Elementos químicos não-petroquímicos & \multirow{5}{*}{14} & \multirow{5}{*}{ Química } \\
\hline 31 & Álcool de cana e de cereais & & \\
\hline 32 & Gasolina pura & & \\
\hline 33 & Óleos combustíveis & & \\
\hline 34 & Outros produtos do refino & & \\
\hline
\end{tabular}

Quadro 6 - Produtos componentes dos setores do modelo de insumo-produto do turismo, 1999. 


\begin{tabular}{|c|c|c|c|}
\hline Ordem & Produtos da Matriz & Ordem & Setores Agregados e Desagregados \\
\hline 35 & Produtos petroquímicos básicos & \multirow{6}{*}{14} & \multirow{6}{*}{ Química } \\
\hline 36 & Resinas & & \\
\hline 37 & Gasolina e álcool & & \\
\hline 38 & Adubos & & \\
\hline 39 & Tintas & & \\
\hline 40 & Outros produtos químicos & & \\
\hline 41 & Produtos farmacêuticos e de perfumaria & 15 & Farmacêutica e Veterinária \\
\hline 42 & Artigos de plástico & 16 & Artigos de plástico \\
\hline 43 & Fios têxteis naturais & \multirow{5}{*}{17} & \multirow{5}{*}{ Indústria têxtil } \\
\hline 44 & Tecidos naturais & & \\
\hline 45 & Fios têxteis artificiais & & \\
\hline 46 & Tecidos artificiais & & \\
\hline 47 & Outros produtos têxteis & & \\
\hline 48 & Artigos do vestuário & 18 & Artigos do vestuário \\
\hline 49 & Produtos de couro e calçados & 19 & $\begin{array}{l}\text { Fabricação de calçados e produtos de couros e } \\
\text { peles }\end{array}$ \\
\hline 50 & Produtos do café & 20 & Indústria do Café \\
\hline 51 & Arroz beneficiado & \multirow{3}{*}{21} & \multirow{3}{*}{ Beneficiamento de Produtos Vegetais } \\
\hline 52 & Farinha de trigo & & \\
\hline 53 & Outros produtos vegetais beneficiados & & \\
\hline 54 & Carne bovina & \multirow{2}{*}{22} & \multirow{2}{*}{ Abate de animais } \\
\hline 55 & Carne de aves abatidas & & \\
\hline 56 & Leite beneficiado & \multirow{2}{*}{23} & \multirow{2}{*}{ Indústria de Laticínio } \\
\hline 57 & Outros laticínios & & \\
\hline 58 & Açúcar & 24 & Fabricação de Açúcar \\
\hline 59 & Óleos vegetais em bruto & \multirow{2}{*}{25} & \multirow{2}{*}{ Fabricação de Óleos Vegetais } \\
\hline 60 & Óleos vegetais refinados & & \\
\hline 61 & Outros produtos alimentares inclusive rações & \multirow{2}{*}{26} & \multirow{2}{*}{ Fabricação de Outros Produtos Alimentares } \\
\hline 62 & Bebidas & & \\
\hline 63 & Produtos diversos & 27 & Indústria diversas \\
\hline 64 & Serviços industriais de utilidade pública & 28 & Serviços industriais de utilidade pública \\
\hline 65 & Produtos da construção civil & 29 & Construção Civil \\
\hline 66 & Margem de comércio & 30 & Comércio \\
\hline \multirow[b]{2}{*}{67} & \multirow[b]{2}{*}{ Margem de transporte } & 31 & Transporte rodoviário de passageiros, regular \\
\hline & & 32 & $\begin{array}{l}\text { Transporte rodoviário de passageiros, não } \\
\text { regular }\end{array}$ \\
\hline
\end{tabular}

Quadro 6 - Produtos componentes dos setores do modelo de insumo-produto do turismo, 1999. 


\begin{tabular}{|c|c|c|c|}
\hline Ordem & Produtos da Matriz & Ordem & Setores Agregados e Desagregados \\
\hline \multirow{11}{*}{67} & \multirow{11}{*}{ Margem de transporte } & 33 & $\begin{array}{l}\text { Transporte regular próprios para exploração de pontos } \\
\text { turísticos }\end{array}$ \\
\hline & & 34 & Transporte rodoviário de cargas \\
\hline & & 35 & Outros transportes terrestres \\
\hline & & 36 & Transporte aquaviário \\
\hline & & 37 & Transporte aéreo, regular \\
\hline & & 38 & Transporte aéreo, não regular \\
\hline & & 39 & Agencias de viagens e organizadores de viagens \\
\hline & & 40 & Atividades auxiliares ao transporte terrestre \\
\hline & & 41 & Atividades auxiliares ao transporte aquaviário \\
\hline & & 42 & Atividades auxiliares ao transporte aéreo \\
\hline & & 43 & Outras atividades auxiliares do transporte \\
\hline 68 & Comunicações & 44 & Comunicações \\
\hline 69 & Seguros & \multirow[t]{2}{*}{45} & \multirow[t]{2}{*}{ Instituições financeiras } \\
\hline 70 & Serviços financeiros & & \\
\hline \multirow[t]{2}{*}{71} & \multirow[t]{2}{*}{ Alojamento e alimentação } & 46 & $\begin{array}{l}\begin{array}{l}\text { Estabelecimentos hoteleiros e outros tipos de } \\
\text { alojamento temporário }\end{array} \\
\end{array}$ \\
\hline & & 47 & $\begin{array}{l}\text { Restaurantes e outros estabelecimentos de serviços de } \\
\text { alimentação }\end{array}$ \\
\hline 72 & Outros serviços & 48 & Serviços recreativos, culturais e desportivos \\
\hline 73 & Aluguel imputado & \multirow[t]{2}{*}{49} & \multirow[t]{2}{*}{ Outros Serviços Prestados às Famílias } \\
\hline 74 & Saúde e educação mercantis & & \\
\hline 75 & Administração pública & \multirow{3}{*}{50} & \multirow{3}{*}{ Administração Pública } \\
\hline 76 & Saúde pública & & \\
\hline 77 & Educação pública & & \\
\hline \multirow[b]{2}{*}{78} & \multirow[b]{2}{*}{ Serviços prestados às empresas } & 51 & Aluguel de automóveis e outros meios de transporte \\
\hline & & 52 & Outros Serviços Prestados às Empresas \\
\hline 79 & Aluguel de imóveis & 53 & Aluguel de Imóveis \\
\hline 80 & Serviços privados não-mercantis & 54 & Serv. Privados não Mercantis \\
\hline
\end{tabular}

Quadro 6 - Produtos componentes dos setores do modelo de insumo-produto do turismo, 1999. 


\subsubsection{A abertura da tabela de produção}

$\mathrm{Na}$ seção anterior, ficou demonstrada a necessidade de desagregação de alguns setores da matriz de insumo-produto com vistas a explicitar as atividades turísticas desenvolvidas no Brasil. Assim, esta subseção tem como finalidade descrever os procedimentos utilizados na desagregação dos setores da matriz de produção do Brasil referente ao período aqui analisado, o ano de 1999.

$\mathrm{Na}$ desagregação dos setores (desagregação das linhas) da matriz de produção, utilizou-se como informações básicas a participação relativa da receita bruta total de cada "subsetor" na receita bruta total do setor, conforme apresentado a seguir. Tais informações foram obtidas em IBGE (1997).

Assim, o valor total da produção do setor de transportes, conforme apresentado na matriz geral do Brasil para o ano de 1999, foi distribuído entre os subsetores considerados neste trabalho, de acordo com a participação de cada um no valor total da produção do setor:

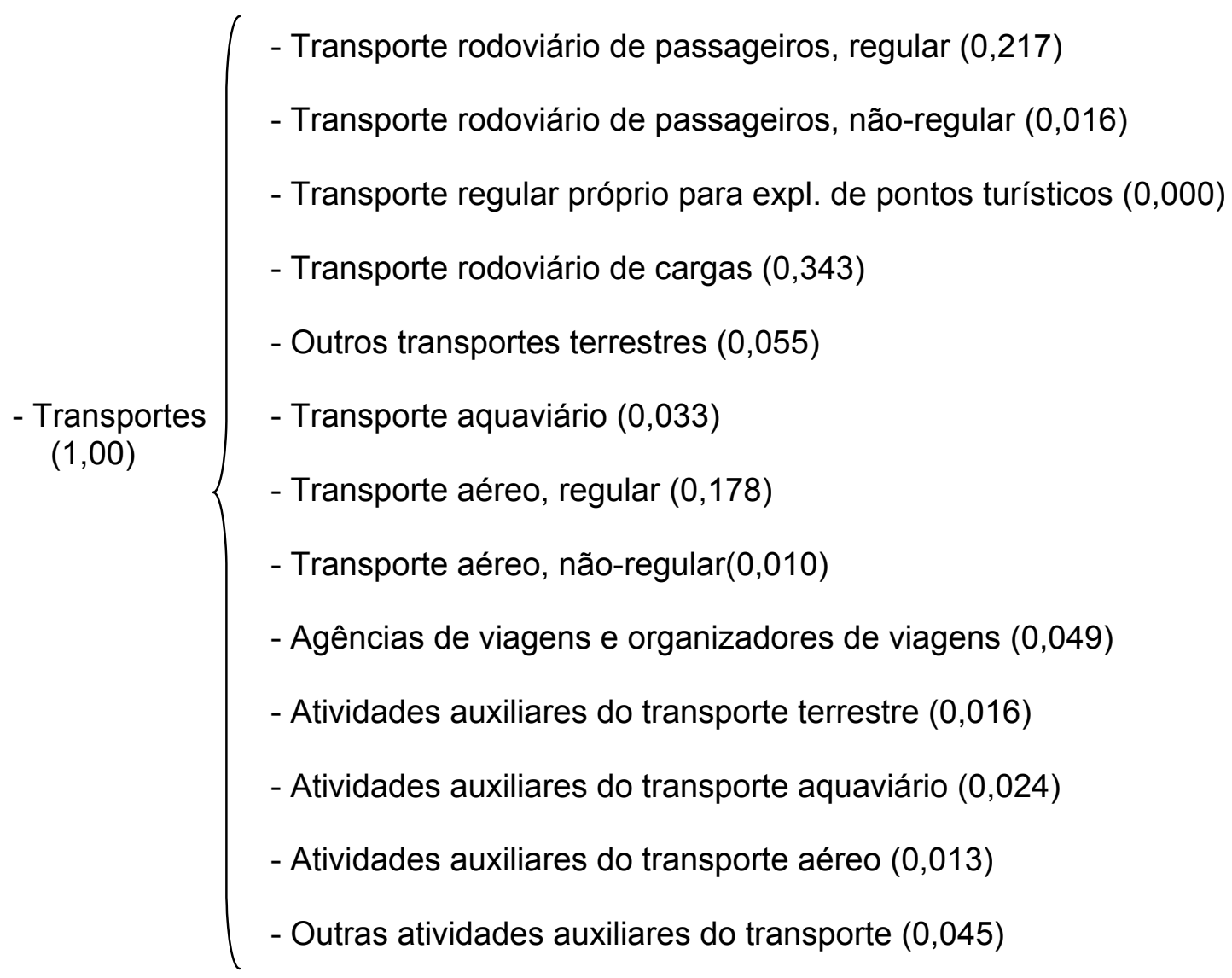


Para o setor de Serviços prestados às famílias, o procedimento foi o seguinte: inicialmente, esse setor foi dividido em dois novos setores: - Alojamento e alimentação; e - Outros serviços, levando-se em consideração a participação dos novos setores no setor de Serviços prestados às famílias. Em seguida, procedeu-se a uma nova desagregação de cada um dos dois novos setores. O setor de Alojamento e alimentação foi desagregado em Estabelecimentos hoteleiros e outros tipos de alojamento temporário; e em Restaurantes e outros estabelecimento de serviços de alimentação. O setor de Outros serviços foi desagregado em dois novos setores: Serviços recreativos, culturais e desportivos; e Outros serviços prestados às famílias. Esses procedimentos foram adotados em virtude da maneira como os dados para desagregação estavam disponíveis.

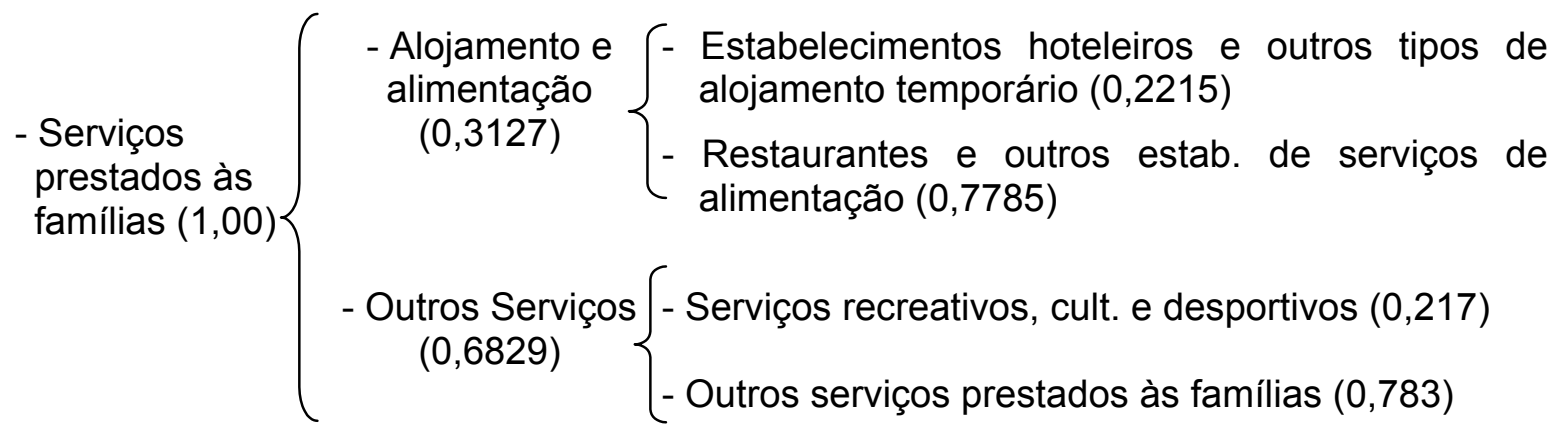

Já o setor Serviços prestados às empresas foi desagregado, de forma semelhante à do setor de Transporte, em dois novos setores: Aluguel de automóveis e outros meios de transportes; e Outros serviços prestados às empresas.

- Serviços prestados
às empresas $(1,00)$$\left\{\begin{array}{l}\text { - Aluguel de automóveis e outros meios de transporte }(0,01) \\ \text { - Outros serviços prestados às empresas }(0,99)\end{array}\right.$

Para realizar as desagregações descritas, observou-se a matriz de produção geral da economia brasileira, procurando identificar quais os produtos produzidos por cada um dos setores que foram desagregados, bem como a participação destes na produção total do setor. Uma vez encontradas as referidas participações na produção dos setores, escolheu-se o produto com maior participação na produção do setor para desagregá-lo, considerando que cada um dos produtos desagregados era produzido 
somente por um setor. Os outros produtos produzidos pelos setores não foram desagregados, apenas distribuídos nos "subsetores", levando-se em consideração sua participação na produção.

Verificou-se também, analisando a matriz de produção geral da economia brasileira, que os produtos de maior projeção turística eram produzidos por outros setores e não somente pelos setores turísticos. Assim, deveria ser feita uma distribuição desses produtos para os correspondentes produtos desagregados, a qual foi feita levando-se em consideração a participação na produção total do setor.

\subsubsection{A abertura da tabela de uso dos insumos}

Para desagregação da matriz de uso que será utilizada na construção do modelo de insumo-produto do turismo no Brasil, partiu-se da tabela de uso geral da economia brasileira elaborada por Guilhoto et al. (2001).

Inicialmente, separaram-se os setores que foram desagregados na matriz de produção, ou seja:

- Transportes.

- Serviços prestados às famílias.

- Serviços prestados às empresas.

Cada um desses setores foi posteriormente desagregado, conforme feito anteriormente, para a matriz de produção (maiores detalhes são apresentados mais adiante).

Analisando as matrizes de uso que foram construídas para a economia brasileira, verificou-se que a matriz de uso para o ano de 1980 era a que mais se aproximava da desagregação pretendida no presente trabalho. Assim, optou-se por utilizar a participação do uso dos produtos utilizados como insumos no processo produtivo de cada setor, em 1980, para fazer a desagregação dos mesmos na matriz de uso para o ano de 1999. Isso foi possível, visto que se assumiu que não houve grandes modificações na estrutura dos transportes no Brasil, considerando do ano de 1980 até o ano de 1999.

Em seguida, procedeu-se a uma compatibilização das classificações de atividades e produtos em 1980 e 1999, de acordo com IBGE (1997a). 
Os procedimentos utilizados na distribuição dos produtos dentro de cada um dos setores desagregados, bem como os utilizados na desagregação dos produtos, são descritos nos tópicos subseqüentes.

\section{Setor de Transporte}

A desagregação do setor de Transportes na matriz de uso dos insumos de 1980 é a que se segue: Transporte rodoviário, Transporte ferroviário, Transporte marítimo e Transporte aéreo.

Em cada um dos vetores anteriormente referidos foi feita uma desagregação do produto transportes, a fim de compatibilizá-lo com a matriz de uso de 1980 (nesta "abertura" do setor, considerou-se a participação dos produtos no produto total, informação obtida na matriz de produção). De posse dos vetores-coluna dos setores dos transportes da matriz de uso de 1980, calculou-se um coeficiente de distribuição da produção do setor para cada produto:

$$
\text { Coef }_{i j}=\frac{x_{i j}}{V P_{j}} \quad(j=\text { rodoviário, ferroviário, marítimo e aéreo })
$$

em que $X_{i j}$ é o produto $i$ usado como insumo no processo produtivo do setor $j$ e $V P_{j}$, o valor da produção do setor $j$.

Em seguida, distribuiu-se o valor da produção total do setor $j$ (obtido anteriormente na matriz de produção) no ano de 1999, levando em consideração os coeficientes de distribuição calculados anteriormente, isto é, o valor da produção total do setor $j$, em 1999, foi multiplicado por cada um dos coeficientes de distribuição dos produtos.

$$
\mathrm{Coef}_{i j} \times \mathrm{P}_{j 99}
$$

Uma vez distribuídos os valores dos produtos entre os setores (Transporte rodoviário, Transporte ferroviário, Transporte marítimo e Transporte aéreo), somou-se nas linhas (estes valores deveriam ser iguais aos dos produtos usados como insumo pelo setor de transporte em 1999). Dos valores encontrados nessas somas, subtraíram-se os valores dos produtos usados como insumo pelo setor de Transportes.

Essa diferença de cada um dos produtos foi, em seguida, distribuída entre os setores Transporte rodoviário, Transporte ferroviário, Transporte marítimo e Transporte 
aéreo, considerando-se, agora, a participação da produção dos mesmos na produção total do setor de Transportes em 1999 (0,5926; 0,1005; 0,0568; e 0,2501, respectivamente). Se a diferença fosse positiva, então deveria diminuir o produto usado como insumo pelo setor o equivalente à participação do setor na produção; se negativa, deveria acrescentar o produto a cada setor o equivalente à sua participação na produção.

A abertura dos setores e produtos explicitados anteriormente ainda não foi suficiente para que os objetivos deste trabalho fossem totalmente atingidos. Assim, os setores foram desagregados, levando-se em consideração a sua participação na produção em:

- Transporte rodoviário $(1,00)\left\{\begin{array}{l}\text { - Transporte rodov. de passageiros, regular }(0,3662) \\ \text { - Transp. rodov. de passageiros, não-regular }(0,0267) \\ \text { - Transp. regular próprio para exploração de pontos } \\ \text { turísticos }(0,0003) \\ - \text { Transporte rodoviário de cargas }(0,5793) \\ \text { - Atividades auxiliares do transp. terrestre }(0,0275)\end{array}\right.$

- Transporte ferroviário $(1,00)\left\{\begin{array}{l}\text { - Outros transportes terrestres }(0,5515) \\ \text { - Outras atividades auxiliares do transporte }(0,4485)\end{array}\right.$

- Transporte hidroviário $(1,00)\left\{\begin{array}{l}\text { - Transporte aquaviário }(0,5812) \\ \text { - Ativ. auxiliares do transporte aquaviário }(0,4188)\end{array}\right.$

- Transporte aéreo $(1,00)$

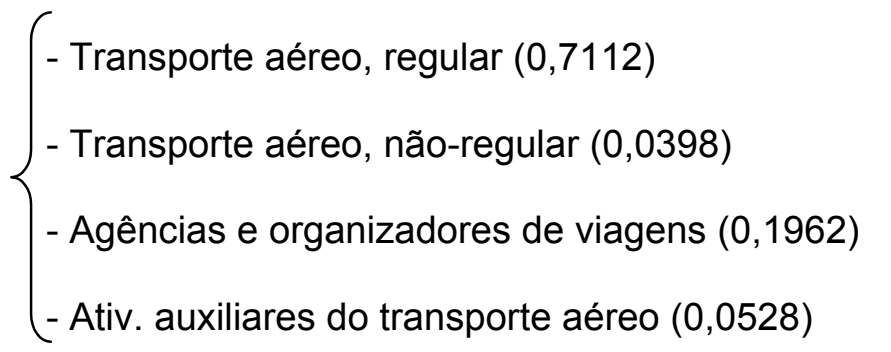


Como era esperado, além do setor de Transportes, outros setores da economia também utilizavam o produto Margem de transporte no seu processo produtivo. Assim, os novos produtos Margem de transporte deveriam ser distribuídos nos demais setores econômicos. No entanto, no caso do Brasil não foi encontrada nenhuma informação relacionada com a utilização do produto Margem de transportes pelos demais setores produtivos que pudesse ser utilizada nessa desagregação. Assim, dada a inexistência dessas informações, partiu-se para a utilização de informações de modelos de insumo-produto construídos para outros países.

Após uma revisão de literatura e análise da Tabela Intersetorial da Economia Turística - TIOT-92 para a Espanha, constatou-se que, em termos de participação, a estrutura do setor de Transportes da Espanha era semelhante à do Brasil. Dessa forma, o produto Margem de transporte foi distribuído nos diversos setores econômicos, considerando-se a mesma participação da TIOT-92. Essa "abertura" procedeu-se da seguinte forma:

- Da matriz de produção que tinha sido construída anteriormente para o turismo no Brasil, isolaram-se todos os valores dos produtos Margem de transporte.

- Agregou-se de modo a deixar esses valores compatíveis com a TIOT-92, ou seja, em Transporte rodoviário de passageiros, Transporte rodoviário de cargas, Transporte ferroviário, Transporte hidroviário, Transporte aéreo, Serviços anexos aos transportes e Agências de viagens.

- Distribuíram-se os valores dos produtos entre os demais setores da economia que utilizavam o produto Margem de transporte no processo produtivo, levando em consideração a participação calculada para a TIOT-92.

Como se pode perceber, os produtos ainda não estão desagregados de forma conveniente com a matriz de produção considerada neste trabalho. Assim, tem-se a necessidade de desagregar novamente os seguintes produtos: Transporte rodoviário de passageiros, Transporte aéreo e Serviços anexos aos transportes. A "abertura" e distribuição dos valores desses produtos para os setores da economia foram feitas considerando a participação de cada um dentro do produto relacionado, de acordo com o observado na matriz de produção. 
A desagregação desses produtos, bem como a participação dos "novos" produtos, é apresentada a seguir:

- Transporte
rodoviário de
passageiros $(1,00)$ $\left\{\begin{array}{l}\text { - Margem de transp. rodov. de passag., regular } 0,931) \\ \text { - Margem de transp. rodov. de passag., não-regular }(0,068) \\ \text { - Margem de transporte regular próprio para exploração de } \\ \text { pontos turísticos }(0,001)\end{array}\right.$

$\left\{\begin{array}{l}\text { - Transporte aéreo, regular }(0,947) \\ \text { - Transporte aéreo, não-regular }(0,053)\end{array}\right.$

- Transporte aéreo $(1,00)$

- Serviços anexos aos transportes $(1,00)$

$$
\left\{\begin{array}{l}
\text { - Margem de ativ. aux. dos transp. terrestres }(0,165) \\
\text { - Margem das ativ. aux. dos transp. aquaviários }(0,242) \\
\text { - Margem de ativ. aux. dos transp. aéreos }(0,134) \\
\text { - Margem de out. ativ. aux. do transporte }(0,458)
\end{array}\right.
$$

\section{Serviços prestados às famílias}

Tomando por base a matriz de uso dos insumos para o ano de 1980 construída para a economia brasileira pelo IBGE (IBGE, 1989), calculou-se a participação de cada insumo no valor da produção dos seguintes setores: Alojamento e alimentação e Outros serviços.

Em seguida, distribuíram-se os valores dos insumos em 1999, da seguinte maneira: em cada um dos vetores anteriormente referidos foi feita uma desagregação do produto Serviços prestados às famílias, a fim de compatibilizá-la com a matriz de uso de 1980 (nessa "abertura" do setor, considerou-se a participação dos produtos no produto total, informação obtida na matriz de produção). De posse dos vetores-coluna dos setores de Serviços prestados às famílias da matriz de uso de 1980, calculou-se um coeficiente de distribuição da produção do setor para cada produto:

$$
\text { Coef }_{i j}=\frac{x_{i j}}{V P_{j}} \quad(j=\text { Alojamento e alimentação e Outros serviços })
$$


em que $X_{i j}$ é o produto $i$ usado como insumo no processo produtivo do setor $j$ e $V P_{j}$, o valor da produção do setor $j$.

Em seguida, distribuiu-se o valor da produção total do setor $j$ (obtido anteriormente na matriz de produção), no ano de 1999, levando em consideração os coeficientes de distribuição calculados anteriormente, isto é, o valor da produção total do setor $j$, no ano de 1999, foi multiplicado por cada um dos coeficientes de distribuição dos produtos, ou seja:

$$
\mathrm{Coef}_{i j} \times P_{j 99}
$$

Uma vez distribuídos os valores dos produtos entre os setores (Alojamento e alimentação e Outros serviços), os quais foram somados nas linhas (estes valores deveriam ser iguais aos dos produtos usados como insumos pelo setor de Serviços prestados às famílias em 1999). Dos valores encontrados nessa soma, subtraíram-se os valores dos produtos usados como insumos pelo setor de Serviços prestados às famílias. Essa diferença deveria ser nula, no entanto, na maioria dos casos, isso não foi verdadeiro, encontrando-se valores positivos e negativos. Ainda, a diferença de cada um dos produtos foi em seguida distribuída entre os setores Alojamento e alimentação e Outros serviços, considerando-se agora a participação da produção dos mesmos na produção total do setor de Serviços prestados às famílias em 1999 (0,3423 e 0,6577 , respectivamente). Se essa diferença fosse positiva, então deveria ser diminuído o produto usado como insumo pelo setor o equivalente à participação do setor na produção; se fosse negativa, deveria ser acrescentado o produto a cada setor o equivalente à participação deste na produção.

A abertura, anteriormente referida, dos setores e produtos ainda não era suficiente para que os objetivos deste trabalho fossem atingidos. Assim, os setores foram novamente desagregados, levando-se em consideração a participação na produção em: Estabelecimentos hoteleiros e outros tipos de alojamento temporário $(0,2215)$ e Restaurantes e outros estabelecimentos de serviços de alimentação $(0,7785)$. Já o setor de Outros serviços foi desagregado em: Atividades recreativas, culturais e desportivas $(0,1011)$ e Outros serviços prestados às famílias $(0,8989)$. As referidas desagregações foram feitas de acordo com a participação no valor da produção das atividades, obtidas na matriz de produção calculada anteriormente. 
O produto Serviços de alojamento e alimentação foi desagregado em: Estabelecimentos hoteleiros e outros tipos de alojamento temporário $(0,2215)$ e Restaurantes e outros estabelecimentos de serviços de alimentação $(0,7785)$. O produto Outros serviços foi desagregado em: Atividades recreativas, culturais e desportivas $(0,5245)$ e Outros serviços prestados às famílias $(0,4755)$. A "abertura" e distribuição dos valores destes produtos nos setores da economia foram feitas considerando a participação na produção, conforme a matriz de produção.

Vale ressaltar que as hipóteses assumidas para o setor de Serviços prestados às famílias foram as mesmas assumidas na construção da TIOT-92.

\section{Serviços prestados às empresas}

Com relação ao produto Serviços prestados às empresas não foi encontrada em nenhuma outra matriz de uso dos insumos previamente construída, informação no nível de desagregação pretendida para o presente trabalho. Dessa forma, a "abertura" deste produto ocorreu de forma diferente da dos dois produtos descritos anteriormente.

Conforme descrito na matriz de produção, o setor Serviços prestados às empresas foi desagregado em: Aluguel de automóveis e outros meios de transporte e Outros serviços prestados às empresas.

Da matriz de produção, retirou-se a produção dos referidos setores, bem como a participação na produção desses dois setores na produção do setor de Serviços prestados às empresas: Aluguel de automóveis e outros meios de transporte $(0,015)$ e Outros serviços prestados às empresas $(0,985)$.

De posse dos vetores-coluna dos setores Aluguel de automóveis e outros meios de transporte e Outros serviços prestados às empresas, fez-se a distribuição dos insumos em cada um deles, levando em consideração a sua participação na produção.

É importante ressaltar que todos os procedimentos utilizados até aqui decorreram do fato da inexistência de um conjunto de informações relacionado com a utilização de insumos pelos setores produtivos da economia brasileira, mais especificamente dos insumos e setores que compõem o segmento do turismo. Para que isso se torne possível, recomenda-se a realização de uma pesquisa aqui no Brasil, 
de modo que se possa conhecer com uma melhor exatidão o uso dos insumos na estrutura produtiva.

A desagregação de setores e produtos nas matrizes de uso e produção utilizadas na construção do modelo de insumo-produto para a economia turística no Brasil gerou algumas divergências nos valores das referidas matrizes. Para solucionar esse problema, lançou-se mão da técnica de balanceamento de matrizes conhecida na literatura como RAS. Essa técnica é apresentada na subseção seguinte.

\subsubsection{Balanceamento das matrizes pelo método RAS}

Conforme visto anteriormente, na construção do modelo de insumo-produto para o segmento do turismo no Brasil foi necessário fazer uma abertura nas matrizes de produção e uso dos insumos. Esse procedimento geralmente resulta em incompatibilidade entre os valores internos das matrizes e os totais das linhas e colunas. Para compatibilizar a distribuição dos valores internos das matrizes com os totais das linhas e colunas, efetuou-se um balanceamento das matrizes pelo método conhecido na literatura de insumo-produto como método RAS.

O método RAS permite, no caso de um problema de desagregação dos setores, gerar uma matriz de coeficientes, $A(1)$, a partir de algumas informações sobre as atividades econômicas, como: produção total dos setores $X(1)$; as vendas interindustriais totais, $U(1)$; e as compras interindustriais totais, $V(1)$, tendo como ponto de partida uma matriz com informações preexistentes, $\boldsymbol{A}(0)$.

A descrição do método RAS, a seguir, será feita conforme a versão tradicional apresentada por Miller e Blair (1985). Portanto, são conhecidos os coeficientes

técnicos, $a_{i j}=\frac{z_{i j}}{X_{j}}$, preexistentes, e pretende-se obter as estimativas desses mesmos coeficientes para um ano 1 qualquer. Para atingir essa meta, necessita-se das seguintes informações:

$A(0) \rightarrow$ matriz dos coeficientes técnicos preexistentes.

$\boldsymbol{X}_{j} \rightarrow$ a produção total de cada setor $j$.

$\sum_{i=1}^{n} z_{i j} \rightarrow$ as vendas interindustriais totais realizadas pelo setor $i$; refere-se à soma nas 
linhas da matriz $\boldsymbol{Z}$ e é representada pela matriz $\boldsymbol{U} i$, na literatura RAS.

$\sum_{j=1}^{n} z_{i j} \rightarrow$ as compras interindustriais totais realizadas pelo setor $j$; refere-se à soma nas colunas da matriz $Z$ e é representada por $V i$, na literatura RAS.

Definem-se, então, as seguintes matrizes, que serão utilizadas para estimar a matriz $\boldsymbol{A}(1)$ :

$$
\begin{gathered}
\boldsymbol{A}(0)=\left[\begin{array}{ccc}
a_{11}(0) & \cdots & a_{1 n}(0) \\
\vdots & \ddots & \vdots \\
a_{n 1}(0) & \cdots & a_{n n}(0)
\end{array}\right] ; \quad \boldsymbol{X}(1)=\left[\begin{array}{c}
X_{1}(0) \\
\vdots \\
X_{n}(1)
\end{array}\right] ; \quad \boldsymbol{U}(1)=\left[\begin{array}{c}
U_{1}(1) \\
\vdots \\
U_{n}(1)
\end{array}\right] \\
\boldsymbol{V}(1)=\left[\begin{array}{lll}
V_{1}(1) & \cdots & V_{n}(1)
\end{array}\right]
\end{gathered}
$$

Suponha-se, inicialmente, que os coeficientes técnicos permanecem estáveis no tempo, ou seja, que $\boldsymbol{A}(0)=\boldsymbol{A}(1)$. Para testar essa hipótese, deve-se investigar se as informações obtidas para o ano 1 são consistentes. Para isso, será necessário converter os coeficientes técnicos em transações intersetoriais, através da relação $z_{i j}=a_{i j} X_{j}$.

Em termos matriciais, sabe-se que $\boldsymbol{A}=\boldsymbol{Z}(\hat{\boldsymbol{X}})^{-1}$; portanto, $\boldsymbol{Z}=\boldsymbol{A}(\hat{\boldsymbol{X}})$. Assim, a matriz de transações intersetoriais que é definida pela hipótese que se está querendo testar é dada por $\boldsymbol{Z}(1)=\boldsymbol{A}(0) \hat{\boldsymbol{X}}(1)$.

Deve-se, então, verificar se os somatórios nas linhas $\left(\boldsymbol{U}^{\top}\right)$ e nas colunas $\left(\boldsymbol{V}^{\top}\right)$ de $\boldsymbol{Z}(1)$ são consistentes com $\boldsymbol{U}(1)$ e $\boldsymbol{V}(1)$, respectivamente. Se $\left(\boldsymbol{U}^{\prime}\right)$ for igual a $\boldsymbol{U}(1)$ e $\boldsymbol{V}(1)$ for igual a $\left(\boldsymbol{V}^{\prime}\right)$, isso significa que a matriz $\boldsymbol{A}(0)$ é igual à matriz $\boldsymbol{A}(1)$, e o trabalho de balanceamento encerra-se com o seguinte cálculo:

$$
\boldsymbol{A}(1)=\boldsymbol{Z}(1)[\hat{\boldsymbol{X}}(1)]^{-1}
$$

Se $\left(\boldsymbol{U}^{1}\right)$ for diferente de $\boldsymbol{U}(1)$ e $\boldsymbol{V}(1)$ for diferente de $\left(\boldsymbol{V}^{\boldsymbol{1}}\right)$, isso significa que a matriz $\boldsymbol{A}(0)$ é diferente da matriz $\boldsymbol{A}(1)$, e, portanto, o procedimento de balanceamento deve, então, ser continuado.

Pós-multiplicando a matriz $Z(1)$ pelo vetor $\boldsymbol{i}$, definido como um vetor- coluna de 
valores unitários, gera-se um vetor-coluna cujos elementos são a soma nas linhas de $Z(1)$, isto é,

$$
\mathrm{U}^{1}=[\mathrm{A}(0) \hat{\mathrm{X}}(1)] \mathbf{i}
$$

em que $\boldsymbol{U}^{1}$ é a soma nas novas linhas, após a primeira distribuição.

Caso $U_{i}^{1}$ seja maior que $U_{i}(1)$, isso significa que os elementos da linha $i$ da matriz $\boldsymbol{A}(0)$ são maiores do que deveriam ser; se $U_{i}^{1}$ for menor que $U_{i}(1)$ significa que os elementos da linha $i$ da matriz $\boldsymbol{A}(0)$ são menores do que deveriam ser. Isso porque se admite que $X_{i}(1)$ contém as informações corretas.

Quando $\boldsymbol{U}^{\prime}$ for diferente de $\boldsymbol{U}(1)$, os elementos da matriz $\boldsymbol{Z}$ devem ser corrigidos pela seguinte proporção:

$$
\frac{U_{i}(1)}{U_{i}^{1}}=r_{i}^{1}
$$

Se cada elemento da linha $i$ da matriz $\boldsymbol{A}(0)$ for multiplicado por $r_{i}^{1}$, isso irá gerar um novo conjunto de coeficientes que, quando multiplicado por $\boldsymbol{X}(1)$, irá somar nas linhas $\boldsymbol{U}(1)$, que é exatamente o que se deseja.

Dessa forma, a primeira estimativa da matriz de coeficientes técnicos, $\boldsymbol{A}^{1}$, será dada por

$$
\boldsymbol{A}^{1}=\boldsymbol{R}^{1} \boldsymbol{A}(0)
$$

em que $\boldsymbol{R}^{1}=[\hat{\boldsymbol{U}}(1)]\left(\hat{\boldsymbol{U}}^{1}\right)^{-1} \quad$ ou $\quad \boldsymbol{R}^{1}=\left[\begin{array}{ccc}r_{1}^{1} & \cdots & 0 \\ \vdots & \ddots & \vdots \\ 0 & \vdots & r_{n}^{1}\end{array}\right]$ é uma matriz cujos elementos são formados pelos valores obtidos da relação entre a soma observada nas linhas, $\boldsymbol{U}(1)$, e a soma calculada nas linhas, $\boldsymbol{U}^{1}$.

O próximo passo consiste em verificar se a soma nas colunas da matriz $\boldsymbol{A}^{1}$ é igual a $V(1)$, isto é, tem-se que comparar $V_{j}^{1} \operatorname{com} V_{(}(1)$.

Pré-multiplicando $\boldsymbol{Z}(1)$ pelo vetor i', definido como uma linha com valores unitários, obtém-se um vetor-linha cujos elementos são a soma nas colunas da matriz $Z(1)$, ou seja, 


$$
\mathrm{V}^{1}=\boldsymbol{i}^{\prime}\left\lfloor\mathrm{A}{ }^{1} \hat{\mathrm{X}}(1)\right\rfloor
$$

em que $V^{1}$ é a soma nas novas colunas, após a primeira distribuição.

Se $\boldsymbol{V}_{\boldsymbol{i}}^{1}$ for igual a $\boldsymbol{V}(1)$, então significa que $\boldsymbol{A}^{1}$ gera soma nas linhas e colunas que correspondem aos observados $\boldsymbol{U}(1)$ e $\boldsymbol{V}(1)$, respectivamente. Entretanto, na maioria dos casos $\boldsymbol{V}_{\boldsymbol{i}}^{1}$ é diferente de $\boldsymbol{V}(1)$, sendo, então, necessário modificar os elementos de $\boldsymbol{A}^{1}$ coluna por coluna. Essa modificação dos elementos da matriz $\boldsymbol{A}^{1}$ é feita multiplicando-os pela seguinte relação:

$$
\frac{V_{\mathrm{i}}(1)}{V_{\mathrm{i}}^{1}}=\mathrm{s}_{\mathrm{i}}^{1}
$$

Desse modo, a segunda estimativa da matriz de coeficientes $\left(\boldsymbol{A}^{2}\right)^{20}$ será dada por

$$
\boldsymbol{A}^{2}=\boldsymbol{A}^{1} \boldsymbol{S}^{1}
$$

em que $S^{1}=\left[\begin{array}{ccc}\mathrm{s}_{1}^{1} & \cdots & 0 \\ \vdots & \ddots & \vdots \\ 0 & \cdots & \mathrm{s}_{\mathrm{n}}^{1}\end{array}\right]$

Dados $\boldsymbol{V}_{i}^{1}$ e $\boldsymbol{V}(1)$ em termos matriciais, $\boldsymbol{S}^{1}$ é obtida da seguinte forma:

$$
S^{1}=[\hat{\mathrm{V}}(1)]\left(\hat{\mathrm{V}}^{1}\right)^{-1}
$$

Pelos procedimentos anteriormente descritos, pode-se dizer que a correção das matrizes se processa simultaneamente, de acordo com

$$
\boldsymbol{A}^{2}=\boldsymbol{R}^{1} \boldsymbol{A}(0) \boldsymbol{S}^{1}
$$

Essas operações entre as matrizes são feitas repetidas vezes até que seja atingida a convergência dos resultados.

Uma vez atingida a convergência dos resultados, referente ao balanceamento das matrizes de produção e de uso dos insumos, partiu-se para a obtenção do modelo de insumo-produto da economia turística brasileira, conforme descrito nos tópicos subseqüentes.

\footnotetext{
${ }^{20}$ Cabe ressaltar que o sobrescrito 2 não significa o quadrado da matriz, mas sim designa qual é a estimativa que está sendo feita.
} 


\subsection{Obtenção da matriz de coeficientes técnicos}

Normalmente, as matrizes de insumo-produto não são disponibilizadas conforme descrito na seção 3.1, mas sim uma tabela de produção nacional e uma tabela de uso nacional, e a partir delas se pode chegar à matriz de Leontief. Esse é o caso do presente trabalho, no qual se partiu das matrizes de produção e uso dos insumos para se chegar ao modelo de insumo-produto da economia turística. Nesta seção são apresentados os procedimentos metodológicos utilizados para percorrer o caminho anteriormente citado. No Quadro 7, sumarizam-se as relações entre as indústrias e os produtos usados na construção das matrizes de insumo-produto.

A tabela de produção nacional, da qual se origina a tabela $\boldsymbol{V}_{(\mathrm{s} \times \mathrm{p})}$, fornece informações sobre a origem setorial dos bens e serviços produzidos em determinado ano na economia. As linhas indicam em quais setores os produtos são produzidos, enquanto as colunas indicam a origem setorial dos produtos. No entanto, na tabela de uso nacional da qual provém a tabela de uso $\boldsymbol{U}_{(\mathrm{p} \times \mathrm{s})}$, mostram-se, nas linhas, os produtos oferecidos para cada setor e, nas colunas, os demandados em cada setor da economia.

\begin{tabular}{|c|c|c|c|c|}
\hline & Produto & Setor & Demanda Final & Produto Total \\
\hline Produto & & $\boldsymbol{U}$ & $E$ & $Q$ \\
\hline Setor & $V$ & $Z$ & $Y$ & $X$ \\
\hline Importações & & $M$ & $M F$ & \\
\hline Valor adicionado & & $W$ & & \\
\hline Insumo total & $Q^{\prime}$ & $X^{\prime}$ & & \\
\hline
\end{tabular}

Quadro 7 - Relações de insumo-produto usadas na construção das matrizes para o turismo.

Fonte: adaptado de Miller e Blair (1985).

A matriz $Z_{(\mathrm{s} \times \mathrm{s})}$ é a matriz de transações intersetoriais contendo a demanda ou consumo setorial intermediários; $\boldsymbol{Y}_{(\mathrm{s} \times 1)}$ é o vetor de demanda final por setor e composto por formação bruta de capital fixo, exportações, variação de estoques, consumo do governo e consumo das famílias; $\boldsymbol{M}_{(1 \times \mathrm{s})}$ é o vetor das importações; $\boldsymbol{W}_{(1 \times \mathrm{s})}$ é o vetor do 
valor adicionado; e $\boldsymbol{E}_{(\mathrm{p} \times 1)}$ é o vetor da demanda final por produto.

Como as matrizes $\boldsymbol{Z}$ e $\boldsymbol{Y}$ não estão disponíveis, não se pode obter diretamente a matriz $\boldsymbol{A}$ (matriz dos coeficientes técnicos). De acordo com Miller \& Blair (1985), para se obter a matriz de Leontief, é preciso, então, utilizar as matrizes $\boldsymbol{V}$ e $\boldsymbol{U}$ que estão disponíveis, conforme descrito nos parágrafos subseqüentes.

Com base na tabela $\boldsymbol{U}$ e no vetor $\boldsymbol{X}_{(\mathrm{s} \times 1)}$, este último representando a produção nacional por setor, pode-se calcular a matriz $\boldsymbol{G}_{(\mathrm{p} \times \mathrm{s})}$ da seguinte forma:

$$
\boldsymbol{G}=\boldsymbol{U}(\hat{\boldsymbol{X}})^{-1}
$$

em que $\boldsymbol{G}_{(\mathrm{p} \times \mathrm{s})}$ é a matriz nacional dos coeficientes técnicos dos insumos domésticos por setor e $(\hat{\boldsymbol{X}})^{-1}$, o vetor $\boldsymbol{X}$ diagonalizado e invertido.

Com base na tabela $\boldsymbol{V}$ e no vetor $\boldsymbol{Q}_{(1 \times \mathrm{p})}^{\prime}$, este último representando a produção nacional por produto, pode-se calcular $\boldsymbol{D}_{(\mathrm{s} \times \mathrm{p})}$, dada por

$$
\boldsymbol{D}=\boldsymbol{V}\left(\hat{\boldsymbol{Q}}^{\prime}\right)^{-1}
$$

em que $\boldsymbol{D}_{(\mathrm{s} \times \mathrm{p})}$ é a matriz de coeficientes técnicos de produto e $\left(\hat{\boldsymbol{Q}}^{\prime}\right)^{-1}$, o vetor $\boldsymbol{Q}$ diagonalizado e invertido. Finalmente, a matriz $\boldsymbol{A}_{(\mathrm{s} \times \mathrm{s})}$ dos coeficiente técnicos dos insumos diretos pode ser estimada por

$$
\boldsymbol{A}=\boldsymbol{D} \boldsymbol{G}
$$

A expressão (28) traz implícita a hipótese adotada nesta tese, que é a da tecnologia baseada na indústria sob o enfoque setor $x$ setor. Tal enfoque é usado na grande maioria dos estudos que utilizam a análise de insumo-produto, por permitir que se diferencie a tecnologia empregada na produção dos diversos produtos.

A partir da matriz $\boldsymbol{A}$, pode-se obter a matriz dos coeficientes técnicos de insumos diretos e indiretos para o turismo, ou matriz inversa de Leontief para o turismo, $\boldsymbol{B}_{(\mathrm{s} \times \mathrm{s})}$, da seguinte maneira:

$$
\boldsymbol{B}=(\boldsymbol{I}-\boldsymbol{A})^{-1}
$$

Essa matriz é também chamada de matriz dos impactos diretos e indiretos, por permitir verificar o impacto na produção, renda e emprego de uma variação na demanda final. 


\subsection{Conceitos e cálculos dos métodos de análise das relações intersetoriais na economia brasileira}

A análise de uma economia no que diz respeito às relações intersetoriais e aos setores-chave, ou à determinação dos setores que apresentam maior capacidade de difundir seus efeitos sobre o sistema econômico e propiciar maior dinamismo na economia, é feita por meio dos índices de ligações.

Esses índices são úteis para determinar os setores que teriam maior poder de encadeamento dentro da economia, ou seja, podem-se calcular os índices de ligações para trás, que determinam quanto um setor demanda dos outros setores, e os índices de ligações para frente, que determinam quanto um setor é demandado pelos demais setores da economia (Guilhoto et al., 1994). Nos subitens seguintes, apresentam-se os principais índices de ligações para uma economia, bem como algumas vantagens e desvantagens de sua utilização.

\subsection{1 Índices de ligações de Hirschman-Rasmussen}

Com o objetivo de efetuar o cálculo dos índices de ligações tanto para frente como para trás de Hirschman-Rasmussen, deve-se tomar por base a seguinte expressão: $\boldsymbol{B}=(\boldsymbol{I}-\boldsymbol{A})^{-1}$, em que $\boldsymbol{B}$ representa a matriz inversa de Leontief, definindo-se $b_{i j}$ como um elemento dessa matriz, $B^{\star}$ como a média de todos os elementos da matriz $\boldsymbol{B}$ e $B_{*_{j}}$ e $B_{i^{*}}$ como, respectivamente, a soma de uma coluna e de uma linha da matriz $\boldsymbol{B}$. Matematicamente, essas relações podem ser assim especificadas:

$$
\begin{gathered}
\boldsymbol{B}^{*}=\frac{\sum_{i=1}^{n} \sum_{j=1}^{n} \boldsymbol{b}_{i j}}{n^{2}} \\
\boldsymbol{B}_{* j}=\sum_{i=1}^{n} \boldsymbol{B}_{i j} \\
\boldsymbol{B}_{i^{*}}=\sum_{j=1}^{n} \boldsymbol{B}_{i j}
\end{gathered}
$$

Seguindo Guilhoto et al. (1994), os cálculos dos índices de ligações de Hirschman-Rasmussen são determinados da seguinte forma: 
- Índices de ligações para trás

$$
U_{j}=\frac{\left[\begin{array}{c}
B_{*_{j}} / n \\
n
\end{array}\right]}{B^{*}}
$$

- Índices de ligações para frente

$$
U_{i}=\frac{\left[B_{i^{*}} / n\right]}{B^{*}}
$$

Os índices de Hirschman-Rasmussen indicam o grau de encadeamento dos setores da economia, tanto para trás como para frente, ou seja, evidenciam o grau com que um setor demanda ou oferta insumos para os demais setores do sistema econômico.

\subsubsection{O índice de dispersão}

Os índices de ligações para frente e para trás refletem, respectivamente, as forças de oferta e demanda de dado setor, e o índice de dispersão pode ser considerado um indicador de distribuição dessas forças. Assim, conforme apresentado por Bulmer-Thomas (1982), este índice complementa os índices de ligações para frente e para trás de Hirschman-Rasmussen, à medida que possibilita interpretar como um impacto setorial distribui-se para outros setores.

As dispersões dos índices de ligações para trás e para frente são, segundo Bulmer-Thomas (1982), determinadas pelas seguintes expressões:

- Dispersão do índice de ligação para trás

$$
V_{j}=\frac{\sqrt{\frac{\sum_{i}^{n}\left(b_{i j}-\frac{B_{*_{j}}}{n}\right)^{2}}{n-1}}}{\frac{B_{*_{j}}}{n}}
$$


A ocorrência de um baixo valor para determinada dispersão do índice de ligação para trás significa que o impacto de uma variação da produção em determinado setor tende a estimular os demais setores de maneira uniforme. No caso de um alto índice de dispersão, isso significa que o impacto vai se concentrar em poucos setores.

- Dispersão do índice de ligação para frente

$$
V_{i}=\frac{\sqrt{\frac{\sum_{i}^{j}\left(b_{i j}-\frac{B_{i j}}{n}\right)^{2}}{n-1}}}{\frac{B_{i^{*}}}{n}}
$$

Para o caso da dispersão do índice de ligação para frente, um valor alto significa que a demanda por esse setor será concentrada em poucos setores, enquanto valor baixo significa que esse setor é demandado de maneira uniforme.

\subsubsection{Campo de influência}

Os índices de Hirschman-Rasmussen avaliam a importância de um setor em termos de seu impacto no sistema como um todo sem, contudo, identificar os principais elos dentro da economia, ou seja, sem identificar quais os coeficientes que, ao serem alterados, teriam maior impacto econômico como um todo. Essa deficiência dos índices de ligações pode ser suprida pela abordagem do campo de influência.

O conceito de campo de influência, segundo Sonis e Hewings (1989 e 1995), permite conhecer como as mudanças nos coeficientes técnicos se distribuem no sistema como um todo, ou seja, quais as relações entre os setores que teriam maior importância dentro do processo produtivo. Assim, o campo de influência pode ser compreendido como uma análise complementar à análise dos índices de ligação para frente e para trás de Hirschman-Rasmussen.

Segundo Guilhoto et al. (1994) e Sonis e Hewings (1995), o procedimento para obtenção do campo de influência requer:

- A matriz dos coeficientes técnicos de produção, $A=\left|a_{i j}\right|$.

- A definição de uma matriz de variações incrementais nos coeficientes diretos de insumo ou matriz de erro, $\boldsymbol{E}=\left|\varepsilon_{i j}\right|$. 
- As correspondentes matrizes inversas de Leontief dadas por $\boldsymbol{B}=\left|b_{i j}\right|$ e $\boldsymbol{B}(\varepsilon)=\left|b_{i j}(\varepsilon)\right|=|\boldsymbol{I}-\boldsymbol{A}-\boldsymbol{\varepsilon}|^{-1}$.

Segundo Sonis e Hewings (1989 e 1995), admitindo-se uma variação muito pequena que só ocorre em um coeficiente direto, isto é:

$$
\varepsilon_{i j}=\left\{\begin{array}{lll}
\varepsilon & \text { para } & i=i_{1}, \quad j=j_{1} \\
0 & \text { para } & i \neq i_{1}, \quad j \neq j_{1}
\end{array}\right.
$$

Se $B-B(\varepsilon)$ corresponde ao impacto resultante da alteração nos coeficientes diretos, para cada coeficiente tem-se uma matriz de alterações ou matriz do campo de influência do coeficiente $a_{i j}$, dado pela expressão

$$
\boldsymbol{F}\left(\varepsilon_{i j}\right)=\frac{\left\lfloor\boldsymbol{B}\left(\varepsilon_{i j}\right)-\boldsymbol{B}\right\rfloor}{\varepsilon_{i j}}
$$

em que $\boldsymbol{F}\left(\varepsilon_{i j}\right)$ é uma matriz do campo de influência do coeficiente $a_{i j}$, com dimensão $(n \times n)$.

$\mathrm{O}$ valor atribuído a cada matriz $\boldsymbol{F}\left(\varepsilon_{\mathrm{j}}\right)$ permite que se determinem quais os coeficientes que possuem o maior campo de influência. Dessa forma, esse valor é definido por

$$
S_{i j}=\sum_{k=1}^{n} \sum_{l=1}^{n}\left[f_{i}\left(\varepsilon_{i j}\right)\right]^{2}
$$

Os coeficientes diretos que possuírem os maiores valores de $S_{i j}$ serão aqueles com maior campo de influência na economia como um todo, ou seja, aqueles que produzem maior impacto.

\subsection{4 Índices puros de ligação}

Os índices de ligações sugeridos por Hirschman-Rasmussen apresentam a desvantagem de não considerar os diferentes níveis de produção de cada setor da economia. Com o objetivo de suprir essa desvantagem, vem surgindo diferentes abordagens para o cálculo de índices de ligações intersetoriais de uma economia, dentre eles o do índice puro de ligação. 
Segundo Guilhoto et al. (1994) e Guilhoto et al. (1996), esse índice de ligação permite isolar dado setor $j$ do restante da economia, de forma a determinar o efeito das ligações totais do setor $j$ na economia. Em outras palavras, o índice puro de ligações indica a diferença entre a produção total na economia e a produção na economia se o setor $j$ não comprasse insumos do resto da economia nem vendesse sua produção para o restante desta.

Esses mesmo autores desenvolveram procedimentos que objetivaram aferir a relevância de dado setor para a economia, relativo ao valor da produção gerado por esse setor. Para isso, torna-se necessário decompor a matriz de coeficientes diretos de Leontief $(\boldsymbol{A})$, da seguinte forma:

$$
A=\left[\begin{array}{ll}
A_{j j} & A_{j r} \\
A_{r j} & A_{r r}
\end{array}\right]=\left[\begin{array}{ll}
A_{j j} & A_{j r} \\
A_{r j} & 0
\end{array}\right]+\left[\begin{array}{cc}
0 & 0 \\
0 & A_{r r}
\end{array}\right]=A_{j}+A_{r}
$$

em que

$A_{j j}$ é a matriz de insumos diretos dentro do setor $j$;

$A_{r j}$ é a matriz de insumos diretos que o setor $j$ adquire do resto da economia;

$\boldsymbol{A}_{j r}$ é a matriz de insumos diretos que o resto da economia adquire do setor $j$;

$\boldsymbol{A}_{r r}$ é a matriz de insumos diretos dentro do resto da economia;

$A_{j}$ refere-se ao setor $j$ isolado do resto da economia; e

$A_{r}$ representa o restante da economia.

Seguindo a abordagem de Guilhoto et al. (1996), a partir da expressão (40) se pode chegar a

$$
\mathbf{B}=(\mathbf{I}-\mathbf{A})^{-1}=\left(\begin{array}{ll}
\mathbf{B}_{\mathrm{jj}} & \mathbf{B}_{\mathrm{jr}} \\
\mathbf{B}_{\mathrm{rj}} & \mathbf{B}_{\mathrm{rr}}
\end{array}\right)=\left(\begin{array}{cc}
\boldsymbol{\Delta}_{\mathrm{jj}} & \mathbf{0} \\
\mathbf{0} & \boldsymbol{\Delta}_{\mathrm{rr}}
\end{array}\right)\left(\begin{array}{cc}
\boldsymbol{\Delta}_{\mathrm{j}} & \mathbf{0} \\
\mathbf{0} & \boldsymbol{\Delta}_{\mathrm{r}}
\end{array}\right)\left(\begin{array}{cc}
\mathbf{I} & \mathbf{A}_{\mathrm{jr}} \boldsymbol{\Delta}_{\mathrm{r}} \\
\mathbf{A}_{\mathrm{rj}} \boldsymbol{\Delta}_{\mathrm{j}} & \mathbf{I}
\end{array}\right)
$$

em que os elementos da expressão (41) são assim definidos:

$\Delta_{j}=\left(\boldsymbol{I}-\boldsymbol{A}_{j j}\right)^{-1}$ representa a interação do setor $j$ com ele mesmo;

$\Delta_{r}=\left(\boldsymbol{I}-\boldsymbol{A}_{r r}\right)^{-1}$ representa a interação do restante da economia com ele mesmo;

$\Delta_{j j}=\left(\boldsymbol{I}-\Delta_{j} \boldsymbol{A}_{j r} \Delta_{r} \boldsymbol{A}_{r j}\right)^{-1}$ representa quanto o setor $j$ tem que produzir para o restante da economia para que ela atenda às suas necessidades; e

$\Delta_{r r}=\left(\boldsymbol{I}-\Delta_{r} \boldsymbol{A}_{r j} \Delta_{j} \boldsymbol{A}_{j r}\right)^{-1}$ representa quanto o restante da economia vai ter que produzir para o setor $j$ para que ele atenda às suas necessidades. 
Considerando as informações contidas na expressão (41) e usando a formulação $\boldsymbol{X}=(\boldsymbol{I}-\boldsymbol{A})^{-1} \boldsymbol{Y}$, expressão (14), é possível derivar um conjunto de índices de ligações que permitam ordenar os setores em termos de importância do valor, bem como analisar como se verifica o processo de produção na economia.

Substituindo a expressão (41) na expressão (14), tem-se

$$
\left(\begin{array}{l}
\mathbf{X}_{\mathrm{j}} \\
\mathbf{X}_{\mathrm{r}}
\end{array}\right)=\left(\begin{array}{cc}
\Delta_{\mathrm{jj}} & \mathbf{0} \\
\mathbf{0} & \Delta_{\mathrm{rr}}
\end{array}\right)\left(\begin{array}{cc}
\Delta_{\mathrm{j}} & \mathbf{0} \\
\mathbf{0} & \Delta_{\mathrm{r}}
\end{array}\right)\left(\begin{array}{cc}
\mathbf{I} & \mathbf{A}_{\mathrm{jr}} \Delta_{\mathrm{r}} \\
\mathbf{A}_{\mathrm{rj}} \Delta_{\mathrm{j}} & \mathbf{I}
\end{array}\right)\left(\begin{array}{l}
\mathbf{Y}_{\mathrm{j}} \\
\mathbf{Y}_{\mathrm{r}}
\end{array}\right)
$$

Procedendo à multiplicação dos dois últimos termos da expressão (42), tem-se

$$
\left(\begin{array}{l}
\mathbf{X}_{j} \\
\mathbf{X}_{\mathbf{r}}
\end{array}\right)=\left(\begin{array}{cc}
\Delta_{\mathrm{jj}} & \mathbf{0} \\
\mathbf{0} & \Delta_{\mathrm{rr}}
\end{array}\right)\left(\begin{array}{cc}
\Delta_{\mathrm{j}} & \mathbf{0} \\
\mathbf{0} & \Delta_{\mathrm{r}}
\end{array}\right)\left(\begin{array}{l}
\mathbf{Y}_{\mathrm{j}}+\mathbf{A}_{\mathrm{jr}} \Delta_{\mathrm{r}} \mathbf{Y}_{\mathbf{r}} \\
\mathbf{A}_{\mathrm{rj}} \Delta_{\mathrm{j}} \mathbf{Y}_{\mathbf{j}}+\mathbf{Y}_{\mathbf{r}}
\end{array}\right)
$$

$\mathrm{Na}$ equação (43), o impacto direto proporcionado pela demanda final do resto da economia sobre o setor $j$ é representado por $A_{j r} \Delta_{r} \boldsymbol{Y}_{r}$, ou seja, representa quanto o setor $j$ precisa produzir para atender ao volume de produção do restante da economia, para dada demanda final $\boldsymbol{Y}_{r}$. No entanto, $\boldsymbol{A}_{r j} \Delta_{j} \boldsymbol{Y}_{j}$ representa o montante que o setor $j$ precisa comprar do restante da economia para atender a determinada demanda final $\boldsymbol{Y}_{\boldsymbol{j}}$. É, portanto, o impacto direto da demanda final do setor $j$ sobre o restante da economia.

Dando continuidade à multiplicação, tem-se

$$
\left(\begin{array}{l}
\mathbf{X}_{j} \\
\mathbf{X}_{\mathrm{r}}
\end{array}\right)=\left(\begin{array}{cc}
\Delta_{\mathrm{jj}} & \mathbf{0} \\
\mathbf{0} & \Delta_{\mathrm{rr}}
\end{array}\right)\left(\begin{array}{l}
\mathbf{A}_{\mathrm{j}} \mathbf{Y}_{\mathrm{j}}+\Delta_{\mathrm{j}} \mathbf{A}_{\mathrm{jr}} \Delta_{\mathrm{r}} \mathbf{Y}_{\mathrm{r}} \\
\Delta_{\mathrm{r}} \mathbf{A}_{\mathrm{rj}} \Delta_{\mathrm{j}} \mathbf{Y}_{\mathbf{j}}+\Delta_{\mathrm{r}} \mathbf{Y}_{\mathrm{r}}
\end{array}\right)
$$

A partir da expressão (44), definem-se os índices puros de ligações para trás e para frente. Assim, o índice puro de ligações para trás pode ser definido como

$$
P B L=\Delta_{\mathrm{r}} \mathbf{A}_{\mathrm{rj}} \Delta_{\mathbf{j}} \mathbf{Y}_{\mathbf{j}}
$$

em que $P B L$ representa o impacto puro do valor da produção total do setor $j$ sobre a economia, não se considerando a demanda de insumos que o setor gera internamente, ou seja, dentro do próprio setor, bem como as demandas da economia como um todo para o setor $j$ e a demanda do setor $j$ para a economia como um todo. 
Quanto ao índice puro de ligações para frente, é definido como

$$
P F L=\Delta_{\mathbf{j}} \mathbf{A}_{\mathbf{j r}} \Delta_{\mathbf{r}} \mathbf{Y}_{\mathbf{r}}
$$

Já o PFL indica o impacto puro sobre o setor $j$ provocado pela produção no resto da economia, ou seja, o restante da economia, para atender à sua demanda final, interage entre si, gerando uma demanda pelo setor $j$. O setor $j$ vai ter que produzir para atender a essa demanda.

Outra vantagem desses índices puros em relação ao de HirschmanRasmussen é que, caso se deseje saber qual é o índice puro do total de ligações $(P T L)$ de cada setor na economia, é possível somar o $P B L$ com o $P F L$, dado que estes índices são expressos em valores correntes. Assim,

$$
P T L=P B L+P F L
$$

em que está representado o impacto puro da produção total no restante da economia no setor $j$.

Conforme especificado anteriormente, os índices puros de ligações são expressos em termos de valor da produção total. Assim, quando se pretende fazer uma análise comparativa, em diferentes períodos, desses índices e dos de ligações de Hirschman-Rasmussen, não é possível utilizar os índices puros de ligações. Para superar esse inconveniente, pode-se fazer uma normalização dos índices puros. Essa normalização é feita dividindo-se o valor da produção em cada setor pelo valor médio da economia.

O índice puro de ligação para trás normalizado é definido como

$$
P B L N=\frac{P B L}{\frac{\sum_{i}^{n} P B L}{n}}
$$

O índice puro de ligações para frente normalizado é

$$
\text { PFLN }=\frac{P F L}{\frac{\sum_{i}^{n} P F L}{n}}
$$


Já o índice puro total normalizado das ligações de cada setor da economia será dado por

$$
P T L N=\frac{P T L}{\frac{\sum_{i}^{n} P T L}{n}}
$$

De acordo com a eq. (50), pode-se perceber que, para obter o índice puro total de ligações normalizado $(P T L N)$ de cada setor da economia, não mais é possível somar o PBLN com o PFLN, visto que estes índices não são expressos em valores correntes.

\subsection{Conceitos e cálculos dos impactos do segmento do turismo na economia brasileira}

Segundo Miller e Blair (1985), as informações de um modelo de insumoproduto podem ser usadas para estimar os efeitos sobre uma economia, em decorrência de variações ocorridas em elementos que são exógenos ao modelo construído para dada economia. Com relação ao segmento do turismo, os impactos econômicos em determinada economia, decorrentes de variações exógenas na demanda final, podem ser, por exemplo, aumento (ou diminuição) nos gastos dos turistas ou aumento (ou diminuição) nos gastos do governo.

Segundo Fletcher \& Snee (1989), em se tratando do segmento do turismo, as variações que podem ocorrer na demanda final poderão provocar três níveis diferentes de impactos econômicos, a saber:

- Impactos diretos $\rightarrow$ dizem respeito aos impactos diretamente associados com os gastos dos turistas ou investimentos, sendo limitados aos setores diretamente envolvidos com as despesas dos turistas com bens e serviços ou aos setores em que foram realizados os investimentos.

- Impactos indiretos $\rightarrow$ estes ocorrem por causa das indústrias direta e indiretamente ligadas à atividade turística que compram bens e serviços das outras indústrias como parte dos insumos de produção deles. Similarmente, os produtores dessas indústrias compram insumos de outras indústrias dentro da economia. 
- Impactos induzidos $\rightarrow$ como a receita gerada pelos gastos dos turistas circula dentro da economia, haverá adições direta e indireta no nível de renda na economia por meio do pagamento recebido pelo uso dos fatores de produção. Parte dessa renda, talvez, será poupada, mas grande parte dela será usada para pagar as despesas das famílias com bens e serviços produzidos por todos os setores, causando receita gerada pela atividade turística.

Para mensurar esses impactos, segundo Miller \& Blair (1985) e Fletcher (1989), dois caminhos devem ser seguidos. A mensuração dos impactos diretos e indiretos é feita por meio dos elementos da matriz inversa de Leontief de um modelo aberto em relação às famílias (o setor família é exógeno à matriz de coeficientes técnicos). Já para mensurar os efeitos diretos, indiretos e induzidos, esses impactos podem ser obtidos via elementos da matriz inversa de Leontief de um modelo fechado em relação às famílias (o setor família é endógeno à matriz de coeficientes técnicos). Assim, a separação desses impactos pode ser feita por diferença. A literatura, geralmente, denomina os efeitos diretos e indiretos como multiplicadores simples, enquanto os efeitos diretos, indiretos e induzidos são denominados multiplicadores totais.

Os impactos econômicos anteriormente referidos podem ser provocados no nível de produto, no nível de renda, no nível de emprego, nas importações, nos salários etc. $\mathrm{Na}$ análise desses impactos de elementos exógenos sobre uma economia, utiliza-se comumente o termo multiplicadores. No caso da presente tese, os impactos econômicos do segmento do turismo analisados são os provocados na produção, na renda e no nível de emprego.

Independentemente do tipo de análise e prazo considerado, o modelo de insumo-produto para análise de impacto ou previsão ${ }^{21}$, segundo Miller \& Blair (1985), segue a forma geral $\boldsymbol{X}=(\boldsymbol{I}-\boldsymbol{A})^{-1} \boldsymbol{Y}$ (para o modelo aberto), em que $\boldsymbol{X}$ é o valor da produção, $(\boldsymbol{I}-\boldsymbol{A})^{-1}$ é a inversa de Leontief e $\boldsymbol{Y}$ é a demanda final; e $\overline{\boldsymbol{X}}=(\boldsymbol{I}-\overline{\boldsymbol{A}})^{-1} \overline{\boldsymbol{Y}}$ (para o modelo fechado), em que $(\boldsymbol{I}-\overline{\boldsymbol{A}})^{-1}$ é a matriz inversa de Leontief com o setor

${ }^{21}$ Quando as mudanças exógenas são determinadas por ações apenas de um ou de poucos agentes e quando as mudanças decorrentes são esperadas para ocorrerem no curto prazo, os referidos autores chamam-nas de análise de impacto. No entanto, quando se pretende analisar em longo prazo, está se lidando com previsão. 
família endogeneizado, $\overline{\boldsymbol{X}}$ é o valor bruto da produção com o setor família endogeneizado e $\overline{\boldsymbol{Y}}$ é a demanda final, considerando-se o setor família como endógeno.

$\mathrm{Na}$ subseção a seguir são apresentadas a conceituação e fundamentação teóricas de alguns desses multiplicadores, bem como as respectivas formas de cálculo. $^{21}$

\subsubsection{Multiplicadores de produção}

A matriz $\boldsymbol{A}$ (ou $\overline{\boldsymbol{A}}$ ) é uma matriz que retrata o impacto que cada setor (indicado nas colunas) exerce sobre si mesmo e sobre os demais setores produtivos (indicado nas linhas) em função, por exemplo, do aumento de uma unidade monetária na produção. Já os multiplicadores de produção são obtidos a partir da matriz inversa de Leontief $(\boldsymbol{I}-\boldsymbol{A})^{-1}$ ou $(\boldsymbol{I}-\overline{\boldsymbol{A}})^{-1}$ e empregados na mensuração do impacto de mudanças exógenas (demanda final) sobre o volume de produção dos diferentes setores da economia.

O multiplicador de produção do setor $j\left(O_{j}\right)$ é definido como o valor total da produção de todos os setores da economia necessário para produzir uma unidade monetária de demanda final do produto do setor $j$. Assim, o multiplicador de produção simples de um setor $j$ pode ser assim expresso:

$$
O_{j}=\sum_{i=1}^{n} b_{i j}
$$

em que

$j$ é um setor qualquer da economia; e $b_{i \mathrm{ij}}$ representa os elementos da matriz inversa de Leontief.

O multiplicador de produção total $\left(\bar{O}_{j}\right)$, que capta os efeitos diretos, indiretos e induzidos ocorridos na produção, dada uma variação exógena na demanda final, pode, em geral, ser expresso por

21 Os conceitos fundamentação teórica e forma de cálculo seguem os apresentados por Miller \& Blair (1985). 


$$
\bar{O}_{j}=\sum_{i=1}^{n} \bar{b}_{i j}
$$

em que

$j$ é um setor qualquer da economia; e

$\bar{b}_{i j}$ representa os elementos da matriz inversa de Leontief com o setor família endogeneizado.

Convém esclarecer que, por estar interessado somente no efeito produto total sobre os $n$-setores originais, no presente caso $n$ será igual a 54 , isto é, não será incluído o setor família, e o somatório deverá ser de $i=1$ até $i=n$; essa observação é válida também para os outros dois multiplicadores apresentados nos tópicos subseqüentes.

\subsubsection{Multiplicadores de renda}

Os multiplicadores de renda permitem a quantificação dos impactos ocorridos no valor das despesas com demanda final na renda recebida pelas famílias. $O$ multiplicador de renda para o setor $j$ é definido como a nova renda gerada em todos os setores da economia resultante do aumento de uma unidade monetária de demanda final pelo produto do setor $j$. Matematicamente, o multiplicador de renda simples $\left(Y_{j}\right)$ pode ser obtido pela seguinte fórmula:

$$
Y_{j}=\sum_{i=\mathbf{1}}^{n} a_{n+\mathbf{1}, i} b_{i j}
$$

em que

$j$ é um setor qualquer da economia;

$a_{n+1}$ é um elemento da linha correspondente ao coeficiente da renda das famílias; e

$b_{\mathrm{ij}}$ representa os elementos da matriz inversa de Leontief.

Já o multiplicador de renda total $\left(\bar{Y}_{j}\right)$ é obtido considerando-se a seguinte expressão matemática: 


$$
\bar{Y}_{j}=\sum_{i=\mathbf{1}}^{n} a_{n+\mathbf{1}, i} \bar{b}_{i j}
$$

em que

jé um setor da economia;

$a_{n+1}$ é um elemento da linha correspondente ao coeficiente da renda das famílias; e.

$\bar{b}_{i j}$ representa os elementos da matriz inversa de Leontief, considerando-se o modelo fechado em relação às famílias.

\subsubsection{Multiplicadores de emprego}

Os multiplicadores de emprego permitem determinar o impacto de variações na demanda final sobre o produto que, por sua vez, leva a variações no emprego. A variação no emprego conduz a uma variação na renda e, conseqüentemente, na demanda do consumidor. O multiplicador de emprego para um setor $j$ é definido como novos empregos gerados em todos os setores da economia resultante do aumento de uma unidade monetária de demanda final pelo produto do setor $j$. O multiplicador de emprego simples é dado por

$$
E_{j}=\sum_{i=1}^{n} w_{n+\mathbf{1}, i} b_{i j}
$$

em que

jé dado setor da economia;

$w_{n+1}$ é o coeficiente de trabalho físico (número de emprego) por unidade monetária produzida; e

$b_{\mathrm{ij}}$ representa os elementos da matriz inversa de Leontief.

O multiplicador de emprego total pode ser calculado como se segue:

$$
\bar{E}_{j}=\sum_{i=1}^{n} w_{n+1, i} \bar{b}_{i j}
$$

em que

jé dado setor da economia; 
$w_{n+1}$ é o coeficiente de trabalho físico (número de emprego) por unidade monetária produzida; e

$\bar{b}_{i j}$ representa os elementos da matriz inversa de Leontief, considerando-se o modelo fechado em relação às famílias.

Vale ressaltar que a diferença entre o multiplicador de emprego em relação aos outros dois multiplicadores é que, neste caso, o multiplicador é dado em unidades físicas e não em unidades monetárias como aqueles.

\subsection{Dimensionamento do segmento do turismo no Brasil: produto interno bruto e pessoal ocupado}

A economia do segmento do turismo deve ser avaliada através de uma visão sistêmica e integrada, tendo como referência a cadeia produtiva do referido segmento e os principais agentes que atuam no seu processo produtivo, direta ou indiretamente (Brasil, 2002). Assim, a mensuração do segmento do turismo é aqui avaliado em seus complexos, considerando-se cada um dos seus componentes, conforme definido mais adiante neste subitem.

O segmento do turismo no Brasil foi definido e será mensurado, em termos de valor adicionado (usado como uma proxy do PIB) e pessoal ocupado, nos seguintes setores da matriz de insumo-produto da economia turística estimada no presente trabalho:

- Transporte rodoviário de passageiros, regular.

- Transporte rodoviário de passageiros, não-regular.

- Transporte regular próprio para exploração de pontos turísticos.

- Transporte aéreo, regular.

- Transporte aéreo, não-regular.

- Atividades de agências de viagens e organizadores de viagens.

- Atividades auxiliares do transporte terrestre.

- Atividades auxiliares do transporte aéreo.

- Estabelecimentos hoteleiros e outros tipos de alojamento temporário.

- Restaurantes e outros estabelecimentos de serviços de alimentação.

- Atividades recreativas, culturais e desportivas. 
- Aluguel de automóveis e outros meios de transporte.

A quantificação do valor adicionado do segmento do turismo, bem como do pessoal ocupado em cada um dos seus setores, é dividida em: i) insumos, ii) os próprios setores e iii) serviços.

Na composição do agregado I (insumos), consideraram-se todos os setores do modelo de insumo-produto que abastecem de insumos e bens de capital o segmento do turismo. Para compor o agregado $S$ (serviços), levaram-se em conta os seguintes setores: Transporte rodoviário de cargas, Outros transportes terrestres, Transporte aquaviário, Atividades auxiliares aos transportes aquaviários, Outras atividades auxiliares ao transporte, Comércio, Comunicações, Instituições financeiras, Outros serviços prestados às famílias, Outros serviços prestados às empresas, Aluguel de imóveis, Administração pública e Serviços privados não-mercantis. Esses setores foram agregados em um macro-setor e receberam a denominação de Serviços nãoturísticos.

Para o cálculo do valor adicionado dos insumos utilizados pelos setores do segmento do turismo $\left(V A_{I k}\right)$, são utilizadas as informações disponíveis nas tabelas de insumo-produto referentes aos valores adquiridos por cada um dos 12 setores anteriormente definidos como componentes do referido segmento. As colunas com os valores dos insumos são multiplicados pelos respectivos coeficientes do valor adicionado $\left(C V A_{i}\right)$, com o objetivo de eliminar o problema da dupla contagem que ocorre quando se levam em consideração os valores dos insumos e não o valor adicionado efetivamente gerado, resultando na seguinte expressão:

$$
V A_{I k}=\sum_{i=1}^{n} z_{i k} * C V A_{i}
$$

em que

$k=1,2, \ldots, 12$ (setores que compõem o segmento do turismo);

$i=1,2, \ldots, 54$ (setores do modelo de insumo-produto);

$V A_{I k}=$ valor adicionado dos insumos para os setores do segmento do turismo;

$z_{i k}=$ valor total do insumo do setor $i$ destinado aos setores do segmento do turismo; e

$C V A_{i}=$ coeficiente do valor adicionado do setor $i$. 
Para obter os coeficientes do valor adicionado por setor, divide-se o valor adicionado a preços básicos do setor $i\left(V A_{P B i}\right)$ pela produção do setor $i\left(X_{i}\right)$ :

$$
C V A_{i}=\frac{V A_{P B i}}{X_{i}}
$$

Dessa forma, para o valor adicionado do insumo $\left(V A_{I}\right)$ total, tem-se

$$
V A_{I}=V A_{I 1}+V A_{I 2}+\Lambda+V A_{I 12}
$$

Para calcular o valor adicionado de cada um dos setores que compõem o segmento do turismo $\left(V A_{T k}\right)$, consideram-se os valores adicionados gerados pelos respectivos setores, conforme definidos no início desta subseção. Tem-se, então, que

$$
V A_{T k}=V A_{P B k}
$$

Para o valor adicionado dos setores que compõem o segmento do turismo $\left(V A_{T}\right)$ total, tem-se

$$
V A_{T}=V A_{T 1}+V A_{T 2}+\Lambda+V A_{T 12}
$$

No caso do valor adicionado referente ao agregado $S$ (serviços), considera-se, para fins de cálculo, o valor adicionado dos setores que compõem o macro-setor Serviços não-turísticos, conforme definido anteriormente. Do valor total obtido, destina-se ao segmento do turismo apenas a parcela correspondente à participação dos produtos que compõem o segmento do turismo na demanda final. A sistemática adotada no cálculo do valor adicionado dos serviços pode ser representada por

$$
V A_{S k}=P D F_{k} * V A_{S-T}
$$

em que

$V A_{S k}$ é o valor adicionado dos serviços para os setores que compõem o segmento do turismo;

$P D F_{k}$ é a participação da demanda final do turismo na demanda final global; e $V A_{S-T}$ é o valor adicionado do segmento serviços, com exceção dos setores que compõem o segmento do turismo.

Para obter a participação da demanda final do turismo na demanda global, 
divide-se a demanda final de cada um dos setores que compõem o segmento do turismo $\left(D F_{k}\right)$ pela demanda final global $(D F G)$ :

$$
P D F_{k}=\frac{D F_{k}}{D F G}
$$

Para obter o valor adicionado do segmento serviços, o procedimento adotado foi o seguinte:

$$
V A_{S-T}=V A T+V A C+V A S
$$

em que

VAT é o valor adicionado dos setores que compõem o segmento do transporte, exceto os setores de transportes que compõem o segmento do turismo;

$V A C$ é o valor adicionado do comércio; e

$V A S$ é o valor adicionado dos setores que compõem o segmento serviços, exceto os setores de serviços que compõem o segmento do turismo.

Para o valor adicionado dos serviços para os setores que compõem o segmento do turismo total $\left(V A_{S}\right)$, tem-se

$$
V A_{S}=V A_{S 1}+V A_{S 2}+\Lambda+V A_{S 12}
$$

O valor adicionado total do segmento do turismo $\left(V A_{\text {Turismo }}\right)$ é dado por

$$
V A_{\text {Turismo }}=V A_{I}+V A_{T}+V A_{S}
$$

Com relação à mensuração do pessoal ocupado na produção dos insumos utilizados pelo segmento do turismo $\left(P O_{\mathrm{Ik}}\right)$, foram utilizadas as informações disponíveis nas tabelas de insumo-produto. As colunas com os valores dos insumos foram multiplicadas pelos respectivos coeficientes do pessoal ocupado $\left(C P O_{\mathrm{i}}\right)$, eliminando-se, dessa forma, o problema da dupla contagem que ocorre quando se considera o pessoal ocupado efetivamente na produção de insumos para esse segmento. Assim, tem-se a seguinte expressão:

$$
P O_{I k}=\sum_{i=1}^{n} z_{i k} * C P O_{i}
$$

em que 
$k=1,2, \ldots, 12$ (setores que compõem o segmento do turismo);

$i=1,2, \ldots, 54$ setores do modelo de insumo-produto;

$P O_{I k}=$ pessoal ocupado na produção dos insumos para os setores do segmento do turismo;

$z_{i k}=$ valor total do insumo do setor $i$ destinado aos setores do segmento do turismo; e

$C P O_{i}=$ coeficiente do pessoal ocupado do setor $i$.

Os coeficientes do pessoal ocupado por setor foram obtidos, dividindo-se a quantidade de pessoas ocupadas no setor $i\left(P O_{i}\right)$ pela produção do setor $i\left(X_{i}\right)$ :

$$
C P O_{i}=\frac{P O_{i}}{X_{i}}
$$

Para obter o pessoal ocupado total no componente insumos $(I)$ para o segmento do turismo $\left(P O_{I}\right)$, faz-se

$$
P O_{I}=P O_{I 1}+P O_{I 2}+\Lambda+P O_{I 12}
$$

Para mensurar o pessoal ocupado em cada um dos setores que compõem o segmento do turismo $\left(P O_{T k}\right)$, considera-se o pessoal ocupado nos respectivos setores:

$$
P O_{T k}=P O_{k}
$$

Assim, para obter o número total de pessoas ocupadas nesses setores $\left(P O_{T}\right)$, procedeu-se da seguinte forma:

$$
P O_{T}=P O_{T 1}+P O_{T 2}+\Lambda+P O_{T 12}
$$

No que diz respeito ao pessoal ocupado no agregado $S$ (serviços), considerase para fins de cálculo o número total de pessoas ocupadas nos setores relativos ao transporte (exceto os transportes que compõem o segmento do turismo), comércio e setores de serviços (excetuando-se os que compõem o segmento do turismo), conforme já definido anteriormente. Do valor total obtido, destina-se ao segmento do turismo apenas a parcela correspondente à participação dos produtos que compõem o segmento do turismo na demanda final.

Desse modo, adotou-se no cálculo do pessoal ocupado nos serviços a seguinte sistemática: 


$$
P O_{S k}=P D F_{k} * P O_{S-T}
$$

em que

$P O_{S k}$ é o pessoal ocupado nos serviços para os setores que compõem o segmento do turismo;

$P D F_{k}$ é a participação da demanda final do turismo na demanda final global, conforme definido anteriormente; e

$P O_{\text {S-T }}$ é o pessoal ocupado no segmento serviços, com exceção dos setores que compõem o segmento do turismo.

Para obter o pessoal ocupado no segmento serviços, com exceção dos setores de serviços que compõem o segmento do turismo, o procedimento adotado foi o que se segue:

$$
P O_{S-T}=P O T+P O C+P O S
$$

em que

POT é o pessoal ocupado nos setores que compõem o segmento transporte, exceto os setores de transportes que compõem o segmento do turismo;

$P O C$ é o pessoal ocupado no comércio; e

$P O S$ é o pessoal ocupado nos setores que compõem o segmento serviços, exceto os setores de serviços que compõem o segmento do turismo.

Para o pessoal ocupado nos serviços dos setores que compõem o segmento do turismo total $\left(P O_{S}\right)$, tem-se

$$
P O_{S}=P O_{S 1}+P O_{S 2}+\Lambda+P O_{S 12}
$$

O pessoal ocupado total do segmento do turismo $\left(P O_{\text {Turismo }}\right)$ é dado por

$$
P O_{\text {Turismo }}=P O_{I}+P O_{T}+P O_{S}
$$

Vale ressaltar aqui que a mensuração do segmento do turismo será feita não somente considerando os agregados, mas também levando-se em conta quanto cada setor que compõe o segmento do turismo adiciona ao mesmo.

No capítulo seguinte são apresentados e discutidos os resultados obtidos da aplicação das metodologias apresentadas neste capítulo. 


\section{RESULTADOS E DISCUSSÃO}

Conforme já foi abordado anteriormente, o turismo não pode ser considerado como um setor econômico dentro de uma estrutura produtiva, tendo em vista que oferta e demanda não apenas um único bem ou serviço, mas, sim, um conjunto de bens e serviços que são produzidos e demandados por diversos setores econômicos. Dessa forma, a análise da contribuição do turismo para a economia brasileira foi feita levando-se em consideração os setores econômicos de maior projeção turística, ou seja, os que ofertam e demandam uma maior quantidade de bens e serviços aos turistas.

O instrumental analítico escolhido para atender aos objetivos deste trabalho foi a teoria de insumo-produto, uma vez que permite identificar as ligações intersetoriais, bem como analisar os impactos econômicos na produção renda e emprego resultantes de variações na demanda final (gastos dos turistas, investimentos etc.), conforme ficou demonstrado na revisão de literatura e no referencial teórico apresentados em capítulos anteriores deste trabalho.

Assim, neste capítulo será apresentado, inicialmente, o modelo de insumoproduto construído para o segmento do turismo no Brasil para o ano de 1999. A partir do referido modelo foi possível identificar a interdependência setorial por meio das ligações interindustriais e dos setores-chave da economia. Em seguida são mostrados os impactos na produção, na renda e no emprego, resultantes de variações na demanda final. Também são apresentadas as estimativas do Valor Adicionado e do Pessoal Ocupado, através das quais procurou-se dimensionar o segmento do turismo no Brasil em 1999, por meio do modelo de insumo-produto, conforme a metodologia proposta no capítulo anterior do presente trabalho. 


\subsection{Análise das relações intersetoriais na economia brasileira e o segmento do turismo}

As tabelas do modelo de insumo-produto construídas para o segmento do turismo no Brasil para o ano de 1999 são apresentadas no Anexo A1. A partir de então foi possível estabelecer indicações sobre a participação dos diversos setores da economia no valor da produção e no valor adicionado, bem como analisar as relações intersetoriais na economia, conforme serão apresentadas e discutidas nesta subseção.

\subsubsection{A participação setorial no valor da produção e no valor adicionado}

Com o objetivo de dimensionar a participação dos setores na economia brasileira, com ênfase na participação do segmento do turismo, serão usados o valor adicionado e o valor da produção. Para esta análise, ao invés de trabalhar com os 54 setores do modelo de insumo-produto para economia turística original, optou-se por fazer uma agregação destes em apenas seis macro-setores, a saber: Agropecuária, Indústria, Serviços industriais de utilidade pública, Construção civil, Serviços nãoturísticos $^{23}$ e Serviços turísticos. Esse último foi desagregado nos seus doze setores originais, conforme mostrado na Tabela 12.

Ao analisar a Tabela 12 pode-se constatar que, dentre os macro-setores considerados, os Serviços não-turísticos foi o que apresentou a maior participação tanto no valor adicionado como no valor da produção, onde os setores que mais contribuíram para esta participação foram Administração pública, Aluguel de imóveis e Comércio (Anexo A2). A segunda maior participação no valor adicionado e no valor da produção ficou para o macro-setor Indústria. A maior contribuição a este macro-setor foi dada pelo setor Indústria química (ver Anexo A2).

Sabe-se que o valor adicionado é dado pela diferença entre o valor bruto da produção e o consumo intermediário, ou seja, é o valor agregado pelos setores

${ }^{23}$ O macro-setor Serviços não-turísticos é composto pelos seguintes setores: Transporte rodoviário de cargas, Outros transportes terrestres, Transporte aquaviário, Atividades auxiliares aos transportes aquaviários, Outras atividades auxiliares ao transporte, Comércio, Comunicações, Instituições financeiras, Outros serviços prestados às famílias, Outros serviços prestados às empresas, Aluguel de imóveis, Administração pública e Serviços privados não-mercantis. 
produtivos no decorrer do processamento da produção. Desse modo, pode-se inferir que os macro-setores acima referidos mostraram-se importantes impulsores da economia brasileira no período analisado.

Tabela 12. Participação setorial no valor da produção e no valor adicionado, Brasil, 1999.

\begin{tabular}{lcc}
\hline \multicolumn{1}{c}{ Macro-setores } & $\begin{array}{c}\text { Participação setorial } \\
\text { no valor da produção } \\
(\%)\end{array}$ & $\begin{array}{c}\text { Participação setorial } \\
\text { no valor adicionado } \\
(\%)\end{array}$ \\
\hline AGROPECUÁRIA & 7,47 & 7,89 \\
INDÚSTRIA & 35,44 & 22,06 \\
S.I.U.P. & 2,81 & 2,73 \\
CONSTRUÇÃO CIVIL & 8,37 & 9,06 \\
SERVIÇOS NÃO-TURÍSTICOS & 41,70 & 54,68 \\
SERVIÇOS TURÍsTICOS & $\mathbf{4 , 2 2}$ & $\mathbf{3 , 5 9}$ \\
Transporte rodoviário de passageiros, regular & 19,72 & 21,78 \\
Transporte rodoviário de passageiros, não-regular & 1,44 & 1,59 \\
Transporte regular para exploração de pontos turísticos & 0,02 & 0,02 \\
Transporte aéreo, regular & 16,17 & 13,55 \\
Transporte aéreo, não-regular & 0,91 & 0,76 \\
Agências e organizadores de viagens & 4,46 & 3,74 \\
Atividades auxiliares aos transp. terrestre & 1,48 & 1,63 \\
Atividades auxiliares aos transp. aéreos & 1,20 & 1,01 \\
Estab. hoteleiros e outros tipos de aloj. temporário & 9,95 & 9,43 \\
Restaurantes outros estab. de serviços de alimentação & 34,98 & 33,14 \\
Atividades, recreativas, culturais e desportivas & 8,73 & 11,90 \\
Aluguel de automóveis outros meios de transporte & 0,95 & 1,46 \\
\hline
\end{tabular}

Fonte: dados estimados pelo autor.

Ainda com base na Tabela 12 e considerando apenas o macro-setor Serviços turísticos, pode-se perceber que o setor Restaurantes e outros estabelecimentos de serviços de alimentação apresenta uma maior participação no valor adicionado e no valor da produção total, enquanto o que apresenta menor participação é o setor Transporte regular para exploração de pontos turísticos. 


\subsubsection{Ligações industriais e setores-chave}

As ligações intersetoriais em uma determinada economia são mensuradas com o objetivo de identificar os setores-chave, onde se espera que os recursos alocados estimulem um crescimento dessa economia. Assim, procurou-se determinar, através de mais de um método, os setores que mais dinamizam a economia, em especial os que compõem o segmento do turismo, conforme será visto a seguir.

\subsubsection{Os índices Hirschman-Rasmussen}

Conforme apresentado no capítulo 4, a partir dos índices de ligações de Hirschman-Rasmussen, é possível identificar e analisar o grau de integração setorial de uma determinada economia, ou seja, a maneira como os setores econômicos se inter-relacionam tanto como demandantes de produtos de outros setores, como ofertantes de produtos a outros setores. No primeiro caso tem-se o índice de ligação para trás e, no segundo caso, o índice de ligações para frente.

Segundo estes autores, quanto maior o índice de ligação para trás, maior será seu poder de compra, isto é, maior a sua influência sobre a demanda por produtos de outros setores. E, quanto maior o índice de ligação para frente, maior será o poder de venda de um determinado setor, isto é, maior sua influência sobre a oferta de produtos para setores outros.

A análise dos índices de ligações para frente e para trás de HirschmanRasmussen é complementada pelos coeficientes de dispersão dos índices de ligações, à medida que estes possibilitam interpretar como um impacto setorial se distribui para os demais setores. A ocorrência de um valor baixo para uma dispersão do índice de ligação para trás significa que o impacto de uma variação na produção no setor tende a estimular os demais, de maneira uniforme, já um valor alto para este coeficiente significa que o impacto será concentrado em poucos setores. Para o caso do coeficiente de dispersão do índice de ligação para frente, um valor alto significa que a demanda por este setor está concentrada em poucos setores, enquanto que um baixo valor significa que este setor é demandado de maneira uniforme pelos demais da economia. 
A Tabela 13 mostra os resultados dos índices de ligações de HirschmanRasmussen e os coeficientes de dispersão destes índices para os setores analisados, bem como a ordem de importância dos mesmos na economia. Esses resultados também são mostrados nas Figuras 3 a 6 , onde podem ser mais bem visualizados e comparados.

Analisando os índices de ligações para trás, observa-se que os setores apresentaram índices bastante heterogêneos, sendo que 28 setores estão mais integrados, indicando, assim, que a economia brasileira no ano de 1999 se encontrava relativamente interligada. Esse cenário pode ser resultado de mudanças econômicas adotadas durante os quatro primeiros anos do plano real e que proporcionaram ao Brasil um certo grau de dinamismo não-verificado nos primeiros cinco anos da década de 1990, período em que, segundo Lima \& Casimiro Filho (2000), a economia brasileira esteve pouco interligada. Essas mudanças modificaram os vínculos entre os fatores econômicos internos e externos e levaram ao incremento na entrada de investimentos diretos estrangeiros, ampliando, assim, o mercado interno brasileiro.

Especificamente, em relação aos investimentos no segmento do turismo, segundo Saab \& Daemon (2001), houve nos últimos anos a entrada de cadeias internacionais de hotéis no país que, em conjunto com outros agentes econômicos, pretendem realizar investimentos significativos na construção e implantação de novas unidades hoteleiras no Brasil. Recentemente, também, instalaram-se aqui no Brasil alguns parques temáticos de propriedade de empresas estrangeiras, alguns já em operação e outros encontram-se em construção (Embratur/FADE, 1999).

Dentre os setores mais integrados, destacam-se, como de maior capacidade de interação com os setores vendedores, os seguintes: Siderurgia (4), Indústria de café (20), Fabricação de óleos vegetais (25), Abate de animais (22) e Fabricação de açúcar. Esses concentraram a demanda por insumos para o processo produtivo brasileiro. 
Tabela13. Índices de ligações para trás e para frente de Rasmussen-Hirschman e coeficiente de dispersão dos índices de ligações, Brasil, 1999.

\begin{tabular}{|c|c|c|c|c|c|c|c|c|c|}
\hline & Setores & $\begin{array}{l}\text { Ligações } \\
\text { para trás }\end{array}$ & Ordem & $\begin{array}{c}\text { Dispersão } \\
\text { para trás }\end{array}$ & Ordem & $\begin{array}{l}\text { Ligações } \\
\text { para frente }\end{array}$ & Ordem & $\begin{array}{l}\text { Dispersão } \\
\text { para frente }\end{array}$ & Ordem \\
\hline 1 & AGROPECUÁRIA & 0,9056 & 40 & 5,1910 & 9 & 3,4300 & 2 & 1,9214 & 52 \\
\hline 2 & EXTRATIVA MINERAL & 0,8279 & 46 & 4,9099 & 12 & 1,3217 & 10 & 3,0444 & 49 \\
\hline 3 & MINERAL Ñ METÁLICO & 0,9982 & 30 & 4,6608 & 17 & 0,8776 & 19 & 5,2645 & 32 \\
\hline 4 & SIDERURGIA & 1,3008 & 1 & 5,0626 & 11 & 1,7334 & 4 & 3,8629 & 43 \\
\hline 5 & METALURGIA & 1,1885 & 8 & 4,2991 & 31 & 1,7056 & 5 & 2,9491 & 50 \\
\hline 6 & MÁQUINAS E EQUIP. & 0,9074 & 39 & 4,4875 & 21 & 1,0020 & 15 & 3,9861 & 42 \\
\hline 7 & MATERIAL ELÉTRICO & 1,1668 & 11 & 3,7324 & 50 & 0,6909 & 31 & 6,1079 & 25 \\
\hline 8 & EQUIP. ELETRÔNICOS & 0,9154 & 38 & 4,5807 & 20 & 0,6051 & 40 & 6,9354 & 12 \\
\hline 9 & AUTOM./CAM/ONIBUS & 1,1066 & 17 & 3,6479 & 51 & 0,5616 & 47 & 7,0135 & 11 \\
\hline 10 & PEÇAS E OUT. VEÍCULOS & 1,1243 & 13 & 3,9953 & 39 & 1,2525 & 12 & 3,5599 & 45 \\
\hline 11 & MADEIRA E MOBILIÁRIO & 1,0627 & 20 & 4,2025 & 34 & 0,6977 & 29 & 6,2672 & 22 \\
\hline 12 & CELULOSE, PAPEL E GRÁF. & 1,1092 & 15 & 4,6674 & 16 & 1,3610 & 9 & 3,7447 & 44 \\
\hline 13 & IND. DA BORRACHA & 1,0770 & 19 & 4,6330 & 18 & 1,1052 & 13 & 4,4010 & 38 \\
\hline 14 & INDÚSTRIA QUÍMICA & 1,0079 & 27 & 5,2134 & 8 & 5,1681 & 1 & 1,0343 & 54 \\
\hline 16 & ARTIGOS PLÁSTICOS & 1,0057 & 28 & 4,3854 & 25 & 0,9479 & 16 & 4,2996 & 40 \\
\hline 17 & IND. TÊXTIL & 1,2400 & 6 & 4,8186 & 13 & 1,4459 & 8 & 4,3648 & 39 \\
\hline 18 & ARTIGOS DO VESTUÁRIO & 1,1699 & 10 & 3,8897 & 42 & 0,5399 & 51 & 7,2381 & 3 \\
\hline 19 & FABRICAÇÃO DE CALÇADOS & 1,0879 & 18 & 4,0794 & 37 & 0,6148 & 38 & 7,1451 & 6 \\
\hline 20 & INDÚSTRIA DO CAFÉ & 1,2714 & 2 & 4,3367 & 27 & 0,6934 & 30 & 7,1035 & 8 \\
\hline 21 & BENEF. PROD. VEGETAIS & 1,1734 & 9 & 3,8807 & 43 & 0,7206 & 27 & 5,6041 & 28 \\
\hline 22 & ABATE DE ANIMAIS & 1,2566 & 4 & 3,9384 & 40 & 0,6906 & 32 & 6,1269 & 24 \\
\hline 23 & INDÚSTRIA DE LATICÍNIOS & 1,1612 & 12 & 4,2679 & 33 & 0,6598 & 34 & 7,0473 & 9 \\
\hline 24 & FABRICAÇÃO DE AÇÚCAR & 1,2525 & 5 & 3,8949 & 41 & 0,7194 & 28 & 6,4118 & 20 \\
\hline 25 & FAB. ÓLEOS VEGETAIS & 1,2676 & 3 & 4,0939 & 36 & 0,8682 & 21 & 5,5819 & 29 \\
\hline 26 & OUTROS PROD. ALIMENT. & 1,2019 & 7 & 3,5537 & 54 & 0,9197 & 18 & 4,5046 & 37 \\
\hline 27 & INDÚSTRIAS DIVERSAS & 0,9940 & 31 & 4,0084 & 38 & 0,6580 & 35 & 5,9965 & 26 \\
\hline 28 & S.I.U.P. & 0,9019 & 41 & 6,1804 & 3 & 1,5554 & 6 & 3,5321 & 47 \\
\hline
\end{tabular}


Tabela 13. Índices de ligações para trás e para frente de Rasmussen-Hirschman e coeficiente de dispersão dos índices de ligações, Brasil, 1999.

\begin{tabular}{|c|c|c|c|c|c|c|c|c|c|}
\hline & Setores & $\begin{array}{l}\text { Ligações } \\
\text { para trás }\end{array}$ & Ordem & $\begin{array}{c}\text { Dispersão } \\
\text { para trás }\end{array}$ & Ordem & $\begin{array}{l}\text { Ligações } \\
\text { para frente }\end{array}$ & Ordem & $\begin{array}{l}\text { Dispersão } \\
\text { para frente }\end{array}$ & Ordem \\
\hline 29 & CONSTRUÇÃO CIVIL & 0,8821 & 44 & 4,6078 & 19 & 0,7241 & 26 & 5,5720 & 30 \\
\hline 30 & COMÉRCIO & 0,9312 & 32 & 4,4839 & 22 & 2,5431 & 3 & 1,5148 & 53 \\
\hline 31 & TRANSP. RODOV. DE PASSAG., REGULAR & 0,9240 & 35 & 4,3214 & 29 & 0,7519 & 24 & 5,1759 & 33 \\
\hline 32 & TRANSP. RODOV. PASSAG., NÃO REGULAR & 0,9240 & 34 & 4,3002 & 30 & 0,5467 & 49 & 7,1300 & 7 \\
\hline 33 & TRANSP. REG. EXPL. DE POS TURÍSTICOS & 0,9240 & 36 & 4,2986 & 32 & 0,5307 & 53 & 7,3459 & 2 \\
\hline 34 & TRANSP. RODOV. DE CARGAS & 0,9240 & 33 & 4,3576 & 26 & 1,1017 & 14 & 3,5333 & 46 \\
\hline 35 & OUTR. TRANSP.TERRESTRES & 1,1071 & 16 & 3,6115 & 53 & 0,5834 & 44 & 6,6776 & 15 \\
\hline 36 & TRANSP. AQUAVIÁRIO & 0,8951 & 42 & 4,4201 & 23 & 0,5758 & 45 & 6,8599 & 13 \\
\hline 37 & TRANSP. AÉREO, REGULAR & 1,0582 & 23 & 3,8790 & 44 & 0,7837 & 23 & 5,1070 & 34 \\
\hline 38 & TRANSP. AÉREO, NÃO REGULAR & 1,0586 & 22 & 3,7788 & 49 & 0,5447 & 50 & 7,1576 & 5 \\
\hline 39 & AGÊNC. E ORG. DE VIAGENS & 1,0623 & 21 & 3,8084 & 48 & 0,7312 & 25 & 5,3454 & 31 \\
\hline 40 & ATIV. AUX. TRANSP. TERRESTRE & 0,9214 & 37 & 4,3233 & 28 & 0,5860 & 43 & 6,6591 & 17 \\
\hline 41 & ATIV. AUX.TRANSP.AQUAVIÁRIOS & 0,8901 & 43 & 4,4161 & 24 & 0,6116 & 39 & 6,4053 & 21 \\
\hline 42 & ATIV. AUX. TRANSP. AÉREOS & 1,0539 & 24 & 3,8086 & 47 & 0,5755 & 46 & 6,7886 & 14 \\
\hline 44 & COMUNICAÇÕES & 0,7436 & 52 & 5,3006 & 6 & 0,9478 & 17 & 4,1197 & 41 \\
\hline 45 & INSTITUIÇÕES FINANCEIRAS & 0,7646 & 48 & 5,5420 & 4 & 1,3146 & 11 & 3,1735 & 48 \\
\hline 46 & ESTAB. HOTEL. E OUTR. TIPOS DE ALOJ. TEMPORÁRIO & 1,0316 & 25 & 3,8294 & 46 & 0,5553 & 48 & 7,0181 & 10 \\
\hline 47 & REST. OUTR. ESTAB. DE SERV. DE ALIMENTAÇÃO & 1,0316 & 26 & 3,8319 & 45 & 0,5894 & 42 & 6,6081 & 18 \\
\hline 48 & ATIV. RECREATIVAS, CULT. E DESPORTIVAS & 0,8324 & 45 & 4,6680 & 15 & 0,5939 & 41 & 6,5570 & 19 \\
\hline 49 & OUTR. SERV. PREST. ÀS FAMÍLIAS & 0,8194 & 47 & 4,7873 & 14 & 0,6386 & 36 & 6,1465 & 23 \\
\hline 50 & ALUGUEL AUTOM. OUTR. MEIOS DE TRANSPORTE & 0,7577 & 50 & 5,1487 & 10 & 0,5392 & 52 & 7,2323 & 4 \\
\hline 51 & OUTR. SERV. PREST. ÀS EMPRESAS & 0,7577 & 49 & 5,4441 & 5 & 1,5485 & 7 & 2,6001 & 51 \\
\hline 52 & ALUGUEL DE IMÓVEIS & 0,5656 & 54 & 6,8930 & 1 & 0,8356 & 22 & 4,6216 & 35 \\
\hline 53 & ADMINISTRAÇÃO PÚBLICA & 0,7559 & 51 & 5,2297 & 7 & 0,8698 & 20 & 4,5145 & 36 \\
\hline 54 & SERV. PRIV. Ñ MERCANTIS & 0,5913 & 53 & 6,5804 & 2 & 0,5305 & 54 & 7,3485 & 1 \\
\hline
\end{tabular}

Fonte: dados estimados pelo autor. 


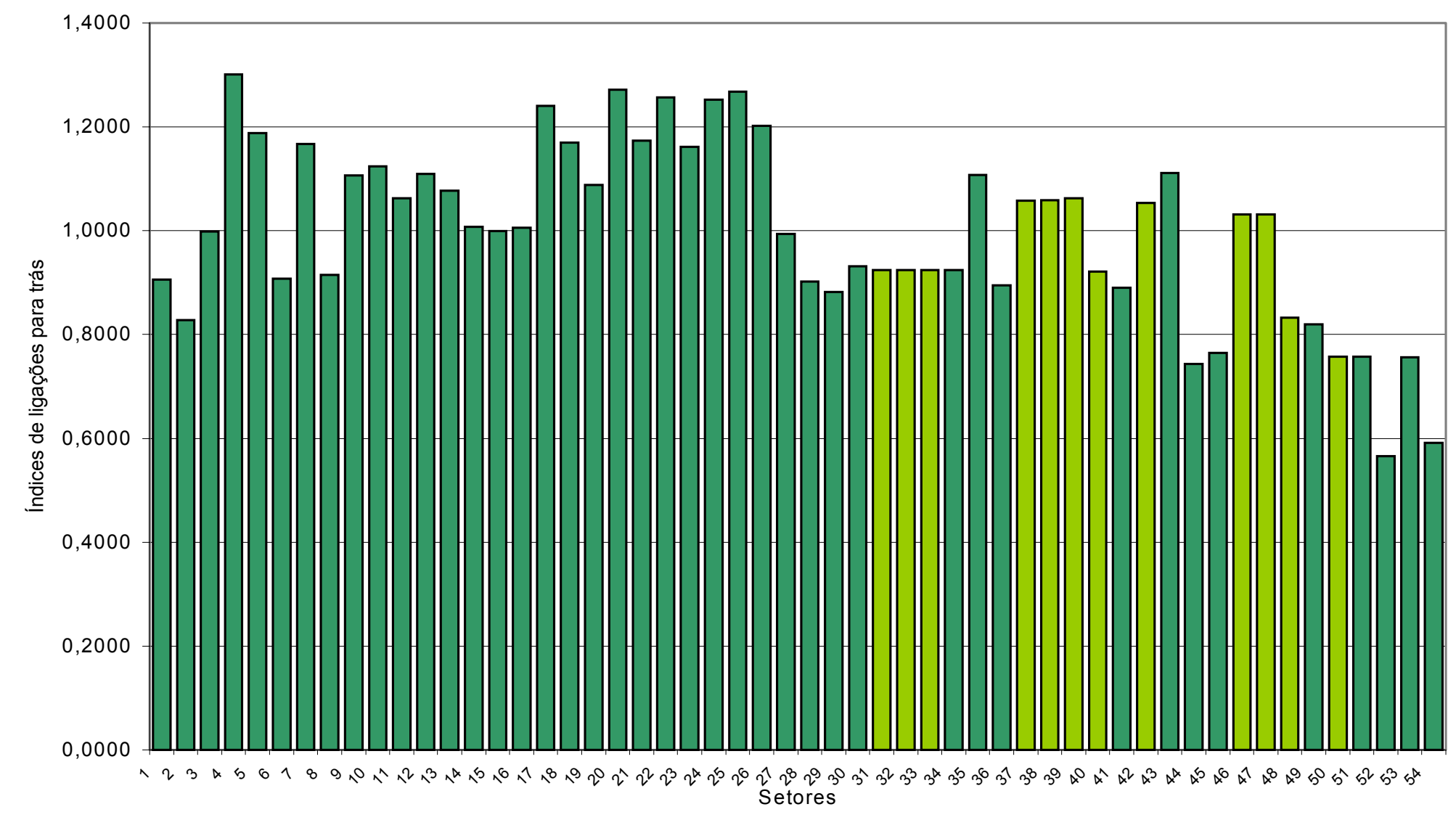

Setores do segmento do turismo

$\square$ Demais setores da economia

Figura 3 - Índices de ligações para trás de Hirschman-Rasmussen, Brasil, 1999. 


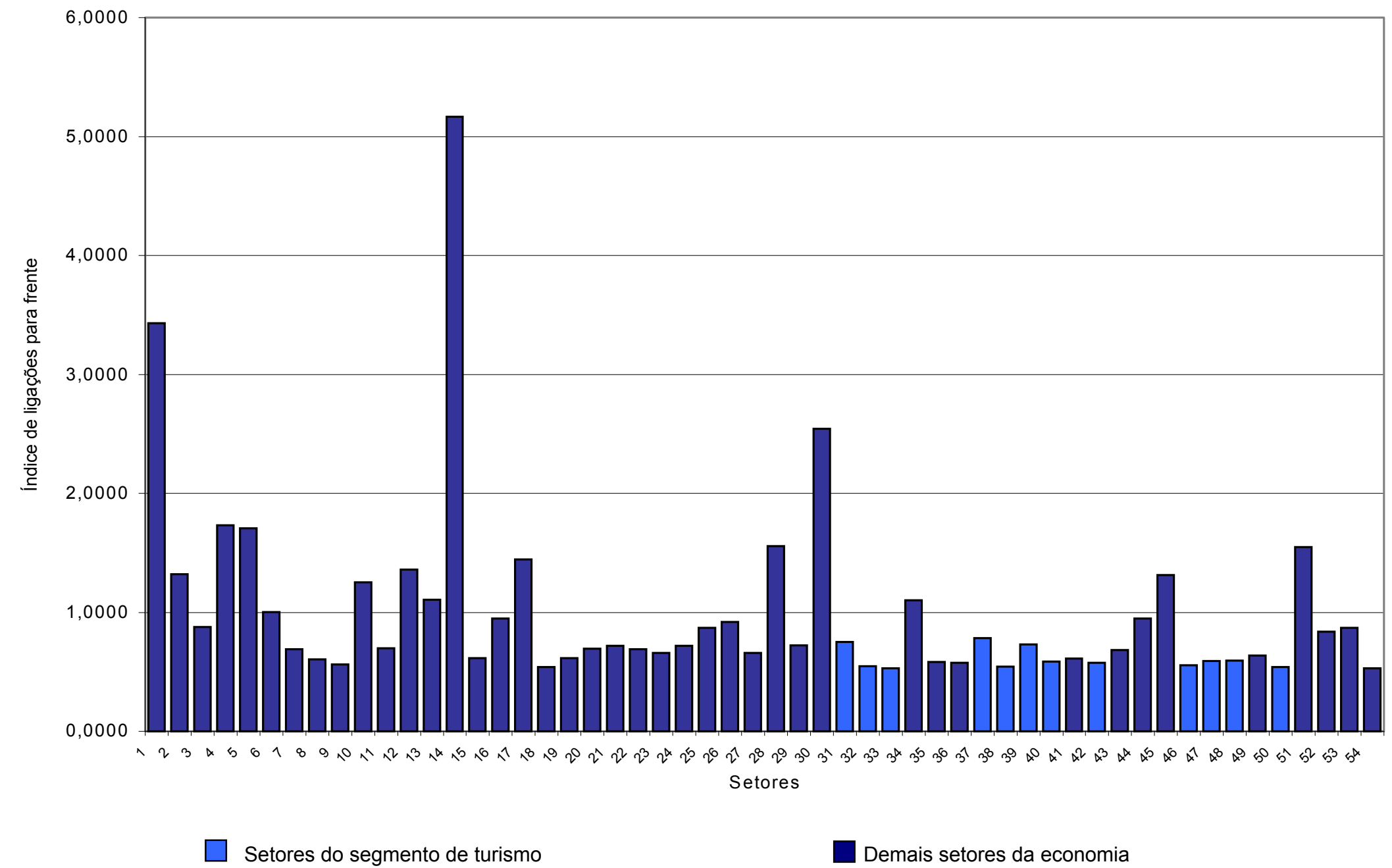

Figura 4 - Índices de ligações para frente de Hirschman-Rasmussen, Brasil, 1999. 
Com relação aos setores que compõem o segmento do turismo, pode-se perceber que, embora não se encontrem entre os cinco principais demandantes, encontram-se entre os setores mais integrados na economia. Os setores vinculados ao turismo que apresentam esta característica são: Transporte aéreo, regular (37), Transporte aéreo, não-regular (38), Agências e organizadores de viagens (39), Atividades auxiliares ao transporte aéreo (42), Estabelecimentos hoteleiros e outros tipos de alojamento temporário (46) e Restaurantes e outros estabelecimentos de serviços de alimentação (47).

No que diz respeito aos índices de ligações para frente, ainda com base na Tabela 13, pode-se observar que a quantidade de setores que ofertam seus produtos como insumos para os demais setores do processo produtivo é menor que os setores os quais demandam, sendo formados por 14 outros (setores com índice superior a média). Considerando os cinco maiores índices de ligações para frente, observa-se que a oferta dos insumos se processou pelos seguintes setores: Indústria química (14), Agropecuária (1), Comércio (30), Siderurgia (4) e Metalurgia (5).

Analisando os setores que compõem o segmento do turismo, percebe-se que todos os setores apresentam índice de ligação para frente inferior à média, isto é, menor que a unidade. Essa informação evidencia que os produtos do segmento do turismo são pouco usados por outros setores no processo produtivo (consumo intermediário baixo), sendo destinados à demanda final, principalmente ao consumo das famílias e à exportação (consumo dos turistas estrangeiros no Brasil).

Com relação aos coeficientes de dispersão dos índices de ligação para trás, (Tabela 13 e Figura 5) observa-se que os maiores coeficientes referem-se aos seguintes setores: Outros produtos alimentares (26), Outros transportes terrestres (35), Outras atividades auxiliares aos transportes (43), Peças e outros veículos (10) e Material elétrico (7). Desse modo, um impacto de uma variação de produção nesses setores estimularia os demais setores de maneira concentrada em poucos setores. Em relação ao segmento do turismo, observa-se que, na quase totalidade dos setores componentes, os coeficientes de variação dos índices são relativamente baixos, indicando que o segmento do turismo está bem articulado com os demais setores da 
economia brasileira. Assim, uma variação de produção nos setores que compõem tal segmento estimularia os demais, de maneira uniforme.

No que diz respeito aos coeficientes de dispersão dos índices de ligação para frente (Tabela 13 e Figura 6), observa-se que os setores os quais compõem o segmento do turismo: Transporte regular para exploração de pontos turísticos (33), Aluguel de automóveis e outros meios de transporte (50), Transporte aéreo, regular (38), Transporte rodoviário, não-regular (32), apresentam valores relativamente altos de dispersão, significando que a demanda por estes setores ocorre de maneira concentrada. Esse resultado está ligado com a demanda final, conforme já foi explicado anteriormente. Já os setores que apresentaram baixos índices de dispersão foram: Indústria química (14), Comércio (30), Agropecuária (1), Outros serviços prestados às empresas (51) e Metalurgia (5), significando que a demanda por estes setores ocorre de maneira uniforme pelos demais setores da economia.

A partir dos índices de ligações para trás e para frente podem-se classificar os setores como setores-chave dentro de um sistema econômico. McGilvray (1977) utiliza-se de um conceito mais restrito para definir um setor-chave. Segundo esse autor, um setor para ser considerado como um setor-chave dentro de uma economia deve apresentar os índices de ligações, tanto para frente como para trás, maiores que 1. Há, entretanto, alguns autores que utilizam um conceito mais abrangente para classificar um setor como sendo um setor-chave. Considerando esse conceito menos restrito, diz-se que um setor pode ser considerado como sendo um setor-chave, se o mesmo apresentar um dos índices de ligação, para trás ou para frente, acima da média, isto é, maior do que 1. 


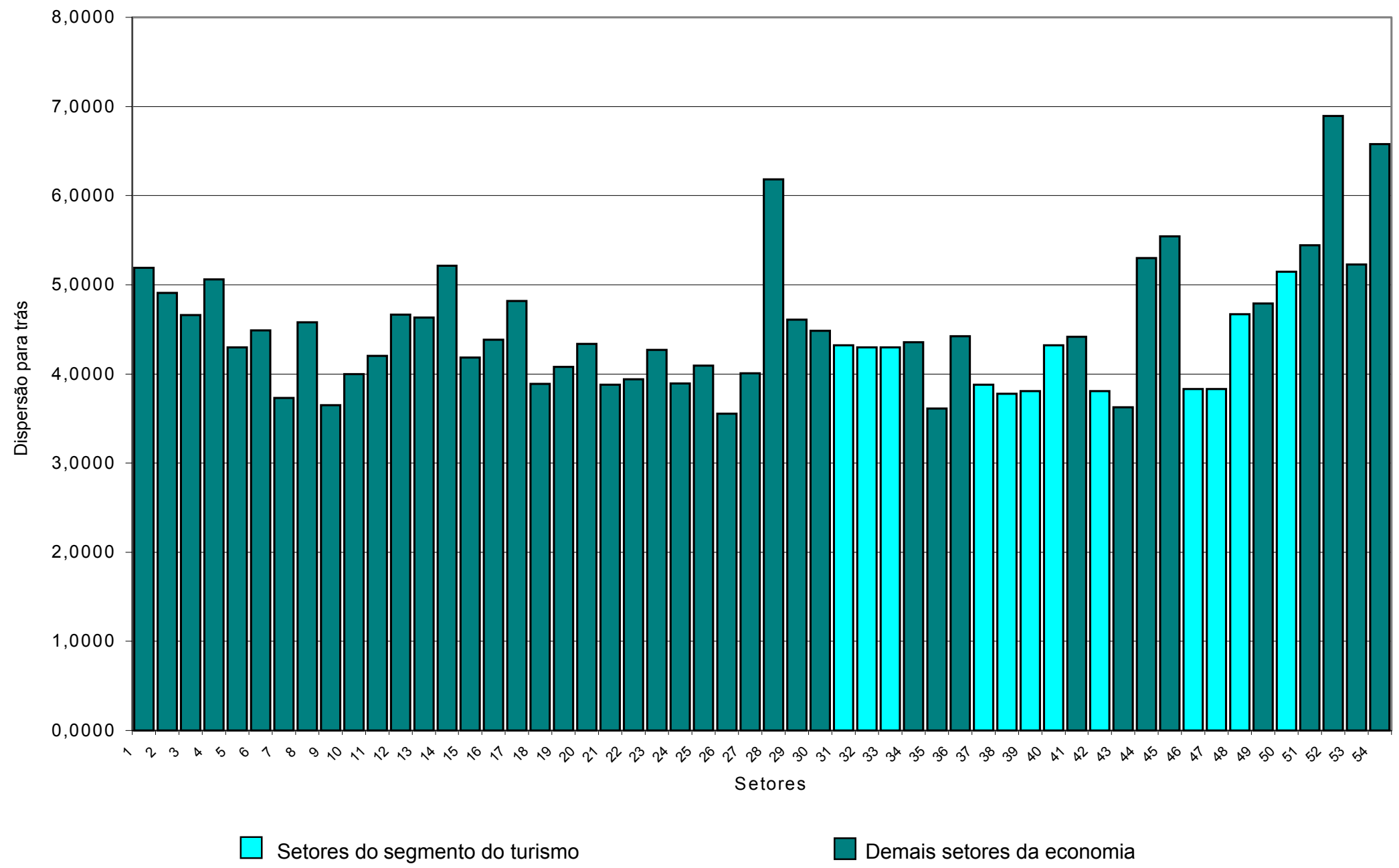

Figura 5 - Coeficiente de dispersão dos índices de ligações para trás de Hirschman-Rasmussen, Brasil, 1999. 


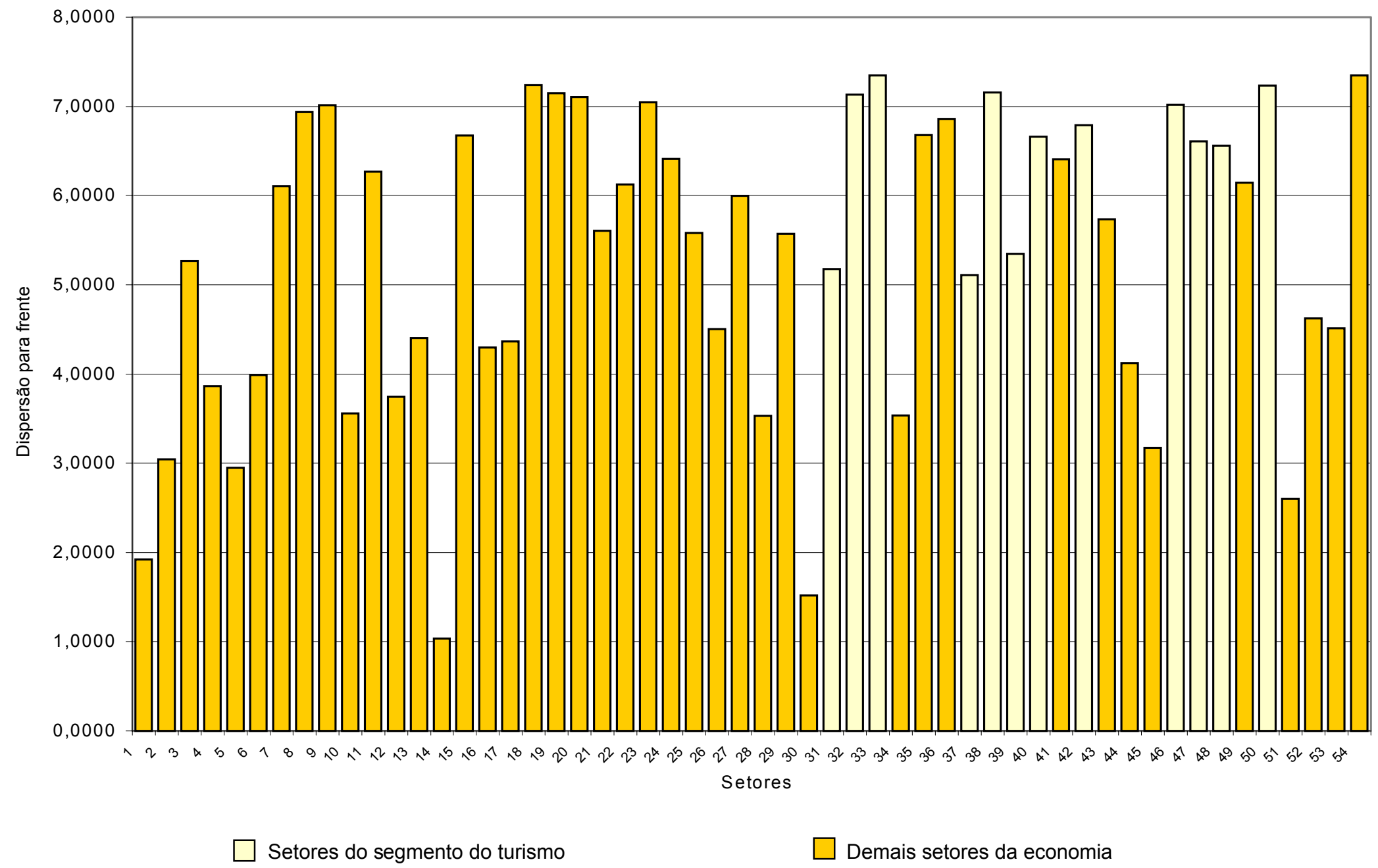

Figura 6 - Coeficiente de dispersão dos índices de ligações para frente de Hirschman-Rasmussen, Brasil, 1999. 
Os setores que podem ser classificados como sendo setores-chave na economia brasileira, para o ano aqui analisado, podem ser vistos na Figura 7.

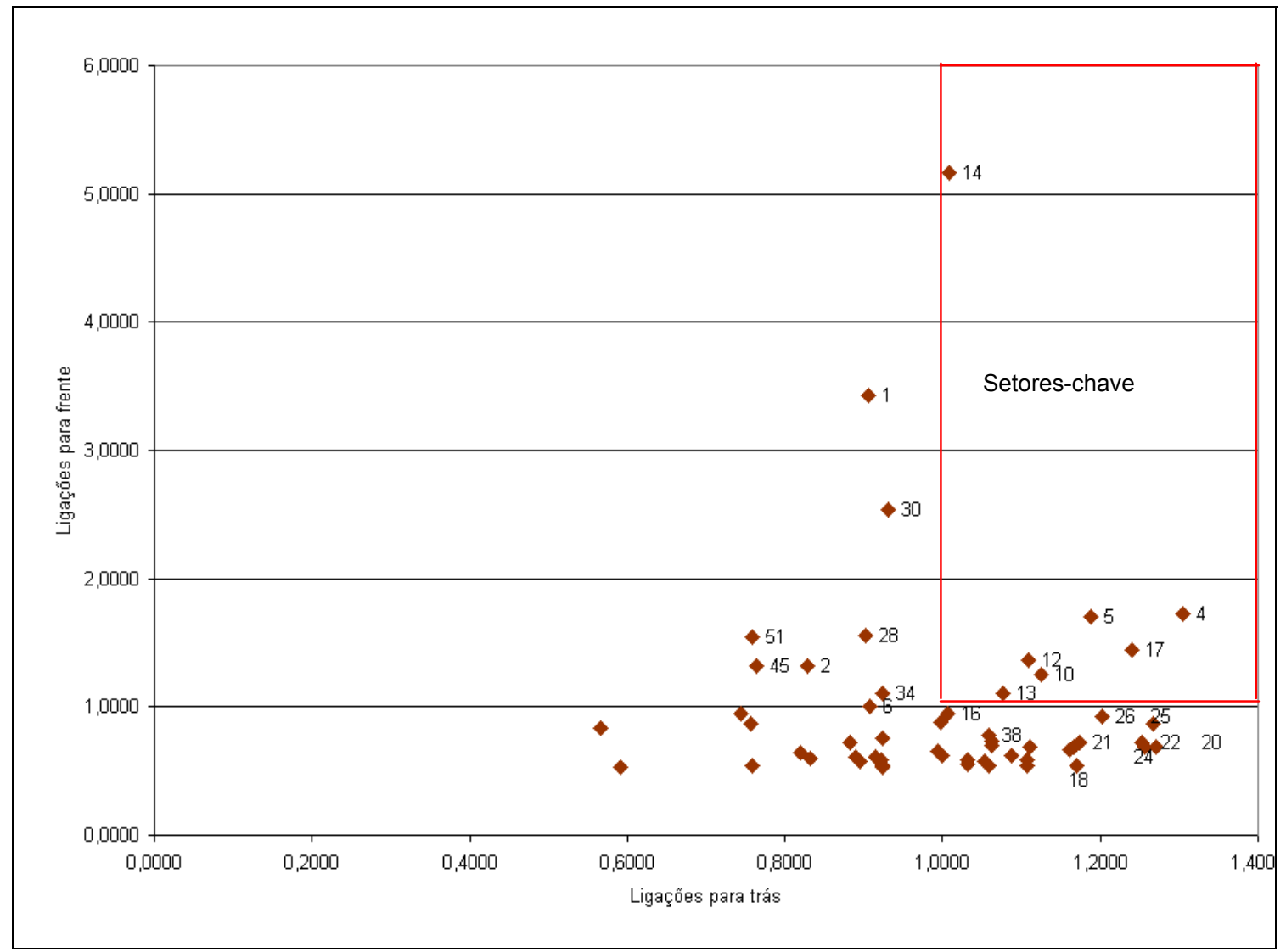

Figura 7 - Setores-chave, Brasil, 1999.

De acordo com a Figura 7 e levando em consideração o conceito mais restrito podem-se destacar sete setores-chave para o crescimento da economia brasileira: Siderurgia (4), Metalurgia (5), Peças e outros veículos (10), Celulose, papel e gráfica (12), Indústria da borracha (13), Indústria química (14) e Indústria têxtil (17). Conforme pode ser observado, todos esses setores pertencem à indústria de transformação. Esse resultado é o reflexo do processo de reestruturação pelo qual este setor vem passando desde o início da década de 1990, com resultados bastante positivos para alguns de seus segmentos. O processo de reestruturação da indústria brasileira inclui um conjunto de reformas com o objetivo de dinamizar a economia brasileira, dentre as 
um conjunto de reformas com o objetivo de dinamizar a economia brasileira, dentre as quais podem-se destacar: reformas destinadas à liberalização do comércio; reformas destinadas à estabilização de preços, privatização de empresas; desregulamentação dos mercados de bens e serviços e eliminação de distorções nos sistemas tributários e financeiros.

Aplicando o critério mais abrangente para classificar um setor como setorchave, tem-se como resultado, além dos anteriormente citados, 29 setores-chave, (21 com ligações para trás e 8 com ligações para frente), sendo que desses, 6 são componentes do segmento do turismo: Transporte aéreo, regular (37), Transporte aéreo, não-regular (38), Agência e organizadores de viagens (39), Atividades auxiliares ao transporte aéreo (42) Estabelecimentos hoteleiros e outros tipos de alojamento temporário (46), Restaurantes e outros estabelecimentos de serviços de alimentação (47). Esse conjunto de reformas para dinamizar a economia brasileira citado no parágrafo anterior, bem como a desvalorização cambial, afetou a estrutura produtiva do segmento do turismo. Verifica-se que ocorreu um avanço tecnológico com reflexos sobre os custos e preços finais dos produtos e serviços ofertados no mercado. Isso fez com que aumentasse o consumo do turismo interno pelos brasileiros e estrangeiros (Brasil, 2002a).

A definição de setores-chave indica os setores mais dinâmicos e, portanto, importantes para o crescimento da economia. Por isso deveriam ser considerados prioritários, quando da implementação de investimentos. "Um crescimento dinâmico para o país só será possível com o fortalecimento dos complexos produtivos para os quais o país revele maior aptidão" (Brasil, 2002b, p. 13).

\subsubsection{Campo de influência}

Com o objetivo de complementar a análise dos índices de HirschmanRasmussen e identificar como se distribuem as alterações dos coeficientes diretos de produção no sistema econômico como um todo, ou seja, identificar os elos da economia, foi calculado o campo de influência.

Assim, as relações intersetoriais mais importantes dentro do processo produtivo da economia brasileira para o ano de 1999 podem ser vistas na Figura 8. 


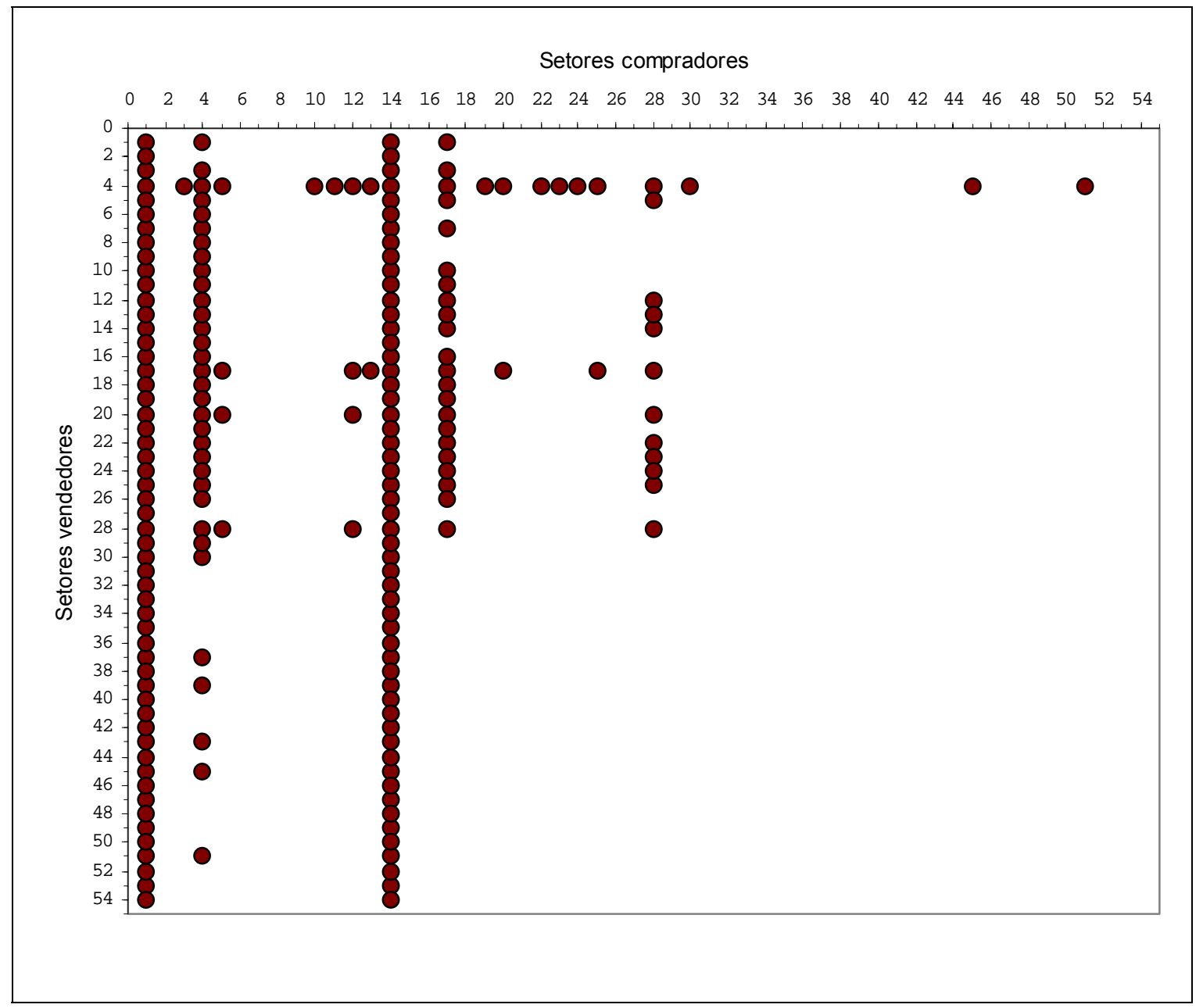

Figura 8 - Coeficientes setoriais com maior campo de influência, Brasil, 1999.

Pode-se perceber que, se ocorressem pequenas alterações nos coeficientes diretos de produção, o setor Siderurgia (4) seria o grande propagador dessas alterações no sistema econômico, visto que o mesmo apresentou 19 coeficientes relativos à venda e 33 coeficientes envolvendo compras. O segundo maior propagador das alterações nos coeficientes diretos de produção no sistema econômico seria o setor Indústria têxtil (17) com 10 coeficientes envolvendo vendas e 22 envolvendo compras.

Considerando somente o lado das compras, ou seja, analisando a importância dos setores como compradores de insumos dos demais setores da economia, podem- 
setor Indústria têxtil (17) com 10 coeficientes envolvendo vendas e 22 envolvendo compras.

Considerando somente o lado das compras, ou seja, analisando a importância dos setores como compradores de insumos dos demais setores da economia, podemse ressaltar: Agropecuária (1) e Industria química (14) comprando de todos os setores do sistema econômico. Este resultado confirma a opinião de alguns analistas econômicos de que a agricultura brasileira está alcançando um avanço tecnológico. Segundo Brasil (2002), em estudo sobre os seis anos do plano real, um indicador expressivo deste avanço é a evolução do consumo de fertilizantes de 11,2 milhões de toneladas em 1994 para 14,3 milhões em 1999. Seguindo esta mesma trajetória, o consumo de nutrientes e matéria-prima por parte deste setor, também tem apresentado crescimento constante.

\subsubsection{Os índices puros de ligações}

Nos cálculos e análises do índice de Hirschman-Rasmussen não se leva em consideração o valor da produção dos setores para medir a importância econômica destes, o que, segundo Guilhoto et al. (1996) é feito pelos índices puros. Assim, alguns comentários merecem ser feitos antes de se analisarem os índices puros de ligação, os quais apresentam a vantagem, em relação aos índices de HirschmanRasmussen, de classificar os setores-chave, considerando, não apenas as suas ligações com outros setores, como também o valor de sua produção total. Por essa razão podem-se eleger setores-chave diferentes dos que foram eleitos anteriormente, quando foi considerado o índice de ligação de Hirschman-Rasmussen.

Na Tabela 14 e Figuras 9, 10 e 11 são apresentados os resultados referentes aos índices puros de ligações intersetoriais para trás, para frente e total, ambos normalizados conforme definido no capítulo anterior, de modo a facilitar a análise. É apresentada, também, a ordem de importância dos 54 setores na economia de acordo

com o índice puro. A análise desses índices tem como objetivo medir a importância de um dado setor para o resto da economia em termos de seu valor da produção. 
Sabe-se que o índice puro de ligação para trás mostra o impacto puro do valor da produção total de um determinado setor sobre o restante da economia. Enquanto o índice puro de ligação para frente mostra o impacto puro da produção total do resto da economia nos setores.

Considerando o índice puro de ligação para trás normalizado, pode-se perceber que os cinco maiores demandantes foram os setores: Construção civil (29), Administração pública (53), Comércio (30), Outros produtos alimentares (26) e Abate de animais (22). Dessa forma, pode-se inferir que, considerando o valor da produção, estes setores foram os que mais impactaram a economia no ano aqui analisado, já os setores que menos provocaram impacto na economia, ou seja, que apresentaram os menores índices puros de ligação para trás normalizados, no ano de 1999, foram: Transporte regular para exploração de pontos turísticos (33), Aluguel de automóveis e outros meios de transportes (51), Atividades auxiliares aos transportes terrestres (40), Atividades auxiliares aos transportes aéreos (42), e Atividades auxiliares aos transportes aquaviários (50).

Analisando os índices puros de ligação para frente normalizados, observa-se que os cinco maiores ofertantes de insumos, ou mais demandados na economia foram: Indústria química (14), Agropecuária (1), Comércio (30), Outros serviços prestados às empresas (51) e Metalurgia (5). Esses são os setores nos quais a produção total do resto da economia gera mais impacto puro, já os menos demandados, o que por conseqüência a produção total do resto da economia gera menos impacto puro foram: Transporte regular para exploração de pontos turísticos (33), Transporte aéreo, regular (38), Artigos de vestuário (18), Aluguel de automóveis e outros meios de transportes (50) e transportes de passageiros, não-regular (32).

Constatou-se, analisando a Tabela 14, que os setores os quais compõem o segmento do turismo apresentaram valores desses índices, de modo geral, baixos, com exceção do setor restaurante e outros estabelecimentos de serviços de alimentação (47). Esse resultado mostra que tanto o impacto puro do valor da produção total dos setores em destaque na economia, evidenciado pelo índice puro de ligação para trás, como o impacto puro da produção total do restante da economia sobre os setores do segmento do turismo, foram relativamente baixos. 
Tabela 14. Índices puros de ligações normalizados para trás, para frente e total, Brasil, 1999.

\begin{tabular}{|c|c|c|c|c|c|c|c|}
\hline & Setores & $\begin{array}{l}\text { Ligações } \\
\text { para trás }\end{array}$ & Ordem & $\begin{array}{l}\text { Ligações } \\
\text { para frente }\end{array}$ & Ordem & $\begin{array}{c}\text { Ligações } \\
\text { totais }\end{array}$ & Ordem \\
\hline 1 & AGROPECUÁRIA & 2,1370 & 8 & 6,2046 & 2 & 4,1620 & 3 \\
\hline 2 & EXTRATIVA MINERAL & 0,2577 & 37 & 1,5929 & 10 & 0,9224 & 20 \\
\hline 3 & MINERAL Ñ METÁLICO & 0,1485 & 40 & 1,7000 & 9 & 0,9209 & 21 \\
\hline 4 & SIDERURGIA & 0,3791 & 36 & 2,0038 & 7 & 1,1879 & 14 \\
\hline 5 & METALURGIA & 0,6910 & 21 & 2,8017 & 5 & 1,7418 & 8 \\
\hline 6 & MÁQUINAS E EQUIP. & 1,0605 & 12 & 0,9695 & 16 & 1,0152 & 17 \\
\hline 7 & MATERIAL ELÉTRICO & 0,9645 & 15 & 0,4867 & 26 & 0,7266 & 27 \\
\hline 8 & EQUIP. ELETRÔNICOS & 0,5400 & 27 & 0,0849 & 42 & 0,3135 & 39 \\
\hline 9 & AUTOM./CAM/ONIBUS & 1,8958 & 10 & 0,0598 & 46 & 0,9817 & 18 \\
\hline 10 & PEÇAS E OUT. VEÍCULOS & 0,8619 & 17 & 1,0516 & 14 & 0,9563 & 19 \\
\hline 11 & MADEIRA E MOBILIÁRIO & 0,7715 & 19 & 0,4552 & 28 & 0,6140 & 29 \\
\hline 12 & CELULOSE, PAPEL E GRÁF. & 0,4844 & 29 & 1,7671 & 8 & 1,1230 & 15 \\
\hline 13 & IND. DA BORRACHA & 0,0994 & 44 & 0,7643 & 20 & 0,4304 & 35 \\
\hline 14 & INDÚSTRIA QUÍMICA & 0,5421 & 26 & 8,9589 & 1 & 4,7323 & 1 \\
\hline 15 & FARMAC. E VETERINÁRIA & 1,0433 & 13 & 0,2475 & 34 & 0,6471 & 28 \\
\hline 16 & ARTIGOS PLÁSTICOS & 0,0954 & 45 & 0,8955 & 19 & 0,4937 & 33 \\
\hline 17 & IND. TÊXTIL & 0,4331 & 33 & 1,1141 & 13 & 0,7722 & 24 \\
\hline 18 & ARTIGOS DO VESTUÁRIO & 1,0174 & 14 & 0,0192 & 51 & 0,5205 & 31 \\
\hline 19 & FABRICAÇÃO CALÇADOS & 0,4379 & 32 & 0,0361 & 48 & 0,2379 & 42 \\
\hline 20 & INDÚSTRIA DO CAFÉ & 0,8541 & 18 & 0,0673 & 44 & 0,4624 & 34 \\
\hline 21 & BENEF. PROD. VEGETAIS & 2,1844 & 7 & 0,5648 & 25 & 1,3781 & 11 \\
\hline 22 & ABATE DE ANIMAIS & 2,4354 & 5 & 0,2655 & 33 & 1,3551 & 12 \\
\hline 23 & INDÚSTRIA DE LATICÍNIOS & 0,5956 & 25 & 0,1166 & 40 & 0,3571 & 38 \\
\hline 24 & FABRICAÇÃO DE AÇÚCAR & 0,5183 & 28 & 0,2460 & 35 & 0,3827 & 36 \\
\hline 25 & FAB. ÓLEOS VEGETAIS & 0,8898 & 16 & 0,6225 & 23 & 0,7567 & 25 \\
\hline 26 & OUTROS PROD. ALIMENT. & 2,6059 & 4 & 0,9443 & 18 & 1,7787 & 7 \\
\hline 27 & INDÚSTRIAS DIVERSAS & 0,3971 & 35 & 0,3671 & 30 & 0,3821 & 37 \\
\hline 28 & S.I.U.P. & 0,4019 & 34 & 2,1340 & 6 & 1,2642 & 13 \\
\hline
\end{tabular}


Tabela 14. Índices puros de ligações normalizados para trás, para frente e total, Brasil, 1999.

\begin{tabular}{|c|c|c|c|c|c|c|c|}
\hline & Setores & $\begin{array}{l}\text { Ligações } \\
\text { para trás }\end{array}$ & Ordem & $\begin{array}{l}\text { Ligações } \\
\text { para frente }\end{array}$ & Ordem & $\begin{array}{c}\text { Ligações } \\
\text { totais }\end{array}$ & Ordem \\
\hline 29 & CONSTRUÇÃO CIVIL & 7,1990 & 1 & 0,7465 & 22 & 3,9867 & 4 \\
\hline 30 & COMÉRCIO & 4,6027 & 3 & 4,5987 & 3 & 4,6007 & 2 \\
\hline 31 & TRANSP. RODOV. DE PASSAG., REGULAR & 0,5979 & 24 & 0,4566 & 27 & 0,5275 & 30 \\
\hline 32 & TRANSP. RODOV. PASSAG., NÃO-REGULAR & 0,0441 & 48 & 0,0337 & 49 & 0,0389 & 50 \\
\hline 33 & TRANSP. REG. EXPL. DE PTOS TURÍSTICOS & 0,0005 & 54 & 0,0004 & 53 & 0,0005 & 54 \\
\hline 34 & TRANSP. RODOV. DE CARGAS & 0,6070 & 23 & 1,1625 & 12 & 0,8835 & 22 \\
\hline 36 & TRANSP. AQUAVIÁRIO & 0,0823 & 46 & 0,0700 & 43 & 0,0761 & 46 \\
\hline 37 & TRANSP. AÉREO, REGULAR & 0,6789 & 22 & 0,3162 & 32 & 0,4983 & 32 \\
\hline 38 & TRANSP. AÉREO, NÃO-REGULAR & 0,0394 & 49 & 0,0189 & 52 & 0,0292 & 52 \\
\hline 39 & AGÊNC. E ORG. DE VIAGENS & 0,0544 & 47 & 0,2330 & 36 & 0,1433 & 44 \\
\hline 40 & ATIV. AUX. TRANSP. TERRESTRE & 0,0256 & 52 & 0,0609 & 45 & 0,0432 & 49 \\
\hline 41 & ATIV. AUX.TRANSP.AQUAVIÁRIOS & 0,0341 & 50 & 0,0888 & 41 & 0,0613 & 47 \\
\hline 42 & ATIV. AUX. TRANSP. AÉREOS & 0,0278 & 51 & 0,0494 & 47 & 0,0385 & 51 \\
\hline 44 & COMUNICAÇÕES & 0,4638 & 31 & 1,0466 & 15 & 0,7540 & 26 \\
\hline 45 & INSTITUIÇÕES FINANCEIRAS & 1,9125 & 9 & 1,5035 & 11 & 1,7089 & 9 \\
\hline 46 & ESTAB. HOTEL. E OUTR. TIPOS DE ALOJ. TEMPORÁRIO & 0,4694 & 30 & 0,1457 & 38 & 0,3082 & 40 \\
\hline 47 & REST. OUTR. ESTAB. DE SERV. DE ALIMENTAÇÃO & 1,8041 & 11 & 0,3439 & 31 & 1,0772 & 16 \\
\hline 48 & ATIV. RECREATIVAS, CULT. E DESPORTIVAS & 0,1074 & 42 & 0,3768 & 29 & 0,2415 & 41 \\
\hline 49 & OUTR. SERV. PREST. ÀS FAMÍLIAS & 2,3463 & 6 & 0,5754 & 24 & 1,4647 & 10 \\
\hline 50 & ALUGUEL AUTOM. OUTR. MEIOS DE TRANSPORTE & 0,0130 & 53 & 0,0310 & 50 & 0,0220 & 53 \\
\hline 51 & OUTR. SERV. PREST. ÀS EMPRESAS & 0,1843 & 39 & 3,6024 & 4 & 1,8859 & 6 \\
\hline 52 & ALUGUEL DE IMÓVEIS & 0,7039 & 20 & 0,9456 & 17 & 0,8242 & 23 \\
\hline 53 & ADMINISTRAÇÃO PÚBLICA & 6,8350 & 2 & 0,7504 & 21 & 3,8058 & 5 \\
\hline 54 & SERV. PRIV. Ñ MERCANTIS & 0,1109 & 41 & 0,0000 & 54 & 0,0557 & 48 \\
\hline
\end{tabular}

Fonte: dados estimados pelo autor. 


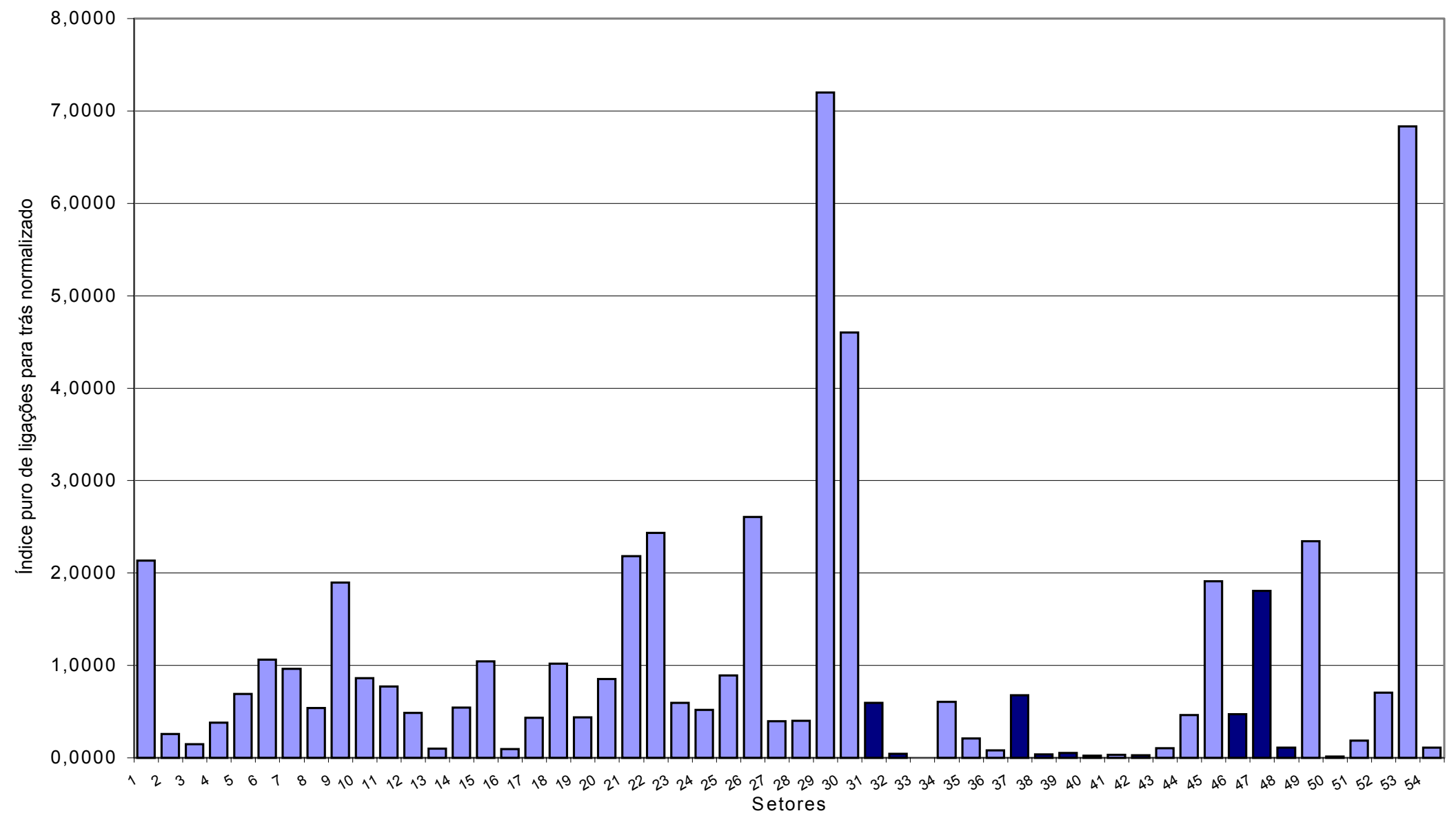

\section{Setores do segmento do turismo \\ $\square$ Demais setores da economia}

Figura 9 - Índices puros de ligações para trás normalizados, Brasil, 1999. 


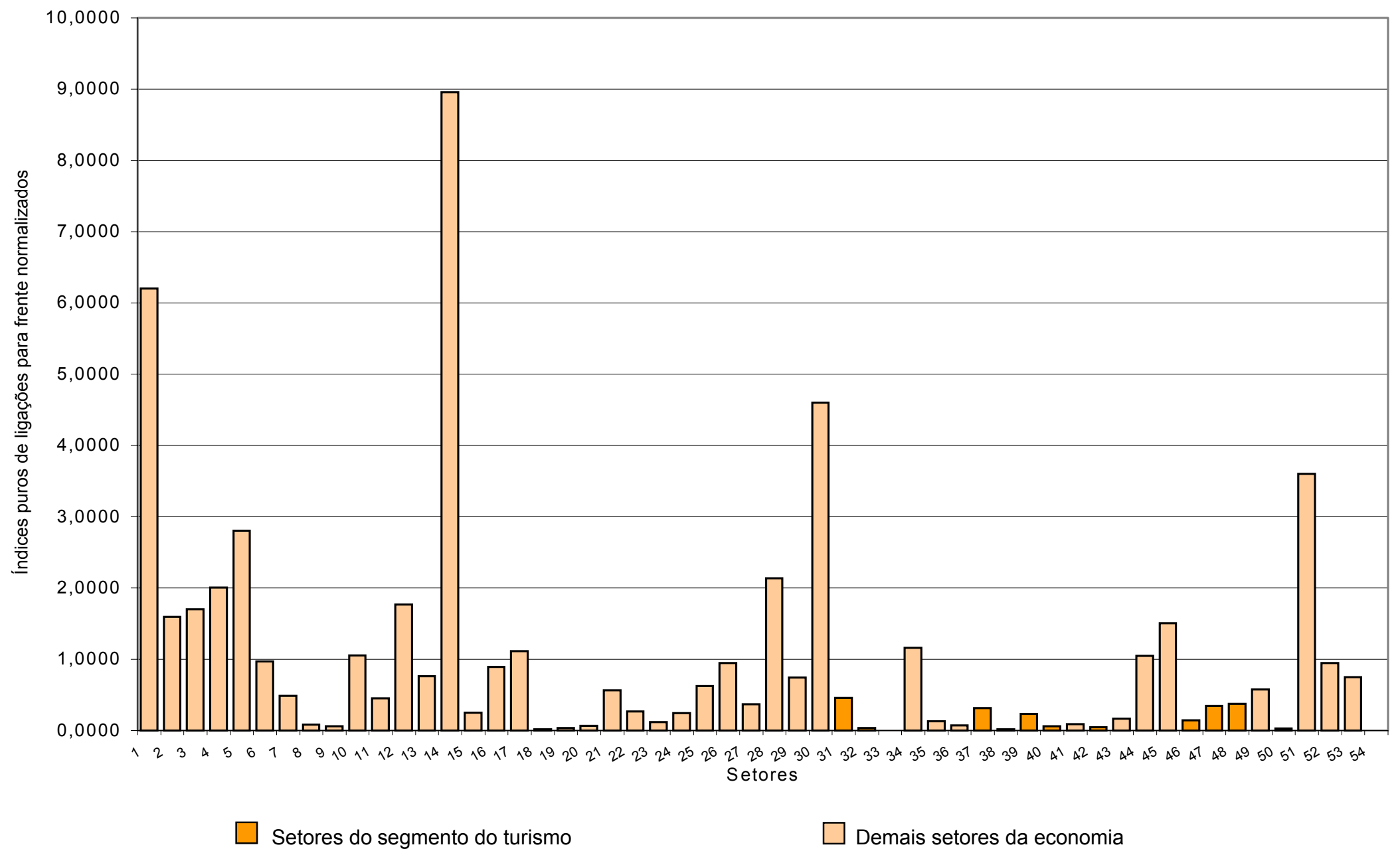

Figura 10 - Índices puros de ligações para frente normalizados, Brasil, 1999. 


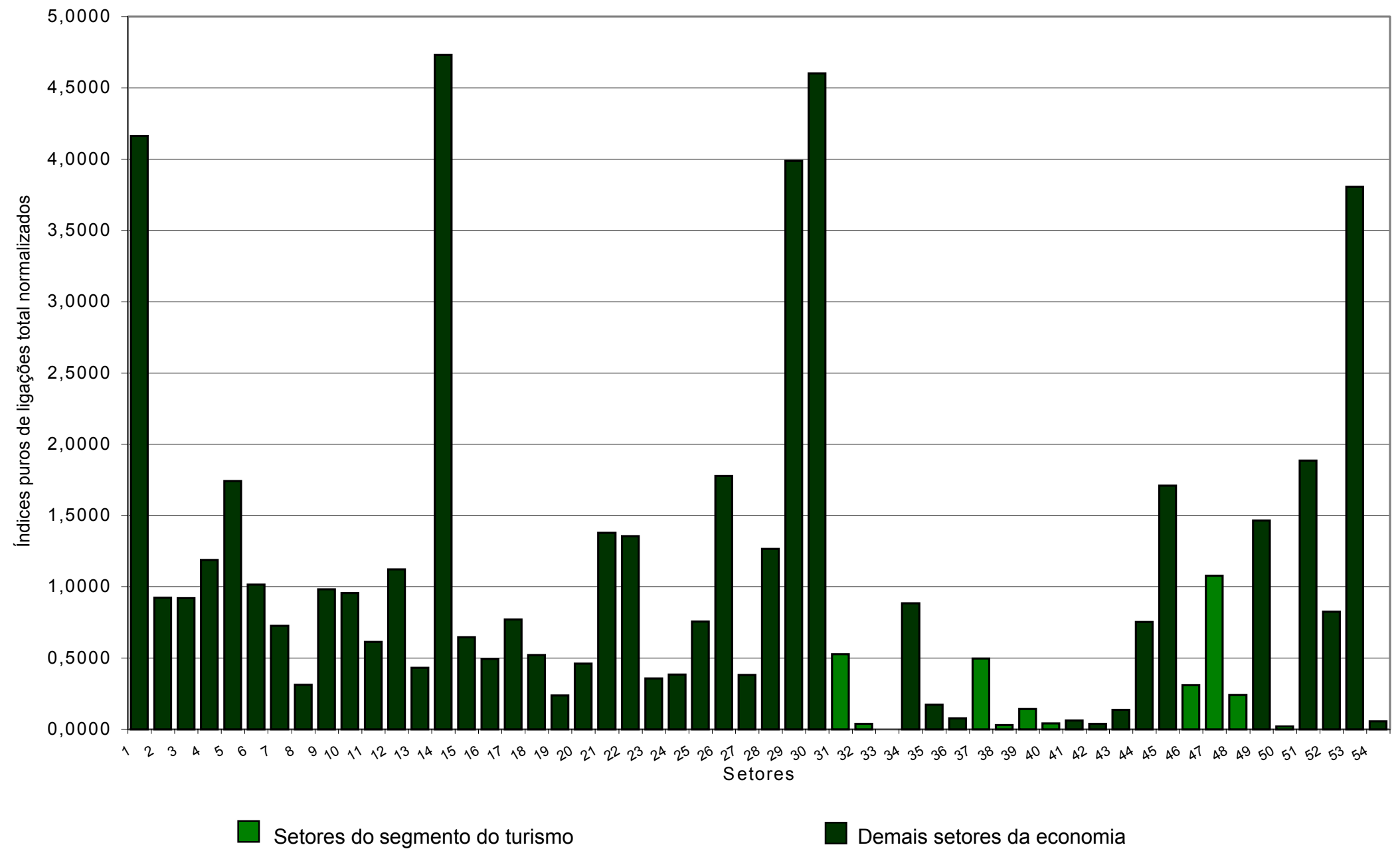

Figura 11 - Índices puros de ligações totais normalizados, Brasil, 1999. 
Para eleger os setores-chave de uma economia, levando-se em consideração os índices puros de ligação normalizados, o critério a ser adotado é o que segue: serão considerados setores-chave aqueles cujos índices puros de ligações totais normalizados forem maior que a unidade. De acordo com esse critério, examinando a Tabela 14 e a Figura 11, tem-se os seguintes setores-chave: Indústria química (14), Comércio (30), Agropecuária (1), Construção civil (29), Administração pública (53), Outros serviços prestados às empresa (51), Outros produtos alimentares (26), Metalurgia (5), Instituições financeiras (45), Outros serviços prestados às famílias (49), Beneficiamentos de produtos vegetais (21), Abate de animais (22), Serviços industriais de utilidade pública (28), Siderurgia (4), Celulose, papel e gráfica (12), Restaurantes e outros estabelecimentos de serviços de alimentação (47) e Máquinas e equipamentos (6).

Como pode ser observado, os setores-chave da economia brasileira no ano de 1999 apresentaram uma grande diversidade. Isso pode ser atribuído à heterogeneidade da estrutura econômica do país e à forma positiva com que os diferentes segmentos vêm reagindo às mudanças econômicas introduzidas desde a implantação do real. O grande número de setores-chave reflete uma economia dinâmica, que está retomando gradativamente o crescimento, graças ao aporte de investimentos diretos estrangeiros, ao aumento das exportações - principalmente manufaturados, ao aperfeiçoamento dos mecanismos de controle de importações, à desvalorização cambial e à adoção de novas tecnologias.

Conforme já mencionado anteriormente, a abordagem dos índices puros de ligação aponta a importância dos setores econômicos, considerando, além das ligações intersetoriais, o seu volume de produção. Dessa forma, esses índices não conseguem captar a importância econômica dos setores com baixos volumes de produção, o que é possível, através dos índices de ligação de Hirschman-Rasmussen, daí o surgimento de divergências na eleição dos setores relevantes da economia. Assim, torna-se necessária uma comparação dos dois índices, para que se chegue a uma identificação correta dos setores-chave.

A Tabela 15 traz os valores dos índices puros de ligação normalizados e dos índices de ligação de Hirschman-Rasmussen. Comparando-se os dois índices, 
observa-se um número maior de setores-chave quando são considerados os índices de ligação de Hirschman-Rasmussen (critério de escolha menos restrito), conforme se pode observar no Quadro 8.

Pelo exposto, no entanto, até aqui observa-se que existe alguma similaridade nos resultados dos setores relevantes, quando se analisam os índices de HirschmanRasmussen e os índices puros de ligação. As principais divergências, entretanto, ocorreram nos setores que fazem parte do segmento do turismo, tendo em vista os baixos volumes de produção destes setores.

Cabe aqui ressaltar que os resultados encontrados estão associados ao nível de agregação adotado. Sendo assim, algumas divergências que foram encontradas na análise dos setores-chave poderiam ser sanadas, caso fosse adotado um outro nível de agregação. 
Tabela 15. Comparação dos índices de ligações de Hirschman-Rasmussen e índices puros de ligação normalizados, Brasil, 1999.

\begin{tabular}{|c|c|c|c|c|c|c|}
\hline & \multirow[t]{3}{*}{ Setores } & \multirow{2}{*}{\multicolumn{2}{|c|}{ Índice de Hirschman-Rasmussen }} & \multirow{2}{*}{\multicolumn{3}{|c|}{ Índice puro normalizado }} \\
\hline & & & & & & \\
\hline & & Ligações para trás & Ligações para frente & Ligações para trás & frente & Ligações totais \\
\hline 1 & AGROPECUÁRIA & 0,9056 & 3,4300 & 2,1370 & 6,2046 & 4,1620 \\
\hline 3 & MINERAL Ñ METÁLICO & 0,9982 & 0,8776 & 0,1485 & 1,7000 & 0,9209 \\
\hline 4 & SIDERURGIA & 1,3008 & 1,7334 & 0,3791 & 2,0038 & 1,1879 \\
\hline 5 & METALURGIA & 1,1885 & 1,7056 & 0,6910 & 2,8017 & 1,7418 \\
\hline 6 & MÁQUINAS E EQUIP. & 0,9074 & 1,0020 & 1,0605 & 0,9695 & 1,0152 \\
\hline 7 & MATERIAL ELÉTRICO & 1,1668 & 0,6909 & 0,9645 & 0,4867 & 0,7266 \\
\hline 8 & EQUIP. ELETRÔNICOS & 0,9154 & 0,6051 & 0,5400 & 0,0849 & 0,3135 \\
\hline 9 & AUTOM./CAM/ONIBUS & 1,1066 & 0,5616 & 1,8958 & 0,0598 & 0,9817 \\
\hline 10 & PEÇAS E OUT. VEÍCULOS & 1,1243 & 1,2525 & 0,8619 & 1,0516 & 0,9563 \\
\hline 11 & MADEIRA E MOBILIÁRIO & 1,0627 & 0,6977 & 0,7715 & 0,4552 & 0,6140 \\
\hline 12 & CELULOSE, PAPEL E GRÁF. & 1,1092 & 1,3610 & 0,4844 & 1,7671 & 1,1230 \\
\hline 13 & IND. DA BORRACHA & 1,0770 & 1,1052 & 0,0994 & 0,7643 & 0,4304 \\
\hline 14 & INDÚSTRIA QUÍMICA & 1,0079 & 5,1681 & 0,5421 & 8,9589 & 4,7323 \\
\hline 15 & FARMAC. E VETERINÁRIA & 0,9991 & 0,6162 & 1,0433 & 0,2475 & 0,6471 \\
\hline 16 & ARTIGOS PLÁSTICOS & 1,0057 & 0,9479 & 0,0954 & 0,8955 & 0,4937 \\
\hline 17 & IND. TÊXTIL & 1,2400 & 1,4459 & 0,4331 & 1,1141 & 0,7722 \\
\hline 18 & ARTIGOS DO VESTUÁRIO & 1,1699 & 0,5399 & 1,0174 & 0,0192 & 0,5205 \\
\hline 19 & FABRICAÇÃO CALÇADOS & 1,0879 & 0,6148 & 0,4379 & 0,0361 & 0,2379 \\
\hline 20 & INDÚSTRIA DO CAFÉ & 1,2714 & 0,6934 & 0,8541 & 0,0673 & 0,4624 \\
\hline 21 & BENEF. PROD. VEGETAIS & 1,1734 & 0,7206 & 2,1844 & 0,5648 & 1,3781 \\
\hline 22 & ABATE DE ANIMAIS & 1,2566 & 0,6906 & 2,4354 & 0,2655 & 1,3551 \\
\hline 23 & INDÚSTRIA DE LATICÍNIOS & 1,1612 & 0,6598 & 0,5956 & 0,1166 & 0,3571 \\
\hline 24 & FABRICAÇÃO DE AÇÚCAR & 1,2525 & 0,7194 & 0,5183 & 0,2460 & 0,3827 \\
\hline 25 & FAB. ÓLEOS VEGETAIS & 1,2676 & 0,8682 & 0,8898 & 0,6225 & 0,7567 \\
\hline 26 & OUTROS PROD. ALIMENT. & 1,2019 & 0,9197 & 2,6059 & 0,9443 & 1,7787 \\
\hline 27 & INDÚSTRIAS DIVERSAS & 0,9940 & 0,6580 & 0,3971 & 0,3671 & 0,3821 \\
\hline 28 & S.I.U.P. & 0,9019 & 1,5554 & 0,4019 & 2,1340 & 1,2642 \\
\hline
\end{tabular}


Tabela 15. Comparação dos índices de ligações de Hirschman-Rasmussen e índices puros de ligação normalizados, Brasil, 1999.

\begin{tabular}{|c|c|c|c|c|c|c|}
\hline & \multirow[t]{2}{*}{ Setores } & \multicolumn{2}{|c|}{ Índice de Hirschman-Rasmussen } & \multicolumn{3}{|c|}{ Índice puro normalizado } \\
\hline & & \multicolumn{2}{|c|}{ Ligações para trás Ligações para frente } & Ligações para trás & $\begin{array}{l}\text { Ligações para } \\
\text { frente }\end{array}$ & Ligações totais \\
\hline 29 & CONSTRUÇÃO CIVIL & 0,8821 & 0,7241 & 7,1990 & 0,7465 & 3,9867 \\
\hline 30 & COMÉRCIO & 0,9312 & 2,5431 & 4,6027 & 4,5987 & 4,6007 \\
\hline 31 & TRANSP. RODOV. DE PASSAG., REGULAR & 0,9240 & 0,7519 & 0,5979 & 0,4566 & 0,5275 \\
\hline 32 & TRANSP. RODOV. PASSAG., NÃO-REGULAR & 0,9240 & 0,5467 & 0,0441 & 0,0337 & 0,0389 \\
\hline 33 & TRANSP. REG. EXPL. DE PTOS TURÍSTICOS & 0,9240 & 0,5307 & 0,0005 & 0,0004 & 0,0005 \\
\hline 35 & OUTR. TRANSP.TERRESTRES & 1,1071 & 0,5834 & 0,2085 & 0,1337 & 0,1712 \\
\hline 36 & TRANSP. AQUAVIÁRIO & 0,8951 & 0,5758 & 0,0823 & 0,0700 & 0,0761 \\
\hline 37 & TRANSP. AÉREO, REGULAR & 1,0582 & 0,7837 & 0,6789 & 0,3162 & 0,4983 \\
\hline 38 & TRANSP. AÉREO, NÃO-REGULAR & 1,0586 & 0,5447 & 0,0394 & 0,0189 & 0,0292 \\
\hline 39 & AGÊNC. E ORG. DE VIAGENS & 1,0623 & 0,7312 & 0,0544 & 0,2330 & 0,1433 \\
\hline 40 & ATIV. AUX. TRANSP. TERRESTRE & 0,9214 & 0,5860 & 0,0256 & 0,0609 & 0,0432 \\
\hline 41 & ATIV. AUX.TRANSP.AQUAVIÁRIOS & 0,8901 & 0,6116 & 0,0341 & 0,0888 & 0,0613 \\
\hline 43 & OUTR. ATIV. AUX. TRANSPORTE & 1,1111 & 0,6843 & 0,1046 & 0,1679 & 0,1361 \\
\hline 44 & COMUNICAÇÕES & 0,7436 & 0,9478 & 0,4638 & 1,0466 & 0,7540 \\
\hline 45 & INSTITUIÇÕES FINANCEIRAS & 0,7646 & 1,3146 & 1,9125 & 1,5035 & 1,7089 \\
\hline 46 & ESTAB. HOTEL. E OUTR. TIPOS DE ALOJ. TEMPORÁRIO & 1,0316 & 0,5553 & 0,4694 & 0,1457 & 0,3082 \\
\hline 47 & REST. OUTR. ESTAB. DE SERV. DE ALIMENTAÇÃO & 1,0316 & 0,5894 & 1,8041 & 0,3439 & 1,0772 \\
\hline 48 & ATIV. RECREATIVAS, CULT. E DESPORTIVAS & 0,8324 & 0,5939 & 0,1074 & 0,3768 & 0,2415 \\
\hline 49 & OUTR. SERV. PREST. ÀS FAMÍLIAS & 0,8194 & 0,6386 & 2,3463 & 0,5754 & 1,4647 \\
\hline 50 & ALUGUEL AUTOM. OUTR. MEIOS DE TRANSPORTE & 0,7577 & 0,5392 & 0,0130 & 0,0310 & 0,0220 \\
\hline 51 & OUTR. SERV. PREST. ÀS EMPRESAS & 0,7577 & 1,5485 & 0,1843 & 3,6024 & 1,8859 \\
\hline 52 & ALUGUEL DE IMÓVEIS & 0,5656 & 0,8356 & 0,7039 & 0,9456 & 0,8242 \\
\hline 53 & ADMINISTRAÇÃO PÚBLICA & 0,7559 & 0,8698 & 6,8350 & 0,7504 & 3,8058 \\
\hline 54 & SERV. PRIV. Ñ MERCANTIS & 0,5913 & 0,5305 & 0,1109 & 0,0000 & 0,0557 \\
\hline
\end{tabular}

Fonte: dados estimados pelo autor. 


\begin{tabular}{|c|c|c|c|c|}
\hline & \multirow[t]{2}{*}{ Setores } & \multicolumn{2}{|c|}{ Índice de Hirschman-Rasmussen } & \multirow{2}{*}{$\begin{array}{c}\text { Índice de ligação } \\
\text { puro total }\end{array}$} \\
\hline & & Ligações para trás & Ligações para frente & \\
\hline 1 & AGROPECUÁRIA & & $\mathrm{X}$ & $\mathrm{X}$ \\
\hline 2 & EXTRATIVA MINERAL & & $X$ & \\
\hline 3 & MINERAL Ñ METÁLICO & & & \\
\hline 4 & SIDERURGIA & $X$ & $X$ & $X$ \\
\hline 5 & METALURGIA & $\mathrm{X}$ & $\mathrm{X}$ & $\mathrm{X}$ \\
\hline 6 & MÁQUINAS E EQUIP. & & $\mathrm{X}$ & $\mathrm{X}$ \\
\hline 7 & MATERIAL ELÉTRICO & $\mathrm{X}$ & & \\
\hline 8 & EQUIP. ELETRÔNICOS & & & \\
\hline 9 & AUTOM./CAM/ONIBUS & $X$ & & \\
\hline 10 & PEÇAS E OUT. VEÍCULOS & $\mathrm{X}$ & $X$ & \\
\hline 11 & MADEIRA E MOBILIÁRIO & $X$ & & \\
\hline 12 & CELULOSE, PAPEL E GRÁF. & $\mathrm{X}$ & $\mathrm{X}$ & $\mathrm{X}$ \\
\hline 13 & IND. DA BORRACHA & $\mathrm{X}$ & $\mathrm{X}$ & \\
\hline 14 & INDÚSTRIA QUÍMICA & $\mathrm{X}$ & $X$ & $X$ \\
\hline 15 & FARMAC. E VETERINÁRIA & & & \\
\hline 16 & ARTIGOS PLÁSTICOS & $X$ & & \\
\hline 17 & IND. TÊXTIL & $X$ & $X$ & \\
\hline 18 & ARTIGOS DO VESTUÁRIO & $\mathrm{X}$ & $\mathrm{X}$ & \\
\hline 19 & FABRICAÇÃO CALÇADOS & $X$ & & \\
\hline 20 & INDÚSTRIA DO CAFÉ & $X$ & & \\
\hline 21 & BENEF. PROD. VEGETAIS & $\mathrm{X}$ & & $\mathrm{X}$ \\
\hline 22 & ABATE DE ANIMAIS & $\mathrm{X}$ & & $\mathrm{X}$ \\
\hline 23 & INDÚSTRIA DE LATICÍNIOS & $X$ & & \\
\hline 24 & FABRICAÇÃO DE AÇÚCAR & $X$ & & \\
\hline 25 & FAB. ÓLEOS VEGETAIS & $X$ & & \\
\hline 26 & OUTROS PROD. ALIMENT. & $\mathrm{X}$ & & $\mathrm{X}$ \\
\hline 27 & INDÚSTRIAS DIVERSAS & & & \\
\hline 28 & S.I.U.P. & & $X$ & $\mathrm{X}$ \\
\hline
\end{tabular}

Quadro 8 - Setores-chave consolidados: critério dos índices de Hirschman-Rasmussen e critério do índice puro de ligação total normalizado. 


\begin{tabular}{|c|c|c|c|c|}
\hline & \multirow[t]{2}{*}{ Setores } & \multicolumn{2}{|c|}{ Índice de Hirschman-Rasmussen } & \multirow{2}{*}{$\begin{array}{c}\text { Índice de ligação } \\
\text { puro total }\end{array}$} \\
\hline & & Ligações para trás & Ligações para frente & \\
\hline 29 & CONSTRUÇÃO CIVIL & & & $\mathrm{X}$ \\
\hline 30 & COMÉRCIO & & $\mathrm{X}$ & $\mathrm{X}$ \\
\hline 31 & TRANSP. RODOV. DE PASSAG., REGULAR & & & \\
\hline 32 & TRANSP. RODOV. PASSAG., NÃO-REGULAR & & & \\
\hline 33 & TRANSP. REG. EXPL. DE POS TURÍSTICOS & & & \\
\hline 34 & TRANSP. RODOV. DE CARGAS & & $\mathrm{X}$ & \\
\hline 35 & OUTR. TRANSP.TERRESTRES & $\mathrm{X}$ & & \\
\hline 36 & TRANSP. AQUAVIÁRIO & & & \\
\hline 37 & TRANSP. AÉREO, REGULAR & $\mathrm{X}$ & & \\
\hline 38 & TRANSP. AÉREO, NÃO-REGULAR & $\mathrm{X}$ & & \\
\hline 39 & AGÊNC. E ORG. DE VIAGENS & $\mathrm{X}$ & & \\
\hline 40 & ATIV. AUX. TRANSP. TERRESTRE & & & \\
\hline 41 & ATIV. AUX.TRANSP.AQUAVIÁRIOS & & & \\
\hline 43 & OUTR. ATIV. AUX. TRANSPORTE & $\mathrm{X}$ & & \\
\hline 44 & COMUNICAÇÕES & & & \\
\hline 45 & INSTITUIÇÕES FINANCEIRAS & & $\mathrm{X}$ & $\mathrm{X}$ \\
\hline 46 & ESTAB. HOTEL. E OUTR. TIPOS DE ALOJ. TEMPORÁRIO & $\mathrm{X}$ & & \\
\hline 47 & REST. OUTR. ESTAB. DE SERV. DE ALIMENTAÇÃO & $\mathrm{X}$ & & $\mathrm{X}$ \\
\hline 48 & ATIV. RECREATIVAS, CULT. E DESPORTIVAS & & & \\
\hline 49 & OUTR. SERV. PREST. ÀS FAMÍLIAS & & & $\mathrm{X}$ \\
\hline 50 & ALUGUEL AUTOM. OUTR. MEIOS DE TRANSPORTE & & & \\
\hline 51 & OUTR. SERV. PREST. ÀS EMPRESAS & & $\mathrm{X}$ & $\mathrm{X}$ \\
\hline 52 & ALUGUEL DE IMÓVEIS & & & \\
\hline 53 & ADMINISTRAÇÃO PÚBLICA & & & $X$ \\
\hline 54 & SERV. PRIV. Ñ MERCANTIS & & & \\
\hline
\end{tabular}

Quadro 8 - Setores-chave consolidados: critério dos índices de Hirschman-Rasmussen e critério do índice puro de ligação total normalizado. 


\subsection{Os impactos de modificações na demanda final sobre a produção, a renda e geração de empregos}

A matriz de insumo produto, construída para a economia brasileira tendo em vista o ano de 1999, com destaque para o segmento do turismo, permite verificar como se modificam a produção, a renda e o número de pessoas ocupadas na economia quando a demanda final em cada um dos setores se altera. Isso pode acontecer, por exemplo, em decorrência de um aumento de investimento num determinado setor, de alteração nos gastos dos turistas, de alteração nas exportações ou nos gastos do governo.

\subsubsection{Os impactos na produção}

Conforme já exposto anteriormente, os impactos provocados na produção de uma dada economia podem ser analisados pelo multiplicador de produção, uma vez que este multiplicador permite verificar qual o impacto que poderá ocorrer nos diversos setores do sistema econômico dado a uma variação na demanda final, ou seja, o multiplicador de produção de um setor $j$ pode ser definido como o valor total da produção de todos os setores da economia, necessário para produzir uma unidade monetária de demanda final do setor $j$.

Na Tabela 16 são apresentados os multiplicadores de produção tipo I e tipo II (com o consumo das famílias exógeno e endógeno ao sistema produtivo, respectivamente). Observando a referida tabela, embora apresente uma ordenação dos multiplicadores em termos de magnitude, pode-se constatar que as diferenças entre alguns valores dos multiplicadores, tanto do tipo I como do tipo II, são relativamente pequenas.

Os cinco maiores multiplicadores, considerando o consumo das famílias como exógeno, foram dos seguintes setores: Siderurgia (4), Indústria do café (20), Fabricação de óleos vegetais (25), Abate de animais (22) e Fabricação de açúcar (24). Já os cinco menores, de acordo com a estrutura produtiva para 1999, foram: Aluguel de imóveis (52), Serviços privados não mercantis (54), Comunicações (44), Administração pública (53) e Aluguel de automóveis e outros meios de transporte (50). 
Tabela 16. Multiplicadores do tipo I e tipo II de produção, renda e emprego, Brasil, 1999.

\begin{tabular}{|c|c|c|c|c|c|c|c|c|c|c|c|c|c|}
\hline & \multirow[b]{2}{*}{ Setores } & \multicolumn{4}{|c|}{ Multiplicadores de Produção } & \multicolumn{4}{|c|}{ Multiplicadores de Renda } & \multicolumn{4}{|c|}{ Multiplicadores de Emprego } \\
\hline & & Tipo I & Ordem & Tipo II & Ordem & Tipo I & Ordem & Tipo II & Ordem & Tipo I & Ordem & Tipo II & Ordem \\
\hline 1 & AGROPECUÁRIA & 1,7069 & 40 & 4,1567 & 45 & 2,2167 & 20 & 5,5534 & 14 & 1,2846 & 45 & 1,8260 & 51 \\
\hline 2 & EXTRATIVA MINERAL & 1,5604 & 46 & 3,9293 & 52 & 2,4247 & 16 & 5,4928 & 16 & 2,2742 & 25 & 8,3346 & 21 \\
\hline 3 & MINERAL Ñ METÁLICO & 1,8815 & 30 & 4,2282 & 42 & 2,1510 & 22 & 4,1614 & 21 & 1,9027 & 29 & 4,7242 & 33 \\
\hline 4 & SIDERURGIA & 2,4518 & 1 & 4,4507 & 36 & 7,2579 & 2 & 15,7552 & 2 & 11,7667 & 4 & 34,4141 & 2 \\
\hline 5 & METALURGIA & 2,2402 & 8 & 4,5342 & 33 & 2,2475 & 18 & 4,1159 & 22 & 2,2958 & 24 & 5,9668 & 28 \\
\hline 6 & MÁQUINAS E EQUIPAMENTOS & 1,7104 & 39 & 4,1663 & 44 & 1,6463 & 34 & 3,2235 & 29 & 2,0988 & 26 & 7,0716 & 25 \\
\hline 7 & MATERIAL ELÉTRICO & 2,1993 & 11 & 4,2813 & 41 & 3,1204 & 11 & 5,6602 & 13 & 4,2339 & 13 & 11,6013 & 16 \\
\hline 8 & EQUIP. ELETRÔNICOS & 1,7254 & 38 & 3,6965 & 53 & 2,4885 & 15 & 4,9061 & 17 & 3,4818 & 17 & 10,7360 & 19 \\
\hline 9 & AUTOM./CAM/ONIBUS & 2,0859 & 17 & 3,9667 & 50 & 5,0894 & 3 & 9,7059 & 5 & 8,5276 & 6 & 24,9815 & 5 \\
\hline 10 & PEÇAS E OUT. VEÍCULOS & 2,1192 & 13 & 4,3210 & 40 & 2,2452 & 19 & 3,9558 & 23 & 3,7169 & 16 & 10,8650 & 18 \\
\hline 11 & MADEIRA E MOBILIÁRIO & 2,0032 & 20 & 4,6538 & 23 & 1,8515 & 25 & 3,3636 & 27 & 1,9136 & 28 & 3,2181 & 38 \\
\hline 12 & CELULOSE, PAPEL E GRÁFICA & 2,0908 & 15 & 4,5740 & 31 & 2,4894 & 14 & 4,3741 & 20 & 2,9642 & 18 & 7,4260 & 23 \\
\hline 13 & IND. DA BORRACHA & 2,0301 & 19 & 4,0348 & 47 & 3,0095 & 12 & 6,4540 & 12 & 5,9869 & 10 & 16,9045 & 10 \\
\hline 14 & INDÚSTRIA QUÍMICA & 1,8998 & 27 & 3,9342 & 51 & 3,5545 & 8 & 8,2695 & 9 & 8,1968 & 8 & 29,4443 & 3 \\
\hline 15 & FARMAC. E VETERINÁRIA & 1,8832 & 29 & 4,1933 & 43 & 2,2829 & 17 & 4,5198 & 19 & 4,3390 & 11 & 13,0024 & 14 \\
\hline 16 & ARTIGOS PLÁSTICOS & 1,8956 & 28 & 4,1443 & 46 & 1,7974 & 28 & 3,4659 & 26 & 1,9956 & 27 & 5,9635 & 29 \\
\hline 17 & IND. TÊXTIL & 2,3373 & 6 & 4,3791 & 37 & 3,4651 & 9 & 6,6544 & 11 & 4,2878 & 12 & 9,0933 & 20 \\
\hline 18 & ARTIGOS DO VESTUÁRIO & 2,2052 & 10 & 4,7805 & 14 & 1,6035 & 35 & 2,6785 & 37 & 1,1952 & 49 & 1,6574 & 53 \\
\hline 19 & FABRICAÇÃO DE CALÇADOS & 2,0507 & 18 & 4,4983 & 35 & 1,9735 & 24 & 3,5103 & 25 & 1,6781 & 34 & 3,0036 & 40 \\
\hline 20 & INDÚSTRIA DO CAFÉ & 2,3964 & 2 & 4,7710 & 15 & 4,9164 & 4 & 11,5184 & 4 & 14,2172 & 2 & 23,1104 & 6 \\
\hline 21 & BENEF. PROD. VEGETAIS & 2,2118 & 9 & 4,5243 & 34 & 4,0885 & 6 & 8,6141 & 7 & 8,2926 & 7 & 13,5299 & 13 \\
\hline 22 & ABATE DE ANIMAIS & 2,3687 & 4 & 4,8047 & 11 & 4,0999 & 5 & 8,6512 & 6 & 11,1498 & 5 & 17,7826 & 8 \\
\hline 23 & INDÚSTRIA DE LATICÍNIOS & 2,1888 & 12 & 4,3307 & 39 & 3,9623 & 7 & 8,6016 & 8 & 11,8789 & 3 & 20,5736 & 7 \\
\hline 24 & FABRICAÇÃO DE AÇÚCAR & 2,3608 & 5 & 4,6949 & 20 & 3,4493 & 10 & 6,7100 & 10 & 8,1061 & 9 & 14,3031 & 12 \\
\hline 25 & FAB. ÓLEOS VEGETAIS & 2,3893 & 3 & 4,6038 & 30 & 8,7762 & 1 & 19,7422 & 1 & 29,3086 & 1 & 50,6868 & 1 \\
\hline 26 & OUTROS PROD. ALIMENTARES & 2,2655 & 7 & 4,6452 & 24 & 2,8587 & 13 & 5,5337 & 15 & 3,8935 & 15 & 7,1622 & 24 \\
\hline 27 & INDÚSTRIAS DIVERSAS & 1,8737 & 31 & 4,3676 & 38 & 2,1553 & 21 & 3,9203 & 24 & 1,8328 & 31 & 4,1963 & 34 \\
\hline 28 & S.I.U.P. & 1,7000 & 41 & 4,5558 & 32 & 1,6691 & 33 & 2,8995 & 32 & 2,8017 & 19 & 17,4843 & 9 \\
\hline
\end{tabular}


Tabela 16. Multiplicadores do tipo I e tipo II de produção, renda e emprego, Brasil, 1999.

\begin{tabular}{|c|c|c|c|c|c|c|c|c|c|c|c|c|c|}
\hline & \multirow[b]{2}{*}{ Setores } & \multicolumn{4}{|c|}{ Multiplicadores de Produção } & \multicolumn{4}{|c|}{ Multiplicadores de Renda } & \multicolumn{4}{|c|}{ Multiplicadores de Emprego } \\
\hline & & Tipo I & Ordem & Tipo II & Ordem & Tipo I & Ordem & Tipo II & Ordem & Tipo I & Ordem & Tipo II & Ordem \\
\hline 29 & CONSTRUÇÃO CIVIL & 1,6628 & 44 & 3,9799 & 48 & 2,1183 & 23 & 4,8153 & 18 & 1,5630 & 37 & 3,6999 & 37 \\
\hline 30 & COMÉRCIO & 1,7552 & 32 & 4,8190 & 10 & 1,3528 & 47 & 2,2834 & 47 & 1,1927 & 50 & 2,2471 & 45 \\
\hline 31 & TRANSP. RODOV. DE PASSAG., REGULAR & 1,7417 & 35 & 4,6314 & 26 & 1,3761 & 43 & 2,3324 & 43 & 1,2040 & 48 & 2,1805 & 47 \\
\hline 32 & TRANSP. RODOV. PASSAG., NÃO-REGULAR & 1,7417 & 34 & 4,6314 & 25 & 1,3761 & 42 & 2,3324 & 42 & 1,2843 & 46 & 2,6457 & 44 \\
\hline 33 & TRANSP. REG. EXPL. DE PTOS TURÍSTICOS & 1,7416 & 36 & 4,6314 & 28 & 1,3761 & 44 & 2,3323 & 44 & 1,3562 & 42 & 3,0619 & 39 \\
\hline 34 & TRANSP. RODOV. DE CARGAS & 1,7417 & 33 & 4,6314 & 27 & 1,3761 & 45 & 2,3323 & 45 & 1,4741 & 39 & 3,7444 & 36 \\
\hline 35 & OUTR. TRANSP.TERRESTRES & 2,0869 & 16 & 4,9016 & 4 & 1,8464 & 26 & 3,0794 & 30 & 1,4603 & 40 & 2,9871 & 42 \\
\hline 36 & TRANSP. AQUAVIÁRIO & 1,6873 & 42 & 4,7985 & 12 & 1,3939 & 40 & 2,3383 & 40 & 1,8866 & 30 & 6,2506 & 27 \\
\hline 37 & TRANSP. AÉREO, REGULAR & 1,9946 & 23 & 4,7558 & 18 & 1,6755 & 31 & 2,8171 & 35 & 4,1911 & 14 & 14,7968 & 11 \\
\hline 38 & TRANSP. AÉREO, NÃO-REGULAR & 1,9953 & 22 & 4,7589 & 16 & 1,6777 & 29 & 2,8203 & 33 & 2,4120 & 23 & 7,0142 & 26 \\
\hline 39 & AGÊNC. E ORG. DE VIAGENS & 2,0023 & 21 & 4,7560 & 17 & 1,6711 & 32 & 2,8095 & 36 & 1,5982 & 36 & 3,8349 & 35 \\
\hline 40 & ATIV. AUX. TRANSP. TERRESTRE & 1,7367 & 37 & 4,6268 & 29 & 1,3753 & 46 & 2,3317 & 46 & 1,3425 & 44 & 2,9996 & 41 \\
\hline 41 & ATIV. AUX.TRANSP.AQUAVIÁRIOS & 1,6778 & 43 & 4,7883 & 13 & 1,3916 & 41 & 2,3358 & 41 & 1,7697 & 32 & 5,4533 & 31 \\
\hline 42 & ATIV. AUX. TRANSP. AÉREOS & 1,9864 & 24 & 4,7508 & 19 & 1,6760 & 30 & 2,8188 & 34 & 1,1796 & 52 & 1,7726 & 52 \\
\hline 43 & OUTR. ATIV. AUX. TRANSPORTE & 2,0943 & 14 & 4,9060 & 3 & 1,8456 & 27 & 3,0773 & 31 & 2,5646 & 21 & 7,9178 & 22 \\
\hline 44 & COMUNICAÇÕES & 1,4016 & 52 & 3,9713 & 49 & 1,5879 & 36 & 3,2421 & 28 & 2,5226 & 22 & 10,8975 & 17 \\
\hline 45 & INSTITUIÇÕES FINANCEIRAS & 1,4411 & 48 & 4,8214 & 9 & 1,3440 & 48 & 2,2088 & 48 & 2,6902 & 20 & 12,5117 & 15 \\
\hline 46 & ESTAB. HOTEL. E OUTR. ALOJ. TEMPORÁRIO & 1,9445 & 25 & 4,8665 & 6 & 1,4011 & 38 & 2,3401 & 38 & 1,3548 & 43 & 2,0571 & 49 \\
\hline 47 & REST. OUTR. ESTAB. DE SERV. DE ALIMENTAÇÃO & 1,9445 & 26 & 4,8664 & 7 & 1,4010 & 39 & 2,3400 & 39 & 1,3692 & 41 & 2,0999 & 48 \\
\hline 48 & ATIV. RECREATIVAS, CULT. E DESPORTIVAS & 1,5691 & 45 & 4,8755 & 5 & 1,2131 & 51 & 1,9586 & 51 & 1,1825 & 51 & 2,1915 & 46 \\
\hline 49 & OUTR. SERV. PREST. ÀS FAMÍLIAS & 1,5444 & 47 & 4,8623 & 8 & 1,1966 & 52 & 1,9322 & 52 & 1,1520 & 53 & 2,0433 & 50 \\
\hline 50 & ALUGUEL AUTOM. OUTR. MEIOS DE TRANSPORTE & 1,4282 & 50 & 4,6817 & 22 & 1,2465 & 50 & 2,0846 & 50 & 1,4794 & 38 & 4,9382 & 32 \\
\hline 51 & OUTR. SERV. PREST. ÀS EMPRESAS & 1,4282 & 49 & 4,6817 & 21 & 1,2465 & 49 & 2,0846 & 49 & 1,2228 & 47 & 2,8301 & 43 \\
\hline 52 & ALUGUEL DE IMÓVEIS & 1,0661 & 54 & 3,3834 & 54 & 1,5114 & 37 & 15,2510 & 3 & 1,7529 & 33 & 28,9004 & 4 \\
\hline 53 & ADMINISTRAÇÃO PÚBLICA & 1,4249 & 51 & 5,4094 & 2 & 1,1681 & 53 & 1,8095 & 53 & 1,6473 & 35 & 5,5085 & 30 \\
\hline 54 & SERV. PRIV. Ñ MERCANTIS & 1,1146 & 53 & 5,4618 & 1 & 1,0218 & 54 & 1,5721 & 54 & 1,0075 & 54 & 1,2213 & 54 \\
\hline
\end{tabular}

Fonte: dados estimados pelo autor. 
Pode-se constatar, ainda, que, embora os setores componentes do segmento do turismo não figurem entre os cinco primeiros colocados, a grande maioria apresentam multiplicadores muito próximo de dois, sendo o menor valor $(1,4282)$ pertencente ao setor Aluguel de automóveis e outros meios de transporte (50) e o maior valor $(2,0023)$ ao setor Agência e organizadores de viagens (39). Isso significa que o aumento de uma unidade monetária na demanda final sobre a produção, implicaria um aumento de total na produção de 2,0023 unidades monetárias. Se esse valor for decomposto, pode-se notar que uma unidade poderá ser direcionada para a demanda final do setor Agência e organizadores de viagens, e 1,0023 unidades monetárias poderão ser exigidas dos demais setores integrantes do processo produtivo da economia brasileira.

Considerando o consumo das famílias como endógeno ao sistema produtivo, as posições alteraram-se de forma bastante significativa, aparecendo agora com os maiores multiplicadores os setores que estão sujeitos a esse consumo. Os sete principais setores para os multiplicadores tipo II foram: Serviços privados não mercantis (54), Administração pública (53), Outras atividades auxiliares aos transportes (43), Outros transportes terrestres (35), Atividades recreativas, culturais e desportivas (48), Estabelecimentos hoteleiros e outros tipos de alojamento temporário (46) e Restaurantes e outros estabelecimentos de serviços de alimentação (47). Os menores multiplicadores foram dos setores que menos estão sujeitos ao consumo das famílias, são eles: Aluguel de imóveis (52), Equipamentos eletrônicos (8), Extrativa mineral (2), Indústria química (14) e Automóveis caminhões e ônibus (9).

O fato de os setores os quais compõem o segmento do turismo não figurarem entre os que possuem os mais elevados valores dos multiplicadores de produção, principalmente os do tipo I, dentro da estrutura produtiva não significa que esses setores tenham pouca importância na economia. O que ocorre é que esses setores quando comparados com os outros da economia, são pouco demandantes de insumos dentro do processo produtivo.

Pelo exposto pode-se inferir que o segmento do turismo, considerando todos os setores os quais o compõem, apresenta-se como um dos que têm relativa importância dentro da economia brasileira, principalmente quando o consumo das 
famílias é endogeneizado ao processo produtivo, isto é, analisando o multiplicador de produção do tipo II. Isso ocorre porque a produção turística satisfaz não só à demanda dos turistas como também a dos residentes nos núcleos receptores e às produções destinadas ao consumo generalizado de bens e serviços para uso do turismo. Existem alguns bens e serviços característicos do turismo os quais se destinam a satisfazer as necessidades dos turistas (hotéis, agências de viagem, etc.), e outros nãocaracterísticos do turismo cuja produção se destina a ser consumida também pelas famílias locais. A importância das atividades não-características do turismo está inserida no papel que desempenha no fornecimento de bens e serviços indispensáveis ao funcionamento do segmento. São exemplos dessas atividades o transporte público, os hospitais, lojas de conveniência etc.

É importante ressaltar que, segundo Brasil (2002), a cadeia produtiva do turismo, ou seja, o conjunto de setores e subsetores os quais participam do seu produto final são influenciados pelo ambiente interno e externo, resultantes de políticas e conjunturas nacionais e internacionais e pelas tendências de consumo mundiais e locais, entre outros fatores. Em 1999 particularmente, o segmento do turismo brasileiro foi beneficiado com a política cambial adotada no início do ano que desvalorizou o real, incentivando o consumo do turismo interno pelos estrangeiros e brasileiros.

\subsubsection{Os impactos na renda das famílias}

Com o objetivo de analisar os impactos na renda recebida pelas famílias, ocasionados por variações na demanda final, optou-se por calcular os multiplicadores de renda que, conforme já exposto anteriormente neste trabalho, podem ser definidos como sendo a renda gerada em todos os setores da economia resultante do aumento de uma unidade monetária de demanda final pelo produto de um determinado setor.

Analisando a Tabela 16, pode-se constatar que os setores que compõem o segmento do turismo apresentam, em sua maioria, baixos valores tanto para o multiplicador de renda do tipo I (com o consumo das famílias considerado exógeno ao processo produtivo), como para o multiplicador do tipo II (com o consumo das famílias endógeno ao processo produtivo). 
Dada a estrutura produtiva do ano de 1999, pode-se verificar que os setores os quais apresentaram os maiores multiplicadores de renda foram: Fabricação de óleos vegetais (25), Siderurgia (4), Automóveis, caminhões e ônibus (9), Indústria do café (20) e Abate de animais (22), considerando o multiplicador de renda do tipo I. Quando se procurou, no entanto, analisar o multiplicador de renda do tipo II, pôde-se verificar que os setores com maiores valores dos multiplicadores no caso anterior se repetiam, também, para este caso, ocorrendo algumas alterações na ordem dos setores e o aparecimento do setor Aluguel de imóveis, bem como a saída do setor Abate de animais, conforme se pode visualizar na Tabela 16.

\subsubsection{Os impactos no emprego}

De acordo com o que foi definido no capítulo 4, o multiplicador de emprego permite determinar o impacto de variações na demanda final sobre o produto que, por sua vez, leva a variações no emprego, as quais conduzem a uma variação na renda e, conseqüentemente, na demanda do consumidor.

Analisando a Tabela 16, verifica-se que os cinco setores com os maiores multiplicadores de emprego, considerando inicialmente o multiplicador do tipo I, foram os seguintes: Fabricação de óleos vegetais (25), Indústria do café (20), Indústria de laticínios (23), Siderurgia (4) e Abate de animais. Já os cinco setores com os menores multiplicadores foram: Serviços privados não mercantis (54), Outros serviços prestados às famílias (49), Atividades auxiliares aos transportes aéreos (42), Atividades recreativas, culturais e desportivas (48) e Comércio (30).

Quando se considera o consumo das famílias endógeno ao sistema produtivo, multiplicador tipo II, os maiores multiplicadores ficaram com os seguintes setores: Fabricação de óleos vegetais (25), Siderurgia (4), Indústria química (14), Aluguel de imóveis (52) e Automóveis, caminhões e ônibus (9). Os cinco setores com os menores valores para o multiplicador do tipo II foram praticamente os mesmos apresentados para o multiplicador do tipo I, com exceção dos setores Atividades recreativas, culturais e desportivas (48) e Comércio (30). Com a saída desses, os setores Artigos do vestuário (18) e Agropecuária (1) passaram a integrar a categoria dos cinco setores que apresentaram os menores valores para os multiplicadores do tipo II. 
Com relação aos setores que compõem o segmento do turismo, pode-se constatar que não apresentam destaque em relação aos demais da estrutura produtiva aqui considerada. Entre eles, no entanto, os maiores multiplicadores de emprego foram verificados nos setores: Transporte aéreo, regular (37), Transporte aéreo, nãoregular (38), Aluguel de automóveis e outros meios de transporte (50) e Agência e organizadores de viagens (39).

A partir dos multiplicadores de emprego é possível quantificar os novos empregos gerados em decorrência de um aumento da demanda final, em cada setor da economia. A seguir é apresentada uma análise de geração de novos empregos na economia, dado a um choque na demanda final de cada um dos setores considerados no modelo de insumo-produto construído no presente trabalho.

\subsubsection{A geração de empregos}

Para a quantificação de empregos gerados é admitida a hipótese de que o aumento na demanda final leva ao crescimento da produção na mesma proporção, implicando aumentos de emprego e expansão da renda, o que leva, por sua vez, ao aumento de demanda por bens de consumo por parte das famílias, implicando aumento da produção desses bens, o que resulta em aumento de empregos nestes setores.

Assim, a geração de novos empregos em uma determinada economia é de grande importância, pois, aumentando o número de pessoas ocupadas, além de contribuir para uma melhoria na qualidade de vida dessas famílias, via aumento da renda das mesmas, proveniente dos salários (parte dessa renda será consumida), criase, também, a possibilidade de gerar outros novos empregos em setores que são responsáveis pela produção dos bens de consumo das famílias. De acordo com Miller \& Blair (1985), os tipos de empregos que podem ser gerados são diretos, indiretos e induzidos.

Os empregos diretos correspondem à mão-de-obra adicional requerida pelos setores onde se observa o aumento da produção, ou seja, nos setores onde ocorreu o aumento na demanda. Os empregos indiretos são os gerados nos setores que fornecem insumos para a produção do setor onde inicialmente ocorreu o aumento da 
demanda. Já os empregos induzidos são aqueles gerados nos setores onde as famílias gastam uma parcela de sua renda ganha nos setores que aumentaram sua produção.

Essa subseção tem como finalidade identificar quais os setores que têm maior capacidade de geração de empregos dentro da estrutura produtiva da economia brasileira, no ano de 1999, com destaque para os setores os quais compõem o segmento do turismo, afim de as políticas que tenham como objetivo a redução no volume de desemprego poderem, então, ser direcionadas para tais setores.

\section{Empregos diretos}

A análise da geração direta de novos empregos foi feita, levando-se em consideração o coeficiente de emprego. Dessa forma, foi analisado o número de empregos diretos que poderiam ser gerados para cada $\mathrm{R} \$ 1$ milhão investidos em cada um dos 54 setores considerados no presente estudo.

Esses resultados estão apresentados na Tabela 17. Verifica-se que os setores Serviços privados não-mercantis (54), Artigos do vestuário (18), Atividades auxiliares aos transportes aéreos (42), Agropecuária (1), Estabelecimentos hoteleiros e outros tipos de alojamento temporário (46), Restaurantes e outros estabelecimentos de serviços de alimentação (47), Outros serviços prestados às famílias (49), Atividades recreativas, culturais e desportivas (48), Transporte rodoviário de passageiros, regular (31), Comércio (30) são os dez mais importantes geradores de empregos diretos, devido à variação na demanda final referida anteriormente. É importante ressaltar que dos dez setores mais importantes para geração de empregos diretos, caso ocorra aumento na demanda final, cinco fazem parte do que a literatura considera como integrante do segmento do turismo.

Além de ser um segmento capaz de gerar um número considerável de empregos diretos, conforme se pode observar na Tabela 17, segundo Osada (2002), sua capacidade de gerá-los é 1,5 vezes mais rápida do que qualquer outro setor industrial. 
Tabela 17. Empregos, diretos, indiretos, induzidos e totais gerados devido um aumento de R\$ 1 milhão na demanda final, 1999.

\begin{tabular}{|c|c|c|c|c|c|c|c|c|c|}
\hline & Setores & $\begin{array}{c}\text { Empregos } \\
\text { Diretos }\end{array}$ & Ordem & $\begin{array}{l}\text { Empregos } \\
\text { Indiretos }\end{array}$ & Ordem & $\begin{array}{l}\text { Empregos } \\
\text { Induzidos }\end{array}$ & Ordem & $\begin{array}{c}\text { Empregos } \\
\text { Totais } \\
\end{array}$ & Ordem \\
\hline 1 & AGROPECUÁRIA & 110 & 4 & 31 & 12 & 60 & 31 & 201 & 6 \\
\hline 2 & EXTRATIVA MINERAL & 10 & 36 & 12 & 48 & 58 & 36 & 79 & 48 \\
\hline 3 & MINERAL Ñ METÁLICO & 20 & 25 & 18 & 29 & 57 & 37 & 96 & 37 \\
\hline 4 & SIDERURGIA & 02 & 53 & 23 & 16 & 49 & 52 & 74 & 50 \\
\hline 5 & METALURGIA & 15 & 28 & 20 & 28 & 56 & 43 & 91 & 40 \\
\hline 6 & MÁQUINAS E EQUIP. & 12 & 33 & 13 & 47 & 60 & 30 & 85 & 41 \\
\hline 7 & MATERIAL ELÉTRICO & 07 & 42 & 22 & 18 & 51 & 48 & 80 & 47 \\
\hline 8 & EQUIP. ELETRÔNICOS & 07 & 43 & 16 & 32 & 48 & 53 & 71 & 51 \\
\hline 9 & AUTOM./CAM/ONIBUS & 03 & 50 & 21 & 21 & 46 & 54 & 69 & 52 \\
\hline 10 & PEÇAS E OUT. VEÍCULOS & 07 & 40 & 20 & 25 & 54 & 46 & 81 & 45 \\
\hline 11 & MADEIRA E MOBILIÁRIO & 49 & 12 & 45 & 8 & 64 & 25 & 159 & 9 \\
\hline 12 & CELULOSE, PAPEL E GRÁF. & 14 & 31 & 27 & 14 & 60 & 29 & 100 & 35 \\
\hline 13 & IND. DA BORRACHA & 04 & 49 & 22 & 17 & 49 & 51 & 75 & 49 \\
\hline 14 & INDÚSTRIA QUÍMICA & 02 & 52 & 17 & 31 & 49 & 50 & 69 & 53 \\
\hline 15 & FARMAC. E VETERINÁRIA & 06 & 45 & 22 & 19 & 56 & 42 & 84 & 42 \\
\hline 16 & ARTIGOS PLÁSTICOS & 14 & 30 & 14 & 45 & 55 & 44 & 82 & 44 \\
\hline 17 & IND. TÊXTIL & 10 & 35 & 34 & 11 & 50 & 49 & 94 & 38 \\
\hline 18 & ARTIGOS DO VESTUÁRIO & 135 & 2 & 26 & 15 & 63 & 26 & 224 & 2 \\
\hline 19 & FABRICAÇÃO DE CALÇADOS & 45 & 14 & 30 & 13 & 60 & 32 & 135 & 18 \\
\hline 20 & INDÚSTRIA DO CAFÉ & 06 & 44 & 86 & 2 & 58 & 35 & 150 & 13 \\
\hline 21 & BENEF. PROD. VEGETAIS & 11 & 34 & 78 & 3 & 56 & 41 & 145 & 14 \\
\hline 22 & ABATE DE ANIMAIS & 09 & 38 & 91 & 1 & 59 & 33 & 159 & 10 \\
\hline 23 & INDÚSTRIA DE LATICÍNIOS & 06 & 47 & 65 & 5 & 52 & 47 & 123 & 25 \\
\hline 24 & FABRICAÇÃO DE AÇÚCAR & 09 & 37 & 65 & 6 & 57 & 38 & 131 & 20 \\
\hline 25 & FAB. ÓLEOS VEGETAIS & 03 & 51 & 71 & 4 & 54 & 45 & 128 & 21 \\
\hline 26 & OUTROS PROD. ALIMENT. & 18 & 26 & 51 & 7 & 58 & 34 & 127 & 23 \\
\hline 27 & INDÚSTRIAS DIVERSAS & 26 & 21 & 21 & 20 & 61 & 28 & 108 & 31 \\
\hline
\end{tabular}


Tabela 17. Empregos, diretos, indiretos, induzidos e totais gerados devido um aumento de R\$ 1 milhão na demanda final, 1999.

\begin{tabular}{|c|c|c|c|c|c|c|c|c|c|}
\hline & Setores & $\begin{array}{c}\text { Empregos } \\
\text { Diretos }\end{array}$ & Ordem & $\begin{array}{c}\text { Empregos } \\
\text { Indiretos }\end{array}$ & Ordem & $\begin{array}{l}\text { Empregos } \\
\text { Induzidos }\end{array}$ & Ordem & $\begin{array}{c}\text { Empregos } \\
\text { Totais }\end{array}$ & Ordem \\
\hline 28 & S.I.U.P. & 05 & 48 & 9 & 52 & 69 & 18 & 83 & 43 \\
\hline 29 & CONSTRUÇÃO CIVIL & 26 & 20 & 15 & 36 & 56 & 40 & 98 & 36 \\
\hline 30 & COMÉRCIO & 71 & 10 & 14 & 46 & 74 & 10 & 159 & 11 \\
\hline 31 & TRANSP. RODOV. DE PASSAG., REGULAR & 72 & 9 & 15 & 38 & 70 & 15 & 157 & 12 \\
\hline 32 & TRANSP. RODOV. PASSAG, NÃO-REGULAR & 52 & 11 & 15 & 37 & 70 & 14 & 137 & 17 \\
\hline 33 & TRANSP. REG. EXPL. DE PTOS TURÍSTICOS & 41 & 17 & 15 & 39 & 70 & 16 & 126 & 24 \\
\hline 34 & TRANSP. RODOV. DE CARGAS & 31 & 18 & 15 & 40 & 70 & 17 & 116 & 26 \\
\hline 35 & OUTR. TRANSP.TERRESTRES & 45 & 15 & 21 & 22 & 68 & 19 & 134 & 19 \\
\hline 36 & TRANSP. AQUAVIÁRIO & 17 & 27 & 15 & 35 & 76 & 8 & 108 & 30 \\
\hline 37 & TRANSP. AÉREO, REGULAR & 6 & 46 & 20 & 26 & 67 & 23 & 94 & 39 \\
\hline 38 & TRANSP. AÉREO, NÃO-REGULAR & 15 & 29 & 21 & 23 & 67 & 22 & 102 & 33 \\
\hline 39 & AGÊNC. E ORG. DE VIAGENS & 30 & 19 & 18 & 30 & 67 & 24 & 115 & 27 \\
\hline 40 & ATIV. AUX. TRANSP. TERRESTRE & 42 & 16 & 15 & 42 & 70 & 13 & 127 & 22 \\
\hline 41 & ATIV. AUX.TRANSP.AQUAVIÁRIOS & 21 & 24 & 16 & 34 & 76 & 9 & 112 & 29 \\
\hline 43 & OUTR. ATIV. AUX. TRANSPORTE & 13 & 32 & 20 & 27 & 68 & 20 & 101 & 34 \\
\hline 44 & COMUNICAÇÕES & 7 & 41 & 11 & 49 & 62 & 27 & 81 & 46 \\
\hline 45 & INSTITUIÇÕES FINANCEIRAS & 8 & 39 & 14 & 43 & 82 & 3 & 105 & 32 \\
\hline 46 & ESTAB. HOTEL. E OUTR. TIPOS DE ALOJ. TEMPORÁRIO & 101 & 5 & 36 & 10 & 71 & 11 & 208 & 3 \\
\hline 47 & REST. OUTR. ESTAB. DE SERV. DE ALIMENTAÇÃO & 97 & 6 & 36 & 9 & 71 & 12 & 204 & 4 \\
\hline 48 & ATIV. RECREATIVAS, CULT. E DESPORTIVAS & 80 & 8 & 15 & 41 & 80 & 5 & 175 & 8 \\
\hline 49 & OUTR. SERV. PREST. ÀS FAMÍLIAS & 90 & 7 & 14 & 44 & 81 & 4 & 185 & 7 \\
\hline 50 & ALUGUEL AUTOM. OUTR. MEIOS DE TRANSPORTE & 23 & 23 & 11 & 51 & 79 & 7 & 113 & 28 \\
\hline 51 & OUTR. SERV. PREST. ÀS EMPRESAS & 49 & 13 & 11 & 50 & 79 & 6 & 139 & 15 \\
\hline 52 & ALUGUEL DE IMÓVEIS & 2 & 54 & 2 & 54 & 56 & 39 & 60 & 54 \\
\hline 53 & ADMINISTRAÇÃO PÚBLICA & 25 & 22 & 16 & 33 & 97 & 2 & 138 & 16 \\
\hline 54 & SERV. PRIV. Ñ MERCANTIS & 494 & 1 & 4 & 53 & 106 & 1 & 603 & 1 \\
\hline
\end{tabular}

Fonte: dados estimados pelo autor. 
Considerando a estrutura produtiva de 1999, os setores que menos gerariam empregos diretos, caso ocorresse um investimento de $\mathrm{R} \$ 1$ milhão em todos os setores, seriam os seguintes: Aluguel de imóveis (52), Siderurgia (4), Indústria química (14), Fabricação de óleos vegetais (25) e Automóveis, caminhões e ônibus (9).

\section{Empregos indiretos}

$\mathrm{Na}$ obtenção de uma estimativa do número de novos empregos indiretos gerados, levou-se em consideração o somatório do coeficiente de emprego multiplicado pela matriz inversa de Leontief. Dessa forma, tem-se os novos empregos gerados direta e indiretamente e, subtraindo os empregos diretos calculados anteriormente, obtêm-se somente os novos empregos gerados de forma indireta.

A análise da geração de empregos indiretos considerou, também, o efeito sobre o número de pessoas ocupadas em um setor, dado ao aumento de $\mathrm{R} \$ 1$ milhão nos investimentos dos outros setores. Na Tabela 17 são apresentados esses resultados.

Ao analisar a referida tabela, constatou-se que ocorreu uma ligeira inversão nos setores os quais mais geram empregos devido a um investimento realizado. Assim, em relação à geração de empregos indiretos, os setores que se destacam são: Abate de animais (22), Aluguel de imóveis (52), Beneficiamento de óleos vegetais (25), Indústria de laticínios (23), Fabricação de açúcar (24), e Outros produtos alimentares (26). Pode-se observar que os empregos indiretos são gerados, em sua grande maioria, nas atividades relacionadas com o segmento alimentício, revelando, provavelmente, o grande efeito de encadeamento desses setores com os demais da economia.

Assim, um provável investimento no segmento do turismo poderá desencadear a geração de empregos nas indústrias direta e indiretamente relacionadas com a atividade turística, como por exemplo, as indústrias alimentares. Um investimento no segmento do turismo poderá provar um aumento na sua produção, e isso fará com que aumente a utilização de insumos, tanto de sua própria produção como produzidos por outros setores, os quais terão de aumentar a sua produção para 
atender a essa nova demanda, o que poderá resultar na necessidade de contratação de novos trabalhadores.

\section{Empregos induzidos}

A análise do potencial de geração de empregos induzidos considera a endogeneização do consumo das famílias. Assim, na obtenção do número de empregos induzidos gerados na economia, leva-se em consideração o somatório do coeficiente de emprego multiplicado pela matriz inversa de Leontief, com o consumo das famílias considerado endógeno; em seguida subtrai-se destes valores o somatório dos coeficientes de emprego multiplicado pela matriz inversa de Leontief. Dessa forma, elimina-se a dupla contagem dos empregos diretos e indiretos.

Os resultados referentes ao número de empregos induzidos gerados na economia brasileira, dado a um investimento de $\mathrm{R} \$ 1$ milhão, podem ser observados na Tabela 17. De acordo com esses resultados, os setores que mais geraram empregos induzidos foram: Serviços privados não mercantis (54), Administração pública (53), Instituições financeiras (45), Outros serviços prestados às famílias (49) e Atividades recreativas, culturais e desportivas (48). Já os setores que menos geram empregos induzidos foram aqueles relacionados com a indústria de transformação.

Considerando apenas os setores que compõem o segmento do turismo, podese perceber que apresentam elevada participação dos empregos induzidos na composição do emprego total, merecendo destacar os setores: Transporte aéreo, regular (37), Aluguel de automóveis e outros meios de transportes (50), Transporte aéreo, não-regular (38), Transporte regular para exploração de pontos turísticos (33) e transporte rodoviário de passageiros, não-regular (32) cujas participações são superiores a $50 \%$ no emprego total (ver Tabela 18).

\section{Emprego total}

O número de empregos totais gerados por $\mathrm{R} \$ 1$ milhão investidos em cada setor produtivo, é composto pela somatória dos empregos diretos, indiretos e induzidos. Através da análise do emprego total, é possível verificar a composição do emprego gerado, bem como identificar quais os setores mais relevantes, ou seja, os "setores-chave" na geração de empregos. 
Analisando a Tabela 18 e Figura 10 e considerando os vinte setores que mais geram empregos totais, dada à estrutura produtiva de 1999, percebe-se que eles recebem uma maior contribuição dos efeitos diretos e induzidos, com exceção dos setores Abate de animais (22), Indústria do café (20), Beneficiamento de produtos vegetais (21) e Fabricação de açúcar (24), que apresentaram relevância como geradores de empregos indiretos e induzidos.

Com relação à geração de empregos pelo segmento do turismo, pode-se perceber que o mesmo segue a tendência apontada por vários autores, como sendo uma das atividades econômicas mais geradora de empregos. De acordo com o modelo de insumo-produto construído para este trabalho, constatou-se que os dez setores que mais geram empregos dado a um investimento de $\mathrm{R} \$ 1$ milhão foram: Serviços privados não mercantis (54), Artigos do vestuário (18), Estabelecimentos hoteleiros e outros tipos de alojamentos temporário (46) Restaurantes e outros estabelecimentos de serviços de alimentação (47), Atividades auxiliares aos transportes aéreos (42), Agropecuária (1), Outros serviços prestados às famílias (49), Atividades recreativas, culturais e desportivas (49), Madeira e mobiliário (11) e Abate de animais (22). E desses setores que mais geram empregos, quatro são componentes do segmento do turismo.

Analisando o segmento do turismo de forma mais desagregada, isto é, considerando os setores componentes deste segmento, pode-se verificar que, dentre estes, os que apresentaram melhor desempenho na geração de emprego total foram: Estabelecimentos hoteleiros e outros tipos de alojamento temporário (46), Restaurantes e outros estabelecimentos de serviços de alimentação (47), Atividades auxiliares aos transportes aéreos (42), Atividades recreativas, culturais e desportivas (48) e Transporte rodoviários de passageiros, regular (31).

Outro resultado importante para o segmento do turismo no Brasil, que pode ser observado, analisando a Tabela 18 e a Figura 10, é a considerável participação dos empregos diretos e induzidos na composição do total de empregos gerados. Tal fato pode estar associado ao considerável efeito multiplicador que este segmento possui dentro de um determinado sistema econômico. 
Tabela 18. Composição do emprego total gerado devido a um aumento de R\$ 1 milhão na demanda final, Brasil, 1999.

\begin{tabular}{|c|c|c|c|c|c|c|c|c|c|}
\hline & & \multicolumn{2}{|c|}{ Diretos } & \multicolumn{2}{|c|}{ Indiretos } & \multicolumn{2}{|c|}{ Induzidos } & \multicolumn{2}{|c|}{ total } \\
\hline & & Part. (\%) & Ordem & Part. (\%) & Ordem & Part. (\%) & Ordem & No. empregos & \\
\hline 1 & AGROPECUÁRIA & 54,8 & 4 & 15,6 & 29 & 29,6 & 52 & 201 & 100 \\
\hline 2 & EXTRATIVA MINERAL & 12,0 & 34 & 15,3 & 33 & 72,7 & 5 & 79 & 100 \\
\hline 3 & MINERAL Ñ METÁLICO & 21,2 & 22 & 19,1 & 25 & 59,7 & 26 & 96 & 100 \\
\hline 4 & SIDERURGIA & 2,9 & 53 & 31,3 & 9 & 65,8 & 18 & 74 & 100 \\
\hline 5 & METALURGIA & 16,8 & 26 & 21,7 & 20 & 61,5 & 23 & 91 & 100 \\
\hline 6 & MÁQUINAS E EQUIP. & 14,1 & 30 & 15,5 & 31 & 70,3 & 8 & 85 & 100 \\
\hline 7 & MATERIAL ELÉTRICO & 8,6 & 39 & 27,9 & 13 & 63,5 & 22 & 80 & 100 \\
\hline 8 & EQUIP. ELETRÔNICOS & 9,3 & 36 & 23,1 & 18 & 67,6 & 12 & 71 & 100 \\
\hline 9 & AUTOM./CAM/ONIBUS & 4,0 & 50 & 30,1 & 10 & 65,9 & 17 & 69 & 100 \\
\hline 10 & PEÇAS E OUT. VEÍCULOS & 9,2 & 37 & 25,0 & 16 & 65,8 & 19 & 81 & 100 \\
\hline & MADEIRA E MOBILIÁRIO & 31,1 & 17 & 28,4 & 12 & 40,5 & 45 & 159 & 100 \\
\hline 12 & CELULOSE, PAPEL E GRÁF. & 13,5 & 32 & 26,5 & 14 & 60,1 & 25 & 100 & 100 \\
\hline & IND. DA BORRACHA & 5,9 & 45 & 29,5 & 11 & 64,6 & 21 & 75 & 100 \\
\hline 14 & INDÚSTRIA QUÍMICA & 3,4 & 52 & 24,4 & 17 & 72,2 & 6 & 69 & 100 \\
\hline 15 & FARMAC. E VETERINÁRIA & 7,7 & 41 & 25,7 & 15 & 66,6 & 15 & 84 & 100 \\
\hline 16 & ARTIGOS PLÁSTICOS & 16,8 & 27 & 16,7 & 28 & 66,5 & 16 & 82 & 100 \\
\hline & IND. TÊXTIL & 11,0 & 35 & 36,2 & 8 & 52,8 & 33 & 94 & 100 \\
\hline 18 & ARTIGOS DO VESTUÁRIO & 60,3 & 2 & 11,8 & 40 & 27,9 & 53 & 224 & 100 \\
\hline 19 & FABRICAÇÃO DE CALÇADOS & 33,3 & 14 & 22,6 & 19 & 44,1 & 40 & 135 & 100 \\
\hline & INDÚSTRIA DO CAFÉ & 4,3 & 49 & 57,2 & 1 & 38,5 & 47 & 150 & 100 \\
\hline & BENEF. PROD. VEGETAIS & 7,4 & 42 & 53,9 & 4 & 38,7 & 46 & 145 & 100 \\
\hline & ABATE DE ANIMAIS & 5,6 & 47 & 57,1 & 2 & 37,3 & 48 & 159 & 100 \\
\hline & INDÚSTRIA DE LATICÍNIOS & 4,9 & 48 & 52,9 & 5 & 42,3 & 43 & 123 & 100 \\
\hline & FABRICAÇÃO DE AÇÚCAR & 7,0 & 43 & 49,7 & 6 & 43,3 & 42 & 131 & 100 \\
\hline & FAB. ÓLEOS VEGETAIS & 2,0 & 54 & 55,8 & 3 & 42,2 & 44 & 128 & 100 \\
\hline & OUTROS PROD. ALIMENT. & 14,0 & 31 & 40,4 & 7 & 45,6 & 38 & 127 & 100 \\
\hline & INDÚSTRIAS DIVERSAS & 23,8 & 21 & 19,8 & 23 & 56,3 & 30 & 108 & 100 \\
\hline 28 & S.I.U.P. & 5,7 & 46 & 10,3 & 45 & 84,0 & 2 & 83 & 100 \\
\hline
\end{tabular}


Tabela 18. Composição do emprego total gerado devido a um aumento de R\$ 1 milhão na demanda final, Brasil, 1999.

\begin{tabular}{|c|c|c|c|c|c|c|c|c|c|}
\hline & \multirow[t]{2}{*}{ Setores } & \multicolumn{2}{|c|}{ Diretos } & \multicolumn{2}{|c|}{ Indiretos } & \multicolumn{2}{|c|}{ Induzidos } & \multicolumn{2}{|c|}{ Total } \\
\hline & & Part. (\%) & Ordem & Part. (\%) & Ordem & Part. (\%) & Ordem & No. empregos & \\
\hline 29 & CONSTRUÇÃO CIVIL & 27,0 & 18 & 15,2 & 34 & 57,8 & 28 & 98 & 100 \\
\hline 30 & COMÉRCIO & 44,5 & 10 & 8,6 & 49 & 46,9 & 36 & 159 & 100 \\
\hline 31 & TRANSP. RODOV. DE PASSAG., REGULAR & 45,9 & 8 & 9,4 & 48 & 44,8 & 39 & 157 & 100 \\
\hline 32 & TRANSP. RODOV. PASSAG., NÃO-REGULAR & 37,8 & 11 & 10,7 & 44 & 51,5 & 34 & 137 & 100 \\
\hline 33 & TRANSP. REG. EXPL. DE POS TURÍSTICOS & 32,7 & 16 & 11,6 & 42 & 55,7 & 31 & 126 & 100 \\
\hline 34 & TRANSP. RODOV. DE CARGAS & 26,7 & 19 & 12,7 & 39 & 60,6 & 24 & 116 & 100 \\
\hline 35 & OUTROS TRANSPORTES TERRESTRES & 33,5 & 13 & 15,4 & 32 & 51,1 & 35 & 134 & 100 \\
\hline 36 & TRANSP. AQUAVIÁRIO & 16,0 & 28 & 14,2 & 35 & 69,8 & 11 & 108 & 100 \\
\hline 37 & TRANSP. AÉREO, REGULAR & 6,8 & 44 & 21,6 & 21 & 71,7 & 7 & 94 & 100 \\
\hline 38 & TRANSP. AÉREO, NÃO-REGULAR & 14,3 & 29 & 20,1 & 22 & 65,6 & 20 & 102 & 100 \\
\hline 39 & AGÊNC. E ORG. DE VIAGENS & 26,1 & 20 & 15,6 & 30 & 58,3 & 27 & 115 & 100 \\
\hline 40 & ATIV. AUX. TRANSP. TERRESTRE & 33,3 & 15 & 11,4 & 43 & 55,2 & 32 & 127 & 100 \\
\hline 41 & ATIV. AUX.TRANSP.AQUAVIÁRIOS & 18,3 & 24 & 14,1 & 36 & 67,5 & 14 & 112 & 100 \\
\hline 42 & ATIV. AUX. TRANSP. AÉREOS & 56,4 & 3 & 10,1 & 46 & 33,5 & 51 & 201 & 100 \\
\hline 43 & OUTR. ATIV. AUX. TRANSPORTE & 12,6 & 33 & 19,8 & 24 & 67,6 & 13 & 101 & 100 \\
\hline 44 & COMUNICAÇÕES & 9,2 & 38 & 14,0 & 37 & 76,9 & 4 & 81 & 100 \\
\hline 45 & INSTITUIÇÕES FINANCEIRAS & 8,0 & 40 & 13,5 & 38 & 78,5 & 3 & 105 & 100 \\
\hline 46 & ESTAB. HOTEL. E OUTR. TIPOS DE ALOJ. TEMPORÁRIO & 48,6 & 6 & 17,2 & 27 & 34,1 & 50 & 208 & 100 \\
\hline 47 & REST. OUTR. ESTAB. DE SERV. DE ALIMENTAÇÃO & 47,6 & 7 & 17,6 & 26 & 34,8 & 49 & 204 & 100 \\
\hline 48 & ATIV. RECREATIVAS, CULT. E DESPORTIVAS & 45,6 & 9 & 8,3 & 50 & 46,0 & 37 & 175 & 100 \\
\hline 49 & OUTR. SERV. PREST. ÀS FAMÍLIAS & 48,9 & 5 & 7,4 & 52 & 43,6 & 41 & 185 & 100 \\
\hline 50 & ALUGUEL AUTOM. OUTR. MEIOS DE TRANSPORTE & 20,3 & 23 & 9,7 & 47 & 70,0 & 10 & 113 & 100 \\
\hline 51 & OUTR. SERV. PREST. ÀS EMPRESAS & 35,3 & 12 & 7,9 & 51 & 56,8 & 29 & 139 & 100 \\
\hline 52 & ALUGUEL DE IMÓVEIS & 3,5 & 51 & 2,6 & 53 & 93,9 & 1 & 60 & 100 \\
\hline 53 & ADMINISTRAÇÃO PÚBLICA & 18,2 & 25 & 11,8 & 41 & 70,1 & 9 & 138 & 100 \\
\hline 54 & SERV. PRIV. Ñ MERCANTIS & 81,9 & 1 & 0,6 & 54 & 17,5 & 54 & 603 & 100 \\
\hline
\end{tabular}

Fonte: dados estimados pelo autor. 


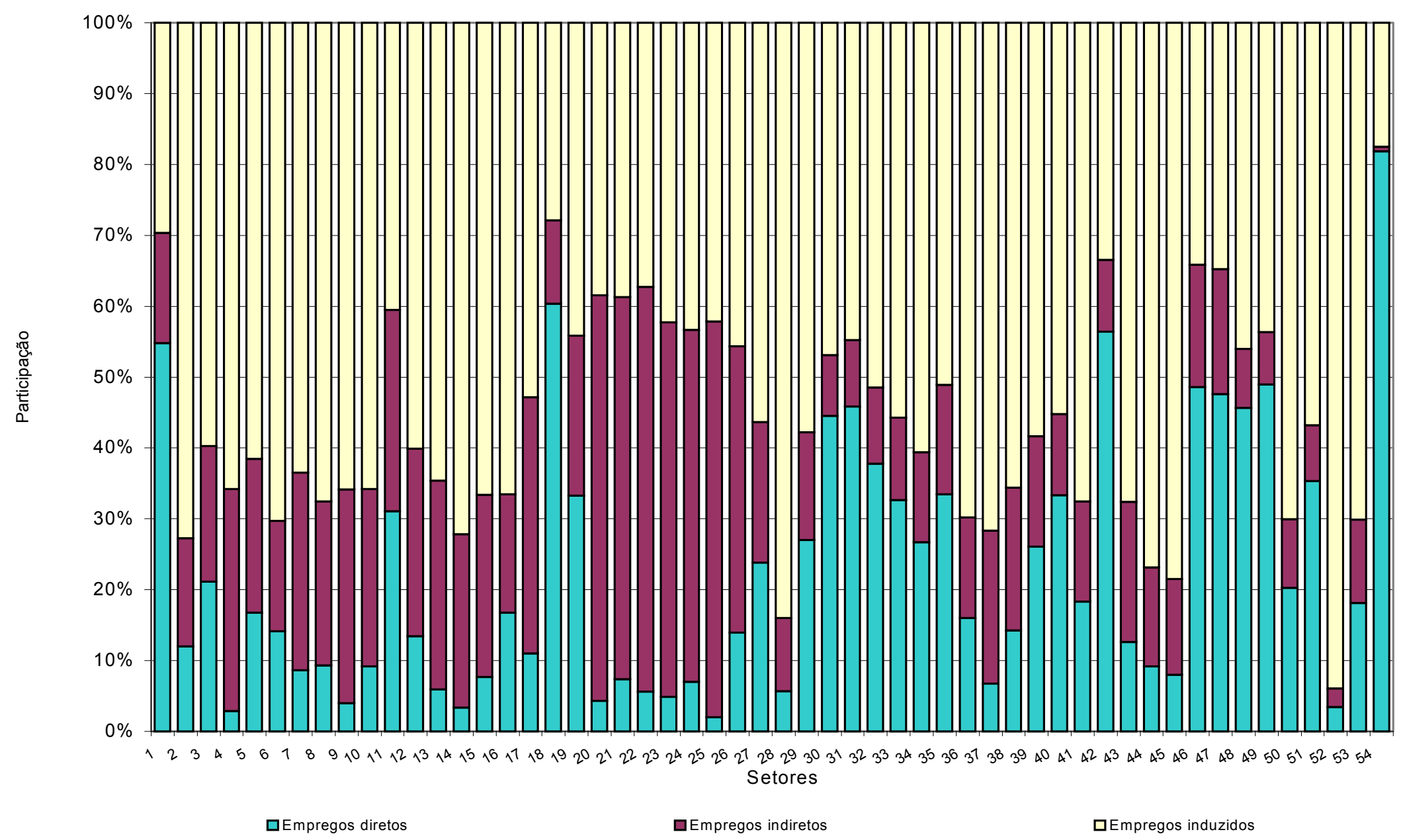

Figura 12 - Composição do emprego total gerado devido a um aumento de $R$ \$ 1 milhão na demanda final, Brasil, 1999. 


\subsection{Dimensionamento do segmento do turismo no Brasil: produto interno bruto e pessoal ocupado}

Com o objetivo de mensurar a participação do segmento do turismo na economia brasileira, procurou-se dimensionar este segmento em termos de pessoal ocupado e de valor adicionado, utilizado como uma proxy para quantificar o Produto Interno Bruto. Conforme foi detalhado anteriormente, o dimensionamento do segmento do turismo foi feito, levando-se em consideração a cadeia produtiva do mesmo, ou seja, consideraram-se todos os seus componentes em cada um dos setores que o compõem. Os resultados para este dimensionamento são apresentados e discutidos nas subseções seguintes.

\subsubsection{O valor adicionado no segmento do turismo}

O dimensionamento do segmento do turismo no Brasil, para o ano de 1999, foi feito, levando-se em consideração o valor adicionado, sendo apresentado a seguir. Em termos de valores, a Tabela 19, 20 e 21 mostram a estrutura de participação dos diversos componentes do turismo.

Vale ressaltar aqui que também é importante mensurar quanto cada setor que compõe o segmento do turismo adiciona ao mesmo levando em consideração cada um dos componentes, isto é, quantificar quanto cada complexo adiciona ao segmento do turismo. Esses resultados são mostrados nas Tabelas 19 e 20.

O valor total do Valor Adicionado do segmento do turismo, bem como em cada um dos seus complexos foi dividido em: insumos, o próprio segmento e serviços, conforme foi definido no capítulo referente à metodologia. Com relação a esses três componentes, as sua participações no segmento, em 1999, foram respectivamente de $17,99 \%, 47,68 \%$ e $34,33 \%$. Em todos os complexos pode-se perceber que a maior participação refere-se ao próprio segmento, e, dentre estes com maior destaque o complexo Atividades recreativas, culturais e desportivas (68,39\%), e a menor participação $(41,60 \%)$ ficou com o complexo Transporte aéreo não-regular. 
Tabela 19. Valor adicionado do segmento de turismo, participação dos agregados (Insumos, Turismo e Serviços) no valor adicionado total de cada setor componente do segmento do turismo, Brasil, 1999.

\begin{tabular}{|c|c|c|c|c|c|c|c|c|}
\hline \multirow[b]{2}{*}{ Setores } & \multicolumn{2}{|c|}{ Insumos } & \multicolumn{2}{|c|}{ Turismo } & \multicolumn{2}{|c|}{ Serviços } & \multicolumn{2}{|c|}{ Total } \\
\hline & $\begin{array}{c}\text { Valor } \\
\text { (R\$ Milhões) } \\
\end{array}$ & $\begin{array}{c}\text { Participação } \\
(\%)\end{array}$ & $\begin{array}{c}\text { Valor } \\
\text { (R\$ Milhões) } \\
\end{array}$ & $\begin{array}{c}\text { Participação } \\
(\%)\end{array}$ & $\begin{array}{c}\text { Valor } \\
\text { (R\$ Milhões) } \\
\end{array}$ & $\begin{array}{c}\text { Participação } \\
(\%)\end{array}$ & $\begin{array}{c}\text { Valor } \\
\text { (R\$ Milhões) } \\
\end{array}$ & $\begin{array}{c}\text { Participação } \\
(\%)\end{array}$ \\
\hline TRANSP. RODOV. DE PASSAGEIROS, REGULAR & 2.195 .070 & 16,19 & 7026.452 & 51,84 & 4.332 .872 & 31,97 & 13.554 .393 & 100,00 \\
\hline TRANSP. RODOV. DE PASSAGEIROS, NÃO-REGULAR & 160.261 & 16,19 & 512.996 & 51,84 & 316.340 & 31,97 & 989.597 & 100,00 \\
\hline TRANSP. REG. PRÓPRIOS EXPL. DE PTOS. TURÍSTICOS & 1.860 & 16,19 & 5.955 & 51,84 & 3.672 & 31,97 & 11.487 & 100,00 \\
\hline TRANSPORTE AÉREO, REGULAR & 2.322 .686 & 22,21 & 4372.703 & 41,80 & 3.764 .630 & 35,99 & 10.460 .018 & 100,00 \\
\hline TRANSPORTE AÉREO, NÃO-REGULAR & 132.863 & 22,58 & 244.838 & 41,60 & 210.790 & 35,82 & 588.491 & 100,00 \\
\hline AGÊNCIAS DE VIAGENS E ORG. DE VIAGENS & 584.705 & 28,04 & 1206.549 & 57,86 & 293.961 & 14,10 & 2.085 .215 & 100,00 \\
\hline ATIVIDADES AUX. AOS TRANSP. TERRESTRE & 167.604 & 19,05 & 526.566 & 59,84 & 185.743 & 21,11 & 879.914 & 100,00 \\
\hline ATIVIDADES AUX. AOS TRANSPORTES AÉREOS & 180.558 & 27,53 & 324.542 & 49,48 & 150.777 & 22,99 & 655.877 & 100,00 \\
\hline ESTAB. HOTEL. E OUT. TIPOS DE ALOJ.TEMPORÁRIO & 1.234 .161 & 17,85 & 3040.736 & 43,97 & 2.640 .788 & 38,19 & 6.915 .685 & 100,00 \\
\hline REST. E OUT. ESTAB. DE SERV. DE ALIMENTAÇÃO & 4.335 .293 & 17,21 & 10690.217 & 42,44 & 10.163.317 & 40,35 & 25.188 .827 & 100,00 \\
\hline ATIV. RECREATIVAS, CULTURAIS E DESPORTIVAS & 771.171 & 13,73 & 3840.004 & 68,38 & 1.004 .720 & 17,89 & 5.615 .895 & 100,00 \\
\hline ALUGUEL DE AUT. E OUTR. MEIOS DE TRANSPORTE & 84.982 & 11,87 & 469.974 & 65,65 & 160.884 & 22,47 & 715.841 & 100,00 \\
\hline SEGMENTO DO TURISMO & 12.171.214 & 17,99 & 3.2261 .533 & 47,68 & 23.228.494 & 34,33 & 67.661 .307 & 100,00 \\
\hline
\end{tabular}

Fonte: dados estimados pelo autor. 
Tabela 20. Participação setorial no valor adicionado dos agregados (insumos, turismo e serviços), no valor adicionado total do segmento do turismo e no valor adicionado do Brasil, Brasil, 1999.

\begin{tabular}{|c|c|c|c|c|c|}
\hline \multirow[b]{2}{*}{ Setores } & Insumos & Turismo & Serviços & Total & \multirow{2}{*}{$\begin{array}{l}\text { Participação } \\
\text { no Valor } \\
\text { Adicionado } \\
\text { do Brasil (\%) }\end{array}$} \\
\hline & $\begin{array}{c}\text { Participação } \\
(\%)\end{array}$ & $\begin{array}{c}\text { Participação } \\
(\%)\end{array}$ & $\begin{array}{c}\text { Participação } \\
(\%)\end{array}$ & $\begin{array}{c}\text { Participação } \\
(\%)\end{array}$ & \\
\hline TRANSP. RODOV. DE PASSAGEIROS, REGULAR & 18,03 & 21,78 & 18,65 & 20,03 & 1,51 \\
\hline TRANSP. RODOV. DE PASSAGEIROS, NÃO-REGULAR & 1,32 & 1,59 & 1,36 & 1,46 & 0,11 \\
\hline TRANSP. REG. EXPL. DE PTOS. TURÍSTICOS & 0,02 & 0,02 & 0,02 & 0,02 & 0,00 \\
\hline TRANSPORTE AÉREO, REGULAR & 19,08 & 13,55 & 16,21 & 15,46 & 1,16 \\
\hline TRANSPORTE AÉREO, NÃO-REGULAR & 1,09 & 0,76 & 0,91 & 0,87 & 0,07 \\
\hline AGÊNCIAS DE VIAGENS E ORG. DE VIAGENS & 4,80 & 3,74 & 1,27 & 3,08 & 0,23 \\
\hline ATIVIDADES AUX. AOS TRANSPORTES TERRESTRES & 1,38 & 1,63 & 0,80 & 1,30 & 0,10 \\
\hline ATIVIDADES AUX. AOS TRANSPORTES AÉREOS & 1,48 & 1,01 & 0,65 & 0,97 & 0,07 \\
\hline ESTAB. HOTEL. E OUT. TIPOS DE ALOJ.TEMPORÁRIO & 10,14 & 9,43 & 11,37 & 10,22 & 0,77 \\
\hline REST. E OUT. ESTAB. DE SERV. DE ALIMENTAÇÃO & 35,62 & 33,14 & 43,75 & 37,23 & 2,81 \\
\hline ATIV. RECREATIVAS, CULTURAIS E DESPORTIVAS & 6,34 & 11,90 & 4,33 & 8,30 & 0,63 \\
\hline ALUGUEL DE AUT. E OUTR. MEIOS DE TRANSPORTE & 0,70 & 1,46 & 0,69 & 1,06 & 0,08 \\
\hline SEGMENTO DO TURISMO & 100 & 100 & 100 & 100 & 7,54 \\
\hline
\end{tabular}

Fonte: dados estimados pelo autor.

Analisando a participação de cada complexo na composição do valor adicionado do segmento do turismo no ano de 1999, percebeu-se que a maior participação coube ao complexo Restaurantes e outros estabelecimentos de serviços de alimentação (37,33\%), seguido por Transporte rodoviário de passageiros, regular (20,03\%), Transporte aéreo, regular (15,46\%) e Estabelecimentos hoteleiros e outros tipos de alojamento temporário (10,22\%).

No que diz respeito à participação do valor adicionado dos componentes do segmento do turismo no valor adicionado do Brasil (R\$ 897.912.074 milhões) tem-se as seguintes participações $1,36 \%, 3,59 \%$ e 2,59\%, respectivamente, enquanto o valor adicionado do turismo total ( $\mathrm{R} \$ 67.661 .241$ milhões) representava $7,54 \%$ do valor adicionado do Brasil, conforme pode ser observado na Tabela 21 e Figura 13. Esse valor ficou abaixo da contribuição do turismo no PIB mundial, que é da ordem de $10 \%$. 
Tabela 21. Dimensionamento do segmento do turismo no Brasil em 1999 - Valor Adicionado.

\begin{tabular}{lrcc}
\hline Agregados & $\begin{array}{c}\text { Valor } \\
\text { Adicionado } \\
\text { (R\$ milhões) }\end{array}$ & $\begin{array}{c}\text { Participação } \\
\text { dos Componentes } \\
(\%)\end{array}$ & $\begin{array}{c}\text { Participação no } \\
\text { Valor Adicionado } \\
\text { Brasil (\%) }\end{array}$ \\
\hline Insumos & 12.171 .214 & 17,99 & 1,36 \\
Turismo & 32.261 .533 & 47,68 & 3,59 \\
Serviços & 23.228 .494 & 34,33 & 2,59 \\
\hline Total & $\mathbf{6 7 . 6 6 1 . 2 4 1}$ & 100,00 & 7,54 \\
Brasil & $\mathbf{8 9 7 . 9 1 2 . 0 7 4}$ & & \\
\hline
\end{tabular}

Fonte: dados estimados pelo autor.

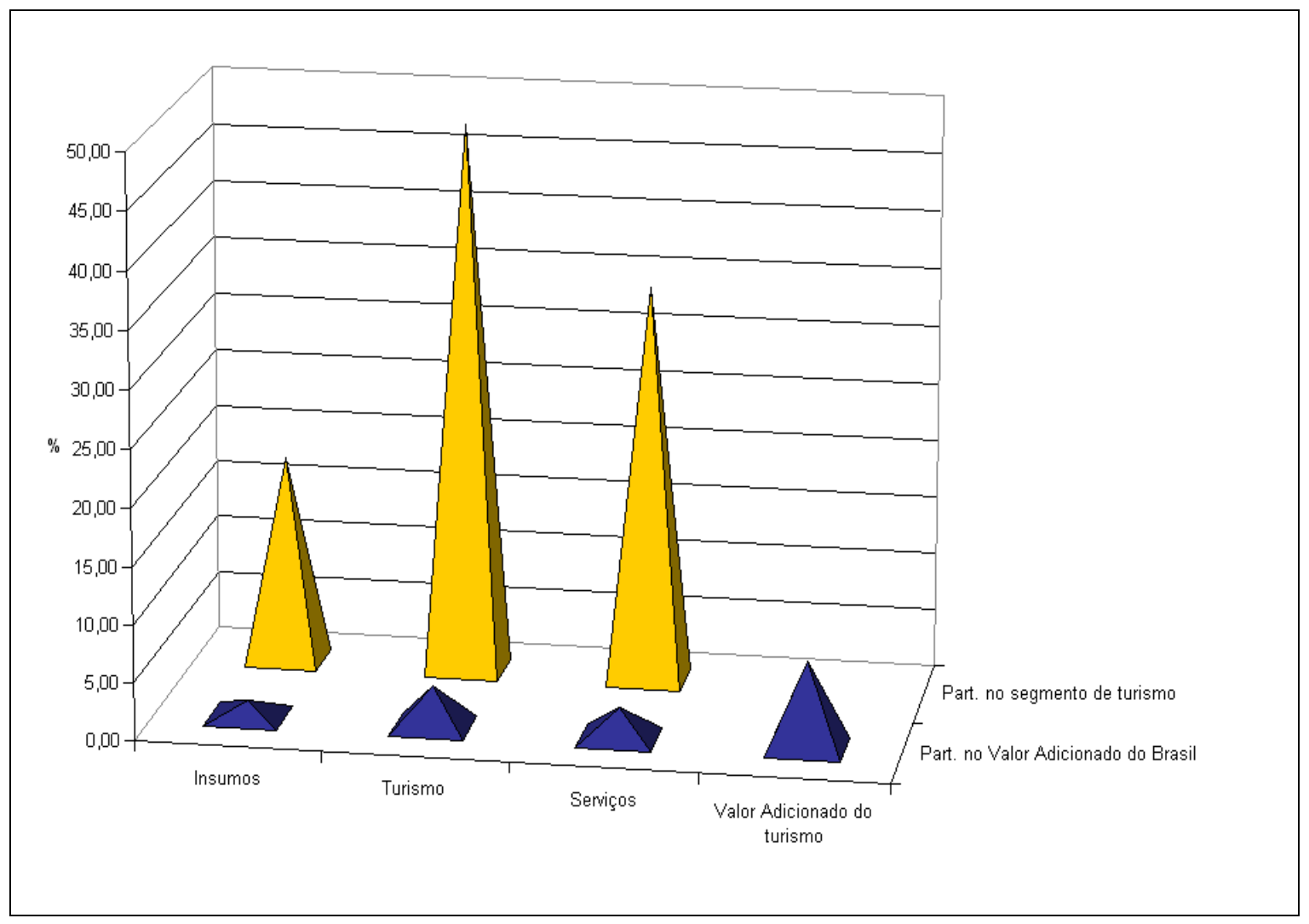

Figura 13 - Dimensionamento do segmento do turismo no Brasil em 1999 - Valor Adicionado. 
No trabalho conduzido pela Embratur/FADE (1998) constatou-se que a participação do turismo no PIB do Brasil vem apresentando valores em torno de $7 \%$ até a metade da década de 90. Assim, de acordo com a estimativa de participação do segmento do turismo no PIB brasileiro obtida no presente estudo (7,54\%), pode-se inferir que este segmento vem apresentando uma melhoria de desempenho. Essa comparação de resultados, entretanto, deve ser analisada com alguma cautela, tendo em vista que não se conhece a metodologia de cálculo do PIB no trabalho conduzido pela Embratur/FADE, fato que não ocorre neste estudo.

Considerando que o valor adicionado pode ser usado como uma proxy da medida da renda do país, pode-se afirmar que o segmento do turismo apresentou um bom desempenho em relação à geração de renda, uma vez que, no período analisado, apresentou uma boa contribuição ao valor adicionado do país. Vale salientar que este desempenho poderá ser melhorado, caso ocorra um melhor incentivo às famílias para fazerem turismo, bem como incentivos aos empresários envolvidos nas atividades que compõem tal segmento.

Outro ponto a merecer ressalva é que o turismo no Brasil como segmento econômico é considerado recente e ainda apresenta um grande potencial para seu crescimento, tendo em vista os recursos turísticos de que dispõe como atrativos. Assim sendo, há possibilidade de expansão do segmento e, com isso, poderá melhorar ainda seu desempenho em termos de geração de renda no país.

\subsubsection{O pessoal ocupado no segmento do turismo}

Com relação ao dimensionamento do segmento do turismo, levando-se em consideração a quantidade de pessoas ocupadas em cada um dos componentes do segmento, os resultados são apresentados nas Tabelas 22, 23 e 24. Constatou-se que, considerando os três agregados do segmento do turismo, no ano de 1999, o referido segmento ocupava em torno de $12 \%$ da força de trabalho no país, aproximadamente 7.113.929 pessoas. Analisando cada um dos agregados em separado, pode-se verificar que a maior contribuição é a do agregado dos setores os quais compõem o segmento do turismo em torno de $8,6 \%$, enquanto a participação dos 
agregados, insumos e serviços foram de 1,30 e 2,30\%, respectivamente. Esses resultados podem também ser visualizados, analisando-se a Figura 14.

Tabela 22. Dimensionamento do segmento do turismo no Brasil em 1999 - Pessoal Ocupado

\begin{tabular}{lccc}
\hline Agregados & Pessoal ocupado & $\begin{array}{c}\text { Participação } \\
\text { dos Agregados } \\
(\%)\end{array}$ & $\begin{array}{c}\text { Participação no } \\
\text { pessoal ocupado } \\
\text { Brasil (\%) }\end{array}$ \\
\hline Insumos & 761.735 & 10,71 & 1,30 \\
Turismo & 5.010 .129 & 70,43 & 8,58 \\
Serviços & 1.342 .065 & 18,87 & 2,30 \\
\hline TOTAL & 7.113 .929 & 100,00 & 12,19 \\
& & & \\
Brasil & 58.380 .602 & &
\end{tabular}

Fonte: dados estimados pelo autor.

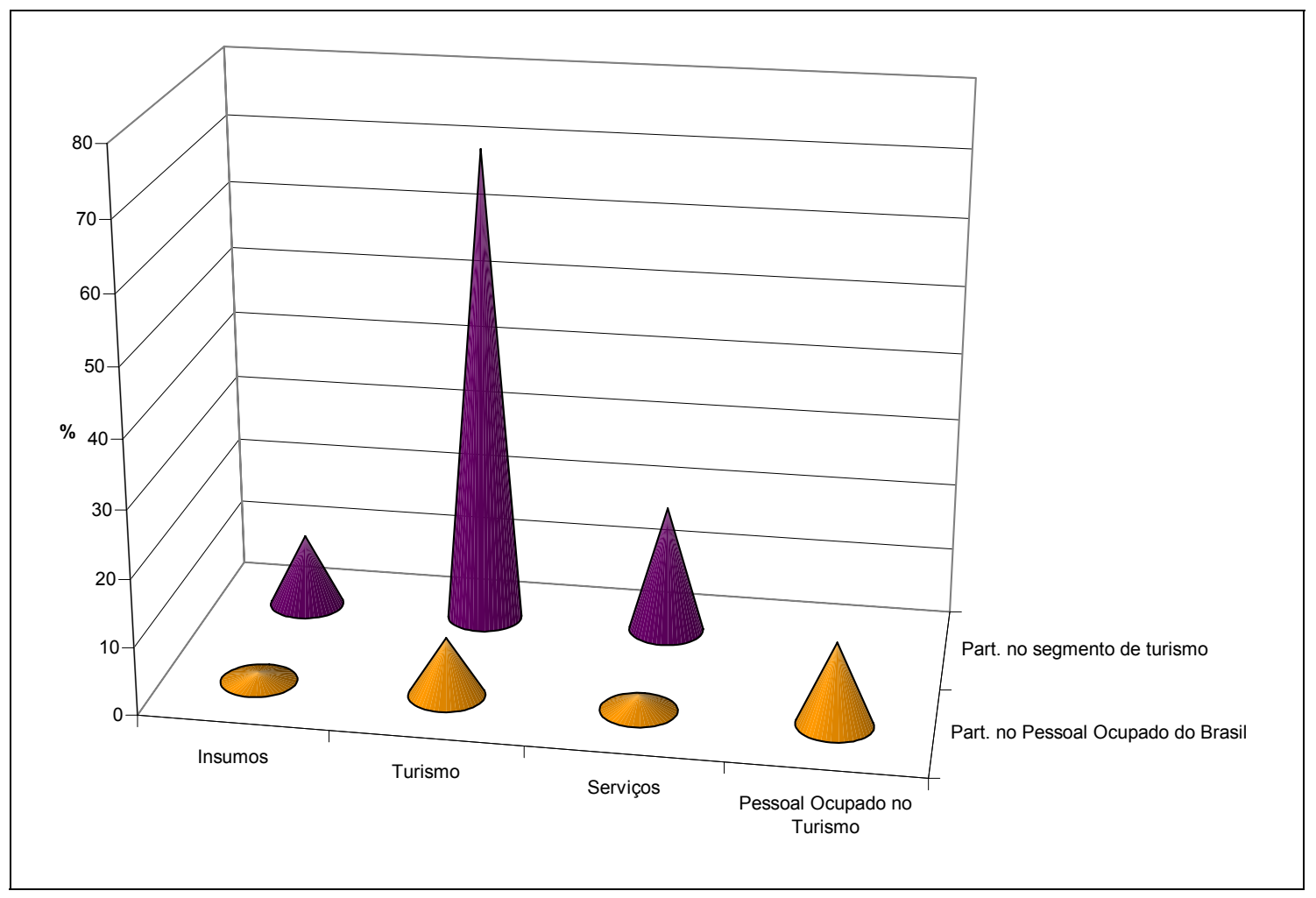

Figura 14 - Dimensionamento do segmento do turismo no Brasil em 1999 - Pessoal Ocupado. 
Considerando a participação do pessoal ocupado dos três componentes do segmento do turismo, constatou-se que o turismo responde por cerca de $70 \%$ das pessoas ocupadas no segmento, ou seja, emprega cerca de 5.010.129 pessoas. Os setores que foram considerados como fornecedores de insumos a serem utilizados no processo produtivo dos setores que compõem o segmento do turismo empregam a menor parcela 10,71\% (761.735 pessoas) do total de pessoas ocupadas no segmento, e os que prestam serviços ao turismo empregam cerca de 1.342 .065 pessoas, o que corresponde a aproximadamente $19 \%$ do total de pessoas ocupadas no segmento do turismo.

Merece, também, aqui ser mensurado o pessoal ocupado nos complexos que compõem o segmento do turismo no Brasil. Estes resultados são apresentados nas Tabelas 23 e 24 . Ao analisar a Tabela 23 percebe-se que a maior parte do pessoal ocupado, dos complexos aqui considerados, encontra-se no próprio segmento (agregado turismo). As participações foram superiores a $50 \%$, com exceção dos complexos Transporte aéreo, regular e Transporte aéreo, não-regular os quais apresentaram uma maior participação do pessoal ocupado no agregado serviços.

Analisando a Tabela 24, constatou-se que do pessoal ocupado total no segmento do turismo no Brasil, no ano de referência do presente estudo, a maior parte encontrava-se no complexo Restaurante e outros estabelecimentos de serviços de alimentação cuja participação é de aproximadamente $48 \%$. Destaca-se a seguir o de Transporte rodoviário de passageiros, regular (18,82\%). A terceira posição, ficou com o complexo Estabelecimentos hoteleiros e outros tipos de alojamento temporário cuja participação é de 13,71\%. As menores contribuições foram dos complexos Transporte regular para exploração de pontos turísticos, Transporte aéreo, não-regular, Aluguel de automóveis e outros meios de transporte e Atividades auxiliares aos transportes terrestres cujas participações foram: $0,01 \%, 0,37 \%, 0,40 \%$ e $0,87 \%$, respectivamente. 
Tabela 23. Pessoal ocupado no segmento de turismo, participação dos agregados (Insumos, Turismo e Serviços) no pessoal ocupado total de cada setor componente do segmento do turismo, Brasil, 1999.

\begin{tabular}{|c|c|c|c|c|c|c|c|c|}
\hline \multirow[b]{2}{*}{ Setores } & \multicolumn{2}{|c|}{ Insumos } & \multicolumn{2}{|c|}{ Turismo } & \multicolumn{2}{|c|}{ Serviços } & \multicolumn{2}{|c|}{ Total } \\
\hline & $\begin{array}{l}\text { Pessoal } \\
\text { Ocupado }\end{array}$ & Part. & $\begin{array}{l}\text { Pessoal } \\
\text { Ocupado }\end{array}$ & Part. & $\begin{array}{l}\text { Pessoal } \\
\text { Ocupado }\end{array}$ & Part. & $\begin{array}{l}\text { Pessoal } \\
\text { Ocupado }\end{array}$ & Part. \\
\hline TRANSPORTE RODOVIÁRIO DE PASSAGEIROS, REGULAR & 82.155 & 6,14 & 1.006 .073 & 75,16 & 250.339 & 18,70 & 1.338 .566 & 100,00 \\
\hline TRANSP. REG. PRÓPRIOS PARA EXPL. DE PTOS. TURÍSTICOS & 70 & 9,04 & 488 & 63,40 & 212 & 27,56 & 770 & 100,00 \\
\hline TRANSPORTE AÉREO, REGULAR & 87.979 & 23,27 & 72.551 & 19,19 & 217.508 & 57,54 & 378.038 & 100,00 \\
\hline TRANSPORTE AÉREO, NÃO-REGULAR & 4.971 & 18,74 & 9.370 & 35,33 & 12.179 & 45,92 & 26.519 & 100,00 \\
\hline ATIVIDADES AUXILIARES AOS TRANSPORTES TERRESTRE & 6.596 & 10,68 & 44.438 & 71,95 & 10.732 & 17,37 & 61.766 & 100,00 \\
\hline ATIVIDADES AUXILIARES AOS TRANSPORTES AÉREOS & 7.218 & 6,43 & 96.404 & 85,82 & 8.711 & 7,75 & 112.333 & 100,00 \\
\hline ESTAB. HOTELEIROS E OUT. TIPOS DE ALOJ.TEMPORÁRIO & 109.258 & 11,20 & 713.620 & 73,16 & 152.576 & 15,64 & 975.454 & 100,00 \\
\hline REST. E OUT. ESTAB. DE SERV. DE ALIMENTAÇÃO & 383.992 & 11,35 & 2.411 .477 & 71,29 & 587.203 & 17,36 & 3.382 .671 & 100,00 \\
\hline ATIVIDADES RECREATIVAS, CULTURAIS E DESPORTIVAS & 47.540 & 7,94 & 493.004 & 82,36 & 58.049 & 9,70 & 598.593 & 100,00 \\
\hline ALUGUEL DE AUT. E OUTROS MEIOS DE TRANSPORTE & 4.141 & 14,38 & 15.352 & 53,33 & 9.295 & 32,29 & 28.789 & 100,00 \\
\hline SEGMENTO DO TURISMO & 761.735 & 10,71 & 5.010 .129 & 70,43 & 1.342 .065 & 18,87 & 7.113 .929 & 100,00 \\
\hline
\end{tabular}

Fonte: dados estimados pelo autor. 
Tabela 24. Participação setorial no pessoal ocupado dos agregados (Insumos, Turismo e Serviços), no pessoal ocupado total do segmento do turismo e no pessoal ocupado do Brasil, Brasil, 1999.

\begin{tabular}{lccccc}
\hline \multicolumn{1}{c}{ Setores } & $\begin{array}{c}\text { Insumos } \\
(\%)\end{array}$ & $\begin{array}{c}\text { Turismo } \\
(\%)\end{array}$ & $\begin{array}{c}\text { Serviços } \\
(\%)\end{array}$ & $\begin{array}{c}\text { Total } \\
(\%)\end{array}$ & $\begin{array}{c}\text { Participação no } \\
\text { Pessoal Ocupado } \\
\text { do Brasil }(\%)\end{array}$ \\
\hline TRANSP. RODOV. DE PASSAGEIROS, REGULAR & 10,79 & 20,08 & 18,65 & 18,82 & 2,29 \\
TRANSP. RODOV. DE PASSAGEIROS, NÃO-REGULAR & 0,79 & 1,05 & 1,36 & 1,08 & 0,13 \\
TRANSP. REG. PARA EXPL. DE PTOS. TURISTICOS & 0,01 & 0,01 & 0,02 & 0,01 & 0,00 \\
TRANSPORTE AÉREO, REGULAR & 11,55 & 1,45 & 16,21 & 5,31 & 0,65 \\
TRANSPORTE AÉREO, NÃO-REGULAR & 0,65 & 0,19 & 0,91 & 0,37 & 0,05 \\
AGÊNCIAS DE VIAGENS E ORG. DE VIAGENS & 2,86 & 1,89 & 1,27 & 1,88 & 0,23 \\
ATIV. AUXILIARES AOS TRANSPORTES TERRESTRE & 0,87 & 0,89 & 0,80 & 0,87 & 0,11 \\
ATIVIDADES AUX. AOS TRANSPORTES AÉREOS & 0,95 & 1,92 & 0,65 & 1,58 & 0,19 \\
ESTAB. HOTEL. E OUT. TIPOS DE ALOJ.TEMPORÁRIO & 14,34 & 14,24 & 11,37 & 13,71 & 1,67 \\
REST. E OUT. ESTAB. DE SERV. DE ALIMENTAÇÃO & 50,41 & 48,13 & 43,75 & 47,55 & 5,79 \\
ATIV. RECREATIVAS, CULTURAIS E DESPORTIVAS & 6,24 & 9,84 & 4,33 & 8,41 & 1,03 \\
ALUGUEL DE AUT. E OUTR. MEIOS DE TRANSPORTE & 0,54 & 0,31 & 0,69 & 0,40 & 0,05 \\
& & & & 100 & 100 \\
SEGMENTO DO TURISMO & 100 & 100 & 100 & 100 & $\mathbf{1 2 , 1 9}$ \\
\hline
\end{tabular}

Fonte: dados estimados pelo autor.

Ainda de acordo com a Tabela 24, o pessoal ocupado no segmento do turismo, considerando a sua cadeia produtiva, representa $12,19 \%$ do pessoal ocupado no Brasil. Na composição desta participação tem-se que as maiores contribuições foram provenientes dos complexos Restaurantes e outros estabelecimentos de serviços de alimentação $(5,79 \%)$, Transporte rodoviário de passageiros, regular $(2,29 \%)$, Estabelecimentos hoteleiros e outros tipos de alojamento temporário $(1,67 \%)$ e Atividades recreativas, culturais e desportivas (1,03\%).

Conforme os resultados apresentados até o presente, na tentativa de dimensionar o segmento do turismo no Brasil, pode-se perceber que proporciona uma contribuição considerável para a economia brasileira, apesar de ser um segmento o qual só recentemente passou a receber um tratamento adequado tanto dos órgãos públicos como do empresariado.

Com relação aos resultados encontrados no presente trabalho, merecem ser feitas algumas considerações. Esses resultados referem-se a uma análise agregada, ou seja, em nível nacional. Devido a extensão territorial do Brasil, no entanto, as macro-regiões apresentam características ambientais, econômicas, culturais e sociais 
macro-regiões apresentam características ambientais, econômicas, culturais e sociais bastante diferenciadas. Isso faz com que, provavelmente, o segmento do turismo venha desenvolvendo também de forma diferente em cada região. Nos últimos anos a região Nordeste é a que vem recebendo maior incentivo para o desenvolvimento do turismo. Assim, acredita-se que a importância desse segmento, tanto em relação à geração de emprego, como à de renda, seja diferente em termos regonais, apresentando melhores desempenhos nas regiões onde o segmento se encontra mais estruturado ou recebendo uma maior quantidade de incentivos para sua estruturação. Dessa forma, é provável que o segmento do turismo apresente participações bastante diferenciadas, tanto no valor adicionado como no pessoal ocupado, em cada uma das regiões brasileiras.

No capítulo a seguir é apresentada uma aplicação do uso dos modelos de insumo-produto na análise de políticas públicas. Procurou-se quantificar os impactos na economia brasileira, levando-se em consideração, inicialmente, os investimentos previstos no Plano Plurianual 2000-2003 para cada uma das regiões do país, bem como os previstos para serem feitos em nível nacional (não especificada a região). É importante ressaltar que no presente trabalho foram considerados apenas os investimentos direcionados aos projetos do segmento do turismo. 


\section{UMA APLICAÇÃO DO MODELO DE INSUMO-PRODUTO NA ANÁLISE DE POLÍTICAS ECONÔMICAS}

Este capítulo tem por finalidade mostrar como o modelo de insumo-produto, construído no presente trabalho e apresentado anteriormente, poderá servir como instrumental de análise, de modo a auxiliar no planejamento e implantação de políticas econômicas, especialmente para o segmento do turismo.

Pretende-se inicialmente fazer um breve resumo do Plano Plurianual, elaborado pelo do Governo Federal para o período de 2000 a 2003 . Em seguida é feita a apresentação dos programas e projetos de turismo contemplados no Plano Plurianual (PPA 2000-2003) e seus respectivos valores a serem investidos, bem como a apresentação e análise dos impactos que poderão ser gerados na economia, caso os investimentos sejam de fato realizados.

\subsection{Os programas e projetos de turismo no Plano Plurianual $2000-2003$}

O Plano Plurianual - 2000/2003 foi instituído pela Lei $n^{\circ} 9.989$, de 21 de julho de 2000 , em cumprimento à Constituição Federal de $1988^{1}$. O referido plano terá como principal meta construir um novo modelo de desenvolvimento voltado para o atendimento das necessidades básicas do cidadão e a melhor distribuição dos frutos do crescimento econômico entre os brasileiros (Brasil, 2002c).

A fim de atingir a meta, o governo federal elaborou um conjunto de diretrizes estratégicas destinadas a consolidar a estabilidade econômica com crescimento sustentado, promover o desenvolvimento sustentável voltado para a geração de

\footnotetext{
${ }^{1}$ De acordo com a Constituição de 1988, o Presidente da República deve encaminhar ao Congresso até o dia 31 de agosto suas metas de governo para quatro anos.
} 
empregos e oportunidades de renda, combater a pobreza e promover a cidadania e a inclusão social e consolidar a democracia e a defesa dos direitos humanos. Quando o Plano Plurianual tramitava pelo Congresso Nacional, mais duas diretrizes foram incorporadas ao mesmo, quais sejam: reduzir as desigualdades inter-regionais e promover os direitos de minorias vítimas de preconceito e discriminação (Brasil, 2002c).

Com base nessas diretrizes, foi possível definir vinte oito macroobjetivos a serem alcançados na execução do Plano Plurianual 2000/2003, a saber: - criar um ambiente macroeconômico favorável ao crescimento sustentável; - sanear as finanças públicas; - elevar o nível educacional da população e ampliar a capacitação profissional; - atingir US\$ 100 bilhões de exportação até 2002; - aumentar a competitividade do agronegócio; - desenvolver a indústria do turismo; - desenvolver a indústria cultural; - promover a modernização da infra-estrutura e a melhoria dos serviços de telecomunicações, energia e transportes; promover a reestruturação produtiva com vistas a estimular a competição no mercado interno; - ampliar o acesso aos postos de trabalho e melhorar a qualidade do emprego; - melhorar a gestão ambiental; - ampliar a capacidade de inovação; - fortalecer a participação do país nas relações econômicas internacionais; - ofertar escola de qualidade para todos; assegurar o acesso e a humanização do atendimento na saúde; - combater a fome; reduzir a mortalidade infantil; - erradicar o trabalho infantil degradante e proteger o trabalhador adolescente; - assegurar os serviços de proteção à população mais vulnerável à exclusão social; promover o Desenvolvimento Integrado do Campo; melhorar a qualidade de vida nas aglomerações urbanas e regiões metropolitanas; ampliar a oferta de habitações e estimular a melhoria das moradias existentes; ampliar os serviços de saneamento básico e de saneamento ambiental das cidades; melhorar a qualidade do transporte e do trânsito urbanos; - promover a cultura para fortalecer a cidadania; - promover a garantia dos direitos humanos; - garantir a defesa nacional como fator de consolidação da democracia e do desenvolvimento; - mobilizar governo e sociedade para a redução da violência.

O Plano Plurianual identifica três tipos de programas cujas ações estão diretamente associadas à concretização do macroobjetivo "Desenvolver a indústria do turismo": um, de caráter mais abrangente que abriga praticamente todas as ações da 
Embratur não-vinculadas ao programa Municipalização do turismo e aos programas regionais. Esse primeiro tipo é composto dos seguintes programas: Turismo: a indústria do novo milênio e Divulgação do Brasil no exterior. Outro, voltado à gestão local do turismo, destinado a capacitação de prefeituras e sociedade na gestão de suas políticas de turismo, que engloba o programa Municipalização do Turismo. E o terceiro tipo engloba um conjunto de programas regionais concebidos em função da captação de recursos externos e que privilegiam a implementação de infra-estrutura urbana e de acesso em áreas com potencial turístico. Compõem esse conjunto os seguintes programas: Desenvolvimento do turismo no Nordeste, Desenvolvimento da infraestrutura turística no Nordeste, Turismo no Nordeste, Turismo no Sudeste, Turismo no Sul, Turismo Verde e Turismo no coração do Brasil (Brasil, 2002d).

Analisando os programas que compõem o Plano Plurianual 2000-2003, podese perceber que alguns mesmo não sendo contemplados dentro do macroobjetivo "Desenvolver a indústria do turismo", foram incorporados por outros. Este é o caso do programas Turismo cultural e Monumenta: preservação do patrimônio histórico, que foram incorporados pelo macroobjetivo "Desenvolver a Indústria Cultural”. Há também o caso de um programa, Qualificação profissional do trabalhador que foi contemplado pelo macroobjetivo "Ampliar o acesso aos postos de trabalho e melhorar a qualidade do emprego", que dentre os seus projetos existe um que trata da Qualificação de agentes de turismo nos municípios.

No Quadro 9 são apresentados os projetos do Plano Plurianual 200-2003 vinculados ao segmento do turismo, bem como os investimentos previstos de serem realizados em cada um deles. Esses investimentos foram distribuídos, entre as cinco regiões do país, nos setores econômicos do modelo de insumo-produto para economia turística, que é parte integrante deste trabalho (Tabela 25).

Após essa distribuição, procedeu-se um choque de investimento na economia, o que foi denominado de choques da fase I. Em seguida, acredita-se que estes investimentos realizados irão produzir um aumento no consumo dos turistas, utilizado para gerar um novo choque na economia, aqui denominado de fase II. 


\begin{tabular}{|c|c|c|}
\hline \multirow{2}{*}{ Programa } & & Valores em $\mathrm{R} \$ 1,00$ \\
\hline & Projeto & Investimento \\
\hline \multirow{24}{*}{$\begin{array}{c}\text { Turismo: a indústria } \\
\text { do novo milênio }\end{array}$} & Ações de infra-estrutura turística & 500.000 \\
\hline & Avaliação da qualidade dos serviços turísticos mediante a capacitação, habilitação e divulgação dos seus resultados & 5.024 .322 \\
\hline & Campanha para promoção do turismo interno & 34.800 .505 \\
\hline & Capacitação de recursos humanos & 4.994 .456 \\
\hline & Captação de investimentos para implantação de infra-estrutura turística - Bolsa de negócios & 1.141 .615 \\
\hline & Construção de centro de convenções e feira de exposições & 62.345 .000 \\
\hline & Desenvolvimento da infra-estrutura turística & 20.000 .000 \\
\hline & Edição de anuário estatístico sobre o turismo & 1.709 .178 \\
\hline & Edição e distribuição de calendário para a prática do turismo incentivado para melhor idade com preços reduzidos & 1.447 .757 \\
\hline & Estruturação do segmento de ecoturismo & 2.630 .191 \\
\hline & Estruturação do segmento de pesca amadora & 2.574 .361 \\
\hline & Financiamento da infra-estrutura turística & 42.222 .371 \\
\hline & Fomento à formação de clubes da melhor idade & 3.066.178 \\
\hline & Fiscalização dos serviços turísticos & 4.213 .980 \\
\hline & Formação da imagem turística do país no exterior & 36.446 .460 \\
\hline & Implantação de centros de informações turísticas & 3.936 .004 \\
\hline & Implantação de centros de informações e estudos vitrine do Brasil & 10.121 .087 \\
\hline & Participação de eventos internacionais & 31.011 .454 \\
\hline & Promoção de eventos para divulgação do turismo interno & 8.962 .816 \\
\hline & Promoção de eventos para divulgação externa e interna do Brasil & 20.000 .000 \\
\hline & Promoção de eventos turísticos voltados para melhor idade & 1.497 .970 \\
\hline & Promoção e captação de eventos internacionais & 793.923 \\
\hline & Sinalização turística & 6.070 .092 \\
\hline & Sistema de informações sobre o fluxo turístico emissivo e receptivo nacional e internacional & 1.314 .466 \\
\hline SUB-TOTAL & & 306.824 .186 \\
\hline
\end{tabular}

Quadro 9 - Investimento previsto por programas e projetos do segmento do turismo contemplado no Plano Plurianual $2000-2003$. 


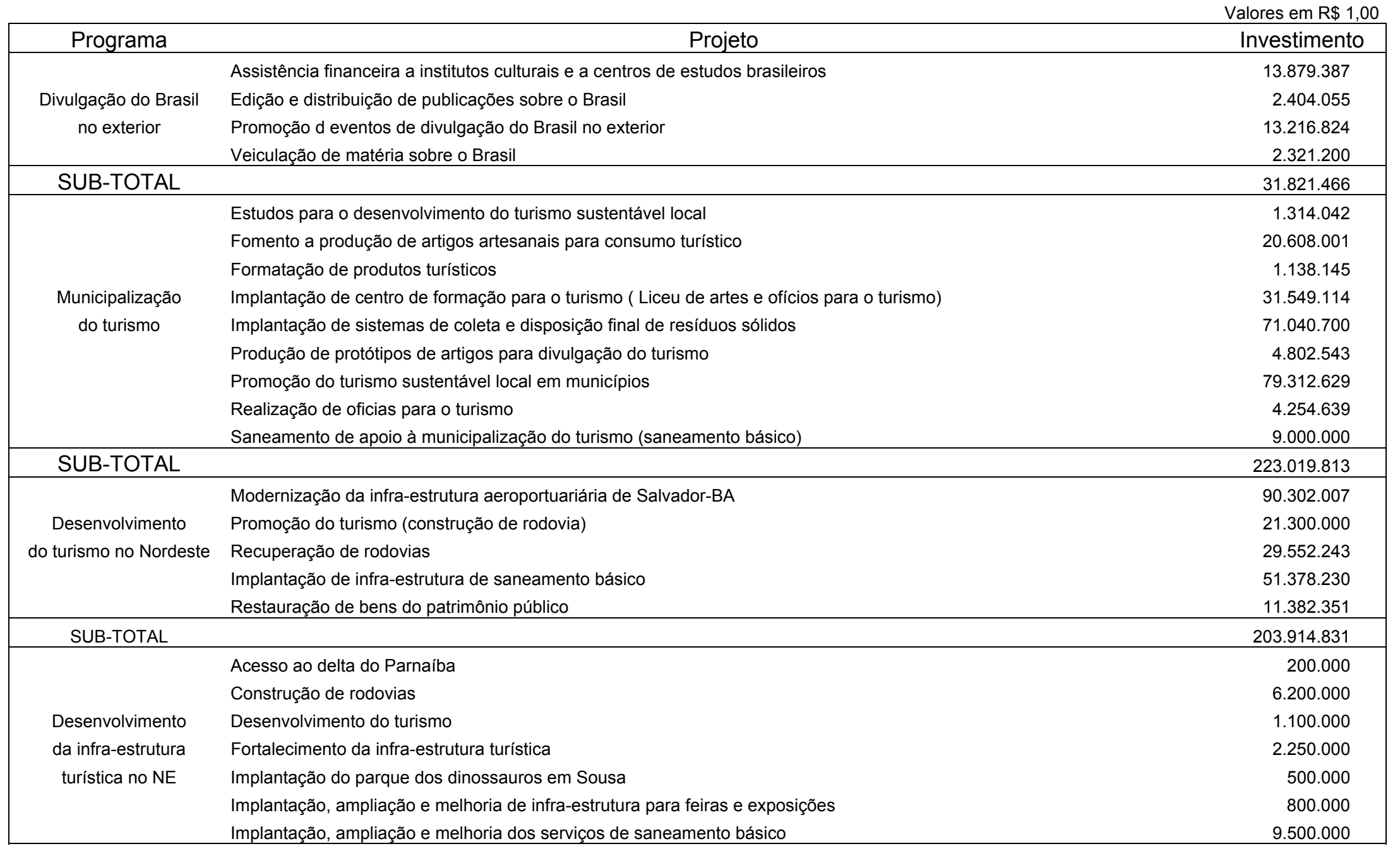

Quadro 9 - Investimento previsto por programas e projetos do segmento do turismo contemplado no Plano Plurianual $2000-2003$. 


\begin{tabular}{|c|c|c|}
\hline \multirow[b]{2}{*}{ Programa } & & Valores em $\mathrm{R} \$ 1,00$ \\
\hline & Projeto & Investimento \\
\hline & Implantação, ampliação e melhoria de infra-estrutura urbana & 45.200 .000 \\
\hline Desenvolvimento & Melhoria do acesso a praias & 10.000 .000 \\
\hline da infra-estrutura & Modernização da infra-estrutura aeroportuária & 10.000 .000 \\
\hline \multirow[t]{3}{*}{ turística no NE } & Recuperação de rodovias & 6.400 .000 \\
\hline & Recuperação de rodovias em municípios com potencial ecoturistico & 100.000 \\
\hline & Restauração de patrimônios históricos & 50.000 \\
\hline \multirow[t]{4}{*}{ SUB-TOTAL } & & 92.300 .000 \\
\hline & Capacitação de agentes nos pólos turísticos & 510.000 \\
\hline & Campanha publicitária para promoção do turismo na região & 40.160 .000 \\
\hline & Capacitação de recursos humanos & 33.340 .000 \\
\hline \multirow[t]{4}{*}{ Turismo no Nordeste } & Desenvolvimento da infra-estrutura turística & 54.400 .000 \\
\hline & Estudos de oportunidades de investimentos e novos segmentos turísticos para região & 3.350 .500 \\
\hline & Elaboração de roteiros turísticos para região & 18.115.500 \\
\hline & Sinalização turística & 36.185 .000 \\
\hline \multirow[t]{5}{*}{ SUB-TOTAL } & & 186.061.000 \\
\hline & Campanha publicitária para promoção do turismo na região centro-oeste & 12.100 .000 \\
\hline & Capacitação de recursos humanos & 10.200 .000 \\
\hline & Construção de terminais turísticos & 500.000 \\
\hline & Desenvolvimento da infra-estrutura turística & 14.323 .000 \\
\hline \multirow{3}{*}{$\begin{array}{l}\text { Turismo no coração } \\
\text { do Brasil }\end{array}$} & Estudos de oportunidades de investimentos e novos segmentos turísticos para região Centro-Oeste & 1.860 .901 \\
\hline & Elaboração de roteiros turísticos para região & 2.461 .190 \\
\hline & Sinalização turística & 8.780 .200 \\
\hline \multirow[t]{3}{*}{ SUB-TOTAL } & & 50.225 .291 \\
\hline & Assistência técnica e financeira em ecoturismo na Amazônia - POECOTUR & 29.418 .494 \\
\hline & Capacitação de recursos humanos & 8.842 .844 \\
\hline \multirow[t]{3}{*}{ Turismo Verde } & Desenvolvimento da infra-estrutura turística & 19.000 .000 \\
\hline & Estudos de oportunidades de investimentos e novos segmentos turísticos para região & 1.557 .801 \\
\hline & Estudos de viabilidade técnica, econômica e ambiental do ecoturismo na Amazônia & 16.239 .696 \\
\hline
\end{tabular}

Quadro 9 - Investimento previsto por programas e projetos do segmento do turismo contemplado no Plano Plurianual 2000-2003. 


\begin{tabular}{|c|c|c|}
\hline & & Valores em $\mathrm{R} \$ 1,00$ \\
\hline Programa & Projeto & Investimento \\
\hline & Fomento a realização de estudos sobre a viabilidade e os procedimentos para implantação de pólos de ecoturismo & 2.953 .088 \\
\hline & Implantação de infra-estrutura nos pólos ecoturísticos & 5.145 .000 \\
\hline Turismo verde & Implantação de infra-estrutura nos pólos ecoturísticos na Amazônia & 35.844 .398 \\
\hline & Sinalização turística & 1.524 .401 \\
\hline & Roteiros turísticos para Amazônia & 1.321 .801 \\
\hline & Financiamento de projetos de desenvolvimento do ecoturismo na Amazônia & 190.000 .000 \\
\hline SUB-TOTAL & & 311.847 .523 \\
\hline & Campanha publicitária para promoção do turismo na região & 43.370 .000 \\
\hline & Capacitação de recursos humanos & 31.870 .000 \\
\hline & Desenvolvimento da infra-estrutura turística & 42.976 .500 \\
\hline Turismo no sul & Estudos de oportunidades de investimentos e novos segmentos turísticos para região & 3.380 .000 \\
\hline & Elaboração de roteiros turísticos para região & 18.230 .000 \\
\hline & Sinalização turística & 34.150 .000 \\
\hline & Desenvolvimento de pólos de turismo & 500.000 \\
\hline SUB-TOTAL & & 174.476 .500 \\
\hline & Campanha publicitária para promoção do turismo na região & 41.250 .000 \\
\hline & Capacitação de recursos humanos & 35.630 .000 \\
\hline Turismo no sudeste & Desenvolvimento da infra-estrutura turística & 17.870 .000 \\
\hline & Estudos de oportunidades de investimentos e novos segmentos turísticos para região & 3.090 .000 \\
\hline & Elaboração de roteiros turísticos para região & 16.870 .000 \\
\hline & Sinalização turística & 33.160 .000 \\
\hline SUB-TOTAL & & 147.870 .000 \\
\hline & Revitalização do patrimônio cultural urbano de áreas & 5.013 .970 \\
\hline & Promoção de eventos culturais em áreas de interesse turístico & 2.118 .400 \\
\hline & Restauração de centros históricos em áreas de interesse turístico-cultural & 2.372 .414 \\
\hline Turismo cultural & Apoio a projetos artísticos e cultural em áreas de interesse turístico & 4.589 .003 \\
\hline & Preservação de bens do patrimônio histórico, artístico e arqueológico em áreas de interesse turístico & 12.802 .031 \\
\hline & Implantação de sinalização em sítios históricos e arqueológicos & 2.130 .300 \\
\hline
\end{tabular}

Quadro 9 - Investimento previsto por programas e projetos do segmento do turismo contemplado no Plano Plurianual $2000-2003$. 


\begin{tabular}{|c|c|c|}
\hline \multirow{3}{*}{ Programa } & & Valores em $\mathrm{R} \$ 1,0$ \\
\hline & Projeto & Investimento \\
\hline & Campanha publicitária para a difusão do turismo cultural & 3.028 .706 \\
\hline \multirow{8}{*}{ Turismo cultural } & Restauração de patrimônio histórico & 3.800 .000 \\
\hline & Capacitação de instrutores e guias culturais em áreas de interesse turístico & 143.130 \\
\hline & Capacitação de recursos humanos para área de turismo cultural & 3.000 .000 \\
\hline & Edição e distribuição de material promocional sobre turismo cultural & 1.500 .000 \\
\hline & Estudos de viabilidade para cessão de próprios da união para exploração turística & 1.097 .040 \\
\hline & Identificação de pólos de turismo cultural & 3.000 .000 \\
\hline & Pesquisa de sítios arqueológicos & 500.000 \\
\hline & Recuperação e revitalização de cidades, próprios e monumentos da união & 3.836 .004 \\
\hline SUB-TOTAL & & 48.930 .998 \\
\hline \multirow{2}{*}{$\begin{array}{c}\text { Monumenta: preservação } \\
\text { do patrimônio histórico }\end{array}$} & $\begin{array}{l}\text { Preservação de bens do patrimônio histórico, artístico e arqueológico em áreas de interesse histórico-cultural } \\
\text { manumenta/BNDES }\end{array}$ & 312.207 \\
\hline & Preservação do patrimônio histórico urbano monumenta & 106.200 .000 \\
\hline SUB-TOTAL & & 106.512 .207 \\
\hline \multicolumn{2}{|c|}{ Qualificação } & \\
\hline \multicolumn{2}{|c|}{ profissional do trabalhador Qualificação de agentes de turismo nos municípios } & 100.404 .845 \\
\hline SUB-TOTAL & & 100.404 .845 \\
\hline TOTAL & & 1.984 .208 .660 \\
\hline
\end{tabular}

Quadro 9 - Investimento previsto por programas e projetos do segmento do turismo contemplado no Plano Plurianual $2000-2003$.

Fonte: Brasil $\left(2002^{\mathrm{a}} \mathrm{c}\right)$ 
Tabela 25. Investimentos previstos para o segmento do turismo no Plano Plurianual 2000-2003.

\begin{tabular}{|c|c|c|c|c|c|c|c|}
\hline \multirow[b]{2}{*}{ Setores } & \multicolumn{6}{|c|}{ Região } & \multirow[b]{2}{*}{ Brasil } \\
\hline & Norte & Nordeste & Sudeste & Centro-Oeste & Sul & $\begin{array}{c}\text { Não } \\
\text { especificada }\end{array}$ & \\
\hline & \multicolumn{7}{|c|}{ Valores em $\mathrm{R} \$ 1,00$} \\
\hline ATIV. RECR., CULTURAIS E DESPORTIVAS & 0 & & 0 & 0 & 0 & 114.717 .580 & 114.717 .580 \\
\hline CONSTRUÇÃO CIVIL & 73.026 .018 & 447.185 .163 & 71.131 .891 & 31.437 .191 & 94.869 .494 & 96.127 .197 & 813.776 .954 \\
\hline IND. EDITORIAL E GRÁFICA & 0 & 0 & 0 & 0 & 0 & 7.060 .990 & 7.060 .990 \\
\hline SERVIÇOS PRESTADOS ÀS EMPRESAS & 262.742 .666 & 79.591 .000 & 80.715 .000 & 21.448 .671 & 73.340 .000 & 280.369 .884 & 798.207 .221 \\
\hline SERVIÇOS PRESTADOS ÀS FAMÍLIAS & 14.201 .294 & 64.198 .000 & 59.222 .900 & 26.608 .050 & 41.662 .600 & 44.553 .071 & 250.445 .915 \\
\hline \multirow[t]{3}{*}{ TOTAL } & 349.969 .978 & 590.974 .163 & 211.069 .791 & 79.493 .912 & 209.872 .094 & 542.828 .722 & 1.984 .208 .660 \\
\hline & \multicolumn{7}{|c|}{ Participação (\%) } \\
\hline & 17,65 & 29,80 & 10,64 & 4,01 & 10,58 & 27,36 & 100 \\
\hline ATIV. RECR., CULTURAIS E DESPORTIVAS & 0,00 & 0,00 & 0,00 & 0,00 & 0,00 & 21,13 & 5,78 \\
\hline CONSTRUÇÃO CIVIL & 20,87 & 75,67 & 33,70 & 39,55 & 45,20 & 17,71 & 40,98 \\
\hline SERVIÇOS PRESTADOS ÀS EMPRESAS & 75,08 & 13,47 & 38,24 & 26,98 & 34,95 & 51,65 & 40,25 \\
\hline SERVIÇOS PRESTADOS ÀS FAMÍLIAS & 4,06 & 10,86 & 28,06 & 33,47 & 19,85 & 8,21 & 12,63 \\
\hline TOTAL & 100 & 100 & 100 & 100 & 100 & 100 & 100 \\
\hline
\end{tabular}

Fonte: elaborada pelo autor a partir de informações de Brasil (2002c). 
Na seção seguinte são apresentadas algumas considerações metodológicas a respeito da execução dos choques (investimento e consumo dos turistas), bem como os efeitos causados por eles na economia brasileira.

\subsection{Os impactos que poderão ser gerados na economia brasileira}

Conforme já mostrado anteriormente, nesta primeira fase serão analisados os resultados da economia, dado que foram investidos no total $\mathrm{R} \$ 1.984 .208 .660,00$ nas cinco regiões do país e distribuídos nos seguintes setores: Construção civil, Indústria editorial e gráfica, Atividades recreativas, culturais e desportivas, Serviços prestados às famílias e Serviços prestados às empresas (Tabela 25). Ainda de acordo com essa tabela, pode-se perceber que a região Nordeste é a região com a maior participação nos investimentos a serem feitos $(29,8 \%$ do total). A região Centro-Oeste será contemplada com a menor parcela dos investimentos do Plano Plurianual (4\%), apesar de apresentar um grande potencial para o turismo, tendo em vista que nesta região estão localizados os cerrados, com sua flora e fauna bastante rica, e o pantanal matogrossense, área de inestimável beleza.

Com relação à distribuição dos investimentos entre os setores, pode-se perceber que a maior parcela dos investimentos destina-se aos setores Construção civil, Serviços prestados às empresas e Serviços prestados às famílias, conforme se pode observar na Tabela 25. Pelos setores contemplados pode-se dizer que nessa primeira fase trata-se apenas de projetos para implantação da infra-estrutura básica para o turismo e qualificação dos agentes envolvidos no referido segmento. A realização desses investimentos irá criar condições, para que aumente o número de brasileiros fazendo turismo interno, assim como de turistas estrangeiros no Brasil, conseqüentemente aumentará o consumo turístico, ocasionando na economia novos impactos os quais serão analisados posteriormente.

Para avaliar o impacto que os projetos vinculados ao turismo do Plano Plurianual 200-2003 poderiam causar na economia brasileira, foram escolhidas as seguintes variáveis, tanto na fase I como na fase II da análise: insumos utilizados no 
processo produtivo, produção, emprego, impostos indiretos líquidos, renda das famílias e valor adicionado.

Para realização dessa análise, partiu-se da seguinte equação, que foi definida anteriormente no capítulo III deste trabalho:

$$
\boldsymbol{X}=\boldsymbol{B} \boldsymbol{Y}
$$

A partir da eq. 76, é possível avaliar o impacto do investimento inicial realizado (na primeira fase da análise) e do aumento do consumo turístico (na segunda fase da análise) sobre o volume de produção, os insumos, o emprego, o volume de impostos indiretos líquidos, a renda das famílias e o valor adicionado numa dada economia. Os referidos impactos podem ser expressos da seguinte maneira:

$$
\begin{gathered}
\Delta \boldsymbol{X}=\boldsymbol{B} \Delta \boldsymbol{Y} \\
\Delta \boldsymbol{I N S}=\boldsymbol{B}(\Delta \hat{X}) \\
\Delta E M P=\varepsilon \Delta \boldsymbol{X} \\
\Delta \boldsymbol{I I L}=\boldsymbol{i} \Delta \boldsymbol{X} \\
\Delta R E N=r \Delta \boldsymbol{X} \\
\Delta V A=\boldsymbol{p} \Delta \boldsymbol{X}
\end{gathered}
$$

em que:

$\Delta \boldsymbol{Y}$ representa o investimento inicial realizado (ou o aumento no consumo turístico, na segunda fase da análise);

$\Delta \boldsymbol{X}$ é um vetor que representa o impacto sobre o volume de produção;

$\triangle \boldsymbol{I N S}$ é um vetor que representa o impacto sobre os insumos utilizados no processo produtivo;

$\triangle \boldsymbol{E M P}$ é um vetor que representa o impacto sobre o emprego;

$\Delta \boldsymbol{I I L}$ é um vetor que representa o impacto sobre o volume de impostos indiretos líquidos;

$\triangle \boldsymbol{R} \boldsymbol{E} \boldsymbol{N}$ é um vetor que representa o impacto sobre a renda das famílias;

$\Delta \boldsymbol{V} \boldsymbol{A}$ é um vetor que representa o impacto sobre o valor adicionado; e, 
$\varepsilon, \boldsymbol{i}, \boldsymbol{r}$ e $\boldsymbol{p}$ são vetores ( $n \times 1)$ em que os elementos são os coeficientes de emprego, de impostos indiretos líquidos, da renda das famílias e do valor adicionado, respectivamente.

A seguir serão apresentados os impactos gerados na economia brasileira, caso ocorram os investimentos previstos no Plano Plurianual 2000-2003. Inicialmente mostram-se os impactos gerados na fase I dos investimentos e, em seguida, os gerados na segunda fase.

\section{- $\quad$ Fase I}

Considerou-se como fase I da avaliação os investimentos iniciais a serem realizados nos setores e nas regiões brasileiras, conforme descritos anteriormente. Os resultados dos impactos gerados na economia brasileira, devido aos investimentos realizados em cada uma das regiões do Brasil, encontram-se apresentados nas Tabelas 26, 27, 28, 29 e 30.

A Tabela 26 mostra os valores das variações ocorridas no fornecimento de insumos diretos utilizados no processo produtivo dos setores que receberam os investimentos, bem como a variação percentual ocorrida. Os resultados mostram que os macro-setores que apresentaram a menor variação no fornecimento de insumos diretos para os setores que receberam o aumento nos investimentos são em ordem crescente: Agropecuária, Serviços industriais de utilidade pública e Serviços turísticos. Esse resultado encontra-se dentro do esperado, uma vez que estes macro-setores não são tipicamente fornecedores de insumos diretamente para os setores que receberam o choque. Já os macro-setores Construção civil, Extrativa mineral e Serviços nãoturísticos apresentaram uma maior variação no fornecimento de insumos diretos para os setores que receberam o choque inicial. 
Tabela 26. Variação dos insumos diretos utilizados no processo produtivo, devido à implantação dos projetos de turismo contemplado no Plano Plurianual 2000-2003, por região de ocorrência do investimento.

\begin{tabular}{|c|c|c|c|c|c|c|c|}
\hline Macro-setores & Norte & Nordeste & Sudeste & $\begin{array}{l}\text { Centro- } \\
\text { Oeste }\end{array}$ & Sul & $\begin{array}{l}\text { Região não } \\
\text { especificada }\end{array}$ & Brasil \\
\hline & \multicolumn{7}{|c|}{ Valores em $\mathrm{R} \$ 1,00$} \\
\hline AGROPECUÁRIA & 92.695 & 364.807 & 360.088 & 103.747 & 323.958 & 1.624 .497 & 2.869 .792 \\
\hline EXTRATIVA MINERAL & 6.425 .015 & 38.847 .393 & 6.327 .205 & 2.768 .755 & 8.362 .380 & 8.940 .299 & 71.671 .049 \\
\hline IND. DE TRANSFORMAÇÃO & 39.638 .702 & 85.284 .830 & 25.504 .398 & 8.906 .822 & 27.929 .117 & 70.283 .908 & 257.547 .776 \\
\hline S.I.U.P. & 2.055 .639 & 1.423 .017 & 1.025 .378 & 294.149 & 960.587 & 3.768 .656 & 9.527 .428 \\
\hline CONSTRUÇÃO CIVIL & 3.531 .122 & 17.085 .883 & 3.020 .937 & 1.274 .434 & 3.874 .836 & 4.894 .497 & 33.681 .708 \\
\hline COMÉRCIO & 7.696 .697 & 16.063 .788 & 4.979 .055 & 1.721 .416 & 5.404 .365 & 13.961 .242 & 49.826 .563 \\
\hline SERVIÇOS TURÍSTICOS & 2.875 .998 & 2.756 .687 & 1.184 .510 & 369.824 & 1.202 .521 & 4.066 .552 & 12.456 .092 \\
\hline \multirow[t]{2}{*}{ SERV. NÃO-TURÍSTICOS } & 30.949 .664 & 22.724 .241 & 12.550 .146 & 3.718 .990 & 12.212 .651 & 42.245 .958 & 124.401 .649 \\
\hline & \multicolumn{7}{|c|}{ Variação (\%) } \\
\hline AGROPECUÁRIA & 0,0001 & 0,0005 & 0,0005 & 0,0001 & 0,0004 & 0,0021 & 0,0037 \\
\hline EXTRATIVA MINERAL & 0,0174 & 0,1055 & 0,0172 & 0,0075 & 0,0227 & 0,0243 & 0,1946 \\
\hline IND. DE TRANSFORMAÇÃO & 0,0128 & 0,0276 & 0,0083 & 0,0029 & 0,0090 & 0,0228 & 0,0834 \\
\hline S.I.U.P. & 0,0067 & 0,0047 & 0,0034 & 0,0010 & 0,0031 & 0,0123 & 0,0312 \\
\hline CONSTRUÇÃO CIVIL & 0,0265 & 0,1285 & 0,0227 & 0,0096 & 0,0291 & 0,0368 & 0,2532 \\
\hline COMÉRCIO & 0,0143 & 0,0299 & 0,0093 & 0,0032 & 0,0100 & 0,0260 & 0,0926 \\
\hline SERVIÇOS TURÍSTICOS & 0,0126 & 0,0121 & 0,0052 & 0,0016 & 0,0053 & 0,0178 & 0,0544 \\
\hline SERV. NÃO-TURÍSTICOS & 0,0258 & 0,0190 & 0,0105 & 0,0031 & 0,0102 & 0,0352 & 0,1038 \\
\hline
\end{tabular}

Fonte: dados estimados pelo autor.

Os resultados da variação ocorrida na utilização dos insumos na forma indireta, devido à implantação dos projetos turísticos contemplados pelo Plano Plurianual 2000-2003, são mostrados na Tabela 27. Nesse caso, pode-se perceber que o impacto, em termos de acréscimos relativos ao montante de insumos utilizados no processo produtivo, foi nos macro-setores Extrativa mineral $(0,113 \%)$, Indústria de transformação $(0,083 \%)$ e Serviços industriais de utilidade pública $(0,082 \%)$, enquanto os menores acréscimos ocorreram nos macro-setores Agropecuária $(0,025 \%)$ e Construção civil $(0,033 \%)$. 
Tabela 27. Variação dos insumos indiretos utilizados no processo produtivo, devido à implantação dos projetos de turismo contemplados no Plano Plurianual 20002003, por região de ocorrência do investimento.

\begin{tabular}{|c|c|c|c|c|c|c|c|}
\hline Macro-setores & Norte & Nordeste & Sudeste & $\begin{array}{c}\text { Centro- } \\
\text { Oeste }\end{array}$ & Sul & $\begin{array}{l}\text { Região não } \\
\text { especificada }\end{array}$ & Brasil \\
\hline & \multicolumn{7}{|c|}{ Valores em $\mathrm{R} \$ 1,00$} \\
\hline AGROPECUÁRIA & 2.721 .025 & 6.261 .531 & 2.001 .353 & 688.707 & 2.154 .944 & 5.739 .184 & 19.641 .543 \\
\hline EXTRATIVA MINERAL & 4.858 .250 & 18.865 .231 & 3.853 .731 & 1.534 .646 & 4.704 .718 & 7.817 .810 & 41.634 .385 \\
\hline IND. DE TRANSFORMAÇÃO & 37.887 .111 & 89.845 .365 & 25.015 .010 & 8.930 .324 & 27.896 .191 & 66.209 .231 & 255.783 .232 \\
\hline S.I.U.P. & 4.130 .433 & 8.218 .343 & 2.449 .464 & 853.923 & 2.685 .793 & 6.686 .639 & 25.024 .596 \\
\hline CONSTRUÇÃO CIVIL & 730.489 & 1.569 .831 & 421.607 & 151.531 & 475.053 & 1.066 .158 & 4.414 .669 \\
\hline COMÉRCIO & 5.699 .375 & 11.790 .026 & 3.498 .114 & 1.222 .544 & 3.839 .232 & 9.582 .684 & 35.631 .976 \\
\hline SERVIÇOS TURÍSTICOS & 2.238 .379 & 4.332 .632 & 1.285 .023 & 448.106 & 1.411 .002 & 3.536 .017 & 13.251.159 \\
\hline \multirow[t]{2}{*}{ SERV. NÃO-TURÍSTICOS } & 14.178 .869 & 23.448 .423 & 7.624 .438 & 2.584 .038 & 8.190 .603 & 21.680 .187 & 77.706 .558 \\
\hline & \multicolumn{7}{|c|}{ Variação (\%) } \\
\hline AGROPECUÁRIA & 0,003 & 0,008 & 0,003 & 0,001 & 0,003 & 0,007 & 0,025 \\
\hline EXTRATIVA MINERAL & 0,013 & 0,051 & 0,010 & 0,004 & 0,013 & 0,021 & 0,113 \\
\hline IND. DE TRANSFORMAÇÃO & 0,012 & 0,029 & 0,008 & 0,003 & 0,009 & 0,021 & 0,083 \\
\hline S.I.U.P. & 0,014 & 0,027 & 0,008 & 0,003 & 0,009 & 0,022 & 0,082 \\
\hline CONSTRUÇÃO CIVIL & 0,005 & 0,012 & 0,003 & 0,001 & 0,004 & 0,008 & 0,033 \\
\hline COMÉRCIO & 0,011 & 0,022 & 0,007 & 0,002 & 0,007 & 0,018 & 0,066 \\
\hline SERVIÇOS TURÍSTICOS & 0,010 & 0,019 & 0,006 & 0,002 & 0,006 & 0,015 & 0,058 \\
\hline SERV. NÃO-TURÍSTICOS & 0,012 & 0,020 & 0,006 & 0,002 & 0,007 & 0,018 & 0,065 \\
\hline
\end{tabular}

Fonte: dados estimados pelo autor.

Os dados mostram, ainda, que, comparando os acréscimos ocorridos na utilização de insumos no processo produtivo, caso ocorram os investimentos previstos para o segmento do turismo no Plano Plurianual 2000-2003, os maiores impactos ocorrem de forma direta.

A Tabela 28 sumariza os resultados dos impactos ocorridos na utilização dos insumos de forma direta e indireta, uma vez que foram realizados os investimentos previstos para o segmento do turismo no Plano Plurianual 2000-2003. 
Tabela 28. Variação dos insumos totais utilizados no processo produtivo, devido à implantação dos projetos de turismo contemplado no Plano Plurianual 2000-2003, por região de ocorrência do investimento.

\begin{tabular}{|c|c|c|c|c|c|c|c|}
\hline Macro-setores & Norte & Nordeste & Sudeste & $\begin{array}{c}\text { Centro- } \\
\text { Oeste }\end{array}$ & Sul & $\begin{array}{l}\text { Região não } \\
\text { especificada }\end{array}$ & Brasil \\
\hline & \multicolumn{7}{|c|}{ Valores em $\mathrm{R} \$ 1,00$} \\
\hline AGROPECUÁRIA & 2.813 .720 & 6.626 .338 & 2.361 .441 & 792.454 & 2.478 .901 & 7.438 .480 & 22.511 .335 \\
\hline EXTRATIVA MINERAL & 11.283 .265 & 57.712 .624 & 10.180 .936 & 4.303 .401 & 13.067.099 & 16.758 .110 & 113.305 .434 \\
\hline IND. DE TRANSFORMAÇÃO & 77.525 .813 & 175.130 .195 & 50.519 .408 & 17.837 .146 & 55.825 .309 & 136.493 .139 & 513.331 .009 \\
\hline S.I.U.P. & 6.186 .073 & 9.641 .360 & 3.474 .843 & 1.148 .073 & 3.646 .380 & 10.455 .295 & 34.552 .024 \\
\hline CONSTRUÇÃO CIVIL & 4.261 .611 & 18.655 .714 & 3.442 .544 & 1.425 .965 & 4.349 .889 & 5.960 .655 & 38.096 .377 \\
\hline COMÉRCIO & 13.396 .073 & 27.853 .813 & 8.477 .169 & 2.943 .961 & 9.243 .597 & 23.543 .927 & 85.458 .539 \\
\hline SERVIÇOS TURÍSTICOS & 5.114 .377 & 7.089 .319 & 2.469 .533 & 817.930 & 2.552 .619 & 7.602 .570 & 25.707 .251 \\
\hline \multirow[t]{2}{*}{ SERV. NÃO-TURÍSTICOS } & 45.128 .533 & 46.172 .664 & 20.174 .584 & 6.303 .027 & 19.884 .218 & 63.926 .146 & 202.108.207 \\
\hline & \multicolumn{7}{|c|}{ Variação (\%) } \\
\hline AGROPECUÁRIA & 0,004 & 0,008 & 0,003 & 0,001 & 0,003 & 0,009 & 0,029 \\
\hline EXTRATIVA MINERAL & 0,031 & 0,157 & 0,028 & 0,012 & 0,035 & 0,046 & 0,308 \\
\hline IND. DE TRANSFORMAÇÃO & 0,025 & 0,057 & 0,016 & 0,006 & 0,018 & 0,044 & 0,166 \\
\hline S.I.U.P. & 0,020 & 0,032 & 0,011 & 0,004 & 0,012 & 0,034 & 0,113 \\
\hline CONSTRUÇÃO CIVIL & 0,032 & 0,140 & 0,026 & 0,011 & 0,033 & 0,045 & 0,286 \\
\hline COMÉRCIO & 0,025 & 0,052 & 0,016 & 0,005 & 0,017 & 0,044 & 0,159 \\
\hline SERVIÇOS TURÍSTICOS & 0,022 & 0,031 & 0,011 & 0,004 & 0,011 & 0,033 & 0,112 \\
\hline SERV. NÃO-TURÍSTICOS & 0,038 & 0,039 & 0,017 & 0,005 & 0,017 & 0,053 & 0,169 \\
\hline
\end{tabular}

Fonte: dados estimados pelo autor.

Conforme foi exposto anteriormente, os investimentos previstos de serem realizados no segmento do turismo serão avaliados segundo seus impactos na produção, na renda das famílias, nos impostos indiretos líquidos, no emprego e no valor adicionado. Os resultados desses impactos encontram-se apresentados nas Tabelas 29 e 30.

As variações ocorridas na utilização dos insumos, vistas anteriormente, provocam variações na produção total da economia, em termos de acréscimos relativos. Analisando as Tabelas 29 e 30 percebe-se que os investimentos previstos para os quatro anos de vigência do Plano Plurianual-2000/2003, poderão causar um aumento de $\mathrm{R} \$ 2.917 .813 .991$ na produção, o que representa um aumento de $0,174 \%$ na produção total da economia.

Comparando-se os resultados dos impactos da variação de uma unidade monetária do investimento nas regiões consideradas no presente trabalho sobre a 
Comparando-se os resultados dos impactos da variação de uma unidade monetária do investimento nas regiões consideradas no presente trabalho sobre a produção total, nota-se que os maiores valores 1,539 e 1,485 são das regiões Nordeste e Sul, respectivamente. Já os menores impactos da variação de uma unidade monetária do investimento $(1,241$ e 1,367) ocorrem quando este acontece nas regiões Centro-Oeste e Sudeste, respectivamente.

No que diz respeito à variação ocorrida no emprego, percebese um aumento de $0,185 \%$ no número de pessoas ocupadas no país, conseqüente da realização dos investimentos previstos durante os quatro anos de vigência do Plano Plurianual 20002003, ou seja, ao final da execução do referido plano terão sido gerados 108.239 novos empregos, sendo 83.509 empregos diretos e 24.730 empregos indiretos, conforme se podem observar na Tabela 29.

Vale ressaltar que esses novos empregos não podem ser considerados permanentes, pois os investimentos serão direcionados para a montagem da infraestrutura básica para o bom funcionamento do segmento do turismo nos anos seguintes. Acredita-se, portanto, que uma vez montada essa infra-estrutura esses postos de trabalho serão extintos. Terão sido criadas, no entanto, as condições necessárias para a geração de outros postos de trabalho que serão permanentes, conforme será visto mais adiante.

Quando comparados os resultados referentes à variação no número de pessoas ocupadas em relação à de uma unidade monetária de investimento (Tabela 30), percebe-se que os menores valores são encontrados nas regiões Nordeste e Centro-Oeste $(0,000045$ e 0,000046 , respectivamente), enquanto os maiores valores foram encontrados nas regiões Norte e (0,000056) e Sul (0,000056). Para investimentos realizados no Brasil, de uma maneira geral, encontrou-se o valor de 0,000055 para a relação acima referida. Cabe aqui ressaltar que, quanto maior for o valor encontrado para relação pessoas ocupadas por unidade monetária de investimento, menor será o volume de investimento necessário para gerar novos postos de trabalho. Assim sendo, pelas informações acima apresentadas, percebe-se que é necessário um maior volume de investimento para gerar um posto de trabalho nas regiões Nordeste e Centro-Oeste e um menor volume para as regiões Norte e Sul. 
Tabela 29. Impactos gerados na economia brasileira, devido à implantação dos projetos do turismo contemplados pelo Plano Plurianual 2000/2003.

\begin{tabular}{|c|c|c|c|c|c|c|c|}
\hline \multirow[t]{2}{*}{ Impactos } & \multicolumn{6}{|c|}{ REGIÕES } & \multirow[b]{2}{*}{ Brasil } \\
\hline & Norte & Nordeste & Sudeste & Centro-Oeste & Sul & $\begin{array}{c}\text { Não } \\
\text { especificada }\end{array}$ & \\
\hline \multicolumn{8}{|l|}{ DIRETOS } \\
\hline Var. do Emprego * & 15.653 & 18.767 & 9.071 & 2.807 & 8.993 & 28.218 & 83.509 \\
\hline Var. dos Imp.Ind.Líquidos ${ }^{* *}$ & 10.570 .158 & 24.174 .203 & 6.775 .565 & 2.411 .776 & 7.543 .921 & 17.636 .553 & 69.112 .175 \\
\hline Var. da renda** & 125.802 .361 & 94.787 .917 & 59.971 .377 & 17.513 .185 & 57.147 .883 & 204.166 .284 & 559.389 .006 \\
\hline Var. do Valor adicionado** & 231.761 .350 & 335.824 .679 & 120.245 .922 & 39.667 .562 & 126.426 .799 & 343.397 .595 & 1.197.323.909 \\
\hline Var. da produção** & 349.969 .978 & 590.974 .163 & 211.069.791 & 79.493 .912 & 209.872 .094 & 542.828 .722 & 1.984 .208 .660 \\
\hline \multicolumn{8}{|l|}{ INDIRETOS } \\
\hline Var. do Emprego * & 4.085 & 7.975 & 2.430 & 842 & 2.650 & 6.748 & 24.730 \\
\hline Var. dos Imp.Ind.Líquidos** & 5.885 .935 & 13.083 .374 & 3.704 .673 & 1.313 .860 & 4.114 .200 & 9.855 .822 & 37.957 .864 \\
\hline Var. da renda** & 36.921 .032 & 60.046 .832 & 19.856 .183 & 6.698 .786 & 21.247 .266 & 56.955 .295 & 201.725.394 \\
\hline Var. do Valor adicionado** & 79.416 .742 & 152.780 .609 & 46.002 .039 & 15.976 .534 & 50.319 .425 & 125.951 .673 & 470.447 .022 \\
\hline Var. da produção*** & 160.351 .014 & 318.534 .028 & 77.507 .558 & 19.163.905 & 101.835 .351 & 256.213 .475 & 933.605 .331 \\
\hline \multicolumn{8}{|l|}{ TOTAIS } \\
\hline Var. do Emprego * & 19.739 & 26.741 & 11.501 & 3.649 & 11.643 & 34.966 & 108.239 \\
\hline Var. dos Imp.Ind.Líquidos** & 16.456 .093 & 37.257 .577 & 10.480 .238 & 3.725 .636 & 11.658 .121 & 27.492 .375 & 107.070 .039 \\
\hline Var. da renda** & 162.723 .393 & 154.834 .749 & 79.827 .560 & 24.211 .971 & 78.395 .149 & 261.121 .579 & 761.114 .400 \\
\hline Var. do Valor adicionado** & 311.178 .092 & 488.605 .288 & 166.247 .961 & 55.644 .096 & 176.746 .224 & 469.349 .269 & 1.667 .770 .930 \\
\hline Var. da produção** & 510.320 .992 & 909.508 .191 & 288.577 .349 & 98.657 .817 & 311.707 .445 & 799.042 .197 & 2.917.813.991 \\
\hline
\end{tabular}

Fonte: dados estimados pelo autor

${ }^{*}$ número de pessoas ocupadas

** valores em $\mathrm{R} \$ 1,00$ 
Tabela 30. Variação percentual dos impactos gerados na economia brasileira, devido à implantação dos projetos do turismo contemplados pelo Plano Plurianual 2000/2003.

\begin{tabular}{|c|c|c|c|c|c|c|c|}
\hline \multirow[t]{2}{*}{ Impactos } & \multicolumn{6}{|c|}{ Regiões } & \multirow[b]{2}{*}{ Brasil } \\
\hline & Norte & Nordeste & Sudeste & Centro-Oeste & Sul & $\begin{array}{c}\text { Não } \\
\text { especificada }\end{array}$ & \\
\hline \multicolumn{8}{|l|}{ DIRETOS } \\
\hline Var. do Emprego (\%) & 0,027 & 0,032 & 0,016 & 0,005 & 0,015 & 0,048 & 0,143 \\
\hline Var. dos Imp.Ind.Líquidos (\%) & 0,020 & 0,047 & 0,013 & 0,005 & 0,015 & 0,034 & 0,133 \\
\hline Var. da renda (\%) & 0,031 & 0,023 & 0,015 & 0,004 & 0,014 & 0,050 & 0,137 \\
\hline Var. do Valor adicionado (\%) & 0,027 & 0,039 & 0,014 & 0,005 & 0,015 & 0,040 & 0,140 \\
\hline Var. da Produção (\%) & 0,021 & 0,035 & 0,013 & 0,005 & 0,012 & 0,032 & 0,118 \\
\hline \multicolumn{8}{|l|}{ INDIRETOS } \\
\hline Var. do Emprego (\%) & 0,007 & 0,014 & 0,004 & 0,001 & 0,005 & 0,012 & 0,042 \\
\hline Var. dos Imp.Ind.Líquidos (\%) & 0,011 & 0,025 & 0,007 & 0,003 & 0,008 & 0,019 & 0,073 \\
\hline Var. da renda (\%) & 0,009 & 0,015 & 0,005 & 0,002 & 0,005 & 0,014 & 0,049 \\
\hline Var. do Valor adicionado (\%) & 0,009 & 0,018 & 0,005 & 0,002 & 0,006 & 0,015 & 0,055 \\
\hline Var. da Produção (\%) & 0,010 & 0,019 & 0,005 & 0,001 & 0,006 & 0,015 & 0,056 \\
\hline \multicolumn{8}{|l|}{ TOTAIS } \\
\hline Var. do Emprego (\%) & 0,034 & 0,046 & 0,020 & 0,006 & 0,020 & 0,060 & 0,185 \\
\hline Var. dos Imp.Ind.Líquidos (\%) & 0,032 & 0,072 & 0,020 & 0,007 & 0,023 & 0,053 & 0,207 \\
\hline Var. da renda (\%) & 0,040 & 0,038 & 0,020 & 0,006 & 0,019 & 0,064 & 0,186 \\
\hline Var. do Valor adicionado (\%) & 0,036 & 0,057 & 0,019 & 0,006 & 0,021 & 0,055 & 0,195 \\
\hline Var. da Produção (\%) & 0,030 & 0,054 & 0,017 & 0,006 & 0,019 & 0,048 & 0,174 \\
\hline Var. do Emprego/Var. investimento & 0,000056 & 0,000045 & 0,000054 & 0,000046 & 0,000055 & 0,000064 & 0,000055 \\
\hline Var. dos Imp.Ind.Líquidos/Var. invest & 0,047 & 0,063 & 0,050 & 0,047 & 0,056 & 0,051 & 0,054 \\
\hline Var. da renda/Var. investimento & 0,465 & 0,262 & 0,378 & 0,305 & 0,374 & 0,482 & 0,384 \\
\hline Var. do Valor adicionado/Var. invest. & 0,889 & 0,827 & 0,788 & 0,700 & 0,842 & 0,866 & 0,841 \\
\hline Var. da produção/Var. investimento & 1,458 & 1,539 & 1,367 & 1,241 & 1,485 & 1,472 & 1,471 \\
\hline
\end{tabular}

Fonte: dados estimados pelo autor 
Um outro aspecto a ser considerado é que, ao realizar os investimentos, o turismo beneficiará de alguma forma o setor público, via aumento na arrecadação de impostos, de forma direta e indireta. Na presente situação, pode-se verificar, analisando as Tabelas 29 e 30, um aumento total nos impostos indiretos líquidos de 0,207\%, ou seja, um aumento de R\$107.070.039. Essa participação pode parecer insignificante, à primeira vista, mas representa cerca de $5,4 \%$ do total de investimentos realizados somente nesta primeira fase do plano.

Quando comparados os impactos da variação de uma unidade monetária dos investimentos sobre os impostos indiretos líquidos, tem-se que o valor para a região Nordeste é maior do que os valores das demais regiões consideradas no presente estudo (ver Tabela 30).

Com relação à renda das famílias, os resultados apresentados na Tabelas 29 e 30 mostram que o impacto em termos de acréscimos relativos à renda total seria também relevante, isto é, haveria um acréscimo de $0,186 \%$ na renda o que corresponde a $\mathrm{R} \$ 761.114 .400$. Desse montante $73,5 \%$ seriam aumentados de forma direta, e $26,5 \%$, de forma indireta.

Quando comparados os resultados com relação a quanto a renda das famílias varia por unidade monetária de variação do investimento, percebe-se que o valor para a região Norte é maior dos que os valores das demais regiões, já o valor para a região Nordeste apresenta-se como o menor valor, quando comparado com as demais regiões consideradas no presente trabalho.

Merece aqui ser ressaltado que, mesmo ocorrendo esse aumento na renda das famílias, não é possível dizer de que maneira seria distribuído nas diferentes classes de rendimento. Para se conseguir detectar isso, seria necessário endogeneizar a demanda pessoal considerando as diferentes classes de renda. Este tipo de análise, entanto, foge ao âmbito deste trabalho.

Conforme já foi tratado no capítulo anterior, o valor adicionado foi utilizado como uma proxy do produto interno bruto. Assim, nesta seção, os comentários referentes ao valor adicionado serão referidos como produto interno bruto, cujo acréscimo devido ao aumento nos investimentos no segmento do turismo foi da ordem de $0,195 \%$, quando se considerou o investimento total no Brasil, ou seja, o produto 
interno bruto aumentou em $\mathrm{R} \$ 1.667 .770 .930$, conforme se pode observar na Tabela 29.

Comparando-se os resultados dos impactos da variação de uma unidade monetária do investimento nas distintas regiões considerados no presente estudo sobre o produto interno bruto brasileiro, tem-se que o valor da região Norte $(0,889)$ supera os valores da demais regiões. O menor impacto da variação de uma unidade monetária no investimento $(0,70)$ ocorre, quando este acontece na região Centro-Oeste do país.

A seguir serão apresentados os resultados da segunda fase da análise, isto é, do período após a realização dos investimentos em infra-estrutura básica e qualificação dos agentes envolvidos no segmento do turismo.

\section{- Fase II}

Conforme já descrito anteriormente, na fase I serão realizados investimentos em infra-estrutura básica que irá criar condições, para que aumente o número de brasileiros fazendo turismo interno, bem como de turistas estrangeiros no Brasil. Com isso aumentará no Brasil o consumo turístico.

De acordo com o Plano Plurianual 2000-2003 até 2003, o número de turistas brasileiros irá aumentar em 50\%, com relação a 1998, passando de 38,2 milhões de turistas para 57,3 milhões, ou seja, haverá um aumento de 19,1 milhões de pessoas fazendo turismo doméstico (Brasil, 2002e). Como não está disponível a informação sobre o consumo turístico brasileiro, procedeu-se da seguinte forma para obtê-lo: admitiu-se um gasto médio de $\mathrm{R} \$ 404,00$ por turista, segundo informações da Embratur/FIPE (1999). Com isso a variação na receita gerada pelos gastos dos turistas internos será de $\mathrm{R} \$ 7,7$ bilhões. Esse valor foi distribuído entre os setores que compõem o segmento do turismo, considerando a estrutura de gastos dos turistas apresentada em Embratur/FIPE (1999), as despesas individuais com viagens apresentadas na POF 95/96 e o consumo das famílias do modelo de insumo-produto construído no presente trabalho.

Com relação ao fluxo de turistas internacionais no Brasil, espera-se ter aumentado em $35 \%$ até 2003 - de 4,8 milhões para 6,5 milhões de turistas. No que 
diz respeito à receita gerada por eles, espera-se um aumento de US\$ 1,8 bilhões. Esse valor da receita admitiu-se ser proveniente do consumo dos turistas. Assim, o valor dos seus gastos foi distribuído entre os setores que compõem o segmento do turismo, de acordo com a estrutura de gastos dos turistas internacionais apresentados pela Embratur (2002).

Uma vez distribuídos os gastos dos turistas domésticos e dos turistas internacionais no Brasil nos diversos setores que compõem o segmento do turismo, geraram-se dois choques na demanda final. Inicialmente considerou-se um aumento no consumo dos turistas domésticos e, em seguida, dos turistas internacionais.

Cada um dos choques foi avaliado, segundo seus impactos nos insumos utilizados no processo produtivo, na produção, na geração de emprego, na renda das famílias, nos impostos indiretos líquidos e no valor adicionado.

As Tabelas 31 e 32 mostram os impactos diretos, indiretos e totais do aumento no consumo dos turistas domésticos e internacionais sobre o fornecimento de insumos para o processo produtivo.

De acordo com o apresentado nessas tabelas, pode-se observar que o aumento no consumo dos turistas domésticos provoca os maiores acréscimos no fornecimento de insumos em todos os macro-setores, quando comparado com o aumento no consumo dos turistas internacionais.

Considerando tanto os turistas domésticos como os internacionais, os maiores acréscimos no fornecimento direto de insumos ocorrerão nos macro-setores Serviços turísticos $(2,25 \%)$, indústria de transformação $(1,00 \%)$ e Comércio $(0,97 \%)$, já os maiores acréscimos no fornecimento indireto de insumos ocorrerão nos macrosetores Agropecuária (0,92\%), Extrativa mineral (0,85\%) e Indústria de Transformação $(0,83 \%)$. Os maiores impactos no fornecimento total de insumos ocorrerão nos macrosetores Serviços turísticos $(3,00 \%)$, Indústria de transformação $(1,83 \%)$ e Comércio $(1,69 \%)$. 
Tabela 31. Variação dos insumos diretos, indiretos e totais utilizados no processo produtivo, devido a um aumento no consumo dos turistas domésticos e internacionais.

\begin{tabular}{|c|c|c|c|}
\hline \multirow{2}{*}{ Macro-setores } & \multicolumn{3}{|c|}{ Valores em $\mathrm{R} \$ 1,00$} \\
\hline & Turistas domésticos & Turistas internacionais & Total \\
\hline \multicolumn{4}{|l|}{ DIRETOS } \\
\hline AGROPECUÁRIA & 202.026 .769 & 99.365 .303 & 301.392 .072 \\
\hline EXTRATIVA MINERAL & 20.634 .584 & 8.060 .454 & 28.695 .038 \\
\hline IND. DE TRANSFORMAÇÃO & 1.911.914.116 & 1.168.291.904 & 3.080.206.021 \\
\hline S.I.U.P. & 85.371 .288 & 40.732 .418 & 126.103.706 \\
\hline CONSTRUÇÃO CIVIL & 35.521 .610 & 20.989 .403 & 56.511 .013 \\
\hline COMÉRCIO & 333.872 .107 & 187.364 .353 & 521.236 .460 \\
\hline SERVIÇOS TURÍSTICOS & 261.190 .306 & 253.708 .456 & 514.898 .762 \\
\hline SERV. NÃO-TURÍSTICOS & 538.921 .434 & 373.470 .722 & 912.392 .155 \\
\hline \multicolumn{4}{|l|}{ INDIRETOS } \\
\hline AGROPECUÁRIA & 464.479 .947 & 253.380 .004 & 717.859 .951 \\
\hline EXTRATIVA MINERAL & 184.740 .736 & 129.068 .109 & 313.808 .844 \\
\hline IND. DE TRANSFORMAÇÃO & 1.576 .355 .245 & 992.306 .097 & 2.568 .661 .342 \\
\hline S.I.U.P. & 132.625 .211 & 77.792 .760 & 210.417 .972 \\
\hline CONSTRUÇÃO CIVIL & 19.705 .332 & 13.255 .665 & 32.960 .997 \\
\hline COMÉRCIO & 239.709 .613 & 146.820 .892 & 386.530 .505 \\
\hline SERVIÇOS TURÍSTICOS & 99.660 .783 & 72.155 .586 & 171.816.369 \\
\hline SERV. NÃO-TURÍSTICOS & 446.511 .116 & 290.604 .498 & 737.115 .614 \\
\hline \multicolumn{4}{|l|}{ TOTAIS } \\
\hline AGROPECUÁRIA & 666.506 .716 & 352.745 .307 & 1.019 .252 .023 \\
\hline EXTRATIVA MINERAL & 205.375 .319 & 137.128 .563 & 342.503 .882 \\
\hline IND. DE TRANSFORMAÇÃO & 3.488.269.361 & 2.160 .598 .002 & 5.648 .867 .363 \\
\hline S.I.U.P. & 217.996 .500 & 118.525 .178 & 336.521 .678 \\
\hline CONSTRUÇÃO CIVIL & 55.226 .942 & 34.245 .069 & 89.472 .010 \\
\hline COMÉRCIO & 573.581 .720 & 334.185 .245 & 907.766 .965 \\
\hline SERVIÇOS TURÍSTICOS & 360.851 .089 & 325.864 .042 & 686.715 .132 \\
\hline SERV. NÃO-TURÍSTICOS & 985.432 .549 & 664.075 .220 & 1.649.507.769 \\
\hline
\end{tabular}

Fonte: dados estimados pelo autor.

Estes acréscimos no fornecimento de insumos devido ao aumento no consumo dos turistas (domésticos e internacionais no Brasil) ocorrem em decorrência dos efeitos multiplicadores do segmento do turismo sobre os diferentes setores produtivos da economia. Um aumento no consumo turístico provocará uma gama de aquisições de bens e serviços de outros setores produtivos para atender a demanda dos setores turísticos. Para esses outros fornecerem insumos aos que compõem o segmento do turismo, necessitarão adquirir outros bens e serviços, e, assim, sucessivamente, de modo que os efeitos serão disseminados por toda a economia. 
Por exemplo, considere-se que ocorreu um aumento na taxa de ocupação dos hotéis. Tal fato provocará um aumento nas compras de alimentos, bem como de outros insumos necessários ao perfeito funcionamento dos hotéis, repercutindo, de forma direta e indireta, em diversos outros segmentos da economia.

Tabela 32. Variação percentual dos insumos diretos, indiretos e totais utilizados no processo produtivo, devido a um aumento no consumo dos turistas brasileiros e internacionais.

\begin{tabular}{|c|c|c|c|}
\hline \multirow[b]{2}{*}{ Macro-setores } & \multicolumn{3}{|c|}{ Variação (\%) } \\
\hline & Turistas domésticos & $\begin{array}{c}\text { Turistas } \\
\text { internacionais }\end{array}$ & Total \\
\hline \multicolumn{4}{|l|}{ DIRETOS } \\
\hline AGROPECUÁRIA & 0,26 & 0,13 & 0,38 \\
\hline EXTRATIVA MINERAL & 0,06 & 0,02 & 0,08 \\
\hline IND. DE TRANSFORMAÇÃO & 0,62 & 0,38 & 1,00 \\
\hline S.I.U.P. & 0,28 & 0,13 & 0,41 \\
\hline CONSTRUÇÃO CIVIL & 0,27 & 0,16 & 0,42 \\
\hline COMÉRCIO & 0,62 & 0,35 & 0,97 \\
\hline SERVIÇOS TURÍSTICOS & 1,14 & 1,11 & 2,25 \\
\hline \multicolumn{3}{|l|}{ INDIRETOS } & 0,76 \\
\hline AGROPECUÁRIA & 0,59 & 0,32 & 0,92 \\
\hline EXTRATIVA MINERAL & 0,50 & 0,35 & 0,85 \\
\hline IND. DE TRANSFORMAÇÃO & 0,51 & 0,32 & 0,83 \\
\hline S.I.U.P. & 0,43 & 0,25 & 0,69 \\
\hline CONSTRUÇÃO CIVIL & 0,15 & 0,10 & 0,25 \\
\hline COMÉRCIO & 0,45 & 0,27 & 0,72 \\
\hline SERVIÇOS TURÍSTICOS & 0,44 & 0,32 & 0,75 \\
\hline SERVIÇOS NÃO-TURÍSTICOS & 0,37 & 0,24 & 0,61 \\
\hline \multicolumn{4}{|l|}{ TOTAIS } \\
\hline AGROPECUÁRIA & 0,85 & 0,45 & 1,30 \\
\hline EXTRATIVA MINERAL & 0,56 & 0,37 & 0,93 \\
\hline IND. DE TRANSFORMAÇÃO & 1,13 & 0,70 & 1,83 \\
\hline S.I.U.P. & 0,71 & 0,39 & 1,10 \\
\hline CONSTRUÇÃO CIVIL & 0,42 & 0,26 & 0,67 \\
\hline COMÉRCIO & 1,07 & 0,62 & 1,69 \\
\hline SERVIÇOS TURÍSTICOS & 1,58 & 1,42 & 3,00 \\
\hline SERVIÇOS NÃO-TURÍSTICOS & 0,82 & 0,55 & 1,38 \\
\hline
\end{tabular}

Fonte: dados estimados pelo autor.

Os dados com relação ao impacto do aumento do consumo dos turistas domésticos e internacionais no Brasil sobre a geração de novos postos de trabalho 
podem ser visualizados na Tabelas 33 e 34 . Os resultados nesse item mostram que os gastos dos turistas contribuirão para geração de 1.044 .188 novos postos de trabalho, sendo $71,28 \%$ (744.278 empregos) criados diretamente pelos gastos dos turistas e $28,72 \%$ (299.910 empregos) gerados devido aos efeitos indiretos desses gastos. Todos esses empregos terão sido gerados ao final do período de ação do Plano Plurianual 2000-2003, ou seja, ao final do ano de 2003. Vale destacar que esses novos postos de trabalhos gerados podem ser considerados permanentes, uma vez que se espera o desempenho do segmento aqui considerado ser mantido por um longo período de tempo.

Tabela 33. Impactos gerados na economia brasileira, devido a um aumento no consumo dos turistas brasileiros e internacionais no Brasil.

\begin{tabular}{|c|c|c|c|}
\hline Impactos & Brasileiros & Internacionais & Total \\
\hline \multicolumn{4}{|l|}{ DIRETOS } \\
\hline Variação do Emprego * & 544.613 & 199.666 & 744.278 \\
\hline Variação dos Impostos Ind.Líquidos** & 392.164 .063 & 191.611 .554 & 583.775 .618 \\
\hline Variação da Renda** & 2.744 .037 .970 & 1.277.965.024 & 4.022.002.994 \\
\hline Variação do Valor adicionado** & 3.618.938.724 & 1.697 .284 .521 & 5.316 .223 .244 \\
\hline Variação da Produção (consumo dos turistas) ${ }^{\star \star}$ & 7.718.016.000 & 4.230 .088 .245 & 11.948.104.245 \\
\hline \multicolumn{4}{|l|}{ INDIRETOS } \\
\hline Variação do Emprego * & 189.393 & 110.517 & 299.910 \\
\hline Variação dos Impostos Ind.Líquidos** & 210.242 .987 & 129.582 .232 & 339.825 .220 \\
\hline Variação da Renda** & 1.091.090.752 & 700.583 .493 & 1.791.674.245 \\
\hline Variação do Valor adicionado** & 2.840 .810 .431 & 1.799 .560 .080 & 4.640 .370 .510 \\
\hline Variação da Produção** & 6.553.240.196 & 4.127.366.626 & 10.680 .606 .822 \\
\hline \multicolumn{4}{|l|}{ TOTAIS } \\
\hline Variação do Emprego * & 734.005 & 310.183 & 1.044 .188 \\
\hline Variação dos Impostos Ind.Líquidos** & 602.407 .050 & 321.193 .787 & 923.600 .837 \\
\hline Variação da Renda** & 3.835 .128 .723 & 1.978 .548 .517 & 5.813 .677 .239 \\
\hline Variação do Valor adicionado** & 6.459 .749 .154 & 3.496 .844 .601 & 9.956 .593 .755 \\
\hline Variação da Produção** & 14.271.256.196 & 8.357 .454 .871 & 22.628.711.067 \\
\hline
\end{tabular}

Fonte: dados estimados pelo autor.

* número de pessoas ocupadas

** valores em $\mathrm{R} \$ 1,00$ 
Tabela 34. Variação percentual dos impactos gerados na economia brasileira devido a um aumento no consumo dos turistas brasileiros e internacionais no Brasil.

\begin{tabular}{|c|c|c|c|}
\hline Impactos & Brasileiros & Internacionais & Total \\
\hline \multicolumn{4}{|l|}{ DIRETOS } \\
\hline Variação do Emprego (\%) & 0,93 & 0,34 & 1,27 \\
\hline Variação dos Impostos Ind.Líquidos (\%) & 0,76 & 0,37 & 1,13 \\
\hline Variação da Renda (\%) & 0,67 & 0,31 & 0,98 \\
\hline Variação do Valor Adicionado (\%) & 0,42 & 0,20 & 0,62 \\
\hline Variação da Produção (\%) & 0,46 & 0,25 & 0,71 \\
\hline \multicolumn{4}{|l|}{ INDIRETOS } \\
\hline Variação do Emprego (\%) & 0,32 & 0,19 & 0,51 \\
\hline Variação dos Impostos Ind.Líquidos (\%) & 0,41 & 0,25 & 0,66 \\
\hline Variação da Renda (\%) & 0,27 & 0,17 & 0,44 \\
\hline Variação do Valor Adicionado (\%) & 0,33 & 0,21 & 0,54 \\
\hline Variação da Produção (\%) & 0,39 & 0,25 & 0,64 \\
\hline \multicolumn{4}{|l|}{ TOTAIS } \\
\hline Variação do Emprego (\%) & 1,26 & 0,53 & 1,79 \\
\hline Variação dos Impostos Ind.Líquidos (\%) & 1,16 & 0,62 & 1,78 \\
\hline Variação da Renda (\%) & 0,94 & 0,48 & 1,42 \\
\hline Variação do Valor Adicionado (\%) & 0,75 & 0,41 & 1,16 \\
\hline Variação da Produção (\%) & 0,85 & 0,50 & 1,35 \\
\hline Variação do Emprego/Variação do consumo & 0,00010 & 0,00007 & 0,00009 \\
\hline Variação dos Imp. Ind.Líquidos/Variação do Consumo & 0,07805 & 0,07593 & 0,07730 \\
\hline Variação da Renda/Variação do consumo & 0,49691 & 0,46773 & 0,48658 \\
\hline Variação do Valor Adicionado/Variação do Consumo & 0,83697 & 0,82666 & 0,83332 \\
\hline Variação da Produção/Variação do Consumo & 1,84908 & 1,97572 & 1,89392 \\
\hline
\end{tabular}

Fonte: dados estimados pelo autor.

Os resultados mostram, ainda, que o turismo interno apresenta um melhor impacto, quando comparado com o turismo internacional no Brasil, conforme se pode observar na Tabela 34. Com relação ao acréscimo no número de empregos, constatou-se que $1,26 \%$ foi devido ao aumento no consumo dos turistas internos, enquanto que o consumo dos turistas internacionais foi responsável pelo aumento de $0,53 \%$ no número de empregos totais do país. Além disso, quando comparados os resultados com relação a quanto o número de pessoas ocupadas varia por unidade monetária de variação no consumo dos turistas, verifica-se que o valor para os turistas internos é superior ao valor para os turistas internacionais no Brasil, requerendo, portanto, um menor aumento no consumo para gerar novos postos de trabalho. Assim, 
caso seja delineada uma política com o objetivo de aumentar o número de empregos, a estratégia adotada deverá ser no sentindo de incentivar o turismo interno.

Os gastos turísticos ou o consumo dos bens e serviços pelos turistas geram impostos que também não são desprezíveis. De acordo com os resultados apresentados nas Tabelas 33 e 34, verifica-se que o impacto do turismo doméstico sobre os impostos indiretos líquidos totais foi de $1,16 \%$ e do turismo internacional no Brasil foi de $0,62 \%$, ou seja, o impacto do turismo doméstico sobre os impostos indiretos líquidos é mais relevante do que o do turismo internacional. Isso fica evidenciado, também, quando se compara o resultado de uma variação do total dos impostos indiretos líquidos sobre o consumo dos turistas.

Quando os turistas consomem bens e serviços nos núcleos receptores, as receitas tributárias dessa atividade podem ser diretas e indiretas. As diretas são oriundas das atividades turísticas, sendo, portanto, mais fáceis de observação. As receitas indiretas, no entanto, são de difícil observação, pois são oriundas de atividades que sofrem impactos devido ao crescimento do segmento do turismo, como por exemplo, a importação de mercadorias a serem consumidas pelos turistas e a compra de insumos por setores do segmento do turismo. De acordo com os resultados apresentados, o aumento no consumo dos turistas poderá ocasionar um acréscimo nos impostos indiretos líquidos, de forma direta de 1,13\%, enquanto que, de forma indireta, poderá ser de $0,66 \%$, conforme se pode observar na Tabela 34 .

Vale ressaltar que o tamanho da contribuição fiscal oriunda do turismo dependerá do nível de alíquotas dos impostos, da intensificação da fiscalização e da eficiência na cobrança dos contribuintes faltosos.

No que diz respeito à renda das famílias, os resultados apresentados nas Tabelas 33 e 34 mostram que o impacto em termos de acréscimos relativos à renda total das famílias pode ser considerado relevante, isto é, ocorrerá um aumento de $\mathrm{R} \$$ 5,8 bilhões dado a um aumento no consumo dos turistas domésticos e internacionais no Brasil. Vale ressaltar que parte desse aumento na renda das famílias dar-se-á, de forma direta, $(0,98 \%)$ e parte, de forma indireta $(0,44 \%)$.

Conforme visto no capítulo anterior deste estudo, atualmente o segmento do turismo apresenta uma considerável contribuição na formação do Produto Interno Bruto 
brasileiro. Desse modo, optou-se por avaliar os impactos do aumento no consumo dos turistas domésticos e turistas internacionais no Brasil sobre essa variável.

De acordo com as Tabelas 33 e 34 o impacto gerado sobre o PIB, dado a um aumento no consumo turístico é considerável, ou seja, a variação no PIB brasileiro será de $1,16 \%$ no total. Desagregando um pouco mais essa informação, verifica-se que o turismo interno ou doméstico apresenta uma maior participação nesse acréscimo $(0,75 \%)$ do que o turismo internacional $(0,41 \%)$.

O aumento no consumo dos turistas, sejam eles domésticos ou internacionais no Brasil, também causa impactos na produção total. Analisando as Tabelas 33 e 34, nota-se que, no presente caso, o aumento no consumo dos turistas domésticos apresentou uma maior variação sobre a produção total da economia em termos relativos, que acrescentou $0,85 \%$ à produção total, enquanto o consumo dos turistas internacionais provocou acréscimo à produção total de $0,50 \%$.

Quando comparados, no entanto, os impactos da variação de uma unidade monetária no consumo dos turistas sobre a produção total, tem-se que o valor para os turistas internacionais $(1,97572)$ é maior do que o valor dos turistas domésticos $(1,84908)$, requerendo, portanto, um menor aumento no consumo para gerar a mesma produção total. Assim, caso seja delineada uma política com o objetivo de aumentar a produção total da economia, deve-se adotar a estratégia de incentivar tanto o turismo internacional, cujo multiplicador é maior, como o turismo doméstico que apresentou uma maior variação na produção total.

$\mathrm{Na}$ Tabela 34, resumem-se os principais resultados obtidos em termos de unidades de acréscimo no emprego e unidade monetárias de acréscimo nos impostos indiretos líquidos, renda das famílias e valor adicionado por unidade monetária de variação do consumo dos turistas domésticos e turistas internacionais no Brasil.

De uma maneira geral, o turismo doméstico pode ser considerado mais eficiente que o internacional no Brasil, medindo-se essa eficiência em termos de unidades de emprego e unidade monetária de impostos indiretos líquidos, renda das famílias e valor adicionado por unidade de acréscimo no consumo dos turistas, entretanto, apesar de o turismo internacional no Brasil ser menos eficiente que o doméstico, não deve ser colocado num segundo plano, pois este pode ser um 
importante gerador de divisas para o país. Esse tipo de análise, porém, foge ao âmbito deste estudo.

Para finalizar, pode-se inferir que o turismo contribui para o crescimento da economia, gerando emprego e renda, contribui para o aumento na produção total da economia e na arrecadação de impostos e interfere positivamente na formação do Produto Interno Bruto brasileiro. 


\section{CONCLUSÕES}

Esta pesquisa teve como objetivos a construção de um modelo de insumoproduto para a economia turística no Brasil, no ano de 1999 e, a partir desse modelo, mensurar e analisar as relações intersetoriais, bem como a capacidade de indução dos investimentos sobre o crescimento da economia. Objetivou-se, também, delinear uma metodologia de mensuração do produto interno bruto do segmento do turismo através do modelo de insumo-produto.

A mensuração e análise dos índices de ligações intersetoriais permitiram a identificação dos setores-chave, considerando o modelo de insumo-produto aqui construído e o nível de agregação utilizado. Dentre os setores que foram classificados como setores-chave, são seis os que foram inicialmente considerados como componentes do segmento do turismo: Transporte aéreo, regular, Transporte aéreo, não regular, Agências e organizadores de viagens, Atividades auxiliares aos transportes aéreos, Estabelecimentos hoteleiros e outros tipos de alojamento temporário e Restaurantes e outros estabelecimentos de serviços de alimentação.

A análise dos impactos que poderiam ocorrer na produção, renda e emprego, caso ocorressem variações na demanda final, mostrou que os setores que compõem o segmento do turismo apresentaram elevados multiplicadores setoriais, para produção e renda, ao contrário do multiplicador de emprego que apresentou valores relativamente baixos na estrutura produtiva aqui considerada. A análise do poder de geração de novos empregos, todavia, caso ocorresse um aumento nos investimentos de $R \$ 1$ milhão nos setores da economia, permite que se conclua que o segmento do turismo compõe-se de setores com grandes possibilidades de gerar novos postos de trabalho, principalmente, quando se considerou o consumo das famílias como endógeno ao sistema. 
Outro resultado importante que merece ser ressaltado em relação à capacidade de geração de empregos pelo segmento do turismo, diz respeito à considerável participação dos empregos diretos e induzidos na composição total de empregos gerados. O fato de os empregos induzidos apresentarem uma considerável participação na composição total dos empregos os quais podem ser gerados na economia, evidencia o efeito multiplicador que o segmento possui dentro da estrutura produtiva do país.

Diante disso, ressalta-se a importância de implantação de políticas e programas para promover o desenvolvimento do segmento do turismo no Brasil, tendo em vista a grande capacidade de gerar postos de trabalho, uma vez que a geração de novos empregos é uma das maiores preocupações aqui no Brasil, atualmente.

Com relação ao Produto Interno Bruto do turismo, os resultados apontam para uma participação de $7,54 \%$ no PIB nacional, havendo amplo espaço para crescimento, conforme observado neste trabalho.

Verificou-se, também, que o aumento no consumo dos turistas domésticos e dos internacionais no Brasil tem impactos diferentes sobre a geração de empregos, os impostos indiretos líquidos, a renda das famílias, o valor adicionado e a produção total. Utilizando-se estes impactos para medir a eficiência do turismo, pode-se concluir que o turismo doméstico é mais eficiente que o internacional no Brasil. $O$ turismo internacional, no entanto, no Brasil não deve ser colocado num segundo plano, pois pode ser um importante gerador de divisas para o país.

A elaboração desta pesquisa permite relatar que são duas as principais contribuições deste estudo: a primeira delas foi a construção de um modelo de insumoproduto para o turismo para 1999. Esse fato vem preencher uma lacuna existente nos institutos de pesquisa e pesquisadores preocupados em conhecer melhor o segmento, com o intuito de recomendar o direcionamento de políticas e programas para o mesmo. Além disso, constitui-se um ponto de partida para estimativas de matrizes de insumoproduto para a economia turística, possibilitando a elaboração de estudos futuros mais detalhados, capazes de detectar com maior precisão a inserção e as contribuições do turismo na economia brasileira. A segunda contribuição refere-se à proposta 
metodológica de estimação do PIB turístico, em termos de valor adicionado, utilizando o modelo de insumo-produto aqui construído.

Obviamente, a presente pesquisa apresenta limitações e, portanto, seus resultados devem ser vistos como indicações do comportamento do segmento do turismo na economia brasileira. Estas limitações, porém, não invalidam o estudo; ao contrário, cria-se um conjunto de informações importantes para orientar o poder público na definição e adoção de políticas específicas para o os setores que compõem o segmento do turismo e o setor privado no direcionamento de seus investimentos.

Como sugestão para trabalhos futuros que possam complementar e/ou aprofundar o presente estudo, pode-se destacar: a) construir e atualizar matrizes para a economia turística a preços constantes de um dado ano-base, permitindo, assim, a separação entre as mudanças ocorridas nos preços relativos e as provenientes de inovação tecnológica; b) construir um modelo de insumo-produto inter-regional para a economia turística e, com isso, mensurar a importância econômica do segmento do turismo nas macro-regiões brasileiras; c) desagregar os setores componentes da demanda final, principalmente o consumo das famílias, para que se possa separar o consumo turístico do consumo não-turístico.

Por último, sugere-se aos órgãos públicos e privados a formação de banco de dados que permita, com maior precisão, construir os modelos de insumo-produto para o segmento do turismo no Brasil e regiões. 


\begin{abstract}
ANEXOS
A1 - Modelo de insumo-produto para economia turística, Brasil, 1999.

A2 - Valor da produção, valor adicionado e participação setorial no valor da produção e no valor adicionado, Brasil, 1999.

A3 - Variação dos insumos indiretos utilizados no processo produtivo, devido à implantação dos projetos de turismo contemplados no Plano Plurianual 2000-2003, por região de ocorrência do investimento.
\end{abstract}

A4 - Variação dos insumos totais utilizados no processo produtivo, devido à implantação dos projetos de turismo contemplados no Plano Plurianual 2000-2003, por região de ocorrência do investimento.

A5 - Variação dos insumos indiretos utilizados no processo produtivo, devido a um aumento no consumo dos turistas brasileiros e internacionais no Brasil.

A6 - Variação dos insumos totais utilizados no processo produtivo, devido a um aumento no consumo dos turistas brasileiros e internacionais no Brasil. 
Tabela A1. Matriz de insumo-produto para economia turística, Brasil, 1999 (valores correntes em 1.000 R\$).

\begin{tabular}{|c|c|c|c|c|c|c|c|c|c|c|c|}
\hline & \multirow[t]{2}{*}{ SETORES } & \multirow{2}{*}{$\begin{array}{l}\text { AGROPECUÁRIA } \\
\\
1\end{array}$} & \multirow{2}{*}{$\begin{array}{l}\text { EXTRATIVA } \\
\text { MINERAL } \\
2\end{array}$} & \multirow{2}{*}{$\begin{array}{l}\text { MINERAL } \\
\text { NÃO } \\
\text { METÁLICO } \\
3\end{array}$} & \multirow{2}{*}{$\begin{array}{r}\text { SIDERURGIA } \\
\\
\\
4\end{array}$} & \multirow{2}{*}{$\begin{array}{r}\text { METALURGIA } \\
\\
5\end{array}$} & \multirow{2}{*}{$\begin{array}{r}\text { MÁQUINAS E } \\
\text { EQUIPAMENTOS } \\
6\end{array}$} & \multirow{2}{*}{$\begin{array}{l}\text { MATERIAL } \\
\text { ELÉTRICO } \\
7\end{array}$} & \multirow{2}{*}{$\begin{array}{r}\text { EQUIPAMENTOS } \\
\text { ELETRÔNICOS } \\
8\end{array}$} & \multirow{2}{*}{$\begin{array}{l}\text { AUTOMÓVEIS } \\
\text { CAMINHÕES } \\
\text { ÔNIBUS } \\
9\end{array}$} & \multirow{2}{*}{$\begin{array}{c}\text { PEÇAS } \\
\text { E OUTROS } \\
\text { VEÍCULOS } \\
10\end{array}$} \\
\hline & & & & & & & & & & & \\
\hline 1 & AGROPECUÁRIA & 18474783 & 13492 & 142768 & 1027182 & 28642 & 146 & 305 & 514 & 187 & 258 \\
\hline 2 & EXTRATIVA MINERAL & 286916 & 713704 & 651925 & 1033754 & 715140 & 516 & 25843 & 19454 & 513 & 514 \\
\hline 3 & MINERAL Ñ METÁLICO & 93433 & 173621 & 3354186 & 212876 & 401691 & 151805 & 293892 & 142356 & 145244 & 114269 \\
\hline 4 & SIDERURGIA & 6504 & 50670 & 298598 & 12654919 & 6797630 & 1574047 & 594050 & 97165 & 836888 & 1162218 \\
\hline 5 & METALURGIA & 201520 & 615837 & 194864 & 856246 & 8205176 & 2825446 & 2798792 & 524188 & 756798 & 3569224 \\
\hline 6 & MÁQUINAS E EQUIP. & 229483 & 610150 & 271239 & 594102 & 727185 & 746877 & 671042 & 140274 & 398700 & 792625 \\
\hline 7 & MATERIAL ELÉTRICO & 12391 & 21905 & 12684 & 54401 & 75423 & 430585 & 1197225 & 301906 & 50525 & 125387 \\
\hline 8 & EQUIP. ELETRÔNICOS & 7222 & 14714 & 12978 & 20253 & 17938 & 58808 & 53740 & 772226 & 11536 & 28609 \\
\hline 9 & AUTOM./CAM/ONIBUS & 5826 & 9491 & 5930 & 10455 & 23257 & 27372 & 9194 & 3021 & 198271 & 96459 \\
\hline 10 & PEÇAS E OUT. VEÍCULOS & 16279 & 19201 & 7730 & 17258 & 63321 & 274359 & 43746 & 12164 & 3853539 & 2414643 \\
\hline 11 & MADEIRA E MOBILIÁRIO & 139211 & 18808 & 21806 & 28784 & 88956 & 65510 & 60231 & 166369 & 82484 & 115985 \\
\hline 12 & CELULOSE, PAPEL E GRÁF. & 60136 & 150920 & 368225 & 87797 & 308292 & 147795 & 213183 & 114419 & 67181 & 137290 \\
\hline 13 & IND. DA BORRACHA & 6117 & 55044 & 55577 & 104179 & 83824 & 242678 & 61645 & 16588 & 846143 & 215214 \\
\hline 14 & INDÚSTRIA QUIMMICA & 13134096 & 1035866 & 1785235 & 830778 & 1768988 & 477444 & 715090 & 124629 & 452059 & 524136 \\
\hline 15 & FARMAC. E VETERINÁRIA & 482183 & 8916 & 4868 & 4709 & 15048 & 2170 & 1984 & 933 & 1646 & 1996 \\
\hline 16 & ARTIGOS PLÁSTICOS & 302703 & 32225 & 47978 & 15777 & 124778 & 188246 & 422437 & 267122 & 236955 & 228324 \\
\hline 17 & IND. TÊXTIL & 216956 & 16064 & 12689 & 6454 & 10132 & 35023 & 9551 & 8202 & 48799 & 67025 \\
\hline 18 & ARTIGOS DO VESTUÁRIO & 2495 & 7033 & 2151 & 5805 & 4185 & 4321 & 2272 & 1623 & 11455 & 3316 \\
\hline 19 & FABRICAÇÃO CALÇADOS & 23838 & 539 & 825 & 675 & 2660 & 8812 & 3503 & 1836 & 15998 & 3403 \\
\hline 20 & INDÚSTRIA DO CAFÉ & 1191 & 227 & 302 & 243 & 548 & 397 & 317 & 219 & 466 & 437 \\
\hline 21 & BENEF. PROD. VEGETAIS & 68243 & 2009 & 2038 & 3321 & 4101 & 1913 & 1565 & 1029 & 2260 & 2140 \\
\hline 22 & ABATE DE ANIMAIS & 77993 & 509 & 1251 & 5694 & 1031 & 688 & 508 & 349 & 700 & 674 \\
\hline 23 & INDÚSTRIA DE LATICIINIOS & 5910 & 709 & 921 & 805 & 1760 & 1213 & 990 & 681 & 1543 & 1419 \\
\hline 24 & FABRICAÇÃO DE AÇÚCAR & 7302 & 863 & 993 & 1162 & 1795 & 789 & 485 & 286 & 599 & 700 \\
\hline 25 & FAB. ÓLEOS VEGETAIS & 982080 & 1581 & 1354 & 1187 & 3368 & 1143 & 974 & 607 & 1296 & 1262 \\
\hline 26 & OUTROS PROD. ALIMENT. & 4172342 & 11087 & 10337 & 5727 & 12718 & 10618 & 4789 & 2935 & 3865 & 5954 \\
\hline 27 & INDÚSTRIAS DIVERSAS & 66545 & 41530 & 23042 & 191776 & 162093 & 16706 & 16556 & 13572 & 27369 & 25386 \\
\hline
\end{tabular}


Tabela A1. Matriz de insumo-produto para economia turística, Brasil, 1999 (valores correntes em 1.000 R\$).

\begin{tabular}{|c|c|c|c|c|c|c|c|c|c|c|c|}
\hline & SETORES & AGROPECUÁRIA & $\begin{array}{c}\text { EXTRATIVA } \\
\text { MINERAL }\end{array}$ & $\begin{array}{l}\text { MINERAL } \\
\text { NÃO } \\
\text { METÁLICO }\end{array}$ & SIDERURGIA & METALURGIA & $\begin{array}{l}\text { MÁQUINAS E } \\
\text { EQUIPAMENTOS }\end{array}$ & $\begin{array}{l}\text { MATERIAL } \\
\text { ELÉTRICO }\end{array}$ & $\begin{array}{c}\text { EQUIPAMENTOS } \\
\text { ELETRÔNICOS }\end{array}$ & $\begin{array}{c}\text { AUTOMÓVEIS } \\
\text { CAMINHÕES } \\
\text { ÔNIBUS }\end{array}$ & $\begin{array}{c}\text { PEÇAS } \\
\text { E OUTROS } \\
\text { VÉ́CULOS }\end{array}$ \\
\hline & & 1 & 2 & 3 & 4 & 5 & 6 & 7 & 8 & 9 & 10 \\
\hline 28 & S.I.U.P. & 455740 & 541170 & 578753 & 785557 & 1046341 & 320401 & 134103 & 49966 & 97447 & 215224 \\
\hline 29 & CONSTRUÇÃO CIVIL & 5125 & 127814 & 43798 & 34595 & 77994 & 70122 & 28744 & 22140 & 29308 & 44802 \\
\hline 30 & COMÉRCIO & 4527994 & 626775 & 851381 & 787136 & 1595934 & 1132644 & 934409 & 644430 & 1516946 & 1368242 \\
\hline 31 & TRANSP. RODOV. DE PASSAG., REGULAR & 518039 & 116751 & 154802 & 168038 & 138385 & 66271 & 53061 & 34878 & 98599 & 42249 \\
\hline 32 & TRANSP. RODOV. PASSAG., NÃO REGULAR & 37822 & 8524 & 11302 & 12268 & 10103 & 4838 & 3874 & 2546 & 7199 & 3085 \\
\hline 33 & TRANSP. REG. EXPL. DE POS TURÍSTICOS & 439 & 99 & 131 & 142 & 117 & 56 & 45 & 30 & 84 & 36 \\
\hline 34 & TRANSP. RODOV. DE CARGAS & 1342551 & 301782 & 400863 & 435350 & 358205 & 171201 & 137293 & 90240 & 255222 & 109197 \\
\hline 35 & OUTR. TRANSP.TERRESTRES & 41050 & 18883 & 14465 & 22572 & 18627 & 5421 & 5085 & 3343 & 15216 & 6536 \\
\hline 36 & TRANSP. AQUAVIÁRIO & 14957 & 17383 & 23002 & 9709 & 8026 & 1653 & 1845 & 1214 & 4044 & 1751 \\
\hline 37 & TRANSP. AÉREO, REGULAR & 16140 & 53890 & 110538 & 58938 & 48686 & 27811 & 32964 & 21669 & 40542 & 17438 \\
\hline 38 & TRANSP. AÉREO, NÃO REGULAR & 904 & 3017 & 6189 & 3300 & 2726 & 1557 & 1846 & 1213 & 2270 & 976 \\
\hline 39 & AGÊNC. E ORG. DE VIAGENS & 54449 & 9230 & 12469 & 19855 & 16386 & 5359 & 7069 & 4648 & 8765 & 3778 \\
\hline 40 & ATIV. AUX. TRANSP. TERRESTRE & 16379 & 3112 & 4359 & 5973 & 4932 & 1616 & 2470 & 1624 & 2639 & 1138 \\
\hline 41 & ATIV. AUX.TRANSP.AQUAVIÁRIOS & 23953 & 4551 & 6375 & 8736 & 7213 & 2363 & 3612 & 2375 & 3859 & 1665 \\
\hline 42 & ATIV. AUX. TRANSP. AÉREOS & 13296 & 2526 & 3538 & 4849 & 4003 & 1311 & 2005 & 1318 & 2142 & 924 \\
\hline 43 & OUTR. ATIV. AUX. TRANSPORTE & 45404 & 8627 & 12083 & 16559 & 13672 & 4479 & 6847 & 4501 & 7314 & 3156 \\
\hline 44 & COMUNICAÇÕES & 39001 & 128472 & 153945 & 133102 & 238090 & 302226 & 153050 & 131336 & 117397 & 122967 \\
\hline 45 & INSTITUIÇŌES FINANCEIRAS & 680309 & 754408 & 251556 & 471348 & 489590 & 190665 & 268173 & 191078 & 339390 & 266720 \\
\hline 46 & ESTAB. HOTEL. E OUTR. TIPOS DE ALOJ. TEMPORÁRII & 2202 & 4946 & 4556 & 3555 & 6616 & 12706 & 5802 & 4752 & 3723 & 4180 \\
\hline 47 & REST. OUTR. ESTAB. DE SERV. DE ALIMENTAÇÃO & 5961 & 11810 & 10938 & 8555 & 15956 & 30279 & 13906 & 11365 & 9098 & 10152 \\
\hline 48 & ATIV. RECREATIVAS, CULT. E DESPORTIVAS & 36030 & 22345 & 12728 & 12925 & 11262 & 11848 & 4908 & 3149 & 8879 & 4663 \\
\hline 49 & OUTR. SERV. PREST. ÀS FAMÍLIAS & 52568 & 26307 & 15300 & 15316 & 14316 & 15752 & 6673 & 4381 & 12022 & 8871 \\
\hline 50 & ALUGUEL AUTOM. OUTR. MEIOS DE TRANSPORTE & 8116 & 7655 & 1374 & 1428 & 1932 & 2221 & 2034 & 1530 & 2645 & 1542 \\
\hline 51 & OUTR. SERV. PREST. ÀS EMPRESAS & 953423 & 904725 & 160656 & 167490 & 225097 & 260286 & 238739 & 179662 & 310260 & 179733 \\
\hline 52 & ALUGUEL DE IMÓVEIS & 16580 & 104861 & 91604 & 29147 & 131162 & 105350 & 66214 & 46748 & 23024 & 46288 \\
\hline 53 & ADMINISTRAÇÃ̃O PÚBLICA & 581670 & 189515 & 83421 & 61981 & 92519 & 71172 & 73095 & 49292 & 112110 & 80737 \\
\hline 54 & SERV. PRIV. Ñ MERCANTIS & 0 & 0 & 0 & 0 & 0 & 0 & 0 & 0 & 0 & 0 \\
\hline
\end{tabular}


Tabela A1. Matriz de insumo-produto para economia turística, Brasil, 1999 (valores correntes em 1.000 R\$).

\begin{tabular}{|c|c|c|c|c|c|c|c|c|c|c|}
\hline SETORES & AGROPECUÁRIA & $\begin{array}{c}\text { EXTRATIVA } \\
\text { MINERAL }\end{array}$ & $\begin{array}{l}\text { MINERAL } \\
\text { NÃo } \\
\text { METÁLICO }\end{array}$ & SIDERURGIA & METALURGIA & $\begin{array}{l}\text { MÁQUINAS E } \\
\text { EQUIPAMENTOS }\end{array}$ & $\begin{array}{l}\text { MATERIAL } \\
\text { ELÉTRICO }\end{array}$ & $\begin{array}{c}\text { EQUIPAMENTOS } \\
\text { ELETRÔNICOS }\end{array}$ & $\begin{array}{c}\text { AUTOMÓVEIS } \\
\text { CAMINHÕES } \\
\text { ÔNIBUS }\end{array}$ & $\begin{array}{c}\text { PEÇAS } \\
\text { E OUTROS } \\
\text { VÉ́CULOS }\end{array}$ \\
\hline & 1 & 2 & 3 & 4 & 5 & 6 & 7 & 8 & 9 & 10 \\
\hline Produção Nacional & 48573801 & 7625896 & 10312622 & 21054745 & 24227572 & 10115035 & 9391773 & 4244094 & 11083162 & 12184919 \\
\hline Importado & 3786448 & 869037 & 923755 & 2055503 & 2657313 & 1270355 & 1631679 & 1664156 & 2676008 & 2335869 \\
\hline Imp Import & 176969 & 56707 & 60080 & 79555 & 200694 & 116924 & 158333 & 144053 & 201959 & 190650 \\
\hline ICM Nac + Importado & 1723698 & 287648 & 905153 & 451877 & 860695 & 576809 & 534557 & 362321 & 953556 & 864556 \\
\hline Zeros (ICM Impot incl acima) & 0 & 0 & 0 & 0 & 0 & 0 & 0 & 0 & 0 & 0 \\
\hline IPI Nac + Importado & 224409 & 154424 & 215803 & 163658 & 497824 & 304053 & 316889 & 165313 & 345686 & 377365 \\
\hline Zeros (IPI Import incl acima) & 0 & 0 & 0 & 0 & 0 & 0 & 0 & 0 & 0 & 0 \\
\hline Outros IIL Nac + Importado & 187766 & 175015 & 62675 & 138229 & 127249 & 47911 & 68760 & 49735 & 92306 & 72520 \\
\hline Zeros (Outros IIL Import incl acima) & 0 & 0 & 0 & 0 & 0 & 0 & 0 & 0 & 0 & 0 \\
\hline CONSUMO INTERMEDIÁRIO & 54673091 & 9168727 & 12480088 & 23943567 & 28571347 & 12431087 & 12101992 & 6629672 & 15352677 & 16025878 \\
\hline REMUNERAÇŌES & 9996826 & 1915901 & 2733090 & 833010 & 5284415 & 5012627 & 1440290 & 986971 & 925648 & 3210409 \\
\hline SALÁRIOS & 8340212 & 1186371 & 1975878 & 551561 & 3964484 & 3618543 & 1064757 & 720829 & 662168 & 2352029 \\
\hline CONTRIBUIÇŌES SOCIAIS EFETIVAS & 1656614 & 729530 & 757212 & 281449 & 1319931 & 1394084 & 375533 & 266142 & 263480 & 858380 \\
\hline PREVIDÊNCIA OFICIAL/ FGTS & 1651913 & 385719 & 726379 & 203774 & 1302949 & 1389214 & 352358 & 238543 & 236069 & 838518 \\
\hline PREVIDÊNCIA PRIVADA & 4701 & 343811 & 30833 & 77675 & 16982 & 4870 & 23175 & 27599 & 27411 & 19862 \\
\hline CONTRIBUIÇÕES SOCIAIS FICTÍCIAS & 0 & 0 & 0 & 0 & 0 & 0 & 0 & 0 & 0 & 0 \\
\hline EXCEDENTE OPERACIONAL BRUTO (EOB) & 61783450 & 11210035 & 5158675 & 5358774 & 5525549 & 9963370 & 1419486 & 2674873 & 3048658 & 2129319 \\
\hline RENDIMENTO DE AUTÔNOMOS & 326553 & 106512 & 61959 & 0 & 391766 & 0 & 0 & 0 & 0 & 0 \\
\hline EOB EXCLUSIVE RENDIMENTOS DE AUTÔNOMOS & 61456897 & 11103523 & 5096716 & 5358774 & 5133783 & 9963370 & 1419486 & 2674873 & 3048658 & 2129319 \\
\hline VALOR ADICIONADO CUSTO FATORES & 71780276 & 13125936 & 7891765 & 6191784 & 10809964 & 14975997 & 2859776 & 3661844 & 3974306 & 5339728 \\
\hline OUTROS IMPOSTOS SOBRE A PRODUÇÃO & 2943 & 1080263 & 996575 & 1466070 & 1876079 & 1412073 & 747258 & 511220 & 948977 & 1082240 \\
\hline OUTROS SUBSÍDIOS À PRODUÇĀO & -981856 & 0 & 0 & 0 & -128 & -92420 & -29748 & 0 & 0 & -190381 \\
\hline VALOR ADICIONADO PREÇO BÁSICO & 70801363 & 14206199 & 8888340 & 7657854 & 12685915 & 16295650 & 3577286 & 4173064 & 4923283 & 6231587 \\
\hline VALOR DA PRODUÇÃO & 125474454 & 23374926 & 21368428 & 31601421 & 41257262 & 28726737 & 15679278 & 10802736 & 20275960 & 22257465 \\
\hline Pessoal Ocupado & 13801692 & 222101 & 432045 & 67801 & 626720 & 344875 & 107711 & 71354 & 56340 & 166656 \\
\hline
\end{tabular}

Fonte: dados estimados pelo autor. 
Tabela A1. Matriz de insumo-produto para economia turística, Brasil, 1999 (valores correntes em 1.000 R\$).

\begin{tabular}{|c|c|c|c|c|c|c|c|c|c|c|c|}
\hline & SETORES & $\begin{array}{l}\text { MADEIRA E } \\
\text { MOBILLÁRIO }\end{array}$ & $\begin{array}{c}\text { CELULOSE, } \\
\text { PAPEL E } \\
\text { GRÁFICA }\end{array}$ & $\begin{array}{c}\text { IND. DA } \\
\text { BORRACHA }\end{array}$ & $\begin{array}{l}\text { INDÚSTRIA } \\
\text { QUIMICA }\end{array}$ & $\begin{array}{l}\text { FARMÁ́CIA E } \\
\text { VETERINÁRIA }\end{array}$ & $\begin{array}{l}\text { ARTIGOS } \\
\text { PLÁSTICOS }\end{array}$ & $\begin{array}{c}\text { IND. TÊXTIL } \\
\text { TÊXTIL }\end{array}$ & $\begin{array}{c}\text { ARTIGOS DO } \\
\text { VESTUÁRIO }\end{array}$ & $\begin{array}{l}\text { FABRICAÇÃ̃O } \\
\text { DE CALÇADOS }\end{array}$ & $\begin{array}{l}\text { INDÚSTRIA } \\
\text { DO CAFÉ }\end{array}$ \\
\hline & & 11 & 12 & 13 & 14 & 15 & 16 & 17 & 18 & 19 & 20 \\
\hline 1 & AGROPECUÁRIA & 2496174 & 718566 & 431591 & 2988171 & 35921 & 38 & 1398863 & 4862 & 41723 & 4906105 \\
\hline 2 & EXTRATIVA MINERAL & 364 & 46320 & 6578 & 13447235 & 25380 & 385 & 531 & 330 & 3467 & 199 \\
\hline 3 & MINERAL Ñ METÁLICO & 67328 & 47168 & 4918 & 288317 & 233611 & 20228 & 2853 & 1293 & 4110 & 20395 \\
\hline 4 & SIDERURGIA & 68608 & 6921 & 2914 & 407647 & 8572 & 2056 & 2510 & 945 & 1210 & 468 \\
\hline 5 & METALURGIA & 347773 & 240669 & 86551 & 704344 & 108262 & 41687 & 79372 & 34215 & 34410 & 14043 \\
\hline 6 & MÁQUINAS E EQUIP. & 80309 & 374112 & 77346 & 1020647 & 71636 & 67917 & 214609 & 20743 & 29331 & 11008 \\
\hline 7 & MATERIAL ELÉTRICO & 7007 & 13400 & 5927 & 52806 & 3952 & 5043 & 8506 & 1378 & 1869 & 947 \\
\hline 8 & EQUIP. ELETRÔNICOS & 4104 & 10644 & 2165 & 26314 & 3278 & 2993 & 7373 & 1136 & 1620 & 744 \\
\hline 9 & AUTOM./CAM/ONIBUS & 3995 & 6565 & 1446 & 16725 & 1730 & 1720 & 3552 & 775 & 917 & 409 \\
\hline 10 & PEÇAS E OUT. VEÍCULOS & 15221 & 9517 & 12299 & 27823 & 3558 & 3114 & 6014 & 1305 & 2847 & 577 \\
\hline 11 & MADEIRA E MOBILIÁRIO & 1741120 & 155351 & 5043 & 62971 & 5203 & 14789 & 13577 & 6903 & 29582 & 1380 \\
\hline 12 & CELULOSE, PAPEL E GRÁF. & 110827 & 6816977 & 22718 & 546952 & 505824 & 181825 & 129280 & 81705 & 157094 & 65502 \\
\hline 13 & IND. DA BORRACHA & 51462 & 57166 & 2044323 & 111275 & 17596 & 23492 & 56478 & 16402 & 274808 & 1455 \\
\hline 14 & INDÚSTRIA QUÍMICA & 835178 & 2228782 & 1471943 & 26737298 & 1949969 & 3261606 & 1895396 & 89772 & 454689 & 68503 \\
\hline 15 & FARMAC. E VETERINÁRIA & 4555 & 13414 & 4025 & 155286 & 917246 & 3245 & 3606 & 643 & 4099 & 364 \\
\hline 16 & ARTIGOS PLÁSTICOS & 409624 & 101899 & 16926 & 311174 & 274834 & 564388 & 132514 & 60615 & 268046 & 22061 \\
\hline 17 & IND. TÊXTIL & 156946 & 53984 & 274009 & 69878 & 10825 & 97419 & 7171573 & 3873300 & 108040 & 21058 \\
\hline 18 & ARTIGOS DO VESTUÁRIO & 2876 & 4411 & 5646 & 11183 & 2223 & 1561 & 12702 & 21314 & 4324 & 801 \\
\hline 19 & FABRICAÇÃ̃O CALÇADOS & 19638 & 3508 & 11232 & 11821 & 2092 & 3989 & 7264 & 51523 & 706972 & 157 \\
\hline 20 & INDÚSTRIA DO CAFÉ & 366 & 825 & 161 & 1059 & 900 & 152 & 389 & 190 & 148 & 2342349 \\
\hline 21 & BENEF. PROD. VEGETAIS & 6338 & 55947 & 1907 & 47408 & 44308 & 977 & 9888 & 848 & 1191 & 6991 \\
\hline 22 & ABATE DE ANIMAIS & 13538 & 4792 & 2482 & 10556 & 33381 & 258 & 3136 & 426 & 365489 & 316 \\
\hline 23 & INDÚSTRIA DE LATICIINIOS & 1169 & 2137 & 552 & 6129 & 12822 & 470 & 1186 & 554 & 1559 & 348 \\
\hline 24 & FABRICAÇÃO DE AÇÚCAR & 661 & 1517 & 261 & 526036 & 19564 & 355 & 765 & 271 & 235 & 152 \\
\hline 25 & FAB. ÓLEOS VEGETAIS & 1390 & 3320 & 875 & 558090 & 1087894 & 740 & 6408 & 619 & 875 & 293 \\
\hline 26 & OUTROS PROD. ALIMENT. & 12374 & 13082 & 2829 & 34575 & 26434 & 3162 & 9364 & 4670 & 6044 & 3294 \\
\hline 27 & INDÚSTRIAS DIVERSAS & 10108 & 217577 & 18471 & 128460 & 16915 & 17848 & 21066 & 14957 & 11568 & 9539 \\
\hline
\end{tabular}


Tabela A1. Matriz de insumo-produto para economia turística, Brasil, 1999 (valores correntes em 1.000 R\$).

\begin{tabular}{|c|c|c|c|c|c|c|c|c|c|c|c|}
\hline & SETORES & $\begin{array}{l}\text { MADEIRA E } \\
\text { MOBILLÁRIO }\end{array}$ & $\begin{array}{c}\text { CELULOSE, } \\
\text { PAPEL E } \\
\text { GRÁFICA }\end{array}$ & $\begin{array}{c}\text { IND. DA } \\
\text { BORRACHA }\end{array}$ & $\begin{array}{l}\text { INDÚSTRIA } \\
\text { QUIMICA }\end{array}$ & $\begin{array}{l}\text { FARMÁ́CIA E } \\
\text { VETERINÁRIA }\end{array}$ & $\begin{array}{l}\text { ARTIGOS } \\
\text { PLÁSTICOS }\end{array}$ & $\begin{array}{c}\text { IND. TÊXTIL } \\
\text { TÊXTIL }\end{array}$ & $\begin{array}{c}\text { ARTIGOS DO } \\
\text { VESTUÁRIO }\end{array}$ & $\begin{array}{l}\text { FABRICAÇÃ̃O } \\
\text { DE CALÇADOS }\end{array}$ & $\begin{array}{l}\text { INDÚSTRIA } \\
\text { DO CAFÉ }\end{array}$ \\
\hline & & 11 & 12 & 13 & 14 & 15 & 16 & 17 & 18 & 19 & 20 \\
\hline 28 & S.I.U.P. & 238497 & 674346 & 80608 & 1427249 & 84647 & 154849 & 328782 & 59953 & 69087 & 34623 \\
\hline 29 & CONSTRUÇÃ̃ CIVIL & 27291 & 78515 & 9094 & 177424 & 30077 & 15923 & 26905 & 9764 & 10404 & 7876 \\
\hline 30 & COMÉRCIO & 1081439 & 1807626 & 505871 & 2932408 & 1138632 & 410691 & 1090640 & 499772 & 447864 & 338059 \\
\hline 31 & TRANSP. RODOV. DE PASSAG., REGULAR & 80869 & 101922 & 25784 & 376152 & 88247 & 24552 & 66679 & 15126 & 25022 & 24960 \\
\hline 32 & TRANSP. RODOV. PASSAG., NÃO REGULAR & 5904 & 7441 & 1882 & 27463 & 6443 & 1793 & 4868 & 1104 & 1827 & 1822 \\
\hline 33 & TRANSP. REG. EXPL. POT. TURÍSTICOS & 69 & 86 & 22 & 319 & 75 & 21 & 57 & 13 & 21 & 21 \\
\hline 34 & TRANSP. RODOV. DE CARGAS & 209246 & 263318 & 66762 & 974828 & 228722 & 63457 & 172643 & 38979 & 64786 & 64605 \\
\hline 35 & OUTR. TRANSP.TERRESTRES & 13754 & 17369 & 4381 & 123102 & 9353 & 2628 & 7583 & 1746 & 685 & 1196 \\
\hline 36 & TRANSP. AQUAVIÁRIO & 2012 & 2586 & 635 & 500943 & 4008 & 1134 & 3063 & 715 & 481 & 404 \\
\hline 37 & TRANSP. AÉREO, REGULAR & 19605 & 24939 & 6223 & 216184 & 37540 & 10514 & 24066 & 5544 & 5886 & 9058 \\
\hline 38 & TRANSP. AÉREO, NÃO REGULAR & 1098 & 1396 & 348 & 12105 & 2102 & 589 & 1348 & 310 & 330 & 507 \\
\hline 39 & AGÊNC. E ORG. DE VIAGENS & 7531 & 9545 & 2395 & 158618 & 5566 & 1577 & 13602 & 3090 & 2297 & 2397 \\
\hline 40 & ATIV. AUX. TRANSP. TERRESTRE & 2631 & 3333 & 837 & 54897 & 1674 & 476 & 4154 & 945 & 802 & 838 \\
\hline 41 & ATIV. AUX.TRANSP.AQUAVIÁRIOS & 3847 & 4874 & 1224 & 80284 & 2449 & 696 & 6075 & 1382 & 1172 & 1225 \\
\hline 42 & ATIV. AUX. TRANSP. AÉREOS & 2136 & 2705 & 679 & 44563 & 1359 & 386 & 3372 & 767 & 651 & 680 \\
\hline 43 & OUTR. ATIV. AUX. TRANSPORTE & 7293 & 9238 & 2320 & 152182 & 4641 & 1319 & 11516 & 2619 & 2222 & 2322 \\
\hline 44 & COMUNICAÇŌES & 114830 & 366375 & 36805 & 428120 & 137463 & 72528 & 94097 & 58199 & 42106 & 41634 \\
\hline 45 & INSTITUIÇŌES FINANCEIRAS & 68824 & 364418 & 43483 & 1400529 & 8609 & 56886 & 238287 & 32948 & 30140 & 49730 \\
\hline 46 & ESTAB. HOTEL. E OUTR. TIPOS DE ALOJ. TEMPORÁRII & 3252 & 7694 & 1182 & 14048 & 9143 & 2296 & 2858 & 1716 & 1380 & 1024 \\
\hline 47 & REST. OUTR. ESTAB. DE SERV. DE ALIMENTAÇÃO & 7900 & 18544 & 2892 & 33793 & 21847 & 5511 & 6972 & 4156 & 3351 & 2486 \\
\hline 48 & ATIV. RECREATIVAS, CULT. E DESPORTIVAS & 9909 & 15657 & 2431 & 20295 & 391 & 2678 & 4139 & 1763 & 1735 & 2842 \\
\hline 49 & OUTR. SERV. PREST. ÀS FAMÍLIAS & 13301 & 20392 & 8533 & 27838 & 1487 & 4051 & 30988 & 26608 & 4154 & 4341 \\
\hline 50 & ALUGUEL AUTOM. OUTR. MEIOS DE TRANSPORTE & 952 & 3996 & 505 & 4818 & 4770 & 743 & 1028 & 1011 & 623 & 625 \\
\hline 51 & OUTR. SERV. PREST. ÀS EMPRESAS & 110345 & 468701 & 58721 & 564237 & 562262 & 86922 & 119337 & 118403 & 72859 & 73299 \\
\hline 52 & ALUGUEL DE IMÓVEIS & 76714 & 200943 & 17168 & 152751 & 67034 & 50947 & 62751 & 69996 & 24159 & 15816 \\
\hline 53 & ADMINISTRAÇÃO PÚBLICA & 63825 & 1012493 & 20028 & 308111 & 214599 & 41420 & 46079 & 33223 & 35928 & 22754 \\
\hline 54 & SERV. PRIV. Ñ MERCANTIS & 0 & 0 & 0 & 0 & 0 & 0 & 0 & 0 & 0 & 0 \\
\hline
\end{tabular}


Tabela A1. Matriz de insumo-produto para economia turística, Brasil, 1999 (valores correntes em 1.000 R\$).

\begin{tabular}{|c|c|c|c|c|c|c|c|c|c|c|}
\hline SETORES & $\begin{array}{l}\text { MADEIRA E } \\
\text { MOBILIÁRIO }\end{array}$ & $\begin{array}{c}\text { CELULOSE, } \\
\text { PAPEL E } \\
\text { GRÁFICA }\end{array}$ & $\begin{array}{c}\text { IND. DA } \\
\text { BORRACHA }\end{array}$ & $\begin{array}{l}\text { INDÚSTRIA } \\
\text { QUIMICA }\end{array}$ & $\begin{array}{l}\text { FARMÁCIA E } \\
\text { VETERINÁRIA }\end{array}$ & $\begin{array}{c}\text { ARTIGOS } \\
\text { PLÁSTICOS }\end{array}$ & $\begin{array}{c}\text { IND. TÊXTIL } \\
\text { TÊXTIL }\end{array}$ & $\begin{array}{l}\text { ARTIGOS DO } \\
\text { VESTUÁRIO }\end{array}$ & $\begin{array}{l}\text { FABRICAÇÃ̃O } \\
\text { DE CALÇADOS }\end{array}$ & $\begin{array}{l}\text { INDÚSTRIA } \\
\text { DO CAFÉ }\end{array}$ \\
\hline & 11 & 12 & 13 & 14 & 15 & 16 & 17 & 18 & 19 & 20 \\
\hline Produção Nacional & 8642126 & 16697026 & 5415954 & 58523441 & 8097072 & 5336044 & 13570664 & 5281548 & 3366239 & 8204605 \\
\hline Importado & 425039 & 1603927 & 713961 & 11559765 & 1127820 & 990077 & 1985708 & 409677 & 332108 & 53468 \\
\hline Imp Import & 40126 & 110648 & 76343 & 769714 & 78197 & 104353 & 177313 & 49645 & 31304 & 2762 \\
\hline ICM Nac + Importado & 462781 & 907646 & 390429 & 1169170 & 445656 & 144918 & 484337 & 560222 & 317420 & 156195 \\
\hline Zeros (ICM Impot incl acima) & 0 & 0 & 0 & 0 & 0 & 0 & 0 & 0 & 0 & 0 \\
\hline IPI Nac + Importado & 127842 & 449291 & 145355 & 389680 & 159343 & 70168 & 80833 & 22823 & 58544 & 13373 \\
\hline Zeros (IPI Import incl acima) & 0 & 0 & 0 & 0 & 0 & 0 & 0 & 0 & 0 & 0 \\
\hline Outros IIL Nac + Importado & 16083 & 88248 & 13689 & 412045 & 6938 & 17649 & 60609 & 8096 & 8069 & 10990 \\
\hline Zeros (Outros IIL Import incl acima) & 0 & 0 & 0 & 0 & 0 & 0 & 0 & 0 & 0 & 0 \\
\hline CONSUMO INTERMEDIÁRIO & 9713998 & 19856786 & 6755732 & 72823815 & 9915026 & 6663209 & 16359464 & 6332011 & 4113684 & 8441393 \\
\hline REMUNERAÇŌES & 2529167 & 3955484 & 659947 & 5621075 & 2009283 & 1677717 & 1503973 & 1333005 & 1108045 & 442480 \\
\hline SALÁRIOS & 1962737 & 2936999 & 493323 & 3477082 & 1470003 & 1215432 & 1117900 & 1056445 & 821738 & 344822 \\
\hline CONTRIBUIÇÕES SOCIAIS EFETIVAS & 566430 & 1018485 & 166624 & 2143993 & 539280 & 462285 & 386073 & 276560 & 286307 & 97658 \\
\hline PREVIDÊNCIA OFICIAL/ FGTS & 565951 & 995826 & 161622 & 1281069 & 506739 & 448106 & 383430 & 276560 & 285452 & 97658 \\
\hline PREVIDÊNCIA PRIVADA & 479 & 22659 & 5002 & 862924 & 32541 & 14179 & 2643 & 0 & 855 & 0 \\
\hline CONTRIBUIÇŌES SOCIAIS FICTÍCIAS & 0 & 0 & 0 & 0 & 0 & 0 & 0 & 0 & 0 & 0 \\
\hline EXCEDENTE OPERACIONAL BRUTO (EOB) & 2956592 & 3567603 & 2226584 & 32381856 & 4612572 & 2226105 & 2243030 & 1583131 & 808740 & 1861041 \\
\hline RENDIMENTO DE AUTÔNOMOS & 580085 & 275910 & 0 & 0 & 0 & 0 & 4856 & 1226915 & 11112 & 9453 \\
\hline EOB EXCLUSIVE RENDIMENTOS DE AUTÔNOMOS & 2376507 & 3291693 & 2226584 & 32381856 & 4612572 & 2226105 & 2238174 & 356216 & 797628 & 1851588 \\
\hline VALOR ADICIONADO CUSTO FATORES & 5485759 & 7523087 & 2886531 & 38002931 & 6621855 & 3903822 & 3747003 & 2916136 & 1916785 & 2303521 \\
\hline OUTROS IMPOSTOS SOBRE A PRODUÇÃO & 629315 & 1325230 & 476773 & 5433768 & 825430 & 541932 & 985363 & 288082 & 288772 & 505155 \\
\hline OUTROS SUBSÍDIOS À PRODUÇÃO & 0 & -46940 & 0 & 0 & 0 & 0 & -59414 & 0 & -48693 & -37422 \\
\hline VALOR ADICIONADO PREÇO BÁSICO & 6115074 & 8801377 & 3363304 & 43436699 & 7447285 & 4445754 & 4672952 & 3204218 & 2156864 & 2771254 \\
\hline VALOR DA PRODUÇÃO & 15829072 & 28658163 & 10119036 & 116260514 & 17362311 & 11108963 & 21032416 & 9536229 & 6270548 & 11212647 \\
\hline Pessoal Ocupado & 781823 & 387727 & 45168 & 270595 & 112543 & 153040 & 217230 & 1291525 & 281477 & 72780 \\
\hline
\end{tabular}

Fonte: dados estimados pelo autor. 
Tabela A1. Matriz de insumo-produto para economia turística, Brasil, 1999 (valores correntes em 1.000 R\$).

\begin{tabular}{|c|c|c|c|c|c|c|c|c|c|c|c|}
\hline & & $\begin{array}{l}\text { BENEFICIAMENTO } \\
\text { PRODUTOS }\end{array}$ & $\begin{array}{l}\text { ABATE DE } \\
\text { ANIMAIS }\end{array}$ & $\begin{array}{l}\text { INDÚSTRIA } \\
\text { DE LATICÍNIOS }\end{array}$ & $\begin{array}{l}\text { FABRICAÇÃO } \\
\text { DE AÇÚCAR }\end{array}$ & $\begin{array}{l}\text { FABICAÇĀo } \\
\text { ÓLEOS }\end{array}$ & $\begin{array}{l}\text { OUTROS } \\
\text { PRODUTOS }\end{array}$ & $\begin{array}{l}\text { INDÚSTRIAS } \\
\text { DIVERSAS }\end{array}$ & $\begin{array}{l}\text { S.I.U.P. } \\
\text { S.I.U.P. }\end{array}$ & $\begin{array}{l}\text { CONSTRUÇÃO } \\
\text { CIVIL }\end{array}$ & COMÉRCIO \\
\hline & & 21 & 22 & 23 & 24 & 25 & 26 & 27 & 28 & 29 & 30 \\
\hline 1 & AGROPECUÁRIA & 12302767 & 13300282 & 2933886 & 2493237 & 5704161 & 4464633 & 32863 & 13718 & 8412 & 529 \\
\hline 2 & EXTRATIVA MINERAL & 3303 & 8164 & 191 & 240 & 2885 & 115245 & 257280 & 16908 & 386053 & 6235 \\
\hline 3 & MINERAL Ñ METÁLICO & 142854 & 5085 & 6842 & 25798 & 6341 & 396549 & 137834 & 5295 & 11778310 & 5616 \\
\hline 4 & SIDERURGIA & 6045 & 3533 & 1612 & 1812 & 6008 & 10134 & 57366 & 1209 & 1278776 & 7246 \\
\hline 5 & METALURGIA & 270886 & 149534 & 81381 & 74088 & 299177 & 402620 & 439831 & 41012 & 8190474 & 128614 \\
\hline 6 & MÁQUINAS E EQUIP. & 109251 & 86842 & 28556 & 306877 & 62305 & 180358 & 70276 & 864339 & 1010700 & 301951 \\
\hline 7 & MATERIAL ELÉTRICO & 6458 & 4637 & 1742 & 9919 & 3738 & 10064 & 40502 & 471125 & 2501918 & 40789 \\
\hline 8 & EQUIP. ELETRÔNICOS & 5223 & 3928 & 1206 & 7272 & 2592 & 7516 & 6441 & 10729 & 43219 & 9937 \\
\hline 9 & AUTOM./CAM/ONIBUS & 3883 & 2908 & 1134 & 2765 & 3074 & 6572 & 1789 & 88379 & 51753 & 11896 \\
\hline 10 & PEÇAS E OUT. VEÍCULOS & 5947 & 4249 & 1737 & 6816 & 4387 & 9230 & 4866 & 17381 & 142142 & 9882 \\
\hline 11 & MADEIRA E MOBILIÁRIO & 69470 & 25145 & 2462 & 5981 & 7913 & 64913 & 87408 & 3671 & 2557267 & 122753 \\
\hline 12 & CELULOSE, PAPEL E GRÁF. & 446514 & 157341 & 79534 & 96035 & 121278 & 856587 & 240648 & 97272 & 97765 & 1910888 \\
\hline 13 & IND. DA BORRACHA & 13748 & 10256 & 3055 & 25334 & 6622 & 20232 & 44245 & 21040 & 279780 & 1574 \\
\hline 14 & INDÚSTRIA QUÍMICA & 329781 & 177371 & 90186 & 253820 & 286318 & 1118484 & 608378 & 473146 & 3674219 & 26377163 \\
\hline 15 & FARMAC. E VETERINÁRIA & 6783 & 10751 & 2375 & 2142 & 4917 & 139250 & 3385 & 9562 & 6080 & 8954 \\
\hline 16 & ARTIGOS PLÁSTICOS & 142374 & 221986 & 147614 & 23791 & 52067 & 308976 & 204105 & 9598 & 2206118 & 698265 \\
\hline 17 & IND. TÊXTIL & 82380 & 11214 & 3076 & 245736 & 234845 & 38370 & 140935 & 12027 & 34186 & 117002 \\
\hline 18 & ARTIGOS DO VESTUÁRIO & 2732 & 2471 & 844 & 5297 & 1114 & 3492 & 1729 & 227 & 11100 & 5527 \\
\hline 19 & FABRICAÇÃO CALÇADOS & 1067 & 22677 & 890 & 364 & 1629 & 7731 & 15555 & 265 & 14399 & 5354 \\
\hline 20 & INDÚSTRIA DO CAFÉ & 4021 & 634 & 243 & 120 & 1101 & 9035 & 151 & 260 & 1276 & 2937 \\
\hline 21 & BENEF. PROD. VEGETAIS & 749369 & 53024 & 49205 & 801 & 264698 & 4380492 & 995 & 824 & 6190 & 7586 \\
\hline 22 & ABATE DE ANIMAIS & 52697 & 1988615 & 348 & 258 & 97468 & 212881 & 7016 & 612 & 1888 & 6214 \\
\hline 23 & INDÚSTRIA DE LATICÍNIOS & 15819 & 7381 & 1477073 & 397 & 1932 & 156336 & 475 & 465 & 4109 & 4872 \\
\hline 24 & FABRICAÇÃO DE AÇÚCAR & 131084 & 750 & 36826 & 1310150 & 587 & 791468 & 244 & 16766 & 1503 & 33222 \\
\hline 25 & FAB. ÓLEOS VEGETAIS & 122871 & 9101 & 36379 & 567 & 3350710 & 2321946 & 702 & 554 & 3684 & 5048 \\
\hline 26 & OUTROS PROD. ALIMENT. & 50546 & 134550 & 20169 & 3389 & 15610 & 1565441 & 10874 & 1147 & 4221 & 91368 \\
\hline 27 & INDÚSTRIAS DIVERSAS & 12402 & 11934 & 9607 & 9370 & 8645 & 26292 & 114072 & 125833 & 387220 & 48930 \\
\hline
\end{tabular}


Tabela A1. Matriz de insumo-produto para economia turística, Brasil, 1999 (valores correntes em 1.000 R\$).

\begin{tabular}{|c|c|c|c|c|c|c|c|c|c|c|c|}
\hline & SETORES & $\begin{array}{c}\text { BENEFICIAMENTO } \\
\text { PRODUTOS } \\
\text { VEGETAIS }\end{array}$ & $\begin{array}{l}\text { ABATE DE } \\
\text { ANIMAIS }\end{array}$ & $\begin{array}{l}\text { INDÚSTRIA } \\
\text { DE LATICÍNIOS }\end{array}$ & $\begin{array}{l}\text { FABRICAÇÃO } \\
\text { DE AÇÚCAR }\end{array}$ & $\begin{array}{c}\text { FABICAÇÃO } \\
\text { ÓLEOS } \\
\text { VEGETAIS }\end{array}$ & $\begin{array}{c}\text { OUTROS } \\
\text { PRODUTOS }\end{array}$ & $\begin{array}{l}\text { INDÚSTRIAS } \\
\text { DIVERSAS }\end{array}$ & $\begin{array}{l}\text { S.I.U.P. } \\
\text { S.I.U.P. }\end{array}$ & $\begin{array}{c}\text { CONSTRUÇÃO } \\
\text { CIVIL }\end{array}$ & COMÉRCIO \\
\hline & & 21 & 22 & 23 & 24 & 25 & 26 & 27 & 28 & 29 & 30 \\
\hline 28 & S.I.U.P. & 215204 & 211567 & 64455 & 170053 & 119366 & 451664 & 73651 & 14164020 & 158569 & 1466662 \\
\hline 29 & CONSTRUÇÃO CIVIL & 26588 & 44086 & 13474 & 48096 & 13804 & 45589 & 14988 & 172467 & 5263316 & 302498 \\
\hline 30 & COMÉRCIO & 2075786 & 1425984 & 344517 & 380991 & 957895 & 2541077 & 451473 & 351346 & 4177262 & 2239134 \\
\hline 31 & TRANSP. RODOV. DE PASSAG., REGULAR & 109873 & 166974 & 36528 & 56250 & 107689 & 169376 & 29443 & 22266 & 392136 & 576281 \\
\hline 32 & TRANSP. RODOV. PASSAG., NĀO REGULAR & 8022 & 12191 & 2667 & 4107 & 7862 & 12366 & 2150 & 1626 & 28630 & 42074 \\
\hline 33 & TRANSP. REG. EXPL. DE POS TURISIICOS & 93 & 142 & 31 & 48 & 91 & 144 & 25 & 19 & 332 & 488 \\
\hline 34 & TRANSP. RODOV. DE CARGAS & 284634 & 432648 & 94577 & 145650 & 279132 & 438358 & 76116 & 52400 & 1015147 & 1481112 \\
\hline 35 & OUTR. TRANSP.TERRESTRES & 8464 & 14441 & 3171 & 2684 & 5078 & 8126 & 2832 & 10606 & 43460 & 339865 \\
\hline 36 & TRANSP. AQUAVIÁRIO & 3441 & 2055 & 459 & 904 & 1691 & 2750 & 1032 & 5301 & 9562 & 31415 \\
\hline 37 & TRANSP. AÉREO, REGULAR & 40092 & 36340 & 7993 & 20388 & 38900 & 61487 & 18304 & 61445 & 64945 & 665182 \\
\hline 38 & TRANSP. AÉREO, NÃO REGULAR & 2245 & 2035 & 448 & 1142 & 2178 & 3443 & 1025 & 3440 & 3636 & 37245 \\
\hline 39 & AGÊNC. E ORG. DE VIAGENS & 9199 & 12096 & 2657 & 5395 & 10291 & 16272 & 3929 & 4852 & 7442 & 325731 \\
\hline 40 & ATIV. AUX. TRANSP. TERRESTRE & 3224 & 3737 & 821 & 1885 & 3598 & 5686 & 1372 & 1675 & 2594 & 113827 \\
\hline 41 & ATIV. AUX.TRANSP.AQUAVIÍRIOS & 4715 & 5465 & 1201 & 2757 & 5261 & 8315 & 2007 & 2449 & 3793 & 166466 \\
\hline 42 & ATIV. AUX. TRANSP. AÉREOS & 2617 & 3033 & 667 & 1531 & 2920 & 4616 & 1114 & 1359 & 2105 & 92399 \\
\hline 43 & OUTR. ATIV. AUX. TRANSPORTE & 8938 & 10359 & 2277 & 5227 & 9973 & 15762 & 3805 & 4642 & 7190 & 315544 \\
\hline 44 & COMUNICAÇŌES & 101259 & 124909 & 37335 & 37565 & 56501 & 192213 & 86805 & 103780 & 279009 & 2033322 \\
\hline 45 & INSTITUIÇŌES FINANCEIRAS & 178949 & 247559 & 53177 & 70664 & 212101 & 294412 & 138000 & 653691 & 511245 & 2534272 \\
\hline 46 & ESTAB. HOTEL. E OUTR. TIPOS DE ALOJ. TEMPORÁRII & 3796 & 3905 & 1552 & 1433 & 1787 & 6138 & 2683 & 16627 & 9214 & 227533 \\
\hline 47 & REST. OUTR. ESTAB. DE SERV. DE ALIMENTAÇÃO & 9376 & 9511 & 3736 & 3461 & 4411 & 15007 & 6425 & 39386 & 22551 & 538783 \\
\hline 48 & ATIV. RECREATIVAS, CULT. E DESPORTIVAS & 8666 & 9311 & 3947 & 6523 & 4078 & 12402 & 3000 & 131305 & 47729 & 58546 \\
\hline 49 & OUTR. SERV. PREST. ÀS FAMILIAS & 14648 & 12131 & 4847 & 17856 & 5755 & 16766 & 5537 & 148055 & 57733 & 68957 \\
\hline 50 & ALUGUEL AUTOM. OUTR. MEIOS DE TRANSPORTE & 2284 & 1999 & 769 & 1009 & 843 & 4424 & 6742 & 6326 & 12619 & 49250 \\
\hline 51 & OUTR. SERV. PREST. ÀS EMPRESAS & 266239 & 233696 & 90311 & 118725 & 97917 & 517991 & 797118 & 746822 & 1485777 & 5806075 \\
\hline 52 & ALUGUEL DE IMÓVEIS & 50781 & 61227 & 16283 & 13852 & 23521 & 204073 & 56122 & 337970 & 170585 & 4044817 \\
\hline 53 & ADMINISTRAÇÃO PÚBLICA & 204288 & 67568 & 27594 & 35550 & 42439 & 244588 & 181270 & 155537 & 301131 & 1330837 \\
\hline 54 & SERV. PRIV. Ñ MERCANTIS & 0 & 0 & 0 & 0 & 0 & 0 & 0 & 0 & 0 & 0 \\
\hline
\end{tabular}


Tabela A1. Matriz de insumo-produto para economia turística, Brasil, 1999 (valores correntes em 1.000 R\$).

\begin{tabular}{|c|c|c|c|c|c|c|c|c|c|c|}
\hline SETORES & $\begin{array}{c}\text { BENEFICIAMENTO } \\
\text { PRODUTOS } \\
\text { VEGETAIS }\end{array}$ & $\begin{array}{l}\text { ABATE DE } \\
\text { ANIMAIS }\end{array}$ & $\begin{array}{l}\text { INDÚSTRIA } \\
\text { DE LATICÍNIOS }\end{array}$ & $\begin{array}{l}\text { FABRICAÇÃO } \\
\text { DE AÇÚCAR }\end{array}$ & $\begin{array}{c}\text { FABICAÇÃO } \\
\text { ÓLEOS } \\
\text { VEGETAIS }\end{array}$ & $\begin{array}{c}\text { OUTROS } \\
\text { PRODUTOS } \\
\text { ALIMENTARES }\end{array}$ & $\begin{array}{l}\text { INDÚSTRIAS } \\
\text { DIVERSAS }\end{array}$ & $\begin{array}{l}\text { S.I.U.P. } \\
\text { S.I.U.P. }\end{array}$ & $\begin{array}{c}\text { CONSTRUÇÃO } \\
\text { CIVIL }\end{array}$ & COMÉRCIO \\
\hline & 21 & 22 & 23 & 24 & 25 & 26 & 27 & 28 & 29 & 30 \\
\hline Produção Nacional & 18733698 & 19569333 & 5833665 & 6066124 & 12567201 & 22917893 & 4496931 & 19502777 & 48760476 & 54858666 \\
\hline Importado & 1474531 & 302928 & 257235 & 331969 & 475247 & 1048487 & 593690 & 1304480 & 3991778 & 2038419 \\
\hline Imp Import & 40200 & 15153 & 9222 & 28769 & 16113 & 59373 & 39864 & 58895 & 422404 & 41750 \\
\hline ICM Nac + Importado & 510670 & 419553 & 714585 & 244662 & 482252 & 1136139 & 199577 & 1549024 & 4398697 & 1931991 \\
\hline Zeros (ICM Impot incl acima) & 0 & 0 & 0 & 0 & 0 & 0 & 0 & 0 & 0 & 0 \\
\hline IPI Nac + Importado & 147102 & 64073 & 30669 & 42096 & 68936 & 385907 & 108411 & 132531 & 1582316 & 480175 \\
\hline Zeros (IPI Import incl acima) & 0 & 0 & 0 & 0 & 0 & 0 & 0 & 0 & 0 & 0 \\
\hline Outros IIL Nac + Importado & 66138 & 56958 & 13211 & 17124 & 54426 & 83621 & 33474 & 100546 & 139525 & 535214 \\
\hline Zeros (Outros IIL Import incl acima) & 0 & 0 & 0 & 0 & 0 & 0 & 0 & 0 & 0 & 0 \\
\hline CONSUMO INTERMEDIÁRIO & 20972340 & 20427998 & 6858588 & 6730744 & 13664175 & 25631420 & 5471947 & 22648253 & 59295196 & 59886215 \\
\hline REMUNERAÇŌES & 1527786 & 1506254 & 471788 & 676542 & 396379 & 3495034 & 1341306 & 12262304 & 9196373 & 30972534 \\
\hline SALÁRIOS & 1107966 & 1163627 & 353910 & 510027 & 298820 & 2609498 & 987364 & 8582533 & 7205977 & 23675725 \\
\hline CONTRIBUIÇÕES SOCIAIS EFETIVAS & 419820 & 342627 & 117878 & 166515 & 97559 & 885536 & 353942 & 3679771 & 1990396 & 7296809 \\
\hline PREVIDÊNCIA OFICIAL/ FGTS & 387579 & 337547 & 115546 & 166515 & 97559 & 857337 & 345821 & 2909371 & 1980139 & 7260675 \\
\hline PREVIDÊNCIA PRIVADA & 32241 & 5080 & 2332 & 0 & 0 & 28199 & 8121 & 770400 & 10257 & 36134 \\
\hline CONTRIBUIÇŌES SOCIAIS FICTÍCIAS & 0 & 0 & 0 & 0 & 0 & 0 & 0 & 0 & 0 & 0 \\
\hline EXCEDENTE OPERACIONAL BRUTO (EOB) & 3520584 & 2465342 & 1369801 & 626914 & 2657785 & 4973464 & 1964661 & 9929390 & 67506464 & 30132359 \\
\hline RENDIMENTO DE AUTÔNOMOS & 32140 & 26232 & 0 & 0 & 0 & 64988 & 115485 & 0 & 4343096 & 15394163 \\
\hline EOB EXCLUSIVE RENDIMENTOS DE AUTÔNOMOS & 3488444 & 2439110 & 1369801 & 626914 & 2657785 & 4908476 & 1849176 & 9929390 & 63163368 & 14738196 \\
\hline VALOR ADICIONADO CUSTO FATORES & 5048370 & 3971596 & 1841589 & 1303456 & 3054164 & 8468498 & 3305967 & 22191694 & 76702837 & 61104893 \\
\hline OUTROS IMPOSTOS SOBRE A PRODUÇĀO & 1221968 & 1151144 & 419266 & 400152 & 797798 & 1612262 & 422624 & 2393161 & 4815163 & 5127967 \\
\hline OUTROS SUBSÍDIOS À PRODUÇÃO & 0 & 0 & 0 & 0 & 0 & 0 & 0 & -86311 & -182611 & -439747 \\
\hline VALOR ADICIONADO PREÇO BÁSICO & 6270338 & 5122740 & 2260855 & 1703608 & 3851962 & 10080760 & 3728591 & 24498544 & 81335389 & 65793113 \\
\hline VALOR DA PRODUÇÃO & 27242678 & 25550738 & 9119443 & 8434352 & 17516137 & 35712180 & 9200538 & 47146797 & 140630585 & 125679328 \\
\hline Pessoal Ocupado & 292412 & 228116 & 54610 & 77222 & 44107 & 632004 & 235996 & 222910 & 3706878 & 8877310 \\
\hline
\end{tabular}

Fonte: dados estimados pelo autor. 
Tabela A1. Matriz de insumo-produto para economia turística, Brasil, 1999 (valores correntes em 1.000 R\$).

\begin{tabular}{|c|c|c|c|c|c|c|c|c|c|c|c|c|}
\hline & SETORES & $\begin{array}{c}\text { TRANSP. } \\
\text { RODOV. DE } \\
\text { PASSAG., } \\
\text { REGULAR }\end{array}$ & $\begin{array}{c}\text { TRANSP. } \\
\text { RODOV. } \\
\text { PASSAG., } \\
\text { NÃO REGULAR }\end{array}$ & $\begin{array}{c}\text { TRANSP. } \\
\text { REG. EXPL. } \\
\text { DE PONTOS } \\
\text { TURISTIICOS } \\
\end{array}$ & $\begin{array}{l}\text { TRANSP. } \\
\text { RODOV. } \\
\text { DE CARGAS }\end{array}$ & $\begin{array}{c}\text { OUTROS } \\
\text { TRANSP. } \\
\text { TERRESTRES }\end{array}$ & $\begin{array}{l}\text { TRANSP. } \\
\text { AQUAVIÁRIO }\end{array}$ & $\begin{array}{c}\text { TRANSP. } \\
\text { AÉREO, } \\
\text { REGULAR }\end{array}$ & $\begin{array}{c}\text { TRANSP. } \\
\text { AÉREO, } \\
\text { NÃO REGULAR }\end{array}$ & $\begin{array}{c}\text { AGÊNCIAS } \\
\text { E ORG. } \\
\text { DE VIAGENS }\end{array}$ & $\begin{array}{c}\text { ATIVIDADES } \\
\text { AUXILIARES } \\
\text { TRANSP. } \\
\text { TERRESTRE } \\
\end{array}$ & $\begin{array}{c}\text { ATIVIDADES } \\
\text { AUXILIARES } \\
\text { TRANSP. } \\
\text { AQUAVIÁRIOS }\end{array}$ \\
\hline & & 31 & 32 & 33 & 34 & 35 & 36 & 37 & 38 & 39 & 40 & 41 \\
\hline 1 & AGROPECUÁRIA & 32 & 2 & 0 & 51 & 0 & 0 & 46 & 3 & 13 & 2 & 0 \\
\hline 2 & EXTRATIVA MINERAL & 265 & 19 & 0 & 420 & 59 & 33 & 576 & 32 & 159 & 20 & 24 \\
\hline 3 & MINERAL Ñ METÁLICO & 187 & 14 & 0 & 296 & 44 & 23 & 279 & 16 & 77 & 14 & 17 \\
\hline 4 & SIDERURGIA & 600 & 44 & 1 & 948 & 1408 & 104 & 2198 & 123 & 606 & 45 & 75 \\
\hline 5 & METALURGIA & 12590 & 919 & 11 & 19913 & 76220 & 2970 & 9775 & 547 & 2697 & 944 & 2140 \\
\hline 6 & MÁQUINAS E EQUIP. & 17521 & 1279 & 15 & 27713 & 46366 & 3344 & 21929 & 1228 & 6051 & 1313 & 2409 \\
\hline 7 & MATERIAL ELÉTRICO & 2384 & 174 & 2 & 3771 & 3737 & 421 & 2743 & 154 & 757 & 179 & 303 \\
\hline 8 & EQUIP. ELETRÔNICOS & 1606 & 117 & 1 & 2541 & 1284 & 287 & 1893 & 106 & 522 & 120 & 207 \\
\hline 9 & AUTOM./CAM/ONIBUS & 3574 & 261 & 3 & 5653 & 6633 & 1229 & 9417 & 527 & 2598 & 268 & 886 \\
\hline 10 & PEÇAS E OUT. VEÍCULOS & 220699 & 16113 & 187 & 349067 & 409823 & 81925 & 638933 & 35775 & 176299 & 16539 & 59023 \\
\hline 11 & MADEIRA E MOBILIÁRIO & 14785 & 1079 & 13 & 23384 & 849 & 331 & 2094 & 117 & 578 & 1108 & 238 \\
\hline 12 & CELULOSE, PAPEL E GRÁF. & 46301 & 3380 & 39 & 73231 & 5865 & 3425 & 48559 & 2719 & 13399 & 3470 & 2467 \\
\hline 13 & IND. DA BORRACHA & 563457 & 41138 & 478 & 891188 & 48237 & 19128 & 103258 & 5782 & 28492 & 42226 & 13781 \\
\hline 14 & INDÚSTRIA QUIMIICA & 2015682 & 147164 & 1708 & 3188090 & 465366 & 117063 & 1853865 & 103802 & 511532 & 151056 & 84338 \\
\hline 15 & FARMAC. E VETERINÁRIA & 368 & 27 & 0 & 583 & 90 & 48 & 1685 & 94 & 465 & 28 & 35 \\
\hline 16 & ARTIGOS PLÁSTICOS & 190035 & 13874 & 161 & 300568 & 42307 & 25083 & 148621 & 8322 & 41009 & 14241 & 18071 \\
\hline 17 & IND. TÊXTIL & 62504 & 4563 & 53 & 98860 & 29724 & 8352 & 44047 & 2466 & 12154 & 4684 & 6017 \\
\hline 18 & ARTIGOS DO VESTUÁRIO & 1421 & 104 & 1 & 2247 & 183 & 95 & 2104 & 118 & 580 & 106 & 69 \\
\hline 19 & FABRICAÇÃO CALÇADOS & 4144 & 303 & 4 & 6554 & 511 & 252 & 1477 & 83 & 407 & 311 & 182 \\
\hline 20 & INDÚSTRIA DO CAFÉ & 144 & 11 & 0 & 228 & 29 & 19 & 173 & 10 & 48 & 11 & 14 \\
\hline 21 & BENEF. PROD. VEGETAIS & 585 & 43 & 0 & 925 & 133 & 85 & 2156 & 121 & 595 & 44 & 61 \\
\hline 22 & ABATE DE ANIMAIS & 237 & 17 & 0 & 374 & 44 & 31 & 1801 & 101 & 497 & 18 & 23 \\
\hline 23 & INDÚSTRIA DE LATICIINIOS & 406 & 30 & 0 & 641 & 94 & 58 & 414 & 23 & 114 & 30 & 42 \\
\hline 24 & FABRICAÇÃO DE AÇÚCAR & 294 & 21 & 0 & 465 & 79 & 29 & 250 & 14 & 69 & 22 & 21 \\
\hline 25 & FAB. ÓLEOS VEGETAIS & 357 & 26 & 0 & 564 & 100 & 53 & 806 & 45 & 222 & 27 & 38 \\
\hline 26 & OUTROS PROD. ALIMENT. & 751 & 55 & 1 & 1188 & 103 & 295 & 210470 & 11785 & 58075 & 56 & 212 \\
\hline 27 & INDÚSTRIAS DIVERSAS & 13579 & 991 & 12 & 21477 & 3189 & 1707 & 9563 & 535 & 2639 & 1018 & 1230 \\
\hline
\end{tabular}


Tabela A1. Matriz de insumo-produto para economia turística, Brasil, 1999 (valores correntes em 1.000 R\$).

\begin{tabular}{|c|c|c|c|c|c|c|c|c|c|c|c|c|}
\hline & SETORES & $\begin{array}{c}\text { TRANSP. } \\
\text { RODOV. DE } \\
\text { PASSAG., } \\
\text { REGULAR }\end{array}$ & $\begin{array}{c}\text { TRANSP. } \\
\text { RODOV. } \\
\text { PASSAG., } \\
\text { NÃO REGULAR }\end{array}$ & $\begin{array}{c}\text { TRANSP. } \\
\text { REG. EXPL. } \\
\text { DE PONTOS } \\
\text { TURISTIICOS }\end{array}$ & $\begin{array}{l}\text { TRANSP. } \\
\text { RODOV. } \\
\text { DE CARGAS }\end{array}$ & $\begin{array}{c}\text { OUTROS } \\
\text { TRANSP. } \\
\text { TERRESTRES }\end{array}$ & $\begin{array}{l}\text { TRANSP. } \\
\text { AQUAVIÁRIO }\end{array}$ & $\begin{array}{l}\text { TRANSP. } \\
\text { AÉREO, } \\
\text { REGULAR }\end{array}$ & $\begin{array}{c}\text { TRANSP. } \\
\text { AÉREO, } \\
\text { NÃO REGULAR }\end{array}$ & $\begin{array}{c}\text { AGÊNCIAS } \\
\text { E ORG. } \\
\text { DE VIAGENS }\end{array}$ & $\begin{array}{l}\text { ATIVIDADES } \\
\text { AUXILIARES } \\
\text { TRANSP. } \\
\text { TERRESTRE }\end{array}$ & $\begin{array}{c}\text { ATIVIDADES } \\
\text { AUXILIARES } \\
\text { TRANSP. } \\
\text { AQUAVIÁRIIOS }\end{array}$ \\
\hline & & 31 & 32 & 33 & 34 & 35 & 36 & 37 & 38 & 39 & 40 & 41 \\
\hline 28 & S.I.U.P. & 38276 & 2795 & 32 & 60539 & 39012 & 5596 & 37914 & 2123 & 10461 & 2868 & 4032 \\
\hline 29 & CONSTRUÇÃO CIVIL & 73015 & 5331 & 62 & 115483 & 18650 & 11107 & 59845 & 3351 & 16513 & 5472 & 8002 \\
\hline 30 & COMÉRCIO & 529712 & 38674 & 449 & 837815 & 133931 & 80228 & 448039 & 25087 & 123626 & 39697 & 57800 \\
\hline 31 & TRANSP. RODOV. DE PASSAG., REGULAR & 35822 & 2615 & 30 & 57747 & 76798 & 5791 & 86987 & 2889 & 8962 & 10547 & 31255 \\
\hline 32 & TRANSP. RODOV. PASSAG., NÃO REGULAR & 2615 & 191 & 2 & 4216 & 5607 & 423 & 6351 & 211 & 654 & 770 & 2282 \\
\hline 33 & TRANSP. REG. EXPL. DE POS TURÍSTICOS & 30 & 2 & 0 & 49 & 65 & 5 & 74 & 2 & 8 & 9 & 26 \\
\hline 34 & TRANSP. RODOV. DE CARGAS & 92164 & 6729 & 78 & 148636 & 199112 & 14917 & 224775 & 7442 & 22491 & 27317 & 81040 \\
\hline 35 & OUTR. TRANSP.TERRESTRES & 7657 & 559 & 6 & 12328 & 43 & 1588 & 15112 & 617 & 9081 & 3378 & 10016 \\
\hline 36 & TRANSP. AQUAVIÁRIO & 3225 & 235 & 3 & 5214 & 5165 & 28710 & 13502 & 259 & 37 & 1614 & 4782 \\
\hline 37 & TRANSP. AÉREO, REGULAR & 5136 & 375 & 4 & 8843 & 1193 & 40281 & 220501 & 408 & 354094 & 16281 & 48311 \\
\hline 38 & TRANSP. AÉREO, NÃO REGULAR & 288 & 21 & 0 & 495 & 67 & 2255 & 12346 & 23 & 19827 & 912 & 2705 \\
\hline 39 & AGÊNC. E ORG. DE VIAGENS & 317676 & 23193 & 269 & 513089 & 22477 & 80777 & 458949 & 25702 & 55 & 5548 & 16468 \\
\hline 40 & ATIV. AUX. TRANSP. TERRESTRE & 95519 & 6974 & 81 & 148470 & 7861 & 24285 & 77166 & 7728 & 18 & 1939 & 5755 \\
\hline 41 & ATIV. AUX.TRANSP.AQUAVIÁRIOS & 139692 & 10199 & 118 & 217130 & 11497 & 35515 & 112851 & 11302 & 27 & 2836 & 8417 \\
\hline 42 & ATIV. AUX. TRANSP. AÉREOS & 77537 & 5661 & 66 & 120520 & 6381 & 19713 & 62639 & 6273 & 15 & 1574 & 4672 \\
\hline 43 & OUTR. ATIV. AUX. TRANSPORTE & 264792 & 19332 & 224 & 411579 & 21793 & 67321 & 213914 & 21423 & 50 & 5375 & 15955 \\
\hline 44 & COMUNICAÇŌES & 139952 & 10218 & 119 & 221354 & 47865 & 24087 & 167384 & 9372 & 46186 & 10488 & 17353 \\
\hline 45 & INSTITUIÇŌES FINANCEIRAS & 176828 & 12910 & 150 & 279679 & 298999 & 29810 & 203079 & 11371 & 56035 & 13252 & 21477 \\
\hline 46 & ESTAB. HOTEL. E OUTR. TIPOS DE ALOJ. TEMPORÁRII & 5536 & 404 & 5 & 8756 & 1414 & 842 & 4539 & 254 & 1252 & 415 & 607 \\
\hline 47 & REST. OUTR. ESTAB. DE SERV. DE ALIMENTAÇĀO & 13167 & 961 & 11 & 20825 & 3362 & 2003 & 10799 & 605 & 2980 & 987 & 1443 \\
\hline 48 & ATIV. RECREATIVAS, CULT. E DESPORTIVAS & 16200 & 1183 & 14 & 25623 & 4137 & 2464 & 13282 & 744 & 3665 & 1214 & 1775 \\
\hline 49 & OUTR. SERV. PREST. ÀS FAMÍLIAS & 20498 & 1497 & 17 & 32420 & 5112 & 2975 & 17051 & 955 & 4705 & 1536 & 2143 \\
\hline 50 & ALUGUEL AUTOM. OUTR. MEIOS DE TRANSPORTE & 2146 & 157 & 2 & 3395 & 381 & 229 & 2939 & 165 & 811 & 161 & 165 \\
\hline 51 & OUTR. SERV. PREST. ÀS EMPRESAS & 253737 & 18525 & 215 & 401322 & 45037 & 27011 & 347556 & 19460 & 95900 & 19015 & 19460 \\
\hline 52 & ALUGUEL DE IMÓVEIS & 64606 & 4717 & 55 & 102183 & 4268 & 5308 & 143528 & 8036 & 39603 & 4842 & 3824 \\
\hline 53 & ADMINISTRAÇÃO PÚBLICA & 55794 & 4074 & 47 & 88247 & 14091 & 6537 & 81252 & 4549 & 22420 & 4181 & 4710 \\
\hline 54 & SERV. PRIV. Ñ MERCANTIS & 0 & 0 & 0 & 0 & 0 & 0 & 0 & 0 & 0 & 0 & 0 \\
\hline
\end{tabular}


Tabela A1. Matriz de insumo-produto para economia turística, Brasil, 1999 (valores correntes em 1.000 R\$).

\begin{tabular}{|c|c|c|c|c|c|c|c|c|c|c|c|}
\hline SETORES & $\begin{array}{l}\text { TRANSP. } \\
\text { RODOV. DE } \\
\text { PASSAG., } \\
\text { REGULAR } \\
\end{array}$ & $\begin{array}{c}\text { TRANSP. } \\
\text { RODOV. } \\
\text { PASSAG., } \\
\text { NÃO REGULAR }\end{array}$ & $\begin{array}{l}\text { TRANSP. } \\
\text { REG. EXPL. } \\
\text { DE PONTOS } \\
\text { TURÍSTICOS } \\
\end{array}$ & $\begin{array}{l}\text { TRANSP. } \\
\text { RODOV. } \\
\text { DE CARGAS }\end{array}$ & $\begin{array}{c}\text { OUTROS } \\
\text { TRANSP. } \\
\text { TERRESTRES }\end{array}$ & $\begin{array}{l}\text { TRANSP. } \\
\text { AQUAVIÍRIO }\end{array}$ & $\begin{array}{c}\text { TRANSP. } \\
\text { AÉREO, } \\
\text { REGULAR }\end{array}$ & $\begin{array}{c}\text { TRANSP. } \\
\text { AÉREO, } \\
\text { NÃO REGULAR }\end{array}$ & $\begin{array}{c}\text { AGÊNCIAS } \\
\text { E ORG. } \\
\text { DE VIAGENS }\end{array}$ & $\begin{array}{c}\text { ATIVIDADES } \\
\text { AUXILIARES } \\
\text { TRANSP. } \\
\text { TERRESTRE }\end{array}$ & $\begin{array}{c}\text { ATIVIDADES } \\
\text { AUXILIARES } \\
\text { TRANSP. } \\
\text { AQUAVIÁRIOS } \\
\end{array}$ \\
\hline & 31 & 32 & 33 & 34 & 35 & 36 & 37 & 38 & 39 & 40 & 41 \\
\hline Produção Nacional & 5606128 & 409300 & 4751 & 8866893 & 2116795 & 786169 & 6161508 & 344997 & 1700130 & 420126 & 566397 \\
\hline Importado & 774900 & 56575 & 657 & 1225615 & 197927 & 117879 & 635131 & 35562 & 175250 & 58071 & 84926 \\
\hline Imp Import & 33198 & 2424 & 28 & 52507 & 28504 & 5716 & 28431 & 1592 & 7845 & 2488 & 4118 \\
\hline ICM Nac + Importado & 393656 & 28741 & 334 & 622623 & 69474 & 32818 & 192728 & 10791 & 53179 & 29501 & 23644 \\
\hline Zeros (ICM Impot incl acima) & 0 & 0 & 0 & 0 & 0 & 0 & 0 & 0 & 0 & 0 & 0 \\
\hline IPI Nac + Importado & 114452 & 8356 & 97 & 181022 & 18399 & 5507 & 42347 & 2371 & 11685 & 8577 & 3968 \\
\hline Zeros (IPI Import incl acima) & 0 & 0 & 0 & 0 & 0 & 0 & 0 & 0 & 0 & 0 & 0 \\
\hline Outros IIL Nac + Importado & 37189 & 2715 & 32 & 58820 & 9499 & 5657 & 30482 & 1707 & 8411 & 2787 & 4076 \\
\hline Zeros (Outros IIL Import incl acima) & 0 & 0 & 0 & 0 & 0 & 0 & 0 & 0 & 0 & 0 & 0 \\
\hline CONSUMO INTERMEDIÁRIO & 6959522 & 508110 & 5898 & 11007481 & 2440597 & 953746 & 7090626 & 397021 & 1956499 & 521551 & 687129 \\
\hline REMUNERAÇŌES & 3033647 & 221484 & 2571 & 4798147 & 774861 & 461484 & 2486469 & 139223 & 686085 & 227343 & 332478 \\
\hline SALÁRIOS & 2260532 & 165040 & 1916 & 3575354 & 577390 & 343877 & 1852800 & 103743 & 511239 & 169406 & 247747 \\
\hline CONTRIBUIÇŌES SOCIAIS EFETIVAS & 773115 & 56445 & 655 & 1222792 & 197471 & 117608 & 633669 & 35481 & 174847 & 57938 & 84731 \\
\hline PREVIDÊNCIA OFICIAL/ FGTS & 726324 & 53028 & 616 & 1148785 & 185519 & 110490 & 595317 & 33333 & 164264 & 54431 & 79603 \\
\hline PREVIDÊNCIA PRIVADA & 46792 & 3416 & 40 & 74008 & 11952 & 7118 & 38352 & 2147 & 10582 & 3507 & 5128 \\
\hline CONTRIBUIÇŌES SOCIAIS FICTÍCIAS & 0 & 0 & 0 & 0 & 0 & 0 & 0 & 0 & 0 & 0 & 0 \\
\hline EXCEDENTE OPERACIONAL BRUTO (EOB) & 3740251 & 273073 & 3170 & 5915743 & 305299 & 711569 & 1363612 & 76352 & 376258 & 280297 & 512652 \\
\hline RENDIMENTO DE AUTÔNOMOS & 1702581 & 124304 & 1443 & 2692875 & 138974 & 323910 & 620723 & 34756 & 171275 & 127592 & 233362 \\
\hline EOB EXCLUSIVE RENDIMENTOS DE AUTÔNOMOS & 2037671 & 148769 & 1727 & 3222868 & 166326 & 387659 & 742889 & 41596 & 204984 & 152704 & 279290 \\
\hline VALOR ADICIONADO CUSTO FATORES & 6773898 & 494558 & 5741 & 10713890 & 1080161 & 1173054 & 3850081 & 215575 & 1062343 & 507640 & 845130 \\
\hline OUTROS IMPOSTOS SOBRE A PRODUÇÃO & 439266 & 32071 & 372 & 694762 & 99265 & 29178 & 675657 & 37832 & 186432 & 32919 & 21021 \\
\hline OUTROS SUBSÍDIOS À PRODUÇÃO & -186713 & -13632 & -158 & -295313 & -47691 & -28403 & -153035 & -8569 & -42227 & -13992 & -20463 \\
\hline VALOR ADICIONADO PREÇO BÁSICO & 7026452 & 512996 & 5955 & 11113339 & 1131735 & 1173828 & 4372703 & 244838 & 1206549 & 526566 & 845688 \\
\hline VALOR DA PRODUÇÃO & 13985974 & 1021106 & 11853 & 22120820 & 3572332 & 2127574 & 11463329 & 641859 & 3163048 & 1048117 & 1532817 \\
\hline Pessoal Ocupado & 1006073 & 52690 & 488 & 684455 & 160095 & 36871 & 72551 & 9370 & 94663 & 44438 & 31463 \\
\hline
\end{tabular}

Fonte: dados estimados pelo autor. 
Tabela A1. Matriz de insumo-produto para economia turística, Brasil, 1999 (valores correntes em 1.000 R\$).

\begin{tabular}{|c|c|c|c|c|c|c|c|c|c|c|c|}
\hline & \multirow[t]{3}{*}{ SETORES } & $\begin{array}{l}\text { ATIVIDADES } \\
\text { AUXILIARES } \\
\text { TRANSP. }\end{array}$ & $\begin{array}{c}\text { OUTRAS } \\
\text { ATIVIDADES } \\
\text { AUXILIARES }\end{array}$ & COMUNICAÇÕES & $\begin{array}{l}\text { INSTITUIÇÕES } \\
\text { FINANCEIRAS }\end{array}$ & $\begin{array}{c}\text { ESTAB. } \\
\text { HOTELEIROS E } \\
\text { OUTROS TIPOS }\end{array}$ & $\begin{array}{c}\text { RESTAURANTES } \\
\text { OUTROS ESTAB. } \\
\text { DE SERVIÇOS }\end{array}$ & $\begin{array}{l}\text { ATIVIDADES } \\
\text { RECREATIVAS, } \\
\text { CULTURAIS E }\end{array}$ & $\begin{array}{c}\text { OUTROS } \\
\text { SERVIÇOS } \\
\text { PRESTADOS }\end{array}$ & $\begin{array}{c}\text { ALUGUEL } \\
\text { AUTOMÓVEIS E } \\
\text { OUTROS MEIOS }\end{array}$ & $\begin{array}{c}\text { OUTROS } \\
\text { SERVIÇOS } \\
\text { PRESTADOS }\end{array}$ \\
\hline & & AÉREOS & TRANSPORTE & & & ALOJ. TEMPORÁRIC & DE ALIMENTAÇĀO & DESPORTIVAS & ÀS FAMíliAS & DE TRANSPORTE & ÀS EMPRESAS \\
\hline & & 42 & 43 & 44 & 45 & 46 & 47 & 48 & 49 & 50 & 51 \\
\hline 1 & AGROPECUÁRIA & 3 & 0 & 6 & 1 & 414341 & 1456686 & 61805 & 549717 & 0 & 3 \\
\hline 2 & EXTRATIVA MINERAL & 43 & 48 & 856 & 8817 & 176 & 619 & 221 & 1962 & 169 & 11434 \\
\hline 3 & MINERAL Ñ METÁLICO & 21 & 36 & 29615 & 1724 & 32649 & 114782 & 26311 & 234015 & 11 & 770 \\
\hline 4 & SIDERURGIA & 163 & 1145 & 3513 & 1528 & 575 & 2022 & 5631 & 50085 & 16 & 1068 \\
\hline 5 & METALURGIA & 726 & 61993 & 199091 & 15799 & 19863 & 69833 & 34914 & 310540 & 623 & 42230 \\
\hline 6 & MÁQUINAS E EQUIP. & 1628 & 37712 & 168765 & 47107 & 5900 & 20744 & 16417 & 146016 & 2419 & 163961 \\
\hline 7 & MATERIAL ELÉTRICO & 204 & 3040 & 272382 & 2573 & 12646 & 44459 & 11722 & 104259 & 436 & 29547 \\
\hline 8 & EQUIP. ELETRÔNICOS & 141 & 1044 & 279321 & 1520 & 567 & 1994 & 10660 & 94817 & 397 & 26942 \\
\hline 9 & AUTOM./CAM/ONIBUS & 699 & 5395 & 4455 & 6192 & 1009 & 3548 & 13684 & 121712 & 40 & 2732 \\
\hline 10 & PEÇAS E OUT. VEÍCULOS & 47422 & 333326 & 65300 & 3733 & 601 & 2111 & 276887 & 2462721 & 49 & 3332 \\
\hline 11 & MADEIRA E MOBLLIÁRIO & 155 & 690 & 2547 & 12044 & 30524 & 107312 & 5920 & 52656 & 259 & 17571 \\
\hline 12 & CELULOSE, PAPEL E GRÁF. & 3604 & 4770 & 185425 & 429026 & 50398 & 177184 & 17596 & 156501 & 48952 & 3318628 \\
\hline 13 & IND. DA BORRACHA & 7664 & 39234 & 15293 & 306 & 137 & 481 & 206825 & 1839570 & 3 & 203 \\
\hline 14 & INDÚSTRIA QUÍMICA & 137594 & 378502 & 129200 & 33872 & 49038 & 172403 & 86750 & 771582 & 3181 & 215675 \\
\hline 15 & FARMAC. E VETERINÁRIA & 125 & 73 & 780 & 2541 & 39534 & 138989 & 62987 & 560223 & 29 & 1951 \\
\hline 16 & ARTIGOS PLÁSTICOS & 11031 & 34410 & 128571 & 5175 & 24456 & 85978 & 31216 & 277643 & 306 & 20756 \\
\hline 17 & IND. TÊXTIL & 3269 & 24176 & 1703 & 14683 & 52868 & 185866 & 116167 & 1033227 & 280 & 18963 \\
\hline 18 & ARTIGOS DO VESTUÁRIO & 156 & 149 & 14846 & 750 & 909 & 3195 & 1082 & 9620 & 17 & 1186 \\
\hline 19 & FABRICAÇĀo CALÇADOS & 110 & 415 & 19856 & 414 & 2705 & 9510 & 4885 & 43449 & 3 & 226 \\
\hline 20 & INDÚSTRIA DO CAFÉ & 13 & 24 & 241 & 865 & 88901 & 312545 & 8516 & 75744 & 6 & 417 \\
\hline 21 & BENEF. PROD. VEGETAIS & 160 & 108 & 694 & 2001 & 146171 & 513888 & 7140 & 63508 & 19 & 1315 \\
\hline 22 & ABATE DE ANIMAIS & 134 & 36 & 512 & 1907 & 291329 & 1024216 & 477 & 4240 & 12 & 805 \\
\hline 23 & INDÚSTRIA DE LATICÍNIOS & 31 & 76 & 456 & 1252 & 73016 & 256700 & 4374 & 38900 & 13 & 878 \\
\hline 24 & FABRICAÇÃO DE AÇÚCAR & 19 & 64 & 1073 & 1524 & 142985 & 502688 & 159 & 1418 & 12 & 838 \\
\hline 25 & FAB. ÓLEOS VEGETAIS & 60 & 81 & 439 & 1356 & 66125 & 232474 & 9515 & 84632 & 12 & 811 \\
\hline 26 & OUTROS PROD. ALIMENT. & 15621 & 84 & 2376 & 3413 & 891255 & 3133356 & 94389 & 839524 & 22 & 1513 \\
\hline 27 & INDÚSTRIAS DIVERSAS & 710 & 2593 & 28878 & 462534 & 1457 & 5122 & 12357 & 109907 & 10516 & 712941 \\
\hline
\end{tabular}


Tabela A1. Matriz de insumo-produto para economia turística, Brasil, 1999 (valores correntes em 1.000 R\$).

\begin{tabular}{|c|c|c|c|c|c|c|c|c|c|c|c|}
\hline & \multirow[t]{3}{*}{ SETORES } & $\begin{array}{c}\text { ATIVIDADES } \\
\text { AUXILIARES } \\
\text { TRANSP. }\end{array}$ & $\begin{array}{c}\text { OUTRAS } \\
\text { ATIVIDADES } \\
\text { AUXILIARES }\end{array}$ & COMUNICAÇŌES & $\begin{array}{l}\text { INSTITUIÇÖES } \\
\text { FINANCEIRAS }\end{array}$ & $\begin{array}{c}\text { ESTAB. } \\
\text { HOTELEIROS E } \\
\text { OUTROS TIPOS }\end{array}$ & $\begin{array}{c}\text { RESTAURANTES } \\
\text { OUTROS ESTAB. } \\
\text { DE SERVIÇOS }\end{array}$ & $\begin{array}{l}\text { ATIVIDADES } \\
\text { RECREATIVAS, } \\
\text { CULTURAIS E }\end{array}$ & $\begin{array}{c}\text { OUTROS } \\
\text { SERVIÇOS } \\
\text { PRESTADOS }\end{array}$ & $\begin{array}{c}\text { ALUGUEL } \\
\text { AUtOMÓVEIS E } \\
\text { OUTROS MEIOS }\end{array}$ & $\begin{array}{c}\text { OUTROS } \\
\text { SERVIÇOS } \\
\text { PRESTADOS }\end{array}$ \\
\hline & & AÉREOS & TRANSPORTE & & & ALOJ. TEMPORÁRIC & DE ALIMENTAÇĀo & DESPORTIVAS & ÀS FAMILIAS & DE TRANSPORTE & ÀS EMPRESAS \\
\hline & & 42 & 43 & 44 & 45 & 46 & 47 & 48 & 49 & 50 & 51 \\
\hline 28 & S.I.U.P. & 2814 & 31730 & 245429 & 457426 & 134860 & 474122 & 63737 & 566898 & 4810 & 326075 \\
\hline 29 & CONSTRUÇÃO CIVIL & 4442 & 15168 & 203458 & 43 & 32275 & 113470 & 21354 & 189928 & 1961 & 132961 \\
\hline 30 & COMÉRCIO & 33253 & 108932 & 414830 & 1117241 & 367677 & 1292631 & 219906 & 1953525 & 13323 & 903218 \\
\hline 31 & TRANSP. RODOV. DE PASSAG., REGULAR & 15082 & 39305 & 64341 & 137283 & 657 & 8302 & 33309 & 103573 & 915 & 62049 \\
\hline 32 & TRANSP. RODOV. PASSAG., NÃO REGULAR & 1101 & 2870 & 4698 & 10023 & 48 & 606 & 2432 & 7562 & 67 & 4530 \\
\hline 33 & TRANSP. REG. EXPL. DE POS TURÍSTICOS & 13 & 33 & 55 & 116 & 1 & 7 & 28 & 88 & 1 & 53 \\
\hline 34 & TRANSP. RODOV. DE CARGAS & 39075 & 101865 & 162327 & 310723 & 2894 & 12099 & 86322 & 268010 & 2341 & 158701 \\
\hline 35 & OUTR. TRANSP.TERRESTRES & 4831 & 12593 & 204298 & 26404 & 485 & 1455 & 4054 & 12659 & 193 & 13054 \\
\hline 36 & TRANSP. AQUAVIÁRIO & 2307 & 6013 & 9083 & 9174 & 466 & 1200 & 1665 & 5220 & 37 & 2528 \\
\hline 37 & TRANSP. AÉREO, REGULAR & 23290 & 60720 & 134432 & 505673 & 1649 & 1368 & 3909 & 12438 & 2652 & 179766 \\
\hline 38 & TRANSP. AÉREO, NÃO REGULAR & 1304 & 3400 & 7527 & 28314 & 92 & 77 & 219 & 696 & 148 & 10065 \\
\hline 39 & AGÊNC. E ORG. DE VIAGENS & 7937 & 20695 & 2717 & 23504 & 51777 & 194304 & 292 & 994 & 302 & 20498 \\
\hline 40 & ATIV. AUX. TRANSP. TERRESTRE & 2774 & 7233 & 930 & 8035 & 754 & 125 & 101 & 344 & 106 & 7157 \\
\hline 41 & ATIV. AUX.TRANSP.AQUAVIÁRIOS & 4057 & 10577 & 1361 & 11751 & 1103 & 183 & 148 & 503 & 154 & 10466 \\
\hline 42 & ATIV. AUX. TRANSP. AÉREOS & 2252 & 5871 & 755 & 6523 & 612 & 102 & 82 & 279 & 86 & 5809 \\
\hline 43 & OUTR. ATIV. AUX. TRANSPORTE & 7690 & 20050 & 2579 & 22275 & 2090 & 347 & 281 & 954 & 293 & 19839 \\
\hline 44 & COMUNICAÇŌES & 12423 & 38930 & 276218 & 1546622 & 53620 & 188511 & 39420 & 350618 & 13410 & 909094 \\
\hline 45 & INSTITUIÇŌES FINANCEIRAS & 15073 & 243188 & 435903 & 6310736 & 3302 & 11608 & 52494 & 466900 & 6692 & 453649 \\
\hline 46 & ESTAB. HOTEL. E OUTR. TIPOS DE ALOJ. TEMPORÁRII & 337 & 1150 & 70416 & 135207 & 441 & 1549 & 368 & 3272 & 449 & 30426 \\
\hline 47 & REST. OUTR. ESTAB. DE SERV. DE ALIMENTAÇÃO & 801 & 2735 & 166666 & 319988 & 1113 & 3913 & 911 & 8099 & 1064 & 72104 \\
\hline 48 & ATIV. RECREATIVAS, CULT. E DESPORTIVAS & 986 & 3365 & 112143 & 1243145 & 9019 & 31709 & 1576 & 14015 & 449 & 30449 \\
\hline 49 & OUTR. SERV. PREST. ÀS FAMILLAS & 1266 & 4158 & 126479 & 1571538 & 73291 & 257667 & 55894 & 497142 & 513 & 34798 \\
\hline 50 & ALUGUEL AUTOM. OUTR. MEIOS DE TRANSPORTE & 218 & 310 & 10381 & 54527 & 224 & 787 & 907 & 8067 & 258 & 17462 \\
\hline 51 & OUTR. SERV. PREST. ÀS EMPRESAS & 25796 & 36630 & 1230189 & 6464205 & 25567 & 89884 & 107243 & 953855 & 30446 & 2064056 \\
\hline 52 & ALUGUEL DE IMÓVEIS & 10653 & 3472 & 286089 & 1339889 & 63535 & 223366 & 2070 & 18411 & 6246 & 423457 \\
\hline 53 & ADMINISTRAÇÃO PÚBLICA & 6031 & 11461 & 251057 & 1254966 & 17620 & 61947 & 29732 & 264074 & 12444 & 843590 \\
\hline 54 & SERV. PRIV. Ñ MERCANTIS & 0 & 0 & 0 & 0 & 0 & 0 & 0 & 0 & 0 & 0 \\
\hline
\end{tabular}


Tabela A1. Matriz de insumo-produto para economia turística, Brasil, 1999 (valores correntes em 1.000 R\$).

\begin{tabular}{|c|c|c|c|c|c|c|c|c|c|c|}
\hline SETORES & $\begin{array}{c}\text { ATIVIDADES } \\
\text { AUXIILIARES } \\
\text { TRANSP. } \\
\text { AÉREOS }\end{array}$ & $\begin{array}{c}\text { OUTRAS } \\
\text { ATIVIDADES } \\
\text { AUXILIARES } \\
\text { TRANSPORTE }\end{array}$ & COMUNICAÇÖES & $\begin{array}{l}\text { INSTITUIÇŌES } \\
\text { FINANCEIRAS }\end{array}$ & $\begin{array}{c}\text { ESTAB. } \\
\text { HOTELEIROS E } \\
\text { OUTROS TIPOS } \\
\text { ALOJ. TEMPORÁRIC }\end{array}$ & $\begin{array}{c}\text { RESTAURANTES } \\
\text { OUTROS ESTAB. } \\
\text { DE SERVIÇOS } \\
\text { DE ALIMENTAÇĀO }\end{array}$ & $\begin{array}{l}\text { ATIVIDADES } \\
\text { RECREATIVAS, } \\
\text { CULTURAIS E } \\
\text { DESPORTIVAS }\end{array}$ & $\begin{array}{c}\text { OUTROS } \\
\text { SERVIÇOS } \\
\text { PRESTADOS } \\
\text { Às FAMÍLIAS }\end{array}$ & $\begin{array}{c}\text { ALUGUEL } \\
\text { AUTOMÓVEIS E } \\
\text { OUTROS MEIOS } \\
\text { DE TRANSPORTE }\end{array}$ & $\begin{array}{c}\text { OUTROS } \\
\text { SERVIÇOS } \\
\text { PRESTADOS } \\
\text { ÀS EMPRESAS }\end{array}$ \\
\hline & 42 & 43 & 44 & 45 & 46 & 47 & 48 & 49 & 50 & 51 \\
\hline Produção Nacional & 457307 & 1721676 & 5980555 & 23977986 & 3285306 & 11550045 & 1857061 & 15746312 & 167163 & 11332550 \\
\hline Importado & 47139 & 160982 & 1039978 & 1516042 & 202623 & 712355 & 254241 & 2261304 & 16810 & 1139630 \\
\hline Imp Import & 2110 & 23183 & 69320 & 26627 & 783 & 2753 & 27068 & 240751 & 949 & 64320 \\
\hline ICM Nac + Importado & 14304 & 56506 & 263856 & 470346 & 297798 & 1046959 & 179973 & 1600740 & 10261 & 695657 \\
\hline Zeros (ICM Impot incl acima) & 0 & 0 & 0 & 0 & 0 & 0 & 0 & 0 & 0 & 0 \\
\hline IPI Nac + Importado & 3143 & 14964 & 153716 & 462584 & 222017 & 780538 & 18668 & 166043 & 4735 & 320972 \\
\hline Zeros (IPI Import incl acima) & 0 & 0 & 0 & 0 & 0 & 0 & 0 & 0 & 0 & 0 \\
\hline Outros IIL Nac + Importado & 2262 & 7726 & 107951 & 497038 & 7033 & 24724 & 11711 & 104165 & 1517 & 102848 \\
\hline Zeros (Outros IIL Import incl acima) & 0 & 0 & 0 & 0 & 0 & 0 & 0 & 0 & 0 & 0 \\
\hline CONSUMO INTERMEDIÁRIO & 526266 & 1985037 & 7615375 & 26950623 & 4015560 & 14117374 & 2348724 & 20119315 & 201435 & 13655977 \\
\hline REMUNERAÇŌES & 184546 & 630227 & 4333953 & 33303742 & 1836834 & 6457697 & 2089689 & 18586350 & 237897 & 16127892 \\
\hline SALÁRIOS & 137515 & 469615 & 3062388 & 26569659 & 1378167 & 4845176 & 1567883 & 13945241 & 176045 & 11934729 \\
\hline CONTRIBUIÇŌES SOCIAIS EFETIVAS & 47031 & 160611 & 1271565 & 6734083 & 458667 & 1612521 & 521806 & 4641109 & 61852 & 4193163 \\
\hline PREVIDÊNCIA OFICIAL/ FGTS & 44184 & 150891 & 984423 & 4843943 & 456708 & 1605634 & 519578 & 4621288 & 61328 & 4157631 \\
\hline PREVIDÊNCIA PRIVADA & 2846 & 9721 & 287142 & 1890140 & 1959 & 6887 & 2229 & 19821 & 524 & 35532 \\
\hline CONTRIBUIÇŌES SOCIAIS FICTÍCIAS & 0 & 0 & 0 & 0 & 0 & 0 & 0 & 0 & 0 & 0 \\
\hline EXCEDENTE OPERACIONAL BRUTO (EOB) & 101207 & 248313 & 11777374 & 17334315 & 1033720 & 3634215 & 1634389 & 15307748 & 209128 & 14177503 \\
\hline RENDIMENTO DE AUTÔNOMOS & 46070 & 113033 & 0 & 2400121 & 623699 & 2192718 & 986115 & 9235988 & 54189 & 3673648 \\
\hline EOB EXCLUSIVE RENDIMENTOS DE AUTÔNOMOS & 55137 & 135279 & 11777374 & 14934194 & 410021 & 1441498 & 648274 & 6071760 & 154939 & 10503855 \\
\hline VALOR ADICIONADO CUSTO FATORES & 285753 & 878539 & 16111327 & 50638057 & 2870554 & 10091913 & 3724078 & 33894098 & 447025 & 30305395 \\
\hline OUTROS IMPOSTOS SOBRE A PRODUÇÃO & 50147 & 80736 & 1220120 & 3933353 & 170182 & 598305 & 115926 & 1031082 & 22950 & 1555844 \\
\hline OUTROS SUBSÍDIOS À PRODUÇÃO & -11358 & -38789 & -50386 & 0 & 0 & 0 & 0 & 0 & 0 & 0 \\
\hline VALOR ADICIONADO PREÇO BÁSICO & 324542 & 920486 & 17281061 & 54571410 & 3040736 & 10690217 & 3840004 & 34925180 & 469974 & 31861239 \\
\hline VALOR DA PRODUÇÃO & 850808 & 2905524 & 24896436 & 81522033 & 7056296 & 24807591 & 6188728 & 55044495 & 671409 & 45517216 \\
\hline Pessoal Ocupado & 96404 & 37097 & 185701 & 682035 & 713620 & 2411477 & 493004 & 4980755 & 15352 & 2239697 \\
\hline
\end{tabular}

Fonte: dados estimados pelo autor. 
Tabela A1. Matriz de insumo-produto para economia turística, Brasil, 1999 (valores correntes em 1.000 R\$).

\begin{tabular}{|c|c|c|c|c|c|c|c|c|c|c|c|c|c|c|}
\hline & \multirow[t]{2}{*}{ SETORES } & \multirow{2}{*}{$\begin{array}{l}\begin{array}{c}\text { ALUGUEL } \\
\text { DE IMÓVEIS }\end{array} \\
52\end{array}$} & $\begin{array}{l}\text { ADMINISTRAÇÃO } \\
\text { PÚBLICA }\end{array}$ & $\begin{array}{l}\text { SERVIÇOS } \\
\text { PRIV. NÃO } \\
\text { MERCANTIS }\end{array}$ & \multirow[t]{2}{*}{$\begin{array}{c}\text { DUMMY } \\
\text { FINANCEIRA }\end{array}$} & \multirow[t]{2}{*}{$\begin{array}{c}\text { Consumo } \\
\text { Intermediário } \\
\text { TOTAL }\end{array}$} & \multirow[t]{2}{*}{$\begin{array}{l}\text { Formaçăo } \\
\text { de capital }\end{array}$} & \multirow[t]{2}{*}{ Exportação } & \multirow[t]{2}{*}{$\begin{array}{l}\text { Variaçăo } \\
\text { de Estoque }\end{array}$} & \multirow{2}{*}{\multicolumn{2}{|c|}{$\begin{array}{l}\text { Cosumo de } \\
\text { Adm. Publica }\end{array}$}} & \multirow[t]{2}{*}{$\begin{array}{l}\text { Consumo das } \\
\text { Familias }\end{array}$} & \multirow[t]{2}{*}{$\begin{array}{c}\text { Demanda } \\
\text { Final } \\
\text { TOTAL }\end{array}$} & \multirow[t]{2}{*}{$\begin{array}{c}\text { PRODUÇÃO } \\
\text { TOTAL }\end{array}$} \\
\hline & & & 53 & 54 & & & & & & & & & & \\
\hline 1 & AGROPECUÁRIA & 0 & 1860462 & 54045 & 0 & 1914507 & 2067463 & 4333306 & 6519772 & rata & 0 & 34191913 & 47112454 & 49026962 \\
\hline 2 & EXTRATIVA MINERAL & 562 & 14983 & 824 & 0 & 16370 & 11371 & 5029363 & 427913 & se & 0 & 88385 & 5557031 & 5573401 \\
\hline 3 & MINERAL Ñ METÁLICO & 142 & 272347 & 10134 & 0 & 282623 & 10460 & 1151401 & 20184 & rata & 0 & 1178741 & 2360786 & 2643409 \\
\hline 4 & SIDERURGIA & 66 & 6299 & 235 & 0 & 6601 & 7308 & 5073111 & 410533 & s & 0 & 83692 & 5574644 & 5581244 \\
\hline 5 & METALURGIA & 3804 & 55593 & 7900 & 0 & 67296 & 780411 & 4387301 & 222743 & 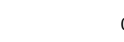 & 0 & 2598138 & 7988593 & 8055889 \\
\hline 6 & MÁQUINAS E EQUIP. & 73065 & 298484 & 4744 & 0 & 376293 & 11592330 & 4526983 & 106488 & & 0 & 1214016 & 17439817 & 17816110 \\
\hline 7 & MATERIAL ELÉTRICO & 19360 & 144030 & 1596 & 0 & 164986 & 2541598 & 1998309 & 146097 & & 0 & 4858238 & 9544241 & 9709227 \\
\hline 8 & EQUIP. ELETRÔNICOS & 1196 & 53084 & 180 & 0 & 54459 & 2883647 & 1983561 & 226271 & & 0 & 4072249 & 9165727 & 9220187 \\
\hline 9 & AUTOM./CAM/ONIBUS & 1453 & 74648 & 396 & 0 & 76498 & 4459276 & 3141361 & 227052 & sina & 0 & 11579992 & 19407682 & 19484180 \\
\hline 10 & PEÇAS E OUT. VEÍCULOS & 1650 & 481384 & 189 & 0 & 483223 & 938188 & 6401606 & 241090 & & 0 & 1982339 & 9563224 & 10046447 \\
\hline 11 & MADEIRA E MOBILIÁRIO & 1219 & 120622 & 1586 & 0 & 123426 & 1451213 & 2354008 & 49148 & & 0 & 5805975 & 9660345 & 9783771 \\
\hline 12 & CELULOSE, PAPEL E GRÁF. & 17238 & 2657230 & 20398 & 0 & 2694866 & 44380 & 2967372 & -22358 & & 0 & 4001161 & 6990555 & 9685421 \\
\hline 13 & IND. DA BORRACHA & 52 & 71295 & 38 & 0 & 71385 & 1117 & 939886 & 249621 & & 0 & 222797 & 1413421 & 1484806 \\
\hline 14 & INDÚSTRIA QUÍMICA & 3556 & 1216837 & 22086 & 0 & 1242478 & -4258 & 5976828 & -223535 & & 0 & 5421214 & 11170248 & 12412727 \\
\hline 15 & FARMAC. E VETERINÁRIA & 202 & 846824 & 310 & 0 & 847337 & 2640 & 602489 & 93932 & & 0 & 13180120 & 13879182 & 14726519 \\
\hline 16 & ARTIGOS PLÁSTICOS & 62753 & 311212 & 15896 & 0 & 389861 & 16354 & 348936 & -67712 & & 0 & 956170 & 1253749 & 1643610 \\
\hline 17 & IND. TÊXTIL & 953 & 281758 & 1382 & 0 & 284093 & 21540 & 1411907 & 242725 & & 0 & 4159823 & 5835996 & 6120089 \\
\hline 18 & ARTIGOS DO VESTUÁRIO & 67 & 48986 & 59 & 0 & 49112 & 112 & 101756 & 10604 & & 0 & 9189476 & 9301949 & 9351061 \\
\hline 19 & FABRICAÇÃO CALÇADOS & 378 & 10407 & 562 & 0 & 11347 & 131 & 2718212 & -123624 & & 0 & 2618465 & 5213184 & 5224531 \\
\hline 20 & INDÚSTRIA DO CAFÉ & 36 & 50795 & 13235 & 0 & 64066 & 1176 & 3414973 & 1841057 & & 0 & 3032750 & 8289955 & 8354022 \\
\hline 21 & BENEF. PROD. VEGETAIS & 97 & 295918 & 12957 & 0 & 308972 & 9106 & 3304807 & -30845 & & 0 & 17133280 & 20416348 & 20725320 \\
\hline 22 & ABATE DE ANIMAIS & 75 & 405168 & 53116 & 0 & 458360 & 12353 & 2408713 & 216117 & & 0 & 18236617 & 20873800 & 21332160 \\
\hline 23 & INDÚSTRIA DE LATICÍNIOS & 63 & 441910 & 11552 & 0 & 453524 & 3955 & 29043 & -67 & & 0 & 6543704 & 6576634 & 7030159 \\
\hline 24 & FABRICAÇÃO DE AÇÚCAR & 261 & 28253 & 15242 & 0 & 43756 & 1195 & 2789690 & -52773 & & 0 & 2113050 & 4851162 & 4894918 \\
\hline 25 & FAB. ÓLEOS VEGETAIS & 63 & 8142 & 10374 & 0 & 18578 & 3134 & 3616662 & 105974 & & 0 & 4867124 & 8592894 & 8611473 \\
\hline 26 & OUTROS PROD. ALIMENT. & 138 & 197335 & 47657 & 0 & 245130 & 7071 & 1919186 & 222498 & & 0 & 21800236 & 23948991 & 24194121 \\
\hline 27 & INDÚSTRIAS DIVERSAS & 29939 & 811078 & 45804 & 0 & 886820 & 776847 & 925243 & 111206 & & 0 & 3292077 & 5105373 & 5992194 \\
\hline
\end{tabular}


Tabela A1. Matriz de insumo-produto para economia turística, Brasil, 1999 (valores correntes em 1.000 R\$).

\begin{tabular}{|c|c|c|c|c|c|c|c|c|c|c|c|c|c|}
\hline & \multirow[t]{2}{*}{ SETORES } & $\begin{array}{l}\text { ALUGUEL } \\
\text { DE IMÓVEIS }\end{array}$ & $\begin{array}{l}\text { ADMINISTRAÇÃ̄O } \\
\text { PÚBLICA }\end{array}$ & $\begin{array}{l}\text { SERVIÇOS } \\
\text { PRIV. NÃO } \\
\text { MERCANTIS }\end{array}$ & \multirow[t]{2}{*}{$\begin{array}{c}\text { DUMMY } \\
\text { FINANCEIRA }\end{array}$} & \multirow[t]{2}{*}{$\begin{array}{c}\text { Consumo } \\
\text { Intermediário } \\
\text { TOTAL }\end{array}$} & \multirow[t]{2}{*}{$\begin{array}{l}\text { Formação } \\
\text { de capital }\end{array}$} & \multirow[t]{2}{*}{ Exportação } & \multirow[t]{2}{*}{$\begin{array}{c}\text { Variação } \\
\text { de Estoque }\end{array}$} & \multirow[t]{2}{*}{$\begin{array}{l}\text { Cosumo de } \\
\text { Adm. Publica }\end{array}$} & \multirow[t]{2}{*}{$\begin{array}{l}\text { Consumo das } \\
\text { Famílias }\end{array}$} & \multirow[t]{2}{*}{$\begin{array}{l}\text { Demanda } \\
\text { Final } \\
\text { TOTAL }\end{array}$} & \multirow[t]{2}{*}{$\begin{array}{c}\text { PRODUÇÃO } \\
\text { TOTAL }\end{array}$} \\
\hline & & 52 & 53 & 54 & & & & & & & & & \\
\hline 28 & S.I.U.P. & 188335 & 3300323 & 51347 & 0 & 3540005 & 15423 & 31843 & 0 & 0 & 16575421 & 16622688 & 20162693 \\
\hline 29 & CONSTRUÇÃO CIVIL & 4271633 & 1157163 & 17822 & 0 & 5446618 & 127318543 & 1875 & 277 & 0 & 8761 & 127329456 & 132776075 \\
\hline 30 & COMÉRCIO & 39807 & 5765262 & 66958 & 0 & 5872027 & 4052280 & 7408890 & 1061434 & 0 & 59360744 & 71883347 & 77755375 \\
\hline 31 & TRANSP. RODOV. DE PASSAG., REGULAR & 2032 & 358384 & 4678 & 0 & 365093 & 129763 & 1243103 & 67479 & 0 & 7509072 & 8949416 & 9314510 \\
\hline 32 & TRANSP. RODOV. PASSAG., NÃO REGULAR & 148 & 26165 & 342 & 0 & 26655 & 9474 & 90758 & 4927 & 0 & 548232 & 653391 & 680046 \\
\hline 33 & TRANSP. REG. EXPL. DE POS TURÍSTICOS & 2 & 304 & 4 & 0 & 309 & 110 & 1054 & 57 & 0 & 6364 & 7585 & 7894 \\
\hline 34 & TRANSP. RODOV. DE CARGAS & 5055 & 851974 & 11803 & 0 & 868832 & 214419 & 2054094 & 70871 & 0 & 6894524 & 9233908 & 10102739 \\
\hline 35 & OUTR. TRANSP.TERRESTRES & 278 & 346475 & 1046 & 0 & 347800 & 23297 & 220083 & 14940 & 0 & 1854077 & 2112397 & 2460196 \\
\hline 36 & TRANSP. AQUAVIÍRIO & 80 & 23585 & 176 & 0 & 23841 & 5494 & 846562 & 3497 & 0 & 489567 & 1345119 & 1368960 \\
\hline 37 & TRANSP. AÉREO, REGULAR & 150 & 258255 & 3725 & 0 & 262130 & 28 & 289 & 59120 & 0 & 7717186 & 7776624 & 8038754 \\
\hline 38 & TRANSP. AÉREO, NÃO REGULAR & 8 & 14460 & 209 & 0 & 14677 & 2 & 16 & 3310 & 0 & 432103 & 435431 & 450109 \\
\hline 39 & AGÊNC. E ORG. DE VIAGENS & 41 & 24867 & 136 & 0 & 25044 & 8 & 468365 & 8800 & 0 & 127119 & 604292 & 629336 \\
\hline 40 & ATIV. AUX. TRANSP. TERRESTRE & 14 & 8392 & 46 & 0 & 8451 & 3 & 162781 & 1713 & 0 & 218569 & 383065 & 391516 \\
\hline 41 & ATIV. AUX.TRANSP.AQUAVIÁRIOS & 20 & 12272 & 67 & 0 & 12359 & 4 & 238058 & 2505 & 0 & 319646 & 560213 & 572572 \\
\hline 42 & ATIV. AUX. TRANSP. AÉREOS & 11 & 6812 & 37 & 0 & 6860 & 2 & 132137 & 1391 & 0 & 177423 & 310953 & 317813 \\
\hline 43 & OUTR. ATIV. AUX. TRANSPORTE & 38 & 23263 & 127 & 0 & 23427 & 7 & 451251 & 4749 & 0 & 605903 & 1061909 & 1085336 \\
\hline 44 & COMUNICAÇÖES & 52942 & 1489768 & 19813 & 0 & 1562522 & 32913 & 90664 & 4635 & 0 & 13118020 & 13246232 & 14808754 \\
\hline 45 & INSTITUIÇŌES FINANCEIRAS & 220039 & 1308986 & 930 & 41217504 & 42747459 & 0 & 390242 & 0 & 0 & 18190036 & 18580278 & 61327737 \\
\hline 46 & ESTAB. HOTEL. E OUTR. TIPOS DE ALOJ. TEMPORÁl & 512 & 948513 & 1799 & 0 & 950824 & 650 & 1487645 & 176 & 0 & 3977065 & 5465535 & 6416359 \\
\hline 47 & REST. OUTR. ESTAB. DE SERV. DE ALIMENTAÇÃO & 1217 & 2244832 & 4269 & 0 & 2250318 & 2285 & 1373035 & 617 & 0 & 19658683 & 21034620 & 23284937 \\
\hline 48 & ATIV. RECREATIVAS, CULT. E DESPORTIVAS & 1458 & 2111903 & 2695 & 0 & 2116056 & 1371 & 2509 & 371 & 0 & 2075179 & 2079429 & 4195485 \\
\hline 49 & OUTR. SERV. PREST. ÀS FAMILLAS & 1677 & 3374870 & 3090 & 0 & 3379637 & 6563 & 34364 & 1201 & 0 & 48245591 & 48287719 & 51667356 \\
\hline 50 & ALUGUEL AUTOM. OUTR. MEIOS DE TRANSPORTE & 623 & 97999 & 310 & 0 & 98932 & 144 & 6840 & 39 & 0 & 325952 & 332975 & 431907 \\
\hline 51 & OUTR. SERV. PREST. ÀS EMPRESAS & 73676 & 11620946 & 36263 & 0 & 11730885 & 1498352 & 3084667 & 2638 & 0 & 949734 & 5535391 & 17266277 \\
\hline 52 & ALUGUEL DE IMÓVEIS & 47382 & 1110552 & 85736 & 0 & 1243670 & 0 & 10234 & 0 & 0 & 118224523 & 118234758 & 119478427 \\
\hline 53 & ADMINISTRAÇÃO PÚBLICA & 16976 & 2573223 & 11914 & 0 & 2602113 & 342488 & 1111679 & 20574 & 181160162 & 2445422 & 185080325 & 187682438 \\
\hline 54 & SERV. PRIV. Ñ MERCANTIS & 0 & 0 & 0 & 0 & 0 & 0 & 0 & 0 & 0 & 10631807 & 10631807 & 10631807 \\
\hline
\end{tabular}




Tabela A1. Matriz de insumo-produto para economia turística, Brasil, 1999 (valores correntes em $1.000 \mathrm{R} \$$ ).

\begin{tabular}{|c|c|c|c|c|c|c|c|c|c|c|c|c|}
\hline \multirow[t]{2}{*}{ SETORES } & $\begin{array}{l}\text { ALUGUEL } \\
\text { DE IMÓVEIS }\end{array}$ & $\begin{array}{l}\text { ADMINISTRAÇĀO } \\
\text { PÚBLICA }\end{array}$ & $\begin{array}{l}\text { SERVIÇOS } \\
\text { PRIV. NÃO } \\
\text { MERCANTIS }\end{array}$ & \multirow[t]{2}{*}{$\begin{array}{l}\text { DUMMY } \\
\text { FINANCEIRA }\end{array}$} & \multirow[t]{2}{*}{$\begin{array}{c}\text { Consumo } \\
\text { Intermediário } \\
\text { TOTAL }\end{array}$} & \multirow[t]{2}{*}{$\begin{array}{l}\text { Formação } \\
\text { de capital }\end{array}$} & \multirow[t]{2}{*}{ Exportaçăo } & \multirow[t]{2}{*}{$\begin{array}{l}\text { Variação } \\
\text { de Estoque }\end{array}$} & \multirow[t]{2}{*}{$\begin{array}{l}\text { Cosumo de } \\
\text { Adm. Publica }\end{array}$} & \multirow[t]{2}{*}{$\begin{array}{l}\text { Consumo das } \\
\text { Familias }\end{array}$} & \multirow[t]{2}{*}{$\begin{array}{c}\text { Demanda } \\
\text { Final } \\
\text { TOTAL }\end{array}$} & \multirow[t]{2}{*}{$\begin{array}{c}\text { PRODUÇÃO } \\
\text { TOTAL }\end{array}$} \\
\hline & 52 & 53 & 54 & & & & & & & & & \\
\hline Produção Nacional & 5142541 & 50124632 & 677837 & 41217504 & 705476770 & 161293740 & 94799051 & 12505434 & 181160162 & 525108462 & 974866849 & 1680343619 \\
\hline Importado & 93120 & 4636964 & 42587 & 0 & 66376707 & 14296577 & 0 & 1516916 & 0 & 30311066 & 46124559 & 112501266 \\
\hline Imp Import & 7629 & 151097 & 3376 & 0 & 4344890 & 1343065 & 0 & 103901 & 0 & 2067436 & 3514401 & 7859291 \\
\hline ICM Nac + Importado & 49372 & 1861356 & 55054 & 0 & 32206464 & 2928583 & 5223836 & 417880 & 0 & 27108655 & 35678954 & 67885418 \\
\hline Zeros (ICM Impot incl acima) & 0 & 0 & 0 & 0 & 0 & 0 & 0 & 0 & 0 & 0 & 0 & 0 \\
\hline IPI Nac + Importado & 35390 & 1034434 & 13180 & 0 & 10952054 & 1888817 & 1650448 & 84918 & 0 & 7297476 & 10921659 & 21873713 \\
\hline Zeros (IPI Import incl acima) & 0 & 0 & 0 & 0 & 0 & 0 & 0 & 0 & 0 & 0 & 0 & 0 \\
\hline Outros III Nac + Importado & 50415 & 448079 & 502 & 0 & 4292167 & 62206 & 135526 & 10311 & 0 & 2044537 & 2252581 & 6544748 \\
\hline Zeros (Outros IIL Import incl acima) & 0 & 0 & 0 & 0 & 0 & 0 & 0 & 0 & 0 & 0 & 0 & 0 \\
\hline CONSUMO INTERMEDIÁRIO & 5378467 & 58256561 & 792535 & 41217504 & 823649052 & 181812988 & 101808861 & 14639360 & 181160162 & 593937631 & 1073359002 & 1897008054 \\
\hline REMUNERAÇŌES & 1896492 & 136808780 & 9412014 & 0 & 360095569 & 0 & 0 & 0 & 0 & 0 & 0 & 360095569 \\
\hline SALÁRIOS & 1601444 & 85742112 & 7991168 & 0 & 255058945 & 0 & 0 & 0 & 0 & 0 & 0 & 255058945 \\
\hline CONTRIBUIÇÕES SOCIAIS EFETIVAS & 295048 & 5877171 & 1420846 & 0 & 59847127 & 0 & 0 & 0 & 0 & 0 & 0 & 59847127 \\
\hline PREVIDÊNCIA OFICIAL/ FGTS & 295048 & 5774389 & 1363169 & 0 & 54815862 & 0 & 0 & 0 & 0 & 0 & 0 & 54815862 \\
\hline PREVIDÊNCIA PRIVADA & 0 & 102782 & 57677 & 0 & 5031265 & 0 & 0 & 0 & 0 & 0 & 0 & 5031265 \\
\hline CONTRIBUIÇÖES SOCIAIS FICTÍCIAS & 0 & 45189497 & 0 & 0 & 45189497 & 0 & 0 & 0 & 0 & 0 & 0 & 45189497 \\
\hline EXCEDENTE OPERACIONAL BRUTO (EOB) & 120566756 & 0 & 343996 & -41217504 & 446595639 & 0 & 0 & 0 & 0 & 0 & 0 & 446595639 \\
\hline RENDIMENTO DE AUTÔNOMOS & 534284 & 0 & 0 & 0 & 49002883 & 0 & 0 & 0 & 0 & 0 & 0 & 49002883 \\
\hline EOB EXCLUSIVE RENDIMENTOS DE AUTÔNOMOS & 120032472 & 0 & 343996 & -41217504 & 397592756 & 0 & 0 & 0 & 0 & 0 & 0 & 397592756 \\
\hline VALOR ADICIONADO CUSTO FATORES & 122463248 & 136808780 & 9756010 & -41217504 & 806691208 & 0 & 0 & 0 & 0 & 0 & 0 & 806691208 \\
\hline OUTROS IMPOSTOS SOBRE A PRODUÇÃO & 773359 & 1440693 & 83262 & 0 & 53109757 & 0 & 0 & 0 & 0 & 0 & 0 & 53109757 \\
\hline OUTROS SUBSÍDIOS À PRODUÇÃO & 0 & 0 & 0 & 0 & -3106399 & 0 & 0 & 0 & 0 & 0 & 0 & -3106399 \\
\hline VALOR ADICIONADO PREÇO BÁSICO & 123236607 & 138249473 & 9839272 & -41217504 & 856694566 & 0 & 0 & 0 & 0 & 0 & 0 & 856694566 \\
\hline VALOR DA PRODUÇÃO & 128615074 & 196506034 & 10631807 & 0 & 1680343618 & 0 & 0 & 0 & 0 & 0 & 0 & 1680343618 \\
\hline Pessoal Ocupado & 266877 & 4929416 & 5253243 & 0 & 58380602 & 0 & 0 & 0 & 0 & 0 & 0 & 58380602 \\
\hline
\end{tabular}

Fonte: dados estimados pelo autor. 
Tabela A2. Valor da produção, valor adicionado (valores correntes em $1.000 \mathrm{R} \$$ ) e participação setorial no valor da produção e no valor adicionado, Brasil, 1999.

\begin{tabular}{|c|c|c|c|c|}
\hline Macro-setores & $\begin{array}{l}\text { Valor da } \\
\text { Produção }\end{array}$ & $\begin{array}{c}\text { Participação } \\
(\%)\end{array}$ & $\begin{array}{c}\text { Valor } \\
\text { Adicionado }\end{array}$ & $\begin{array}{c}\text { Participação } \\
(\%)\end{array}$ \\
\hline AGROPECUÁRIA & 125474454 & 7,47 & 70801363 & 7,89 \\
\hline INDÚSTRIA & 595510178 & 35,44 & 198072813 & 22,06 \\
\hline S.I.U.P. & 47146797 & 2,81 & 24498544 & 2,73 \\
\hline CONSTRUÇÃO CIVIL & 140630585 & 8,37 & 81335389 & 9,06 \\
\hline SERVIÇOS NÃO-TURÍSTICOS & 700671490 & 41,70 & 490942432 & 54,68 \\
\hline SERVIÇOS TURÍSTICOS & 70910119 & 4,22 & 32261533 & 3,59 \\
\hline TOTAL & 1680343622 & 100 & 897912074 & 100 \\
\hline Indústria & 595510178 & 100 & 198072813 & 100 \\
\hline EXTRATIVA MINERAL & 23374926 & 3,93 & 14206199 & 7,17 \\
\hline MINERAL Ñ METÁLICO & 21368428 & 3,59 & 8888340 & 4,49 \\
\hline SIDERURGIA & 31601421 & 5,31 & 7657854 & 3,87 \\
\hline METALURGIA & 41257262 & 6,93 & 12685915 & 6,40 \\
\hline MÁQUINAS E EQUIP. & 28726737 & 4,82 & 16295650 & 8,23 \\
\hline MATERIAL ELÉTRICO & 15679278 & 2,63 & 3577286 & 1,81 \\
\hline EQUIP. ELETRÔNICOS & 10802736 & 1,81 & 4173064 & 2,11 \\
\hline AUTOM./CAM/ONIBUS & 20275960 & 3,40 & 4923283 & 2,49 \\
\hline PEÇAS E OUT. VEÍCULOS & 22257465 & 3,74 & 6231587 & 3,15 \\
\hline MADEIRA E MOBILIÁRIO & 15829072 & 2,66 & 6115074 & 3,09 \\
\hline CELULOSE, PAPEL E GRÁF. & 28658163 & 4,81 & 8801377 & 4,44 \\
\hline IND. DA BORRACHA & 10119036 & 1,70 & 3363304 & 1,70 \\
\hline INDÚSTRIA QUÍMICA & 116260514 & 19,52 & 43436699 & 21,93 \\
\hline FARMAC. E VETERINÁRIA & 17362311 & 2,92 & 7447285 & 3,76 \\
\hline ARTIGOS PLÁSTICOS & 11108963 & 1,87 & 4445754 & 2,24 \\
\hline IND. TÊXTIL & 21032416 & 3,53 & 4672952 & 2,36 \\
\hline ARTIGOS DO VESTUÁRIO & 9536229 & 1,60 & 3204218 & 1,62 \\
\hline FABRICAÇÃO CALÇADOS & 6270548 & 1,05 & 2156864 & 1,09 \\
\hline INDÚSTRIA DO CAFÉ & 11212647 & 1,88 & 2771254 & 1,40 \\
\hline BENEF. PROD. VEGETAIS & 27242678 & 4,57 & 6270338 & 3,17 \\
\hline ABATE DE ANIMAIS & 25550738 & 4,29 & 5122740 & 2,59 \\
\hline INDÚSTRIA DE LATICÍNIOS & 9119443 & 1,53 & 2260855 & 1,14 \\
\hline FABRICAÇÃO DE AÇÚCAR & 8434352 & 1,42 & 1703608 & 0,86 \\
\hline FAB. ÓLEOS VEGETAIS & 17516137 & 2,94 & 3851962 & 1,94 \\
\hline OUTROS PROD. ALIMENT. & 35712180 & 6,00 & 10080760 & 5,09 \\
\hline INDÚSTRIAS DIVERSAS & 9200538 & 1,54 & 3728591 & 1,88 \\
\hline
\end{tabular}


Tabela A2. Valor da produção, valor adicionado(valores correntes em $1.000 \mathrm{R} \$$ ) e participação setorial no valor da produção e no valor adicionado, Brasil, 1999.

\begin{tabular}{|c|c|c|c|c|}
\hline Setores & $\begin{array}{c}\text { Valor da } \\
\text { Produção }\end{array}$ & $\begin{array}{c}\text { Participação } \\
(\%)\end{array}$ & $\begin{array}{c}\text { Valor } \\
\text { Adicionado }\end{array}$ & $\begin{array}{c}\text { Participação } \\
(\%)\end{array}$ \\
\hline Serviços turísticos & 70910119 & 100 & 32261533 & 100 \\
\hline TRANSP. RODOV. DE PASSAG., REGULAR & 13985974 & 19,72 & 7026452 & 21,78 \\
\hline TRANSP. RODOV. PASSAG., NÃO-REGULAR & 1021106 & 1,44 & 512996 & 1,59 \\
\hline TRANSP. REG. EXPL. DE PTOS. TURÍSTICOS & 11853 & 0,02 & 5955 & 0,02 \\
\hline TRANSP. AÉREO, REGULAR & 11463329 & 16,17 & 4372703 & 13,55 \\
\hline TRANSP. AÉREO, NÃO-REGULAR & 641859 & 0,91 & 244838 & 0,76 \\
\hline AGÊNC. E ORG. DE VIAGENS & 3163048 & 4,46 & 1206549 & 3,74 \\
\hline ATIV. AUX. TRANSP. TERRESTRE & 1048117 & 1,48 & 526566 & 1,63 \\
\hline ATIV. AUX. TRANSP. AÉREOS & 850808 & 1,20 & 324542 & 1,01 \\
\hline ESTAB. HOTEL. E OUTR. TIPOS DE ALOJ. TEMPORÁRIO & 7056296 & 9,95 & 3040736 & 9,43 \\
\hline REST. OUTR. ESTAB. DE SERV. DE ALIMENTAÇÃO & 24807591 & 34,98 & 10690217 & 33,14 \\
\hline ATIV. RECREATIVAS, CULT. E DESPORTIVAS & 6188728 & 8,73 & 3840004 & 11,90 \\
\hline ALUGUEL AUTOM. OUTR. MEIOS DE TRANSPORTE & 671409 & 0,95 & 469974 & 1,46 \\
\hline Serviços não-turísticos & 700671490 & 100 & 490942432 & 100 \\
\hline COMÉRCIO & 125679328 & 17,94 & 65793113 & 13,40 \\
\hline TRANSP. RODOV. DE CARGAS & 22120820 & 3,16 & 11113339 & 2,26 \\
\hline OUTR. TRANSP.TERRESTRES & 3572332 & 0,51 & 1131735 & 0,23 \\
\hline TRANSP. AQUAVIÁRIO & 2127574 & 0,30 & 1173828 & 0,24 \\
\hline ATIV. AUX.TRANSP.AQUAVIÁRIOS & 1532817 & 0,22 & 845688 & 0,17 \\
\hline OUTR. ATIV. AUX. TRANSPORTE & 2905524 & 0,41 & 920486 & 0,19 \\
\hline COMUNICAÇÕES & 24896436 & 3,55 & 17281061 & 3,52 \\
\hline INSTITUIÇÕES FINANCEIRAS & 81522033 & 11,63 & 54571410 & 11,12 \\
\hline OUTR. SERV. PREST. ÀS FAMÍLIAS & 55044495 & 7,86 & 34925180 & 7,11 \\
\hline OUTR. SERV. PREST. ÀS EMPRESAS & 45517216 & 6,50 & 31861239 & 6,49 \\
\hline ALUGUEL DE IMÓVEIS & 128615074 & 18,36 & 123236607 & 25,10 \\
\hline ADMINISTRAÇÃO PÚBLICA & 196506034 & 28,05 & 138249473 & 28,16 \\
\hline SERV. PRIV. Ñ MERCANTIS & 10631807 & 1,52 & 9839272 & 2,00 \\
\hline
\end{tabular}

Fonte: dados estimados pelo autor. 
Tabela A3. Variação dos insumos indiretos utilizados no processo produtivo, devido à implantação dos projetos de turismo contemplados no Plano Purianual 2000-2003, por região de ocorrência do investimento (valores em $R \$ 1,00$ ).

\begin{tabular}{|c|c|c|c|c|c|c|c|c|c|c|}
\hline & SETORES & AGROPECUÁRIA & $\begin{array}{c}\text { EXTRATIVA } \\
\text { MINERAL }\end{array}$ & $\begin{array}{c}\text { IND. } \\
\text { TRANSFOR- } \\
\text { MAÇÃO }\end{array}$ & S.I.U.P. & $\begin{array}{c}\text { CONSTRUÇÃOO } \\
\text { CIVIL }\end{array}$ & COMÉRCIO & $\begin{array}{c}\text { SERVIÇOS } \\
\text { TURISTICOS }\end{array}$ & $\begin{array}{l}\text { SERVIÇOS } \\
\text { NÄO } \\
\text { TURÍSTICOS }\end{array}$ & TOTAL \\
\hline \multicolumn{11}{|l|}{ NORTE } \\
\hline & AGROPECUÁRIA & 414.290 & 56.726 & 2.108 .028 & 1.800 & 255 & 56 & 65.215 & 74.654 & 2.721 .025 \\
\hline & EXTRATIVA MINERAL & 8.529 & 1.658 .271 & 2.784 .001 & 2.913 & 368.624 & 1.263 & 7.079 & 27.569 & 4.858 .250 \\
\hline & IND. DE TRANSFORMAÇÃO & 453.618 & 1.566 .699 & 26.856 .379 & 297.509 & 682.133 & 3.193 .200 & 1.267 .700 & 3.569 .873 & 37.887 .111 \\
\hline & S.I.U.P. & 10.220 & 293.578 & 1.399 .322 & 1.858 .444 & 4.805 & 156.331 & 36.328 & 371.406 & 4.130 .433 \\
\hline & CONSTRUÇÃO CIVIL & 115 & 33.577 & 157.846 & 22.629 & 159.497 & 32.243 & 24.854 & 299.727 & 730.489 \\
\hline & COMÉRCIO & 101.539 & 409.727 & 3.657 .585 & 46.100 & 126.586 & 238.668 & 207.199 & 911.972 & 5.699 .375 \\
\hline & SERVIÇOS TURISTIICOS & 15.916 & 160.065 & 567.665 & 38.093 & 17.998 & 290.705 & 260.471 & 887.465 & 2.238 .379 \\
\hline & SERVIÇOS NÃO TURÍSTICOS & 85.022 & 788.741 & 5.262 .457 & 291.448 & 117.718 & 1.934 .882 & 469.836 & 5.228 .765 & 14.178 .869 \\
\hline & Total & 1.089 .250 & 4.967.384 & 42.793 .283 & 2.558 .935 & 1.477 .617 & 5.847 .347 & 2.338 .682 & 11.371 .432 & 72.443 .931 \\
\hline \multicolumn{11}{|c|}{ NORDESTE } \\
\hline & AGROPECUÁRIA & 975.658 & 325.327 & 4.844 .621 & 2.805 & 1.116 & 117 & 55.742 & 56.144 & 6.261 .531 \\
\hline & EXTRATIVA MINERAL & 20.086 & 9.343 .640 & 7.850 .467 & 4.540 & 1.613 .695 & 2.627 & 6.733 & 23.442 & 18.865 .231 \\
\hline & IND. DE TRANSFORMAÇÃO & 1.068 .276 & 8.189 .272 & 64.411 .934 & 463.685 & 2.986 .121 & 6.639 .467 & 1.712 .741 & 4.373 .869 & 89.845 .365 \\
\hline & S.I.U.P. & 24.068 & 1.524 .288 & 3.055 .164 & 2.896.494 & 21.035 & 325.051 & 39.596 & 332.647 & 8.218 .343 \\
\hline & CONSTRUÇÃO CIVIL & 271 & 152.040 & 299.581 & 35.269 & 698.219 & 67.041 & 35.151 & 282.259 & 1.569 .831 \\
\hline & COMÉRCIO & 239.125 & 2.170 .804 & 6.973 .186 & 71.849 & 554.145 & 496.250 & 279.834 & 1.004 .832 & 11.790 .026 \\
\hline & SERVIÇOS TURÍSTICOS & 37.483 & 848.372 & 1.301 .072 & 59.371 & 78.790 & 604.449 & 361.498 & 1.041 .597 & 4.332 .632 \\
\hline & SERVIÇOS NÃO TURÍSTICOS & 200.228 & 3.755 .119 & 8.328 .392 & 454.239 & 515.326 & 4.023.107 & 651.204 & 5.520 .809 & 23.448 .423 \\
\hline & Total & 2.565 .195 & 26.308 .861 & 97.064 .419 & 3.988 .252 & 6.468 .447 & 12.158 .110 & 3.142 .499 & 12.635 .600 & 164.331 .382 \\
\hline \multicolumn{11}{|c|}{ SUDESTE } \\
\hline & AGROPECUÁRIA & 347.697 & 54.341 & 1.539 .569 & 1.011 & 206 & 36 & 26.473 & 32.021 & 2.001 .353 \\
\hline & EXTRATIVA MINERAL & 7.158 & 1.573 .600 & 1.957 .295 & 1.636 & 297.776 & 799 & 2.984 & 12.481 & 3.853 .731 \\
\hline & IND. DE TRANSFORMAÇÃO & 380.704 & 1.429 .414 & 18.141 .404 & 167.117 & 551.030 & 2.020 .689 & 604.448 & 1.720 .205 & 25.015 .010 \\
\hline & S.I.U.P. & 8.577 & 266.931 & 851.837 & 1.043 .926 & 3.882 & 98.928 & 15.999 & 159.386 & 2.449 .464 \\
\hline & CONSTRUÇÃO CIVIL & 96 & 28.529 & 91.882 & 12.711 & 128.842 & 20.404 & 12.092 & 127.051 & 421.607 \\
\hline & COMÉRCIO & 85.217 & 376.438 & 2.236 .518 & 25.895 & 102.257 & 151.031 & 98.912 & 421.846 & 3.498 .114 \\
\hline & SERVIÇOS TURÍSTICOS & 13.358 & 147.089 & 365.929 & 21.398 & 14.539 & 183.961 & 124.982 & 413.768 & 1.285 .023 \\
\hline & SERVIÇOS NÃO TURÍSTICOS & 71.356 & 686.628 & 2.788 .881 & 163.712 & 95.093 & 1.224 .413 & 225.983 & 2.368 .372 & 7.624.438 \\
\hline & Total & 914.164 & 4.562 .970 & 27.973.315 & 1.437 .406 & 1.193 .624 & 3.700 .260 & 1.111 .873 & 5.255 .129 & 46.148 .741 \\
\hline
\end{tabular}


Tabela A3. Variação dos insumos indiretos utilizados no processo produtivo, devido à implantação dos projetos de turismo contemplados no Plano Purianual 2000-2003, por região de ocorrência do investimento (valores em $R \$ 1,00$ ).

\begin{tabular}{|c|c|c|c|c|c|c|c|c|c|}
\hline SETORES & AGROPECUARIA & $\begin{array}{c}\text { EXTRATIVA } \\
\text { MINERAL }\end{array}$ & $\begin{array}{c}\text { IND. } \\
\text { TRANSFOR- } \\
\text { MAÇÃO }\end{array}$ & S.I.U.P. & $\begin{array}{c}\text { CONSTRUÇÃOO } \\
\text { CIVIL }\end{array}$ & COMÉRCIO & $\begin{array}{c}\text { SERVIÇOS } \\
\text { TURISTICOS }\end{array}$ & $\begin{array}{l}\text { SERVIÇOS } \\
\text { NÄO } \\
\text { TURÍSTICOS }\end{array}$ & TOTAL \\
\hline \multicolumn{10}{|l|}{ CENTRO-OESTE } \\
\hline AGROPECUÁRIA & 116.680 & 23.517 & 530.533 & 334 & 85 & 12 & 8.081 & 9.464 & 688.707 \\
\hline EXTRATIVA MINERAL & 2.402 & 678.560 & 724.847 & 541 & 123.344 & 278 & 927 & 3.747 & 1.534 .646 \\
\hline IND. DE TRANSFORMAÇÃO & 127.757 & 606.938 & 6.458 .379 & 55.215 & 228.247 & 701.747 & 199.405 & 552.638 & 8.930 .324 \\
\hline S.I.U.P. & 2.878 & 113.182 & 303.188 & 344.908 & 1.608 & 34.356 & 5.085 & 48.718 & 853.923 \\
\hline CONSTRUÇÃO CIVIL & 32 & 11.752 & 31.748 & 4.200 & 53.369 & 7.086 & 4.020 & 39.325 & 151.531 \\
\hline COMÉRCIO & 28.597 & 160.286 & 764.467 & 8.556 & 42.357 & 52.450 & 32.619 & 133.212 & 1.222 .544 \\
\hline SERVIÇOS TURISTIICOS & 4.483 & 62.635 & 130.140 & 7.070 & 6.022 & 63.886 & 41.465 & 132.405 & 448.106 \\
\hline SERVIÇOS NÃO TURÍSTICOS & 23.946 & 285.887 & 937.133 & 54.090 & 39.389 & 425.215 & 74.909 & 743.468 & 2.584 .038 \\
\hline Total & 306.776 & 1.942 .757 & 9.880 .435 & 474.913 & 494.421 & 1.285 .030 & 366.510 & 1.662.977 & 16.413 .819 \\
\hline \multicolumn{10}{|l|}{ SUL } \\
\hline AGROPECUÁRIA & 364.992 & 71.146 & 1.660 .053 & 1.061 & 260 & 39 & 26.399 & 30.993 & 2.154 .944 \\
\hline EXTRATIVA MINERAL & 7.514 & 2.053 .993 & 2.249.149 & 1.717 & 376.260 & 872 & 3.012 & 12.202 & 4.704 .718 \\
\hline IND. DE TRANSFORMAÇÃO & 399.640 & 1.841 .630 & 20.167 .607 & 175.366 & 696.264 & 2.203.381 & 637.914 & 1.774 .389 & 27.896.191 \\
\hline S.I.U.P. & 9.004 & 343.505 & 950.002 & 1.095 .459 & 4.905 & 107.872 & 16.426 & 158.621 & 2.685 .793 \\
\hline CONSTRUÇÃO CIVIL & 101 & 35.832 & 100.046 & 13.339 & 162.801 & 22.248 & 12.832 & 127.853 & 475.053 \\
\hline COMÉRCIO & 89.456 & 486.142 & 2.408.486 & 27.173 & 129.208 & 164.686 & 104.352 & 429.728 & 3.839.232 \\
\hline SERVIÇOS TURÍSTICOS & 14.022 & 189.967 & 407.045 & 22.454 & 18.371 & 200.593 & 132.497 & 426.053 & 1.411 .002 \\
\hline SERVIÇOS NÃO TURISTICOS & 74.905 & 870.167 & 2.975 .930 & 171.794 & 120.157 & 1.335 .113 & 239.368 & 2.403 .170 & 8.190 .603 \\
\hline Total & 959.635 & 5.892 .381 & 30.918 .319 & 1.508 .364 & 1.508 .226 & 4.034 .803 & 1.172 .800 & 5.363 .008 & 51.357 .536 \\
\hline \multicolumn{10}{|l|}{ REGIÃO NÃO ESPECIFICADA } \\
\hline AGROPECUÁRIA & 1.095 .237 & 5.911 & 4.442.276 & 3.042 & 357 & 99 & 83.478 & 108.784 & 5.739 .184 \\
\hline EXTRATIVA MINERAL & 22.548 & 2.376 .199 & 4.845 .559 & 4.924 & 515.589 & 2.220 & 9.278 & 41.494 & 7.817 .810 \\
\hline IND. DE TRANSFORMAÇÃO & 1.199.207 & 2.309 .205 & 48.319 .435 & 502.829 & 954.090 & 5.612 .127 & 1.863 .002 & 5.449 .335 & 66.209 .231 \\
\hline S.I.U.P. & 27.018 & 433.748 & 2.239 .850 & 3.141 .020 & 6.721 & 274.755 & 49.729 & 513.800 & 6.686 .639 \\
\hline CONSTRUÇÃO CIVIL & 304 & 51.851 & 255.682 & 38.246 & 223.087 & 56.668 & 37.226 & 403.094 & 1.066 .158 \\
\hline COMÉRCIO & 268.432 & 600.980 & 6.389 .084 & 77.915 & 177.054 & 419.464 & 304.983 & 1.344 .772 & 9.582 .684 \\
\hline SERVIÇOS TURÍSTICOS & 42.077 & 234.747 & 972.210 & 64.383 & 25.174 & 510.921 & 383.144 & 1.303 .361 & 3.536 .017 \\
\hline SERVIÇOS TNÃO TURÍSTICOS & 224.769 & 1.199 .540 & 8.055 .570 & 492.586 & 164.651 & 3.400 .602 & 694.488 & 7.447.981 & 21.680 .187 \\
\hline Total & 2.879 .592 & 7.212.182 & 75.519 .665 & 4.324 .945 & 2.066 .722 & 10.276 .856 & 3.425.327 & 16.612 .622 & 122.317.911 \\
\hline
\end{tabular}


Tabela A3. Variação dos insumos indiretos utilizados no processo produtivo, devido à implantação dos projetos de turismo contemplados no Plano Purianual 2000-2003, por região de ocorrência do investimento (valores em $R \$ 1,00$ ).

\begin{tabular}{|c|c|c|c|c|c|c|c|c|c|c|}
\hline & SETORES & AGROPECUÁRIA & $\begin{array}{c}\text { EXTRATIVA } \\
\text { MINERAL }\end{array}$ & $\begin{array}{c}\text { IND. } \\
\text { TRANSFOR- } \\
\text { MAÇÃO }\end{array}$ & S.I.U.P. & $\begin{array}{c}\text { CONSTRUÇÃO } \\
\text { CIVIL }\end{array}$ & COMERRIO & $\begin{array}{c}\text { SERVICCOS } \\
\text { TURISTICOS }\end{array}$ & $\begin{array}{l}\text { SERVIÇOS } \\
\text { NÄO } \\
\text { TURÍSTICOS }\end{array}$ & TOTAL \\
\hline \multicolumn{11}{|l|}{ BRASIL } \\
\hline & AGROPECUÁRIA & 3.314 .556 & 611.767 & 15.125 .080 & 10.053 & 2.279 & 360 & 265.388 & 312.061 & 19.641 .543 \\
\hline & EXTRATIVA MINERAL & 68.238 & 17.684.262 & 20.411 .319 & 16.272 & 3.295 .287 & 8.059 & 30.012 & 120.935 & 41.634 .385 \\
\hline & IND. DE TRANSFORMAÇÃO & 3.629 .201 & 15.943 .158 & 184.355 .138 & 1.661 .720 & 6.097 .884 & 20.370 .610 & 6.285 .211 & 17.440 .309 & 255.783 .232 \\
\hline & S.I.U.P. & 81.764 & 2.975 .233 & 8.799 .363 & 10.380 .250 & 42.956 & 997.291 & 163.161 & 1.584 .578 & 25.024.596 \\
\hline & CONSTRUÇÃO CIVIL & 919 & 313.582 & 936.785 & 126.394 & 1.425 .815 & 205.690 & 126.175 & 1.279 .308 & 4.414 .669 \\
\hline & SERVIÇOS TURÍSTICOS & 127.341 & 1.642 .874 & 3.744 .061 & 212.768 & 160.895 & 1.854 .516 & 1.304 .057 & 4.204 .648 & 13.251.159 \\
\hline & SERVIÇOS NÃO TURÍSTICOS & 680.226 & 7.586 .082 & 28.348 .363 & 1.627 .869 & 1.052 .334 & 12.343 .332 & 2.355 .788 & 23.712 .565 & 77.706 .558 \\
\hline & Total & 8.714 .612 & 50.961 .335 & 284.149 .436 & 14.292 .814 & 13.209.057 & 37.302 .407 & 11.557.691 & 52.900 .767 & 473.088 .119 \\
\hline
\end{tabular}

Fonte: dados estimados pelo autor. 
Tabela A4. Variação dos insumos totais utilizados no processo produtivo, devido à implantação dos projetos de turismo contemplados no Plano Plurianual 2000-2003, por região de ocorrência do investimento (valores em $R \$ 1,00$ ).

\begin{tabular}{|c|c|c|c|c|c|c|c|c|c|c|}
\hline & MACRO-SETORES & AGROPECUÁRIA & $\begin{array}{c}\text { EXTRATIVA } \\
\text { MINERAL }\end{array}$ & $\begin{array}{c}\text { IND. } \\
\text { TRANSFOR- } \\
\text { MAÇÃOO }\end{array}$ & S.I.U.P. & $\begin{array}{c}\text { CONSTRUÇÃO } \\
\text { CIVIL }\end{array}$ & COMÉRCIO & $\begin{array}{l}\text { SERVIÇOS } \\
\text { TURÍSTICOS }\end{array}$ & $\begin{array}{c}\text { SERVIÇOS } \\
\text { NÃO } \\
\text { TURISTIICOS }\end{array}$ & TOTAL \\
\hline \multicolumn{11}{|l|}{ NORTE } \\
\hline & AGROPECUÁRIA & 414.290 & 56.726 & 2.108 .028 & 1.800 & 4.623 & 56 & 65.215 & 162.981 & 2.813 .720 \\
\hline & EXTRATIVA MINERAL & 8.529 & 1.658 .271 & 2.784 .001 & 2.913 & 6.685 .280 & 1.263 & 7.079 & 135.929 & 11.283 .265 \\
\hline & IND. DE TRANSFORMAÇÃO & 453.618 & 1.566 .699 & 26.856 .379 & 297.509 & 12.371.019 & 3.193 .200 & 1.267 .700 & 31.519 .689 & 77.525 .813 \\
\hline & S.I.U.P. & 10.220 & 293.578 & 1.399 .322 & 1.858 .444 & 87.146 & 156.331 & 36.328 & 2.344 .704 & 6.186 .073 \\
\hline & CONSTRUÇÃO CIVIL & 115 & 33.577 & 157.846 & 22.629 & 2.892 .608 & 32.243 & 24.854 & 1.097 .738 & 4.261.611 \\
\hline & COMÉRCIO & 101.539 & 409.727 & 3.657 .585 & 46.100 & 2.295 .736 & 238.668 & 207.199 & 6.439 .519 & 13.396 .073 \\
\hline & SERVIÇOS TURÍSTICOS & 15.916 & 160.065 & 567.665 & 38.093 & 326.413 & 290.705 & 260.471 & 3.455 .048 & 5.114 .377 \\
\hline & SERVIÇOS NÃO TURISTIICOS & 85.022 & 788.741 & 5.262 .457 & 291.448 & 2.134 .912 & 1.934 .882 & 469.836 & 34.161 .235 & 45.128 .533 \\
\hline & Total & 1.089 .250 & 4.967.384 & 42.793 .283 & 2.558 .935 & 26.797 .738 & 5.847 .347 & 2.338 .682 & 79.316 .844 & 165.709 .464 \\
\hline \multicolumn{11}{|c|}{ NORDESTE } \\
\hline & AGROPECUÁRIA & 975.658 & 325.327 & 4.844 .621 & 2.805 & 27.866 & 117 & 55.742 & 394.201 & 6.626 .338 \\
\hline & EXTRATIVA MINERAL & 20.086 & 9.343 .640 & 7.850 .467 & 4.540 & 40.294 .632 & 2.627 & 6.733 & 189.899 & 57.712 .624 \\
\hline & IND. DE TRANSFORMAÇÃO & 1.068 .276 & 8.189 .272 & 64.411 .934 & 463.685 & 74.564 .667 & 6.639 .467 & 1.712 .741 & 18.080 .153 & 175.130 .195 \\
\hline & S.I.U.P. & 24.068 & 1.524 .288 & 3.055 .164 & 2.896 .494 & 525.264 & 325.051 & 39.596 & 1.251 .436 & 9.641 .360 \\
\hline & CONSTRUÇÃO CIVIL & 271 & 152.040 & 299.581 & 35.269 & 17.434 .811 & 67.041 & 35.151 & 631.550 & 18.655 .714 \\
\hline & COMÉRCIO & 239.125 & 2.170 .804 & 6.973 .186 & 71.849 & 13.837 .241 & 496.250 & 279.834 & 3.785 .524 & 27.853 .813 \\
\hline & SERVIÇOS TURÍSTICOS & 37.483 & 848.372 & 1.301.072 & 59.371 & 1.967 .412 & 604.449 & 361.498 & 1.909 .662 & 7.089.319 \\
\hline & SERVIÇOS NÃO TURÍSTICOS & 200.228 & 3.755 .119 & 8.328 .392 & 454.239 & 12.867 .899 & 4.023.107 & 651.204 & 15.892 .476 & 46.172 .664 \\
\hline & Total & 2.565 .195 & 26.308 .861 & 97.064 .419 & 3.988 .252 & 161.519 .791 & 12.158 .110 & 3.142 .499 & 42.134 .901 & 348.882 .028 \\
\hline \multicolumn{11}{|c|}{ SUDESTE } \\
\hline & AGROPECUÁRIA & 347.697 & 54.341 & 1.539 .569 & 1.011 & 4.461 & 36 & 26.473 & 387.854 & 2.361.441 \\
\hline & EXTRATIVA MINERAL & 7.158 & 1.573 .600 & 1.957 .295 & 1.636 & 6.450 .592 & 799 & 2.984 & 186.870 & 10.180 .936 \\
\hline & IND. DE TRANSFORMAÇÃO & 380.704 & 1.429 .414 & 18.141 .404 & 167.117 & 11.936 .732 & 2.020 .689 & 604.448 & 15.838 .900 & 50.519 .408 \\
\hline & S.I.U.P. & 8.577 & 266.931 & 851.837 & 1.043 .926 & 84.087 & 98.928 & 15.999 & 1.104 .559 & 3.474 .843 \\
\hline & CONSTRUÇÃO CIVIL & 96 & 28.529 & 91.882 & 12.711 & 2.791 .063 & 20.404 & 12.092 & 485.767 & 3.442 .544 \\
\hline & COMÉRCIO & 85.217 & 376.438 & 2.236 .518 & 25.895 & 2.215 .144 & 151.031 & 98.912 & 3.288 .014 & 8.477 .169 \\
\hline & SERVIÇOS TURÍSTICOS & 13.358 & 147.089 & 365.929 & 21.398 & 314.954 & 183.961 & 124.982 & 1.297 .863 & 2.469 .533 \\
\hline & SERVIÇOS NÃO TURÍSTICOS & 71.356 & 686.628 & 2.788 .881 & 163.712 & 2.059 .966 & 1.224 .413 & 225.983 & 12.953 .645 & 20.174 .584 \\
\hline & Total & 914.164 & 4.562 .970 & 27.973.315 & 1.437 .406 & 25.856 .999 & 3.700 .260 & 1.111 .873 & 35.543 .472 & 101.100 .458 \\
\hline
\end{tabular}


Tabela A4. Variação dos insumos totais utilizados no processo produtivo, devido à implantação dos projetos de turismo contemplados no Plano Plurianual 2000-2003, por região de ocorrência do investimento (valores em $R \$ 1,00$ ).

\begin{tabular}{|c|c|c|c|c|c|c|c|c|c|}
\hline MACRO-SETORES & AGROPECUÁRIA & $\begin{array}{c}\text { EXTRATIVA } \\
\text { MINERAL }\end{array}$ & $\begin{array}{c}\text { IND. } \\
\text { TRANSFOR- } \\
\text { MAÇÃOO }\end{array}$ & S.I.U.P. & $\begin{array}{c}\text { CONSTRUÇÃO } \\
\text { CIVIL }\end{array}$ & COMÉRCIO & $\begin{array}{l}\text { SERVIÇOS } \\
\text { TURÍSTICOS }\end{array}$ & $\begin{array}{c}\text { SERVIÇOS } \\
\text { NÄO } \\
\text { TURISTICOS } \\
\end{array}$ & TOTAL \\
\hline \multicolumn{10}{|l|}{ CENTRO-OESTE } \\
\hline AGROPECUÁRIA & 116.680 & 23.517 & 530.533 & 334 & 1.966 & 12 & 8.081 & 111.331 & 792.454 \\
\hline EXTRATIVA MINERAL & 2.402 & 678.560 & 724.847 & 541 & 2.842 .620 & 278 & 927 & 53.226 & 4.303.401 \\
\hline IND. DE TRANSFORMAÇÃO & 127.757 & 606.938 & 6.458 .379 & 55.215 & 5.260 .230 & 701.747 & 199.405 & 4.427.476 & 17.837 .146 \\
\hline S.I.U.P. & 2.878 & 113.182 & 303.188 & 344.908 & 37.055 & 34.356 & 5.085 & 307.420 & 1.148 .073 \\
\hline CONSTRUÇÃO CIVIL & 32 & 11.752 & 31.748 & 4.200 & 1.229 .954 & 7.086 & 4.020 & 137.173 & 1.425 .965 \\
\hline COMÉRCIO & 28.597 & 160.286 & 764.467 & 8.556 & 976.160 & 52.450 & 32.619 & 920.825 & 2.943.961 \\
\hline SERVIÇOS TURÍSTICOS & 4.483 & 62.635 & 130.140 & 7.070 & 138.793 & 63.886 & 41.465 & 369.458 & 817.930 \\
\hline SERVIÇOS NÃO TURISTICOS & 23.946 & 285.887 & 937.133 & 54.090 & 907.777 & 425.215 & 74.909 & 3.594 .070 & 6.303 .027 \\
\hline Total & 306.776 & 1.942 .757 & 9.880 .435 & 474.913 & 11.394 .556 & 1.285 .030 & 366.510 & 9.920 .978 & 35.571 .955 \\
\hline \multicolumn{10}{|l|}{ SUL } \\
\hline AGROPECUÁRIA & 364.992 & 71.146 & 1.660 .053 & 1.061 & 5.935 & 39 & 26.399 & 349.276 & 2.478.901 \\
\hline EXTRATIVA MINERAL & 7.514 & 2.053 .993 & 2.249 .149 & 1.717 & 8.582 .348 & 872 & 3.012 & 168.495 & 13.067.099 \\
\hline IND. DE TRANSFORMAÇÃO & 399.640 & 1.841 .630 & 20.167 .607 & 175.366 & 15.881 .518 & 2.203 .381 & 637.914 & 14.518 .252 & 55.825 .309 \\
\hline S.I.U.P. & 9.004 & 343.505 & 950.002 & 1.095 .459 & 111.876 & 107.872 & 16.426 & 1.012 .237 & 3.646 .380 \\
\hline CONSTRUÇÃO CIVIL & 101 & 35.832 & 100.046 & 13.339 & 3.713 .438 & 22.248 & 12.832 & 452.052 & 4.349 .889 \\
\hline COMÉRCIO & 89.456 & 486.142 & 2.408 .486 & 27.173 & 2.947 .192 & 164.686 & 104.352 & 3.016 .109 & 9.243 .597 \\
\hline SERVIÇOS TURÍSTICOS & 13.862 & 188.430 & 401.806 & 21.965 & 410.136 & 196.971 & 132.034 & 1.187 .415 & 2.552 .619 \\
\hline SERVIÇOS NÕA TURISTICOS & 74.027 & 861.264 & 2.953.942 & 160.833 & 2.708 .902 & 1.333 .663 & 230.624 & 11.560 .964 & 19.884 .218 \\
\hline Total & 958.596 & 5.881 .940 & 30.891 .091 & 1.496 .913 & 34.361 .345 & 4.029 .732 & 1.163 .594 & 32.264 .800 & 111.048 .012 \\
\hline \multicolumn{10}{|l|}{ REGIÃO NÃO ESPECIFICADA } \\
\hline AGROPECUÁRIA & 1.095 .237 & 80.710 & 4.619 .321 & 3.042 & 6.043 & 99 & 1.229 .136 & 404.891 & 7.438 .480 \\
\hline EXTRATIVA MINERAL & 22.548 & 2.376 .199 & 4.868 .593 & 4.924 & 8.738 .778 & 2.220 & 501.075 & 243.773 & 16.758 .110 \\
\hline IND. DE TRANSFORMAÇÃO & 1.199.207 & 2.309 .205 & 50.880 .999 & 502.829 & 16.170 .990 & 5.612 .127 & 21.146 .017 & 38.671 .764 & 136.493 .139 \\
\hline S.I.U.P. & 27.018 & 433.748 & 2.406 .000 & 3.141 .020 & 113.915 & 274.755 & 1.231 .193 & 2.827 .648 & 10.455 .295 \\
\hline CONSTRUÇÃO CIVIL & 304 & 51.851 & 275.027 & 38.246 & 3.781 .123 & 56.668 & 433.052 & 1.324 .383 & 5.960 .655 \\
\hline COMÉRCIO & 268.432 & 600.980 & 6.834 .459 & 77.915 & 3.000 .910 & 419.464 & 4.381 .281 & 7.960 .486 & 23.543 .927 \\
\hline SERVIÇOS TURÍSTICOS & 42.077 & 234.747 & 1.020 .812 & 64.383 & 426.677 & 510.921 & 1.201.210 & 4.101.742 & 7.602 .570 \\
\hline SERVIÇOS NÃO TURÍSTICOS & 224.769 & 1.199 .540 & 8.728 .380 & 492.586 & 2.790 .687 & 3.400 .602 & 7.725 .841 & 39.363 .739 & 63.926 .146 \\
\hline Total & 2.879 .592 & 7.286 .981 & 79.633 .590 & 4.324 .945 & 35.029 .123 & 10.276 .856 & 37.848 .806 & 94.898 .427 & 272.178 .321 \\
\hline
\end{tabular}


Tabela A4. Variação dos insumos totais utilizados no processo produtivo, devido à implantação dos projetos de turismo contemplados no Plano Plurianual 2000-2003, por região de ocorrência do investimento (valores em $R \$ 1,00$ ).

\begin{tabular}{|c|c|c|c|c|c|c|c|c|c|c|}
\hline & MACRO-SETORES & AGROPECUÁRIA & $\begin{array}{l}\text { EXTRATIVA } \\
\text { MINERAL }\end{array}$ & $\begin{array}{c}\text { IND. } \\
\text { TRANSFOR- } \\
\text { MAÇÃO }\end{array}$ & S.I.U.P. & $\begin{array}{c}\text { CONSTRUÇÃO } \\
\text { CIVIL }\end{array}$ & COMÉRCIO & $\begin{array}{l}\text { SERVIÇOS } \\
\text { TURÍSTICOS }\end{array}$ & $\begin{array}{l}\text { SERVIÇOS } \\
\text { NÃO } \\
\text { TURÍSTICOS }\end{array}$ & TOTAL \\
\hline \multicolumn{11}{|l|}{ BRASIL } \\
\hline & AGROPECUÁRIA & 3.314 .556 & 611.767 & 15.302 .125 & 10.053 & 50.895 & 360 & 1.411 .046 & 1.810 .534 & 22.511 .335 \\
\hline & EXTRATIVA MINERAL & 68.238 & 17.684 .262 & 20.434 .354 & 16.272 & 73.594 .249 & 8.059 & 521.809 & 978.190 & 113.305 .434 \\
\hline & IND. TRANSFORMAÇÃO & 3.629 .201 & 15.943 .158 & 186.916.702 & 1.661 .720 & 136.185 .156 & 20.370 .610 & 25.568 .226 & 123.056 .234 & 513.331 .009 \\
\hline & S.I.U.P. & 81.764 & 2.975 .233 & 8.965 .513 & 10.380 .250 & 959.343 & 997.291 & 1.344 .626 & 8.848 .004 & 34.552 .024 \\
\hline & CONSTRUÇÃO CIVIL & 919 & 313.582 & 956.130 & 126.394 & 31.842 .996 & 205.690 & 522.001 & 4.128 .664 & 38.096 .377 \\
\hline & COMÉRCIO & 812.366 & 4.204 .377 & 22.874 .701 & 257.488 & 25.272 .383 & 1.522 .550 & 5.104 .197 & 25.410 .477 & 85.458 .539 \\
\hline & SERVIÇOS TURÍSTICOS & 127.341 & 1.642 .874 & 3.792 .663 & 212.768 & 3.593 .288 & 1.854 .516 & 2.122 .123 & 12.361 .678 & 25.707 .251 \\
\hline & SERVIÇOS NÃO TURÍSTICOS & 680.226 & 7.586 .082 & 29.021 .173 & 1.627 .869 & 23.501.974 & 12.343 .332 & 9.387 .141 & 117.960 .411 & 202.108.207 \\
\hline & Total & 8.714 .612 & 50.961 .335 & 288.263.361 & 14.292 .814 & 295.000 .285 & 37.302 .407 & 45.981 .170 & 294.554 .193 & 1.035.070.177 \\
\hline
\end{tabular}

Fonte: dados estimados pelo autor. 
Tabela A5. Variação dos insumos indiretos utilizados no processo produtivo, devido a um aumento no consumo dos turistas brasileiros e internacionais no Brasil (valores em $R \$ 1,00$ ).

\begin{tabular}{|c|c|c|c|c|c|c|c|c|c|c|}
\hline TURISTAS & MACRO-SETORES & AGROPECUÁRIA & $\begin{array}{c}\text { EXTRATIVA } \\
\text { MINERAL }\end{array}$ & $\begin{array}{c}\text { IND. } \\
\text { TRANSFOR- } \\
\text { MAÇÃO } \\
\end{array}$ & $\begin{array}{ll}\text { S.I.U.P. } \\
\text { S. }\end{array}$ & $\begin{array}{c}\text { CONSTRUÇÃO } \\
\text { CIVIL }\end{array}$ & COMÉRCIO & $\begin{array}{c}\text { SERVIÇOS } \\
\text { TURISTICOS }\end{array}$ & $\begin{array}{c}\text { SERVIÇOS } \\
\text { NÂO } \\
\text { TURISTICOS } \\
\end{array}$ & TOTAL \\
\hline \multicolumn{11}{|c|}{ BRASILEIROS } \\
\hline & AGROPECUÁRIA & 98.136 .049 & 427.785 & 363.432 .077 & 63.429 & 3.304 & 2.413 & 1.086 .061 & 1.328 .829 & 464.479.947 \\
\hline & EXTRATIVA MINERAL & 2.020 .373 & 15.370 .984 & 161.647 .103 & 102.663 & 4.777 .059 & 54.088 & 158.667 & 609.798 & 184.740 .736 \\
\hline & IND. DE TRANSFORMAÇÃO & 107.451.963 & 25.495 .229 & 1.091 .456 .453 & 10.484.167 & 8.839 .882 & 136.723 .725 & 88.618 .497 & 107.285 .329 & 1.576 .355 .245 \\
\hline & S.I.U.P. & 2.420 .843 & 4.954 .034 & 44.452 .673 & 65.491 .336 & 62.272 & 6.693 .628 & 1.460 .798 & 7.089 .628 & 132.625 .211 \\
\hline & CONSTRUÇÃO CIVIL & 27.224 & 949.815 & 5.704 .916 & 797.448 & 2.066 .953 & 1.380 .554 & 1.755 .677 & 7.022 .745 & 19.705.332 \\
\hline & COMÉRCIO & 24.052 .214 & 6.167 .004 & 159.768 .461 & 1.624.547 & 1.640 .450 & 10.219 .073 & 13.481 .021 & 22.756 .843 & 239.709 .613 \\
\hline & SERVIÇOS TURÍSTICOS & 3.770 .248 & 2.403 .684 & 26.939 .678 & 1.342 .402 & 233.243 & 12.447.162 & 27.578 .890 & 24.945 .475 & 99.660 .783 \\
\hline & SERVIÇOS NÃO TURÍSTICOS & 20.139 .859 & 19.155 .505 & 158.838 .018 & 10.270 .591 & 1.525 .531 & 82.846 .132 & 35.647 .698 & 118.087 .782 & 446.511 .116 \\
\hline & Total & 258.018 .773 & 74.924 .039 & 2.012.239.380 & 90.176 .584 & 19.148 .693 & 250.366 .775 & 169.787.308 & 289.126 .429 & 3.163 .787 .982 \\
\hline \multicolumn{11}{|c|}{ INTERNACIONAIS } \\
\hline & AGROPECUÁRIA & 51.938 .007 & 236.378 & 199.724 .647 & 34.487 & 2.049 & 1.406 & 707.374 & 735.656 & 253.380 .004 \\
\hline & EXTRATIVA MINERAL & 1.069 .272 & 9.056 .742 & 115.432 .138 & 55.818 & 2.962 .154 & 31.513 & 110.379 & 350.092 & 129.068.109 \\
\hline & IND. DE TRANSFORMAÇÃO & 56.868 .408 & 16.777 .011 & 673.258 .995 & 5.700 .265 & 5.481 .426 & 79.659 .183 & 85.224 .211 & 69.336 .598 & 992.306 .097 \\
\hline & S.I.U.P. & 1.281 .219 & 3.276 .063 & 27.768 .397 & 35.607 .784 & 38.613 & 3.899 .901 & 1.285 .283 & 4.635 .500 & 77.792 .760 \\
\hline & CONSTRUÇÃO CIVIL & 14.408 & 661.771 & 3.563 .871 & 433.574 & 1.281 .674 & 804.351 & 1.674 .371 & 4.821 .645 & 13.255 .665 \\
\hline & COMÉRCIO & 12.729 .513 & 4.012 .565 & 94.747 .444 & 883.270 & 1.017 .208 & 5.953 .926 & 12.749 .759 & 14.727.207 & 146.820 .892 \\
\hline & SERVIÇOS TURÍSTICOS & 1.995 .385 & 1.563 .414 & 16.691 .328 & 729.867 & 144.629 & 7.252 .076 & 27.173 .548 & 16.605 .339 & 72.155 .586 \\
\hline & SERVIÇOS NÃO TURÍSTICOS & 10.658 .918 & 13.180 .944 & 97.219 .164 & 5.584 .143 & 945.950 & 48.268 .545 & 35.850 .152 & 78.896 .682 & 290.604 .498 \\
\hline & Total & 136.555 .130 & 48.764 .889 & 1.228 .405 .985 & 49.029 .208 & 11.873 .703 & 145.870 .901 & 164.775.077 & 190.108 .720 & 1.975 .383 .612 \\
\hline \multicolumn{11}{|l|}{ TOTAL } \\
\hline & AGROPECUÁRIA & 150.074 .056 & 664.163 & 563.156 .725 & 97.916 & 5.352 & 3.819 & 1.793 .500 & 2.064 .420 & 717.859 .951 \\
\hline & EXTRATIVA MINERAL & 3.089 .646 & 24.427.726 & 277.079 .241 & 158.481 & 7.739 .213 & 85.601 & 270.287 & 958.650 & 313.808 .844 \\
\hline & IND. DE TRANSFORMAÇÃO & 164.320 .370 & 42.272 .241 & 1.764 .715 .448 & 16.184.432 & 14.321 .308 & 216.382.908 & 178.366.722 & 172.097.912 & 2.568 .661 .342 \\
\hline & S.I.U.P. & 3.702 .062 & 8.230 .096 & 72.221 .070 & 101.099.121 & 100.885 & 10.593 .529 & 2.801 .087 & 11.670 .122 & 210.417 .972 \\
\hline & CONSTRUÇÃOO CIVIL & 41.632 & 1.611 .586 & 9.268 .787 & 1.231 .022 & 3.348 .627 & 2.184 .905 & 3.516 .873 & 11.757 .565 & 32.960 .997 \\
\hline & COMÉRCIO & 36.781 .727 & 10.179.569 & 254.515 .906 & 2.507 .817 & 2.657 .658 & 16.172.999 & 26.880 .807 & 36.834 .023 & 386.530 .505 \\
\hline & SERVIÇOS TURÍSTICOS & 5.765 .633 & 3.967 .097 & 43.631 .006 & 2.072 .270 & 377.872 & 19.699.238 & 55.848 .977 & 40.454 .276 & 171.816 .369 \\
\hline & SERVIÇOS NÃO TURÍSTICOS & 30.798 .777 & 32.336 .449 & 256.057 .183 & 15.854 .734 & 2.471 .481 & 131.114.677 & 74.023 .414 & 194.458.899 & 737.115 .614 \\
\hline & Total & 394.573 .903 & 123.688 .927 & 3.240 .645 .365 & 139.205.792 & 31.022 .397 & 396.237 .676 & 343.501 .667 & 470.295 .867 & 5.139.171.594 \\
\hline
\end{tabular}

Fonte: dados estimados pelo autor. 
Tabela A6. Variação dos insumos totais utilizados no processo produtivo, devido a um aumento no consumo dos turistas brasileiros e internacionais no Brasil (valores em $\mathrm{R} \$ 1,00$ ).

\begin{tabular}{|c|c|c|c|c|c|c|c|c|c|c|}
\hline TURISTAS & MACRO-SETORES & AGROPECUÁRIA & $\begin{array}{c}\text { EXTRATIVA } \\
\text { MINERAL }\end{array}$ & $\begin{array}{c}\text { IND. } \\
\text { TRANSFOR- } \\
\text { MAÇÃO }\end{array}$ & S.I.U.P. & $\begin{array}{c}\text { CONSTRUÇÃO } \\
\text { CIVIL }\end{array}$ & COMÉRCIO & $\begin{array}{l}\text { SERVIÇOS } \\
\text { TURISTICOS }\end{array}$ & $\begin{array}{l}\text { SERVIÇOS } \\
\text { NÄO } \\
\text { TURÍSTICOS }\end{array}$ & TOTAL \\
\hline \multicolumn{11}{|c|}{ BRASILEIROS } \\
\hline & AGROPECUÁRIA & 98136049 & 427785 & 363432077 & 63429 & 3304 & 2413 & 203112896 & 1328763 & 666506716 \\
\hline & EXTRATIVA MINERAL & 2020373 & 15370984 & 161647103 & 102663 & 4777059 & 54088 & 20794491 & 608558 & 205375319 \\
\hline & IND. DE TRANSFORMAÇÃO & 107451963 & 25495229 & 1091456453 & 10484167 & 8839882 & 136723725 & 2005056627 & 102761315 & 3488269361 \\
\hline & S.I.U.P. & 2420843 & 4954034 & 44452673 & 65491336 & 62272 & 6693628 & 86887092 & 7034622 & 217996500 \\
\hline & CONSTRUÇÃO CIVIL & 27224 & 949815 & 5704916 & 797448 & 2066953 & 1380554 & 37364112 & 6935920 & 55226942 \\
\hline & COMÉRCIO & 24052214 & 6167004 & 159768461 & 1624547 & 1640450 & 10219073 & 348003155 & 22106816 & 573581720 \\
\hline & SERVIÇOS TURISTICOS & 3770248 & 2403684 & 26939678 & 1342402 & 233243 & 12447162 & 289865735 & 23848936 & 360851089 \\
\hline & SERVIÇOS NÄO TURÍSTICOS & 20139859 & 19155505 & 158838018 & 10270591 & 1525531 & 82846132 & 577094696 & 115562218 & 985432549 \\
\hline & Total & 258018773 & 74924039 & 2012239380 & 90176584 & 19148693 & 250366775 & 3568178804 & 280187147 & 6553240196 \\
\hline \multicolumn{11}{|c|}{ INTERNACIONAIS } \\
\hline & AGROPECUÁRIA & 51938007 & 236378 & 199724647 & 34487 & 2049 & 1406 & 100072676 & 735656 & 352745307 \\
\hline & EXTRATIVA MINERAL & 1069272 & 9056742 & 115432138 & 55818 & 2962154 & 31513 & 8170833 & 350092 & 137128563 \\
\hline & IND. DE TRANSFORMAÇÃO & 56868408 & 16777011 & 673258995 & 5700265 & 5481426 & 79659183 & 1253516116 & 69336598 & 2160598002 \\
\hline & S.I.U.P. & 1281219 & 3276063 & 27768397 & 35607784 & 38613 & 3899901 & 42017701 & 4635500 & 118525178 \\
\hline & CONSTRUÇÃO CIVIL & 14408 & 661771 & 3563871 & 433574 & 1281674 & 804351 & 22663775 & 4821645 & 34245069 \\
\hline & COMÉRCIO & 12729513 & 4012565 & 94747444 & 883270 & 1017208 & 5953926 & 200114112 & 14727207 & 334185245 \\
\hline & SERVIÇOS TURISTICOS & 1995385 & 1563414 & 16691328 & 729867 & 144629 & 7252076 & 280882005 & 16605339 & 325864042 \\
\hline & SERVIÇOS NÃO TURISTICOS & 10658918 & 13180944 & 97219164 & 5584143 & 945950 & 48268545 & 409320873 & 78896682 & 664075220 \\
\hline & Total & 136555130 & 48764889 & 1228405985 & 49029208 & 11873703 & 145870901 & 2316758091 & 190108720 & 4127366626 \\
\hline \multicolumn{11}{|l|}{ TOTAL } \\
\hline & AGROPECUÁRIA & 150074056 & 664163 & 563156725 & 97916 & 5352 & 3819 & 303185572 & 2064420 & 1019252023 \\
\hline & EXTRATIVA MINERAL & 3089646 & 24427726 & 277079241 & 158481 & 7739213 & 85601 & 28965325 & 958650 & 342503882 \\
\hline & IND. DE TRANSFORMAÇÃO & 164320370 & 42272241 & 1764715448 & 16184432 & 14321308 & 216382908 & 3258572743 & 172097912 & 5648867363 \\
\hline & S.I.U.P. & 3702062 & 8230096 & 72221070 & 101099121 & 100885 & 10593529 & 128904793 & 11670122 & 336521678 \\
\hline & CONSTRUÇÃ̃ CIVIL & 41632 & 1611586 & 9268787 & 1231022 & 3348627 & 2184905 & 60027886 & 11757565 & 89472010 \\
\hline & COMÉRCIO & 36781727 & 10179569 & 254515906 & 2507817 & 2657658 & 16172999 & 548117267 & 36834023 & 907766965 \\
\hline & SERVIÇOS TURISTICOS & 5765633 & 3967097 & 43631006 & 2072270 & 377872 & 19699238 & 570747740 & 40454276 & 686715132 \\
\hline & SERVIÇOS NÃO TURISTICOS & 30798777 & 32336449 & 256057183 & 15854734 & 2471481 & 131114677 & 986415569 & 194458899 & 1649507769 \\
\hline & Total & 394573903 & 123688927 & 3240645365 & 139205792 & 31022397 & 396237676 & 5884936895 & 470295867 & 10680606822 \\
\hline
\end{tabular}

Fonte: dados estimados pelo autor. 


\section{REFERÊNCIAS BIBLIOGRÁFICAS}

ABDALLAH, P.R. Atividade pesqueira no Brasil: política e evolução. Piracicaba, 1998. 137p. Tese (Doutorado) - Escola Superior de Agricultura "Luiz de Queiroz", Universidade de São Paulo.

ARCHER, B. Importance of tourism for economy of Bermuda. Annals of Tourism Research, v.22, n.4, p.918-930, 1995.

ARCHER, B.; FLETCHER, J. The economic impact of tourism in the Seychelles. Annals of Tourism Research, v.23, n.1, p.32-47, 1996.

AULICINO, M.P. Alguns impactos sócio-econômicos da atividade turística sobre municípios paulistas. São Paulo, 1994. 113p. Dissertação (Mestrado) - Escola de Comunicação e Artes, Universidade de São Paulo.

AYRES, M.L.A.; DAEMON, I.G.; FERNANDES, P.C.S.; OLIVEIRA, R.J.A. PRODETUR: infra-estrutura e seus reflexos no turismo. http://www.bndes.gov.br/publica/informe.htm (13/03/2001)

BACHA, C.J.C. Análise custo-benefício dos programas federais de incentivos ao reflorestamento no Brasil. Piracicaba: ESALQ/USP/CNPq, 1995. 93p. (Relatório de pesquisa)

BENI, M.C. Análise do desempenho do sistema nacional de turismo instituído na administração pública. São Paulo, 1991. Tese (Livre Docência) - Escola de Comunicação e Artes, Universidade de São Paulo. 
BANCO DO NORDESTE DO BRASIL. Descrição, objetivos, metas e componentes. Fortaleza: PRDETUR/NE, 1995.

BANCO DO NORDESTE DO BRASIL. Prodetur Nordeste: metas http://www.bnb.gov.br/prodetur (02/03/2001)

BANCO NACIONAL DE DESENVOLVIMENTO ECONÔMICO E SOCIAL. Programa de turismo. http://www.bndes.gov.br/atuar/programa.htm (13/03/2001)

BRASIL, H.S. Análise econômica do turismo no Brasil. http://www.embratur.gov.br/economia (21/01/2002a)

BRIASSOULIS, H. Methodological issues: tourism input-output analysis. Annals of Tourism Research, v.18, n.3, p.485-495, 1991.

BULL, A. The economics of travel and tourism. New York: Wiley Halsted Press, 1991, 246p.

BULMER-THOMAS, V. Input-output analysis in developing countries: source, methods and applications. New York: Wiley, 1992. 297p.

CARVALHO, V.N.S. Turismo e hotelaria desenvolvendo a economia. In: LAGE, B.H. G.; MILONE, P.C. (Org.). Turismo: teoria e prática. São Paulo: Atlas, 2000. 376p.

CONSIDERA, C.M.; RAMOS, R.L.O.; MAGALHÃES, K.M.M.; FILGUEIRAS, H.V.; SOBRAL, C.B. Matrizes de insumo-produto regionais 1985 e 1992: metodologia e resultados. Rio de Janeiro: Instituto de Pesquisas Econômica Aplicada, 1997. http://www.nemesis.org.br (10/05/2000)

CRUZ, R. C. Política de turismo e território. São Paulo: Contexto, 2000. 167p.

DERVIS, K. J. M.; ROBINSON, S. General equilibrium models for development policy. Cambridge: Cambridge University Press, 1982. 526p.

ESPANHA. Ministerio de Comercio y Turismo. Instituto de Estudios Turísticos. Tabla intersectorial de la economía turística: TIOT-92. Madri: Instituto de Estudios Turísticos, 1996. 351p. (Série Informe sobre turismo, 6) 
FERRAZ, J. A. Regime jurídico do turismo. Campinas: Papirus, 1992. 162p.

FLETCHER, J. Input-output analysis and tourism impact studies. Annals of Tourism Research, v.16, n.4, p.514-529, 1989.

FLETCHER, J.; SNEE, H. Input-output analysis. In: WITT, S. F.; MOUTINHO, L. (Ed.). Tourism: marketing and management handbook. 1.ed. Cambridge: Prentice Hall International, 1989. p.223-226.

GUILHOTO, J.J.M. Um modelo computável de equilíbrio geral para planejamento e análise de políticas agrícolas (PAPA), na economia brasileira. Piracicaba, 1995. 258p. Tese (Livre Docência) - Escola Superior de Agricultura "Luiz de Queiroz", Universidade de São Paulo.

GUILHOTO, J.J.M.; SONIS, M.; HEWINGS, G.J.D. Linkages and multipliers in a multiregional framework: integration of alternative approaches. Urbana: University of Illinois/Regional Economics Applications Laboratory, 1996. (Discussion paper)

GUILHOTO, J.J.M.; SONIS, M.; HEWINGS, G.J.D.; MARTINS, E.B. Índices de ligações e setores-chave na economia brasileira: 1959-1980. Pesquisa e Planejamento Econômico, v.24, n.2, p.287-314, ago. 1994.

GUILHOTO, J.J.M.; OLIVEIRA, A.F.; GRAMEIRO, A. H. et al. Notas metodológicas de construção da matriz de insumo-produto para economia brasileira para 1999. Piracicaba: DEAS/ESALQ/USP, 2001. (Relatório de atividades)

HADDAD, P. R. Análise de insumo-produto regional e interregional: multiplicadores de produção, de renda e de emprego. In: HADDAD, P. R (Org.). Economia regional: teoria e métodos de análise. Fortaleza: BNB/ETENE, 1989. cap.6, p.287-364.

INFORME BB. Turismo. Revista de Comércio Exterior, n.21, p.16-20, fev. 1999.

INSTITUTO BRASILEIRO DE GEOGRAFIA E ESTATÍSTICA. Matriz de relações intersetoriais: Brasil - 1980. Rio de Janeiro: IBGE, 1989. 203p. 
INSTITUTO BRASILEIRO DE GEOGRAFIA E ESTATÍSTICA. Estrutura produtiva da economia brasileira: censo cadastro 1995. Rio de Janeiro: IBGE, 1997. 142p.

INSTITUTO BRASILEIRO DE GEOGRAFIA E ESTATÍSTICA. Sistema de contas nacionais: Brasil, 1990-1995. Rio de Janeiro: IBGE, 1997a. 298p.

INSTITUTO BRASILEIRO DE GEOGRAFIA E ESTATÍSTICA. Contas nacionais: Brasil, 1995-1998. http://www.ibge.gov.br (29/12/2001)

INSTITUTO BRASILEIRO DE TURISMO. Anuário estatístico do turismo. Brasília: EMBRATUR, 1998. 353p.

INSTITUTO BRASILEIRO DE TURISMO; FUNDAÇÃO DE APOIO AO DESENVOLVIMENTO DA UFPE. Estudo econômico-financeiro dos meios de hospedagens e parque temáticos no Brasil. Brasília: EMBRATUR, 1998. 180p.

INSTITUTO BRASILEIRO DE TURISMO; FUNDAÇÃO DE APOIO AO DESENVOLVIMENTO DA UFPE. Estudo econômico-financeiro dos meios de hospedagens e parque temáticos no Brasil. In: INSTITUTO BRASILEIRO DE TURISMO. Estudos do turismo brasileiro. Brasília: EMBRATUR, 1999. cap. 4, p.181-220.

INSTITUTO BRASILEIRO DE TURISMO; FUNDAÇÃO INSTITUTO DE PESQUISASECONÔMICAS. Estatísticas de turismo: mercado interno de turismo1998. http://www.embratur.gov.br (09/09/2000a)

INSTITUTO BRASILEIRO DE TURISMO. Estatísticas de turismo. http://www.embratur.gov.br (16/10/2000b)

INSTITUTO BRASILEIRO DE TURISMO. Estatísticas de turismo: mão-de-obra empregada nos setores da atividade turística. http://www.embratur.gov.br $(14 / 02 / 2001)$

INSTITUTO BRASILEIRO DE TURISMO. Estatísticas de turismo: sistema de incentivos fiscais de 1969-1999. http://www.embratur.gov.br (08/03/2001b) 
INSTITUTO BRASILEIRO DE TURISMO. Tendências del mercado turístico: las americas 2000. http://www.embratur.gov.br (09/09/2001c)

INSTITUTO BRASILEIRO DE TURISMO. Demanda turística internacional - 2000. http://www.embratur.gov.br (26/03/2002)

INSTITUTO BRASILEIRO DE TURISMO. Métodos de estimativa dos impactos do turismo na economia brasileira. Brasília: Embratur, 1991. 137p.

INSTITUTO DE PLANEJAMENTO ECONÔMICO E SOCIAL; COMISSÃO DE AVALIAÇÃO DE INCENTIVOS FISCAIS. Relatório de avaliação dos incentivos fiscais regidos pelo decreto-lei $\mathrm{n}^{\circ}$. 1.376, de 12 de dezembro de 1974. IPEA/COMIF: Brasília, 1986.

ITO, C.A. Fronteiras e turismo no mercosul. In: LEMOS, A. I. G. Turismo: impactos sócio-ambientais. São Paulo: Hucitec, 1996. p.280-283.

LAGE, B. H. G; MILONE, P.C. Economia do turismo. Campinas: Papirus, 1991. 122p.

LAGE, B.H.G; MILONE, P.C. Impactos sócio-econômicos globais do turismo. In: LAGE, B. H.G.; MILONE, P.C. (Org.). Turismo: teoria e prática. São Paulo: Atlas, 2000. 376p.

LIMA, P.V.P.S.; CASIMIRO FILHO, F. Análise da estrutura produtiva da agropecuária brasileira no período de 1993 e 1995. In: CONGRESSO BRASILEIRO DE ECONOMIA E SOCIOLOGIA RURAL, 38., Rio de Janeiro, 2000. Anais. Brasília: SOBER, 2000. (CR-ROM, paper 1368).

LIN, T.; HALBRENDT, C.; LIANG, C.; WOOD, N. The impact of the tourism on the Vermont economy: the input-output analysis./Apresentado ao American Agricultural Economics Association Annual Meeting. Nashville, Tennessee, 1999.

LOPES, J.C. O turismo e o desenvolvimento regional do Norte e Nordeste. Informações FIPE, n.120, p.15-17, jul. 1990. 
LUNDEBERG, D.E.; KRISHNAMOORTHY, M.; STAVENGA, M.H. Tourism economics. New York: John Wiley \& Sons, 1995. 196p.

McGILVRAY, J. Linkages, key sectors and development strategy In: Leontief, W. (Ed.). Structure, system and economic policy. Cambridge: University Press, 1977. p.4956.

MELO, J.A.M.; SOUZA, M.A. Importância e desempenho da atividade turística na região Nordeste do Brasil. Revista Econômica do Nordeste, v.28, n.1, p.27-49, jan./mar. 1997.

MIERNYK, W.H. Elementos de análise de insumo-produto. São Paulo: Atlas, 1974. 146p.

MILLER, R.E.; BLAIR, P.D. Input-output analysis: foundations and extensions. Englewood Ciffs: Prentice-Hall, 1985. 464p.

MILLER, R.E. Regional and interregional input-output analysis. In: ISARD, W.; AZIS, J. I.; DRENNAN, M.P.; MILLER, R.E.; SALTZMAN, S.; THORBECKE, E. Methods of interregional and regional analysis. Aldrshot: Ashgate, 1998. p.41-133.

MINISTÉRIO DO PLANEJAMENTO, ORÇAMENTO E GESTÃO. Avança Brasil: 365 programas e foco no cidadão. http://www.planejamento.gov.br (21/02/2002).

MINISTÉRIO DO PLANEJAMENTO, ORÇAMENTO E GESTÃO. Relatório de avaliação do avança Brasil. http://www.planejamento.gov.br (27/03/2002a).

MINISTÉRIO DO PLANEJAMENTO, ORÇAMENTO E GESTÃO. Relatório de avaliação do avança Brasil. http://www.planejamento.gov.br (27/03/2002b).

MONTOYA, M.A. A matriz insumo-produto internacional do mercosul em 1990: a desigualdade regional e o impacto intersetorial do comércio inter-regional. Piracicaba, 1998. 217p. Tese (Doutorado) - Escola Superior de Agricultura "Luiz de Queiroz", Universidade de São Paulo.

OLIVEIRA, A.P. Turismo e desenvolvimento: planejamento e organização. São Paulo: Atlas, 2000. 175p. 
OSADA, N.M. Indústria do turismo na América Latina e no Brasil. http://www10.amchan.com.br/bil.nsf/Think+Tanks?Open.View (13/03/2002)

PACI, E. El papel del turismo en el sistema económico. In: ESPANHA. Ministerio de Comercio y Turismo. Instituto de Estudios Turísticos. Tabla intersectorial de la economía turística: TIOT-92. Madri: Instituto de Estudios Turísticos, 1996. p.154211. (Série Informe sobre turismo, 6)

RODRIGUES, R.L. A evolução do cooperativismo agropecuário na economia paranaense (1980-1995): uma análise de insumo-porduto. Piracicaba, 2000. 171p. Tese (Doutorado) - Escola Superior de Agricultura "Luiz de Queiroz", Universidade de São Paulo.

SAAB, W.G.L. Considerações sobre o desenvolvimento do setor de turismo no Brasil. BNDES Setorial, n.10, p. 285-312, set. 1999.

SAAB, W.G.L.; DAEMON, I.G.O segmento hoteleiro no Brasil. BNDES Setorial, n.13, p.127-156, mar. 2001.

SECRETARIA DE POLÍTICA INDUSTRIAL; MINISTÉRIO DA INDÚSTRIA, COMÉRCIO E TURISMO. Ações setoriais para o aumento da competitividade da indústria brasileira. http://www.midc.gov.br/publica/ (06/03/2002).

SECRETARIA DE COMUNICAÇÃO DE GOVERNO. 6 anos do Real: crescimento e desenvolvimento social. http://planalto.gov.br (06/03/2002)

SONIS, M.; HEWINGS, G.J.D. Erro and sensitivity input-output analysis: a new approach. In: MILLER, R.E.; POLENSKE, K.R.; ROSE, A.Z. (Ed.). Frontiers of input-output analysis. New York: Oxford University Press, 1989. p. 232-244.

SONIS, M.; HEWINGS, G.J.D. Fieds of influence in input-output systems. Urbana: University of Illinois / Regional Economics Applications Laboratory, 1995. 27p.

TEIXEIRA, M.S.G. Investimentos no turismo do Ceará: uma análise dos impactos sobre produto, renda e emprego. São Paulo, 1996. 188p. Tese (Doutorado) Escola de Comunicações e Artes, Universidade de São Paulo. 
WAGNER, J. Estimating the economic impacts of tourism. Annals of Tourism Research, v.24, n.3, p.592-608, 1997.

WIEN, E. S. The economic impact of travel and tourism in mountain area: the case of Vorarlberg (Austria). Revue de Turisme, n.2, p.25-29, 1989.

WORLD BANK. Growth of output. http://www.worldbank.org/data (02/04/2001).

WORLD TOURISM ORGANIZATION. Tourism highlights. http://www.worldtourism.org $(12 / 11 / 2000)$. 